\title{
Hot Isostatic Pressing and Heat Treatment Development of Powder Metallurgy Beta Gamma Titanium Aluminide Alloys
}

\author{
By \\ Daniel E. Laurin, B. Eng

\begin{abstract}
A thesis submitted to
the Faculty of Graduate Studies and Research
\end{abstract} \\ in partial fulfillment of \\ the requirements for the degree of \\ Master of Applied Science \\ Ottawa-Carleton Institute for \\ Mechanical and Aerospace Engineering \\ Department of Mechanical and Aerospace Engineering \\ Carleton University \\ Ottawa, Ontario, Canada \\ January 2010 \\ (C) 2010 \\ Daniel E. Laurin
}




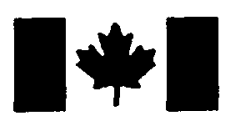

Library and Archives Canada

Published Heritage

Branch

395 Wellington Street Ottawa ON K1A ON4 Canada

NOTICE:

The author has granted a nonexclusive license allowing Library and Archives Canada to reproduce, publish, archive, preserve, conserve, communicate to the public by telecommunication or on the Internet, loan, distribute and sell theses worldwide, for commercial or noncommercial purposes, in microform, paper, electronic and/or any other formats.

The author retains copyright ownership and moral rights in this thesis. Neither the thesis nor substantial extracts from it may be printed or otherwise reproduced without the author's permission.
Bibliothèque et

Archives Canada

Direction du

Patrimoine de l'édition

395, rue Wellington

Ottawa ON K1A ON4

Canada
Your file Votre référence ISBN: 978-0-494-63208-6

Our file Notre référence

ISBN: 978-0-494-63208-6
In compliance with the Canadian Privacy Act some supporting forms may have been removed from this thesis.

While these forms may be included in the document page count, their removal does not represent any loss of content from the thesis.
AVIS:

L'auteur a accordé une licence non exclusive permettant à la Bibliothèque et Archives Canada de reproduire, publier, archiver, sauvegarder, conserver, transmettre au public par télécommunication ou par l'Internet, prêter, distribuer et vendre des thèses partout dans le monde, à des fins commerciales ou autres, sur support microforme, papier, électronique et/ou autres formats.

L'auteur conserve la propriété du droit d'auteur et des droits moraux qui protège cette thèse. $\mathrm{Ni}$ la thèse ni des extraits substantiels de celle-ci ne doivent être imprimés ou autrement reproduits sans son autorisation.

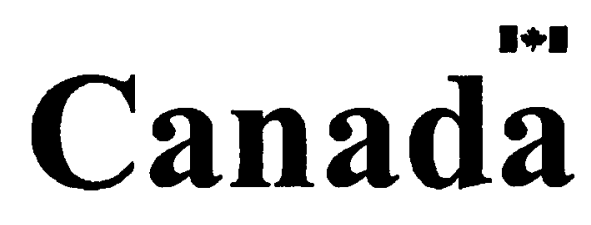

Conformément à la loi canadienne sur la protection de la vie privée, quelques formulaires secondaires ont été enlevés de cette thèse.

Bien que ces formulaires aient inclus dans la pagination, il n'y aura aucun contenu manquant. 
The undersigned recommend to

the Faculty of Graduate Studies and Research

acceptance of the thesis

\title{
Hot Isostatic Pressing and Heat Treatment Development of Powder Metallurgy Beta Gamma Titanium Aluminide Alloys
}

\author{
Submitted by Daniel E. Laurin \\ in partial fulfilment of the requirements for the degree of \\ Master of Applied Science
}

Dr. H.M.J. Saari, Thesis Supervisor

Dr. D.Y. Seo, Thesis Co-Supervisor

Dr. M.I. Yaras, Chair, Department of Mechanical and Aerospace Engineering

Carleton University

2010

ii 


\begin{abstract}
Titanium aluminide (TiAl) alloys are attractive materials for use in gas turbine engines, as they possess excellent high temperature properties with the added benefit of having a low density. However, processing these materials in a cost effective and efficient way has been very challenging. Research is now being directed at newly developed beta gamma TiAl alloys that utilize the beta $(\beta)$ phase, which becomes soft at high temperature, to improve their hot workability. This thesis explores a powder metallurgy processing route for two beta gamma TiAl alloys. The hot isostatic pressing conditions used to consolidate the powders were optimized to generate a microstructure that would result in excellent hot workability. However, the softening characteristics of the $\beta$ phase that improve the hot workability are also detrimental to the high temperature mechanical properties. Therefore, a heat treatment that would be applied following all wrought processing steps was designed to remove the $\beta$ phase and develop a fully lamellar microstructure. An aging heat treatment was then used to precipitate fine $\beta$ particles at the lamellar interfaces to improve the primary creep properties.
\end{abstract}




\section{Acknowledgements}

I would like to express my sincere gratitude to my two thesis supervisors, Dr. Henry Saari and Dr. Dongyi Seo, for their guidance and support throughout the completion of this thesis. I would like to thank all the staff in building M-13 at the National Research Council of Canada for their technical expertise and assistance in performing my experimental work. I would also like to thank NSERC for financial support, Dr. Xiahuoa for STEM analysis, and Dr. Y-W. Kim, UES and Crucible Research Corp. for supplying the powder alloys. Finally, I would like to thank my wife, family, and friends for all their support and encouragement. 


\section{Table of Contents}

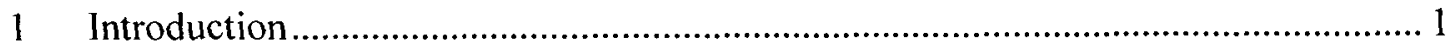

$1.1 \quad$ Lightweight Alloys in the Aerospace Industry …............................................. 1

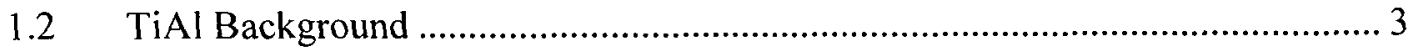

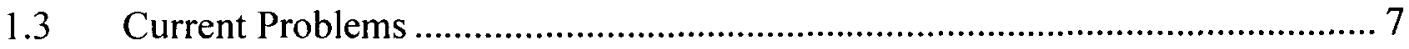

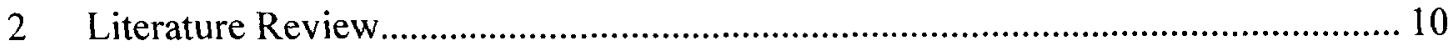

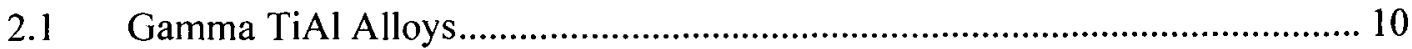

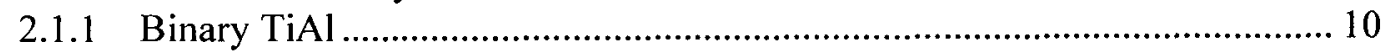

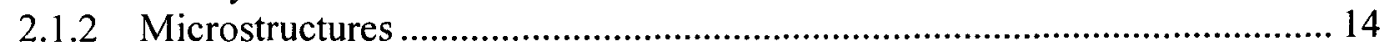

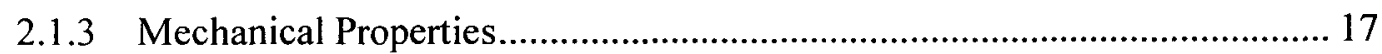

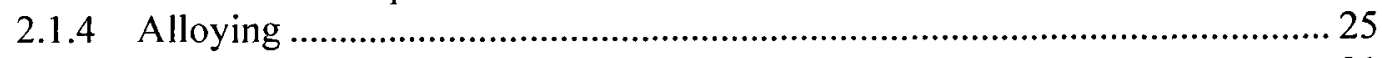

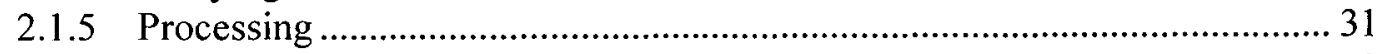

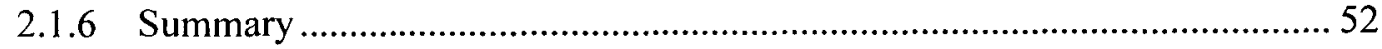

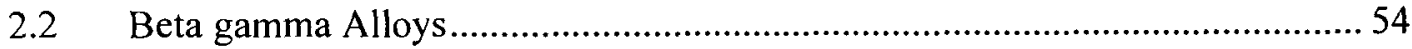

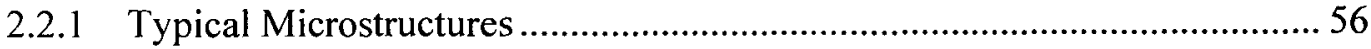

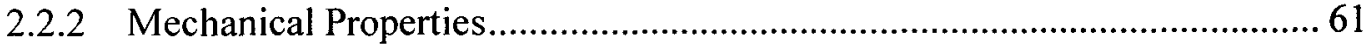

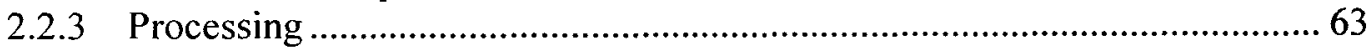

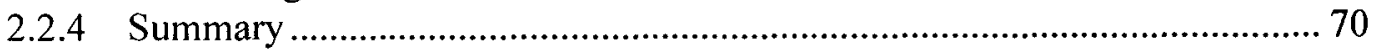

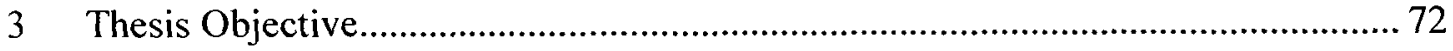

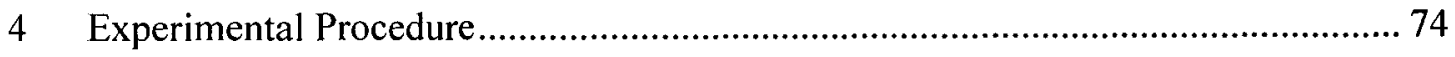

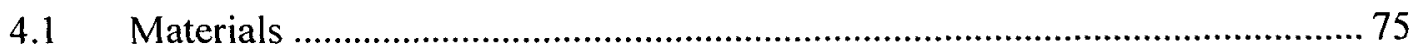

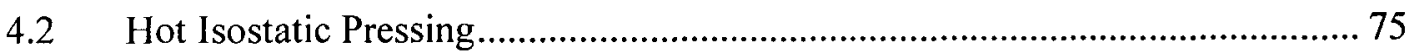

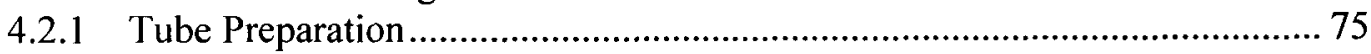

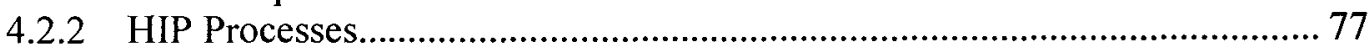

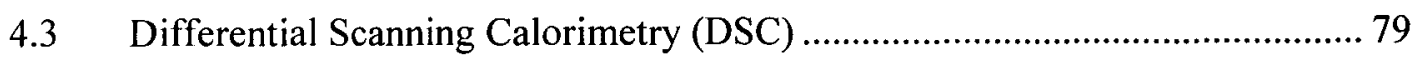

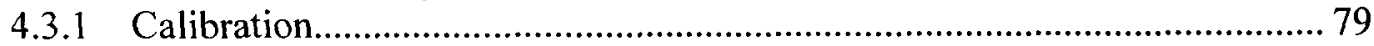

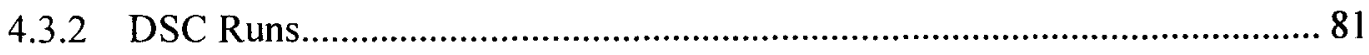

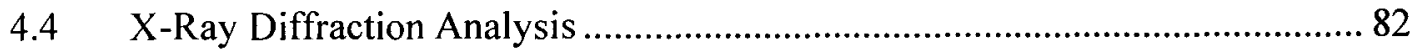

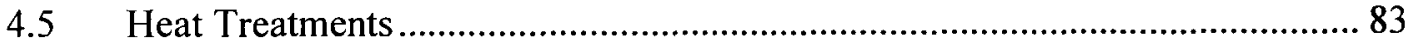

4.5.1 Step Cooled Solution Heat Treatments (SCSHT) ...................................... 84

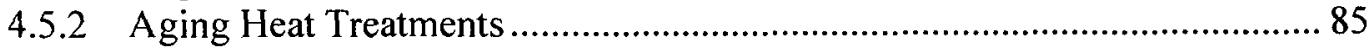

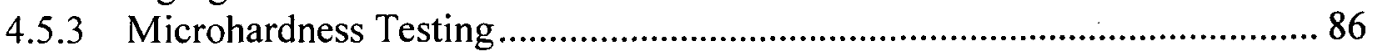

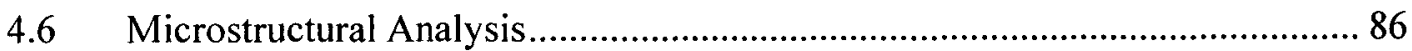

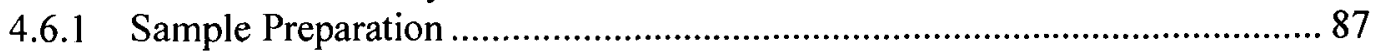

4.6.2 Microstructural Analysis Techniques ..................................................... 91 


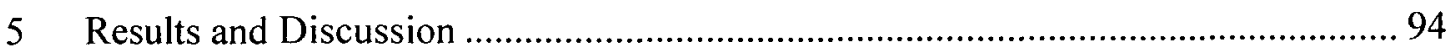

5.1 The Microstructure of the Gas Atomized Powders............................................ 94

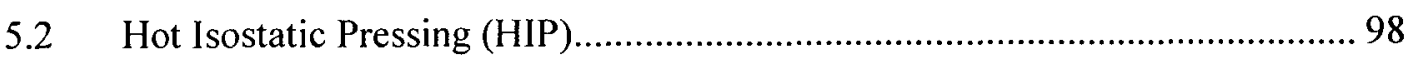

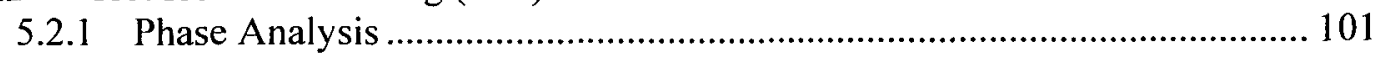

5.2.2 Effect of the Cooling Rate on $\beta$ Phase Volume Fraction............................ 102

5.2.3 Effect of HIP Temperature and Duration on $\beta$ Phase Volume Fraction ..... 104

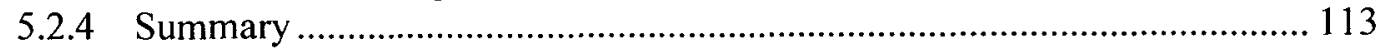

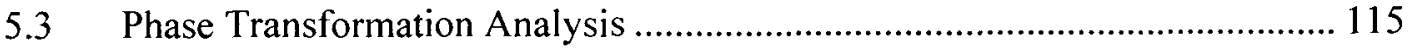

5.3.1 Differential Scanning Calorimetry (DSC) ………..................................... 116

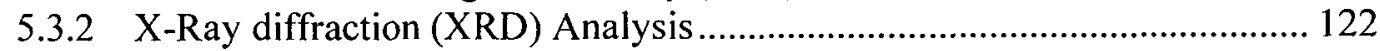

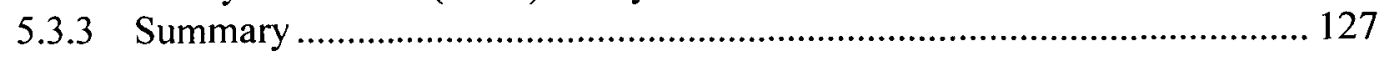

5.4 Step Cooled Solution Heat Treatments (SCSHT)......................................... 127

5.4.1 Effect of the Furnace to Air Cooling Transition Temperature $\left(\mathrm{T}_{\mathrm{F} / \mathrm{A}}\right)$.......... 131

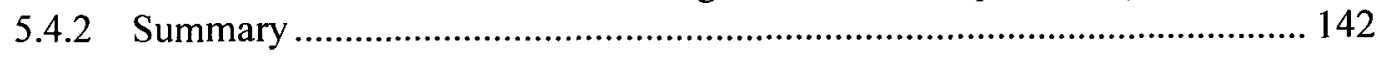

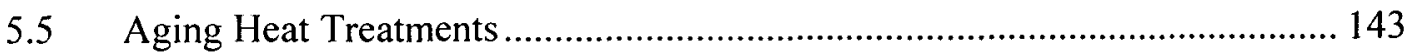

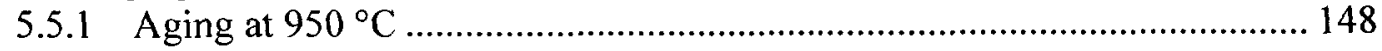

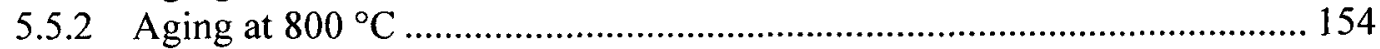

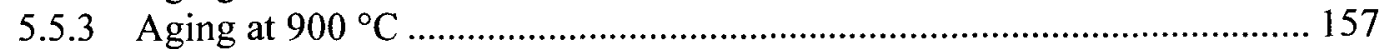

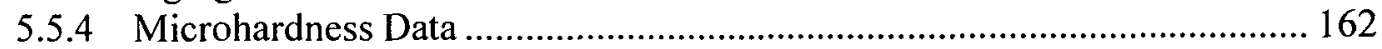

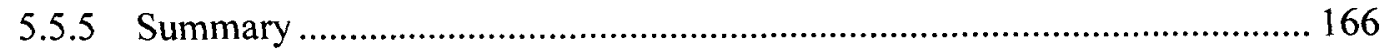

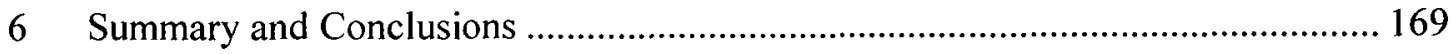

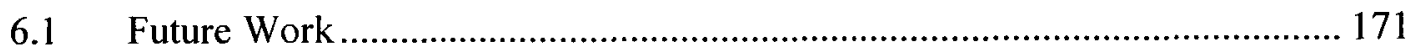

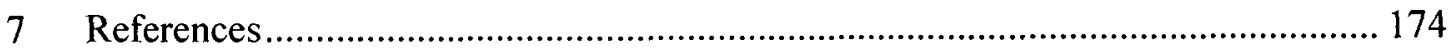




\section{List of Tables}

Table 1. Mechanical Property dependence on microstructure of a Ti-46.5Al2.5V-1Cr Alloy [21].

Table 2. The phase volume fractions for varying powder particle size range [50] ........47

Table 3. Beta gamma TiAl alloy groups and their phase fields [55] ..........................58

Table 4. Tensile Properties of wrought processes Ti-42Al-10V [56] ............................63

Table 5. The HIP conditions used to consolidate the powder alloys............................78

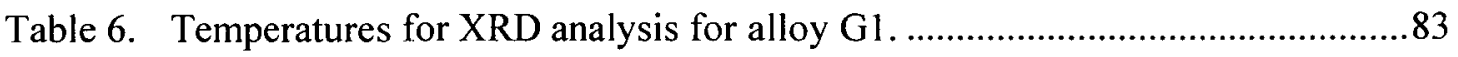

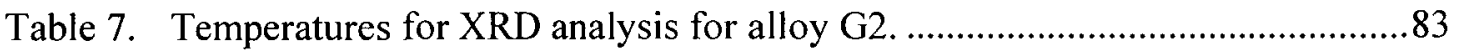

Table 8. Step cooled solution heat treatment conditions for both G1 and G2 ..............84

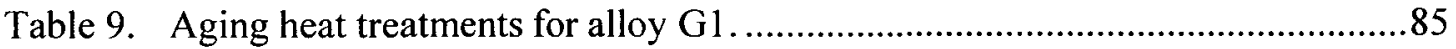

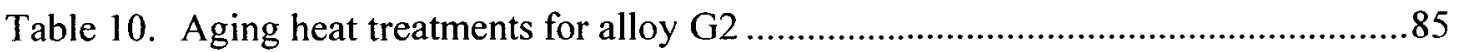

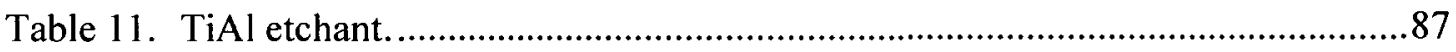

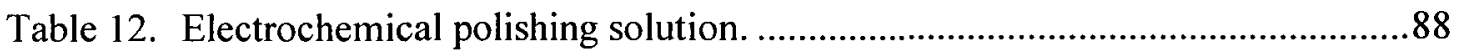

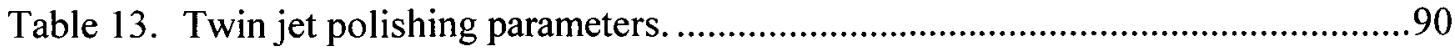

Table 14. The $\beta$ forming effectiveness of $\mathrm{Mn}$ and $\mathrm{Mo}$ in terms of a niobium equivalent [59].

Table 15. The $\beta$ forming effectiveness of alloys G1 and G2 in terms of a niobium equivalent.

Table 16. TEM-EDS of Gl (all in at. \%).

Table 17. TEM-EDS of G2 (all in at. \%).

Table 18. Summary of phase fractions in G2 for various HIP conditions.

Table 19. The Comparison of the measured experimental melting temperatures of pure metals to their theoretical melting temperatures. 


\section{List of Figures}

Figure 1. The increased use of titanium in commercial aircraft. ................................2

Figure 2. The increased use of titanium in aircraft engines. ...................................

Figure 3. GEnx engine cutaway showing the location of the $\gamma$-TiAl LPT

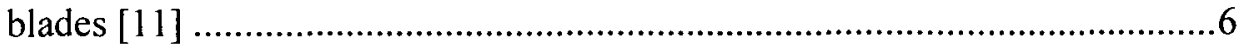

Figure 4. The crystal structure of a) $\alpha-\mathrm{Ti}_{3} \mathrm{Al}$ and b) $\gamma$-TiAl [27].............................13

Figure 5. "Easy" and "hard" slip systems in $\gamma$-TiAl [4] .......................................13

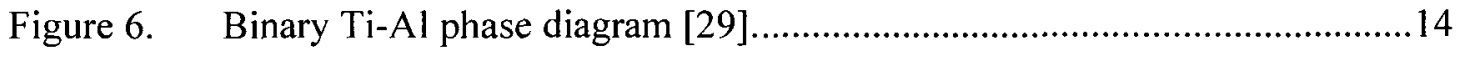

Figure 7. The four typical microstructures of $\gamma$-TiAl: a) Duplex (D) b) Near

Gamma (NG) c) Near Lamellar (NL) and d) Fully Lamellar (FL)

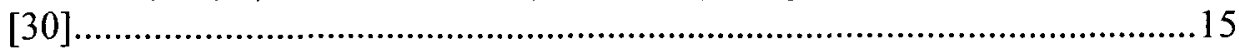

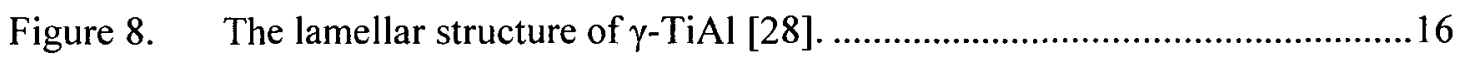

Figure 9. Binary phase diagram from [14] with heat treatment temperatures

used to develop particular microstructures marked; FL: Fully

Lamellar, NL: Nearly Lamellar, D: Duplex, NG: Near Gamma

[32]

Figure 10. Stress-Strain curves of a TiAl alloy with either a duplex or fully

lamellar microstructures for various grain sizes [34].

Figure 11. Room temperature ductility of binary $\mathrm{TiAl}$ at various aluminum $\mathrm{Al}$

concentrations [14].

Figure 12. The effect of grain size on fracture strain [18].

Figure 13. The relationship between fracture toughness and elongation of the lamellar microstructures [34].

Figure 14. Hall-Petch relationship for gamma TiAl with various microstructures [34]

Figure 15. Creep behavior for TiAl alloys with various microstructures tested at $800^{\circ} \mathrm{C}$ and $69 \mathrm{MPa}$ [33]. .25 
Figure 16. Phase boundary shift in the binary Ti-Al system from alloying additions [17].

Figure 17. The effect of aluminum content on a) the fracture toughness of ascast binary alloys, and $\mathrm{b}$ ) the strength of high $\mathrm{Nb}$ alloys for various temperatures [14].....

Figure 18. The effect of Boron on grain size; (a) Ti-48Al-2Cr-2Nb-1B and (b) $\mathrm{Ti}-48-2 \mathrm{Cr}-2 \mathrm{Nb}[3]$.

Figure 19. Typical processing routes for gamma TiAl alloys [42].

Figure 20. The volume fraction of secondary gamma-phase as a function of the $\mathrm{Al}$ concentration [14].

Figure 21. Schematic of Electrode Induction Melting Gas Atomization technique (EIGA) showing the (1) electrode, (2) induction coil, and (3) gas nozzle [17].

Figure 22. Schematic of Plasma Melting Gas Atomization technique (PIGA) showing the (1) plasma torch, (2) cold copper crucible, (3) induction heated cold copper funnel, and (4) gas nozzle [17]. . .40

Figure 23. SEM image of Ar gas atomized Ti-50Al-2Nb alloy powder [17].

Figure 24. Powder particle size distribution of Ti-46Al-9Nb powders atomized using EIGA or PIGA techniques [17].

Figure 25. Increase in oxygen concentrations in $\mathrm{Ti}-45 \mathrm{Al}-7.5 \mathrm{Nb}$ for two different powder particle size distributions when exposed to air [17].

Figure 26. Cooling rates for $\mathrm{Ti}-49 \mathrm{Al}$ powder particles at $1750 \mathrm{~K}$ with various atomization gases [17].

Figure 27. The effects of HIP temperature and powder particle size on grain size [17].

Figure 28. Compact Density versus the HIP temperature [54].

Figure 29. $\beta$ solidification versus solidification with peritectic reaction [55]..............55

Figure 30. Beta gamma TiAl alloy groups [55]. 
Figure 31. Typical microstructures of as-cast and cast+HIP Beta gamma alloys [55].

Figure 32. Forged and aged $\left(900^{\circ} \mathrm{C} / 24 \mathrm{hrs}\right)$ beta gamma TiAl alloy containing $75 \% \gamma, 9 \% \alpha_{2}$, and $16 \% \beta[55]$ 59

Figure 33. Forged $(70 \%)$ and aged $\left(1100^{\circ} \mathrm{C} / 17 / \mathrm{FC}\right)$ beta gamma TiAl Alloy with composition $\mathrm{Ti} 42 \mathrm{Al}-\mathrm{xNb}-3 \mathrm{~V}$ [18].

Figure 34. Forged at $1300^{\circ} \mathrm{C}$ and aged $\left(1200^{\circ} \mathrm{C} / 2 \mathrm{~h}\right)$ beta gamma TiAl alloy [45].

Figure 35. Strength and Temperature domains of various aerospace materials [18].

Figure 36. Microstructure of wrought processed Ti-42Al-10V, (a) optical micrograph, (b) back scattering electron image, (c) TEM image [56]

Figure 37. Typical processing routes for beta gamma TiAl alloys [44]. .64

Figure 38. Processing efficiency map for a beta gamma TiAl alloy with the composition Ti-42Al-6Nb-3Mn-0.2B $(\varepsilon=0.06)[40]$.

Figure 39. Microstructure of beta gamma TiAl alloy forged at $1050^{\circ} \mathrm{C}$ : (a) $1 / \mathrm{s}$

$$
\text { (b) } 10^{-1} / \mathrm{s} \text { (c) } 10^{-2} / \mathrm{s}[40] \text {. }
$$

Figure 40. The effect of the $\beta$ phase on forging at $1300^{\circ} \mathrm{C}[18]$. .68

Figure 41. Hot forged samples of a) a conventional TiAl alloy and b) a TiAl alloy containing the $\beta$ phase [45]. .68

Figure 42. Improved machinability of beta gamma TiAl alloys. Shows a) particulate turnings of a TiAl alloy with no $\beta$ phase and $b$ ) curled turnings of a TiAl alloy with approximately $25 \% \beta$ phase [45].

Figure 43. The proposed processing route for the beta gamma alloys........................73

Figure 44. Hydraulic crimper used to crimp the stainless steel tubes...........................76

Figure 45. A Stainless steel tube filled with powder, ready for vacuum encapsulation. 
Figure 46. Tubes filled with alloy powders connected to the diffusion pump at a pressure of $1 \times 10^{-5} \mathrm{mbar}$, and in a furnace at $230^{\circ} \mathrm{C}$

Figure 47. The sealed tubes ready for hot isostatic pressing......................................77

Figure 48. The hot isostatic press used to consolidate the powders. ...........................78

Figure 49. Netzsch 404C differential scanning calorimeter....................................79

Figure 50. DSC calibration temperature program for silver. ..................................... 81

Figure 51. The Temperature program used for the baseline and Sample DSC

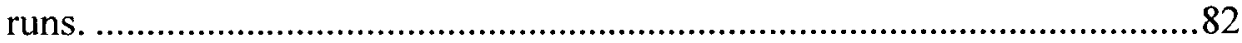

Figure 52. Lindburg/blue $\mathrm{M}$ box furnace used for heat treatments..............................84

Figure 53. Step cooling during the solution heat treatment process.........................85

Figure 54. LECO LM247AT microhardness testers used for microhardness

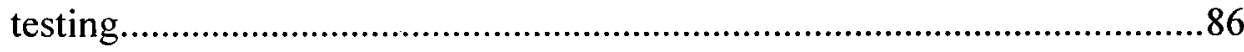

Figure 55. Polishing wheel used for mechanical polishing of samples ......................87

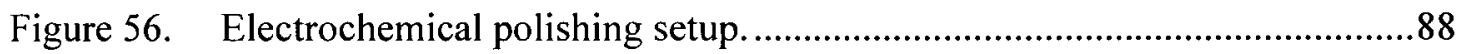

Figure 57. Buehler IsoMet 2000 cutter used to cut slices for TEM samples...............89

Figure 58. a) Brass holder used for mechanical polishing of slices used for TEM samples, and b) Puncher used to punch $3 \mathrm{~mm}$ diameter TEM samples from the mechanically polished slices.

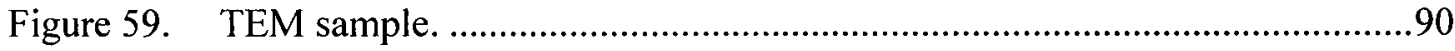

Figure 60. Twin-Jet polishing setup and power supply........................................90

Figure 61. Olympus PMG-3 optical microscope equipped with CCD........................91

Figure 62. Philips XL30S FEG scanning electron microscope equipped with an EDAX from Pheonics systems.

Figure 63. Jeol JEM-2100F field emission electron microscope ................................92

Figure 64. Threshold tool in Photoshop used to determine the $\beta$ phase volume fraction. 
Figure 65. The microstructure of the alloy Gl gas atomized powder particles. .95

Figure 66. The microstructure of the alloy G2 gas atomized powder particles. .95

Figure 67. SEM-EDS line scan across the interdendritic zone of the gas atomized powder of alloy G1.

Figure 68. SEM-EDS point analysis of the powder of alloy G2. Spot analyses

1 is in the interdendritic region and spot analysis 3 is in the dendritic core. Spot analysis 2 is in the white phase with a vein morphology

Figure 69. SEM-EDS point analysis of the powder of alloy G1. Spot analysis 1 is in the dendritic core and spot analysis 2 is in the white phase with a vein morphology.

Figure 70. As-HIP'ed microstructure of alloy Gl showing a two phase near- $\gamma$ microstructure with $\gamma$ grains (dark gray), $\alpha_{2}$ grains (light gray). This sample was HIP'ed at $1250^{\circ} \mathrm{C} / 200 \mathrm{MPa} / 2$ hours.

Figure 71. As-HIP'ed microstructure of alloy G2 showing a three phase near- $\gamma$ microstructure with $\gamma$ grains (dark gray), $\alpha_{2}$ grains (light gray), and $\beta$ grains (white). This sample was HIP'ed at $1250^{\circ} \mathrm{C} / 200 \mathrm{MPa} / 2$ hours.

Figure 72. Angular dark field-TEM micrographs of alloy a) G1, and b) G2 HIP'ed at $1250^{\circ} \mathrm{C}$ with a cooling rate of $8.5^{\circ} \mathrm{C} / \mathrm{min}$. The $\beta$-phase in $\mathrm{G} 1$ is rich in $\mathrm{Ti}, \mathrm{Nb}$, and $\mathrm{Mn}$. The $\beta$-phase in $\mathrm{G} 2$ is rich in $\mathrm{Ti}$, $\mathrm{Nb}$, and $\mathrm{Mo}$.

Figure 73. BSE images of the microstructures of alloys $\mathrm{G} 1$ and $\mathrm{G} 2$ resulting from HIP at a temperature of $1250^{\circ} \mathrm{C}$ with cooling rates between $3.0^{\circ} \mathrm{C} / \mathrm{min}$ and $17.5^{\circ} \mathrm{C} / \mathrm{min}\left(\alpha_{2}\right.$-phase appears as light gray, $\beta$-phase appears as white). The images for G1 and G2 are at $10,000 \mathrm{x}$ and 5,000x magnification, respectively.

Figure 74. Plot showing the volume fraction of $\beta$-phase for various cooling rates. Samples were HIP'ed at $1250^{\circ} \mathrm{C}$.

Figure 75. BSE images of the microstructures of alloys $\mathrm{G} 1$ and $\mathrm{G} 2$ resulting from HIP at temperatures between $1200^{\circ} \mathrm{C}$ and $1300^{\circ} \mathrm{C}$ with a cooling rate of $17.5^{\circ} \mathrm{C}\left(\alpha_{2}\right.$-phase appears as light gray, $\beta$-phase appears as white). The images for both $\mathrm{G} 1$ and $\mathrm{G} 2$ are at $10,000 \mathrm{x}$ magnification. 
Figure 76. Plot showing the volume fraction of $\beta$-phase in alloy $\mathrm{G} 2$ for various HIP temperatures. Samples were cooled at a rate of $17.5^{\circ} \mathrm{C} / \mathrm{min}$.

Figure 77. BSE micrograph of alloy G2 HIP'ed at 1200 for 2 hours showing some coarse grained regions (white circle).

Figure 78. The dependence of the a) $\beta$ phase volume fraction on annealing temperature (air cooling) and b) the flow stress on the hot working temperature and strain rate [62].

Figure 79. Forging test of Ti-43Al-4Nb-1Mo-0.1B, forged to an overall strain of $1.3[61]$

Figure 80. Calculated phase fractions of alloy with composition Ti-43Al-4Nb$1 \mathrm{Mo}-0.1 \mathrm{~B}$ showing the local minimum in $\beta$ phase at the $\alpha$ transus temperature $\left(T_{\alpha}\right)[61]$.

Figure 81. BSE image of alloy G2 HIP'ed at $1200^{\circ} \mathrm{C}$ for 4 hours, showing some coarse grained regions (white circles)

Figure 82. BSE images showing the microstructure of alloy G2 step-HIP'ed at

a) $1250 / 1 \mathrm{hr}+1200 / 2 \mathrm{hrs}$ and b) $1250 / 1 \mathrm{hr}+1100 / 3 \mathrm{hrs}$

Figure 83. The DCS signal measured during two melting cycles of pure silver.

Figure 84. The DCS signal measured during two melting cycles of pure gold.

Figure 85. The DCS signal measured during two melting cycles of pure nickel.

Figure 86. The temperature calibration curve used for the DSC runs of the TiAl samples.

Figure 87. The DSC signal measured during the heating cycle of alloy G1 119

Figure 88. DSC signal measured during the heating cycle of alloy G2 ...................120

Figure 89. DSC signal measured during the cooling cycle of alloy G1 ......................121

Figure 90. DSC signal measured during the cooling cycle of alloy G2 .....................122

Figure 91. The XRD patterns of alloy Gl quenched from various temperatures. 
Figure 92. The XRD patterns of alloy $\mathrm{G} 2$ quenched from various temperatures.

Figure 93. The proposed processing sequence for the powder beta gamma TiAl alloys.

Figure 94. The equilibrium phase of a Ti-44Al alloy with the addition of varying amounts of $\beta$ stabilizing elements (xMeff) [55]

Figure 95. Optical and BSE micrographs showing the effect of the furnace to air cooling transition temperature on the microstructure of alloy G1.

Figure 96. BSE micrograph of alloy G1 solution heat treated with a step cool transition temperature of $T_{\mathrm{F} / \mathrm{A}}=1270^{\circ} \mathrm{C}$, showing evidence of severe coarsening of the $\gamma$ lamellae.

Figure 97. BSE image of alloy $\mathrm{G} 1$ heat treated with a step cool transition temperature of $\mathrm{T}_{\mathrm{F} / \mathrm{A}}=1280^{\circ} \mathrm{C}$, showing a mixture of planar and well interlocked grain boundary morphologies.

Figure 98. BSE image of alloy $\mathrm{G} 1$ heat treated with a step cool transition temperature of $\mathrm{T}_{\mathrm{F} / \mathrm{A}}=1290^{\circ} \mathrm{C}$, showing the formation of equiaxed $\gamma$ and $\beta$ phase at the grain boundaries.

Figure 99. The a) angular dark field and b) bright field TEM images of alloy G1 solution heat treated with $T_{F / A}=1280^{\circ} \mathrm{C}$. The bright contrast lamellae in the angular dark field imaged are $\alpha_{2}$ phase and the dark contrast lamellar are $\gamma$ phase.

Figure 100. Optical and BSE micrographs showing the effect of the furnace to air cooling transition temperature on the microstructure of alloy G2.

Figure 101. Alloy $\mathrm{G} 2$ solution heat treated with a step cool transition temperature of $\mathrm{T}_{\mathrm{F} / \mathrm{A}}=1270{ }^{\circ} \mathrm{C}$, showing evidence of coarsening of the $\gamma$ lamellae.

Figure 102. Alloy G2 heat treated with a step cool transition temperature of $\mathrm{TF} / \mathrm{A}=1280^{\circ} \mathrm{C}$.

Figure 103. Alloy G2 heat treated with a step cool transition temperature of $\mathrm{TF} / \mathrm{A}=1290^{\circ} \mathrm{C}$, showing the formation of massive $\gamma$ and $\beta$ phases at the grain boundaries 
Figure 104. TEM images of $\mathrm{G} 2$ solution heat treated with $\mathrm{T}_{\mathrm{F} / \mathrm{A}}=1280^{\circ} \mathrm{C}$, showing EDS results (all in at.\%) in a) bright field and b) angular dark field modes.

Figure 105. Optical micrographs showing the effect of the aging conditions on the overall microstructure of alloy G1 (all at the same magnification)

Figure 106. Optical micrographs showing the effect of the aging conditions on the overall microstructure of alloy G2 (all the same magnification)

Figure 107. BSE images showing the effect of the aging conditions on the grain boundary morphology of alloy G1 (all at 1000x magnification).

Figure 108. BSE images showing the effect of the aging conditions on the grain boundary morphology of alloy G2 (all at 4000x magnification).

Figure 109. BSE images showing the effect of the aging conditions on the lamellae in alloy G1 (all at 50000x magnification).

Figure 110. BSE images showing the effect of the aging conditions on the lamellae in alloy G2 (all at 50000x magnification).

Figure 111. OM micrograph of alloy G1 aged at $950{ }^{\circ} \mathrm{C}$ for 6 hours showing discontinuous coarsening.

Figure 112. BSE images of alloy $\mathrm{Gl}$ aged at $950^{\circ} \mathrm{C}$ for a) 6 hours and b) 24 hours, showing the degraded lamellar structure cause by dissolution of the $\alpha_{2}$ lamellae.

Figure 113. Angular dark field TEM image of alloy $\mathrm{G} 1$ aged at $950^{\circ} \mathrm{C}$ for 24 hours. The bright contrast lamellae are $\alpha_{2}$ and the dark contrast lamellae are $\gamma$. The black arrows indicate discontinuities of the $\alpha_{2}$ lamellae.

Figure 114. Angular dark field TEM image of alloy G2 aged at $950^{\circ} \mathrm{C}$ for 24 hours with EDS analysis showing that the white precipitates are rich in $\mathrm{Ti}$ and $\mathrm{Mo}$, and are identified as the $\beta$ phase (all in at.\%). The light and dark lamellae are identified as $\alpha_{2}$ and $\gamma$ lamellae, respectivly. 
Figure 115. BSE micrograph of alloy $\mathrm{G} 2$ aged at $950{ }^{\circ} \mathrm{C}$ for 6 hours showing on-edge lamellar structure with interfacial $\beta$ precipitates formed in the $\alpha_{2}$ lamellae.

Figure 116. BSE micrograph of alloy $\mathrm{G} 2$ aged at $950^{\circ} \mathrm{C}$ for 6 hours showing the $\beta$ phase precipitation at the lamellar colony boundaries.

Figure 117. BSE images of alloy G1 aged at $800^{\circ} \mathrm{C}$ for a) 6 hours and b) 24 hours showing the precipitation of the $\beta$ phase at the lamellar colony boundary triple points.

Figure 118. BSE images of alloy G1 aged at $800^{\circ} \mathrm{C}$ for a) 6 hours and b) 24 hours showing the fine $\beta$ precipitates that formed at the boundaries between two adjacent lamellar colonies.

Figure 119. BSE images of alloy $\mathrm{G} 2$ aged at $800^{\circ} \mathrm{C}$ for a) 6 hours and b) 24 hours showing the fine $\beta$ precipitates that formed at the lamellar colony boundaries.

Figure 120. BSE images of alloy G1 aged at $900^{\circ} \mathrm{C}$ for a) 24 hours and b) 96 hours showing the $\beta$ precipitates that formed at the lamellar colony boundary triple points.

Figure 121. BSE images of alloy $\mathrm{G} 2$ aged at $900^{\circ} \mathrm{C}$ for 6 hours showing the $\beta$ phase that formed at the lamellar colony boundaries.

Figure 122. BSE images of alloy $\mathrm{G} 2$ aged at $900^{\circ} \mathrm{C}$ for a) 24 hours and b) 96 hours showing the formation of intergranular $\beta$ precipitates.

Figure 123. BSE micrograph of alloy $\mathrm{G} 2$ aged at $900{ }^{\circ} \mathrm{C}$ for 96 hours showing the $\beta$ phase that formed at the lamellar colony boundaries. 162

Figure 124. BSE micrograph of alloy $\mathrm{G} 2$ aged at $900^{\circ} \mathrm{C}$ for 24 hours showing the formation of $\beta$ precipitates at the lamellar interfaces.

Figure 125. The effect of aging at $800^{\circ} \mathrm{C}$ on the lamellar grain microhardness...........165

Figure 126. The effect of aging at $900^{\circ} \mathrm{C}$ on the lamellar grain microhardness...........165

Figure 127. The effect of aging at $950^{\circ} \mathrm{C}$ on the lamellar grain microhardness...........166 


\section{Introduction}

\subsection{Lightweight Alloys in the Aerospace Industry}

The aerospace industry in constantly trying to increase the efficiency and allowable payload of commercial aircraft. Replacing the materials of some components in an aircraft with higher strength or less dense materials is crucial to reducing the weight. As an example, if the fuel consumption of a 747 is reduced by $10 \%$ the allowable payload can increase by 10 tons [1]. Unlike the automotive industry, the aerospace industry is willing to pay a significantly larger amount of money for any degree of weight savings. A cost of $\$ 10$ for a $1 \mathrm{lb}$ weight saving is acceptable to engineers in the automotive industry, whereas the aerospace industry is willing to pay on the order of $\$ 1000$ for the same weight reduction [1]. The use of a lower density material is much more effective at reducing the overall weight than using a smaller amount of higher strength material. This has led to a wide spread effort to develop new lightweight materials in order to increase the fuel efficiency of modern aircraft and combat rising fuel cost, as well as environmental concerns. As a testament to this effort, the use of titanium to replace heavy structural components has been increasing steadily since the late 1950 's, as seen in Figure 1. The majority of the titanium in a typical aircraft is found in the gas turbine engines. Currently, titanium accounts for approximately $1 / 3$ of a current commercial aircraft gas turbine engine's weight and has been increasing steadily increasing since the 1950's, as seen in Figure 2. In fact, a large amount of attention has been directed towards reducing the weight of the gas turbine engines, where there is a significant weight reduction 
potential. The high temperature locations of the engine that contain heavy nickel-base alloys have been of particular interest. Through the development of lighter nickel base superalloys, and also low density titanium aluminide intermetallics, the weight of modern gas turbine engines is being reduced very effectively.

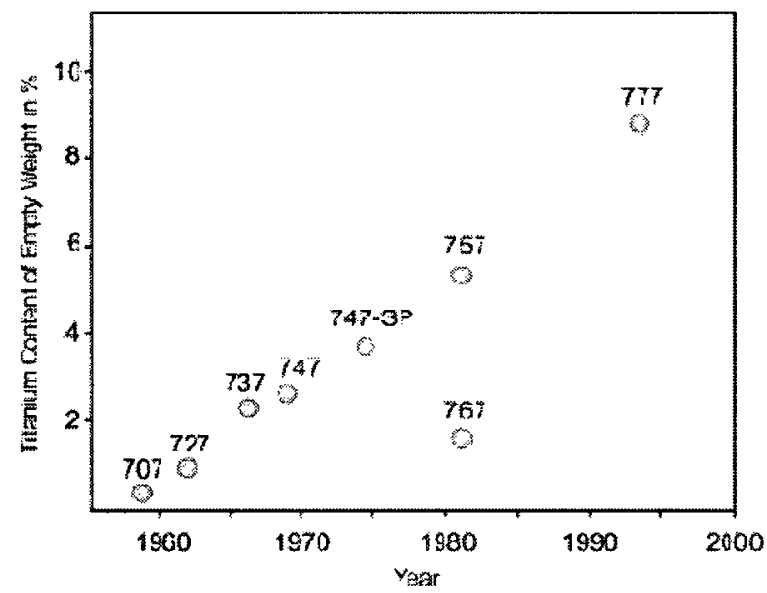

Figure 1. The increased use of titanium in commercial aircraft.

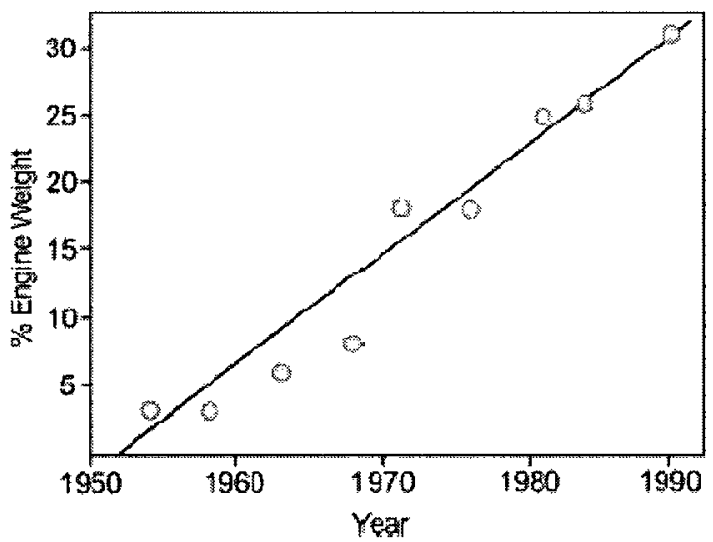

Figure 2. The increased use of titanium in aircraft engines. 
Throughout the last 30 years there has been a significant effort to replace the existing $\mathrm{Ni}$ base super alloy components with much lighter titanium aluminide intermetallics (TiAl) $[2,3,4]$. As a result of the high aluminum content, TiAl alloys have a very low density. These alloys also have good oxidation behavior, a high melting point, thermal stability, and good creep properties [1,2,3]. They also have excellent mechanical properties at high temperatures (up to $760^{\circ} \mathrm{C}$ ) due to their ordered crystal structure $[1,5]$. TiAl alloys are also very resistant to titanium fires, which can occur when the $\mathrm{Ti}$ compressor blades rub against the casing [1].

\subsection{TiAl Background}

The first major development program for gamma titanium aluminide $(\gamma$-TiAl $)$ alloys was conducted by Pratt and Whitney from 1975 to 1983. During this time, first generation TiAl alloy compositions designed for wrought processing were evaluated on the basis of ductility and creep resistance. Of these first generation alloy compositions, Ti-48Al-1V$0.1 \mathrm{C}$ showed the best combination of mechanical properties; however Ti-48Al-1 V-0.1C and all other first generation alloys were not adequate for gas turbine applications as a result of a lack of sufficient strength and creep resistance [6,7].

The second major development program was conducted by General Electric (GE) Corporate Research Center from 1986 to 1991. During this program S.C. Huang first developed the second generation alloy composition $\mathrm{Ti}-48 \mathrm{Al}-2 \mathrm{Nb}-2 \mathrm{Cr}(48-2-2)$, which was found to give the best combination of mechanical properties $[6,8]$. Huang's intention 
was to develop an alloy composition that would maximize the room temperature ductility and toughness without detrimentally affecting the creep resistance [9]. The addition of chromium $(\mathrm{Cr})$ was to increase the ductility and the addition of niobium $(\mathrm{Nb})$ was to increase the oxidation resistance [9]. Since its inception, 48-2-2 has been one of the most widely studied TiAl alloy compositions, and designers have been very interested in incorporating a TiAl alloy into a gas turbine engine for many years [10].

The first real opportunity to evaluate $48-2-2$ as a gas turbine blade material came in the early 1990 s during the development of General Electric's GE90 engine designed for the Boeing 777 . The weight of the engine was a critical design challenge and the use of 48-2-2 offered exceptional weight reduction possibilities over other design concepts. The designers at GE had determined that if 48-2-2, at half the density of nickel-based alloys, was used for the blades in the last two stages of the turbine and as the nozzle material, the potential weight savings would be more than $136 \mathrm{~kg}$ [10]. The design team then developed a program that would focus on the mechanical behaviour and producability of 48-2-2 in order to convince the chief turbine design leader that its incorporation into the GE90 engine would be successful. The program consisted of replacing the $5^{\text {th }}$ stage low pressure turbine (LPT) blades of the CF6-80C engine with 48-2-2 and conducting a cyclic endurance test of the engine. The $48-2-2$ blades were cast oversized $(2.5 \mathrm{~cm}$ per side) to deal with solidification porosity and achieve fill of the mold [8]. The test was not done in the GE90 engine in order to avoid certification issues during its development [10]. During the test at GE's Peebles, Ohio test facility in the summer of 1993, the engine 
was exposed to 1000 simulated flight cycles with visual inspections of the components every 50 to 100 hours. Evaluation of the blades after the test showed no signs of distress, other than the normal wear that is seen in conventional blade materials [10]. In the summer of 1994, the same 98 blades were reinstalled in another CF6 engine and exposed to an additional 500 simulated flight cycles without mishap [10]. Even though the test was successful, it was found that the cost of production was much too high. The cast scrap rate, the required use of virgin material, and electrochemical machining all increased the cost [10]. 48-2-2 was not selected for the final design of the GE90 since the weight reduction requirements could be achieved at a lower cost and lower risk [10].

In recent years significant improvements have been made to TiAl investment casting technologies. As a result, the Ni superalloy blades of the $6^{\text {th }}$ and $7^{\text {th }}$ turbine stages of GE Aircraft Engines' new generation 225-340 kN thrust class engine, called the GEnx, have been replaced with blades made from 48-2-2, as shown in Figure 3 [4]. Since the blades are rotational components, a reduction in their mass results in a reduction in the centrifugal load applied to the LPT disk. As a result, the mass of the Ni alloy disk can be reduced to maintain the same stress level. Furthermore, the weight of shafts and bearing can also then be reduced to account for lower loads. 


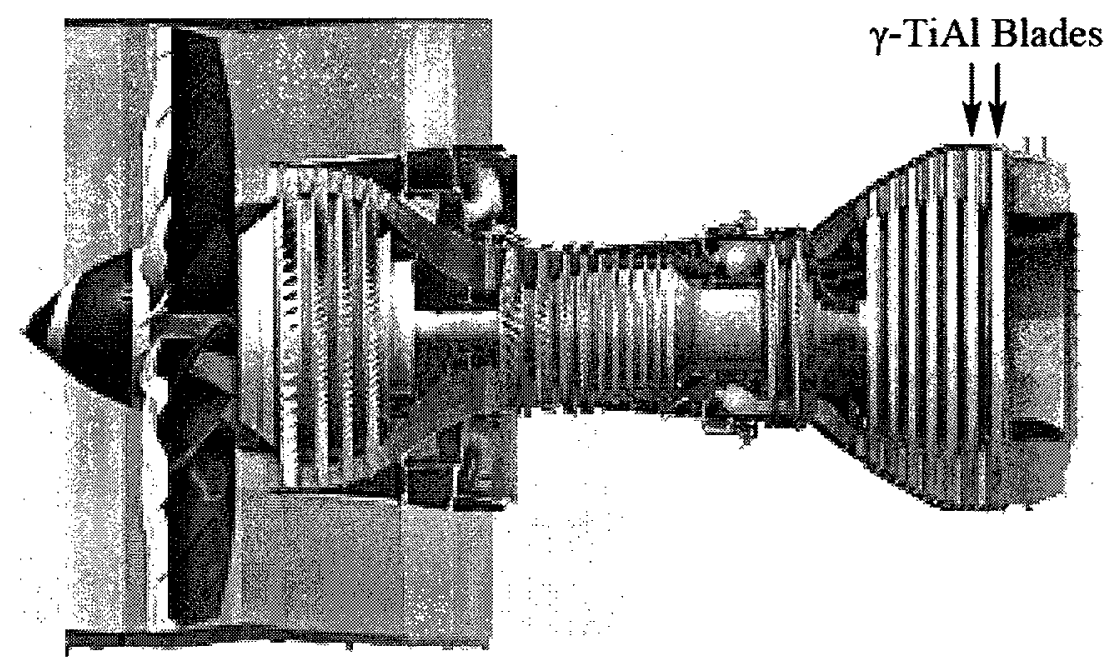

Figure 3. GEnx engine cutaway showing the location of the $\gamma$-TiAl LPT blades [11]

There were several other second generation titanium aluminide intermetallic alloys that were developed in the 1990's. The ABB alloy Ti-47Al-2W-0.5Si, and TiB2(45XD) made by Howmet-Pratt and Whitney are alloy compositions that resulted in a good balance of mechanical properties $[2,12]$. More recently, researchers found that with the addition of 5-10 at.\% niobium $(\mathrm{Nb})$ the oxidation and creep resistance was significantly improved. These new alloys are called TNB alloys [13]. In an effort to further improve the creep and oxidation resistance, the effect of composition on the microstructural evolution during solidification and cooling were considered. In the 2000's it was determined that alloys containing less aluminum and more $\beta$ stabilizing elements solidify through the $\beta$ phase resulting in several desirable microstructural features [13]. These alloys, called TNM alloys, have compositions within Ti-(43-47)Al-X(Nb,Mo,B,C) and avoid the peritectic reaction that is observed during the solidification of conventional gamma TiAl alloys. As a result, the cast microstructures of TNM alloys are chemically 
homogeneous with relatively fine grains $(50-60 \mu \mathrm{m})$, and free of sharp casting textures [13]. Utilizing similar alloy compositions to TMN alloys, it was found that by further decreasing the aluminum content and increasing the $\beta$ stabilizing elements, the $\beta$ phase could be stable at room temperatures. The $\beta$ phase has been shown to significantly improve the hot workability and machinability of a TiAl alloy $[14,18,44,45,55]$. These newly developed alloys have compositions within Ti-(40-45)Al-(2-7)Nb(1-10)(Mn, Cr, V,Mo) and are called beta gamma alloys.

Other notable applications for TiAl alloys are high pressure compressor blades and stators $[4,14]$. However, the brittle nature of TiAl makes them susceptible to foreign object impact damage since they are not protected by the filtering effects of the combustor [4]. Furthermore, the much thinner blade makes casting very challenging as a result of fill difficulties at the leading and trailing edges. Forging could potentially work however it is more expensive [4]. TiAl alloys have also been considered for several static structural components such as radial diffusers, rib stiffened panels, and TiAl honeycomb panels $[4,7]$.

\subsection{Current Problems}

There are many reasons why TiAl alloys have not been integrated into every new aeroengine being produced. $\mathrm{TiAl}$ alloys have a large scatter in mechanical properties due to textures and microstructure heterogeneity from initial solidification as well as through the processing of the materials [2,15]. Additionally, heterogeneities are generally more 
detrimental in intermetallics [2]. The properties of TiAl are also highly sensitive to the composition. Because of the large amounts of alloying additions used in TiAl alloys and the presence of two peritectic reactions in the binary phase diagram, it is very difficult to avoid segregation during the initial casting process [14]. Intermetallics are also generally more susceptible to harmful effects from thermal or thermal mechanical treatment [2]. Controlling all these parameters becomes even more difficult for larger components.

Other major problems associated with TiAl alloys are their lack of ductility at room temperature and their low fracture toughness $[2,3,5,12,15]$. Typically, a ductility greater than or equal to $1 \%$ elongation is deemed acceptable to most engineers. Though it may seem small, it is very difficult to reach this value. In fact, cast TiAl very rarely reach a ductility that high $[3,12]$. There is a desperate need to improve the ductility and fracture toughness without reducing the high temperature properties. This has become even more important for a damage tolerant design philosophy.

The other major problem is the difficulty in processing these materials to final products $[3,5,12,15]$. Although production of TiAl components is possible at a pilot level, scale up to a full production process for industry is not a simple or cost effective task [12]. Other problems include poor machinability and the current level of repair and joining technology for these materials [12]. GE has resolved some of these issues, at least for their alloy composition and application, and has successfully introduced TiAl LPT blades into the commercial market. However there are still barriers to the widespread use 
of TiAl alloys and more work needs to be done. New alloys such as beta gamma TiAl are being developed in order to improve processing and reduce the overall cost of producing turbine blades and other gas turbine engine components [16]. These particular alloys have excellent hot workability and can be forged using conventional methods. Their machinability is also far superior to conventional gamma TiAl alloys. Perhaps beta gamma alloys are the next step in providing more cost effective weight reduction in gas turbine engines. 


\section{Literature Review}

The following literature review is an overview of the current status of $\mathrm{TiAl}$ alloys and is divided into two parts. Section 2.1 focuses on conventional gamma TiAl. Section 2.2 focuses on the newly developed beta gamma TiAl alloys. For each type of alloy the microstructures, mechanical properties, and the processing routes are covered.

\subsection{Gamma TiAl Alloys}

Despite the obvious potential benefits associated with $\mathrm{TiAl}$ alloys for use in gas turbine engines, there are very few applications currently being utilized. However, there has been a significant improvement in the mechanical properties of these alloys through the development of new processes leading to improved microstructures. Understanding the advantages and downfalls of a given microstructure, as well as how to achieve it, are key to further development of TiAl alloys.

\subsubsection{Binary TiAl}

In general, intermetallic compounds between low density elements such as titanium and aluminum have excellent potential for use as structural materials in aerospace applications. They also typically exhibit excellent high temperature properties [4]. Furthermore, the symmetry of the parent metal lattice is reduced, therefore reducing the available deformation modes. A lower number of deformation modes usually result in a material that exhibits increased strength, especially at high temperature, but unfortunately 
with the detrimental effect of reduced ductility and fracture toughness [4]. Because of the brittle nature of intermetallic compounds there has not been a wide use of these alloys as structural materials. Beyond the brittle nature of titanium-aluminum intermetallic compounds, benefits such as low density, high modulus and good high temperature mechanical properties have maintained a high degree of interest for these materials. Binary titanium-aluminum intermetallic compounds have compositions typically ranging from $44-48 \%$ aluminum (as low as $42 \%$ ) [3]. Most of the attention has been placed on the development of gamma TiAl.

Conventional gamma TiAl Alloys have two primary phases that make up their microstructure: the gamma $(\gamma)-\mathrm{TiAl}$ phase and the alpha-2 $\left(\alpha_{2}\right)-\mathrm{Ti}_{3} \mathrm{Al}$ phase. The $\gamma$ phase is the major constituent typically accounting for $80-95 \%$ of the material by volume, and can be controlled by the aluminum content and with the addition of alloying elements $[17,18]$. The $\gamma$-TiAl phase has a face centered tetragonal (FCT) $\mathrm{Ll}_{0}$ structure, as illustrated in Figure 4(b) [4]. The tetragonality is very small with $\mathrm{c} / \mathrm{a}=1.04$, however, the ordered structure creates differences among the $<110>$ slip vectors [4]. The slip systems in the $\gamma$-phase can be divided into "easy" and "hard" systems [4]. This is illustrated in Figure 5. The $1 / 2$ [110] dislocations are the lowest in energy whereas the [101] and [011] are higher energy superdislocations that destroy the ordered structure and result in complex faulted structure. This implies that dislocation slip along these directions may only occur if dislocations move in pairs as to not disturb the ordered structure $[4,14,21]$. The $\alpha_{2}-\mathrm{Ti}_{3} \mathrm{Al}$ phase has a hexagonal closed packed (HCP) D0 $0_{19}$ structure, as shown in 
Figure 4(a) [4]. $\mathrm{Ti}_{3} \mathrm{Al}$ undergoes a rapid order-disorder reaction at approximately 1125 ${ }^{\circ} \mathrm{C}$, which has seemingly no nucleation barrier $[22,23,24]$. Both the $\gamma$-TiAl and $\alpha_{2}-\mathrm{Ti}_{3} \mathrm{Al}$ phases have limited ductility at room temperature [4]. The low ductility of the $\alpha_{2}$ phase at room temperature and temperatures up to $600{ }^{\circ} \mathrm{C}$ is in large part caused by its longrange order resulting in a reduction in slip systems and in the occurrence of planar slip [4]. Similarly, the long-range order of the $\gamma$ phase also decreases its plastic deformation capability resulting in low ductility at temperatures up to $750{ }^{\circ} \mathrm{C}$ [4]. A third phase, called the beta $(\beta)$ phase, can be stabilized through the use of appropriate alloying elements. The $\beta$ phase exists as both a disordered phase (A2) and an ordered phase (B2) with a body centered cubic (BCC) structure [4]. The $\beta$ phase order-disorder transformation temperature is typically within the range of $1000{ }^{\circ} \mathrm{C}$ and $1200^{\circ} \mathrm{C}$ [25]. Furthermore, an ordered orthorhombic phase called the $\mathrm{O}$ phase can be achieved with the addition of niobium and is based on the compound $\mathrm{Ti}_{2} \mathrm{AlNb}$ [4]. The temperatures and compositions at which these phases are stable can be determined from the Ti-Al binary phase diagram shown in Figure 6. As seen in Figure 6, for compositions with aluminum content ranging from 44 to 49 atomic percent the solidification is completed with a peritectic reaction $(\mathrm{L}$ $\rightarrow \mathrm{L}+\beta \rightarrow \beta+\alpha \rightarrow \alpha)$ or $(\mathrm{L} \rightarrow \mathrm{L}+\beta \rightarrow \alpha)$ or $(\mathrm{L} \rightarrow \mathrm{L}+\beta \rightarrow \mathrm{L}+\alpha \rightarrow \alpha)$. This peritectic reaction can result in significant compositional segregation. As a result, new alloys that solidify through the $\beta$ phase (below 44 at. $\%$ aluminum on the phase diagram shown in Figure 6) are being developed in order to avoid the detrimental effects of the peritectic reaction. These alloys are discussed further in section 2.2. 


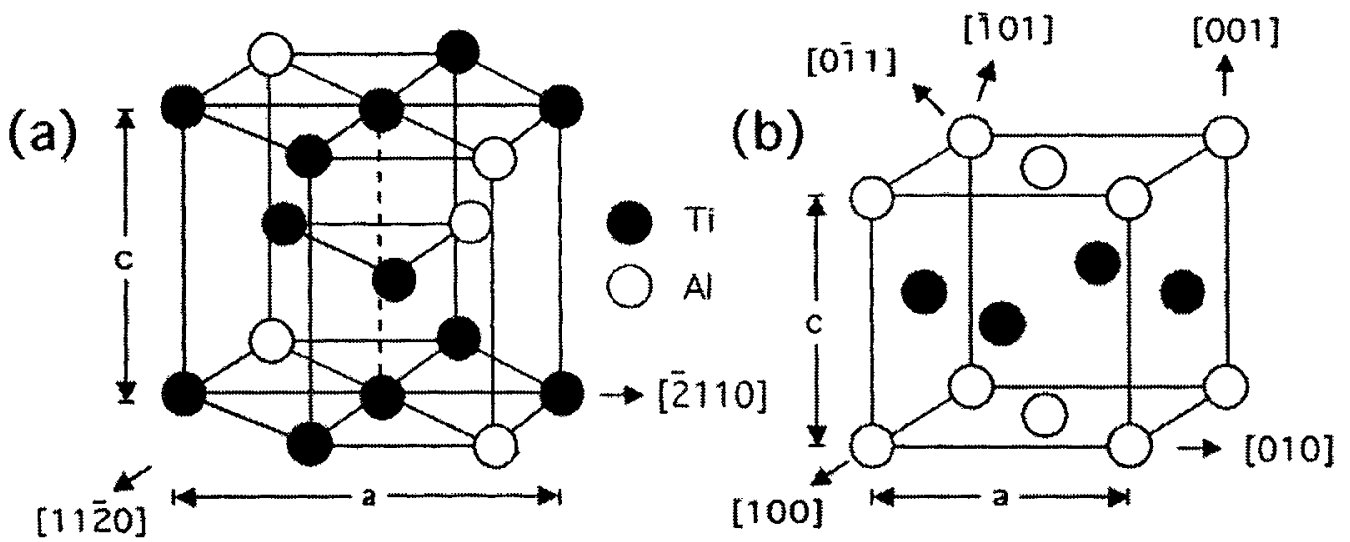

Figure 4. The crystal structure of a) $\alpha-\mathrm{Ti}_{3} \mathrm{Al}$ and b) $\gamma$-TiAl [27].

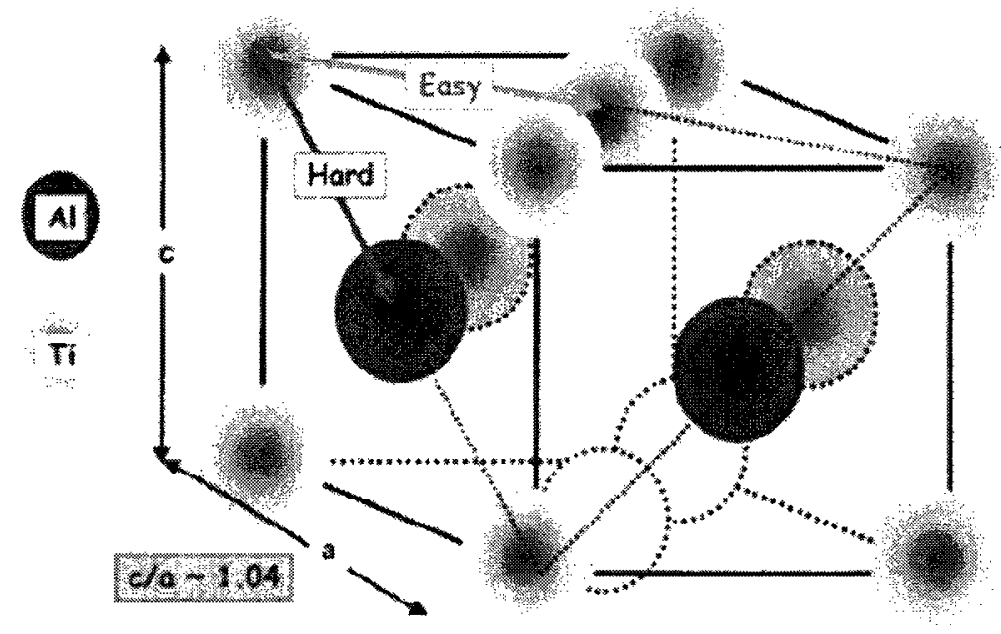

Figure 5. "Easy" and "hard" slip systems in $\gamma$-TiAl [4]. 


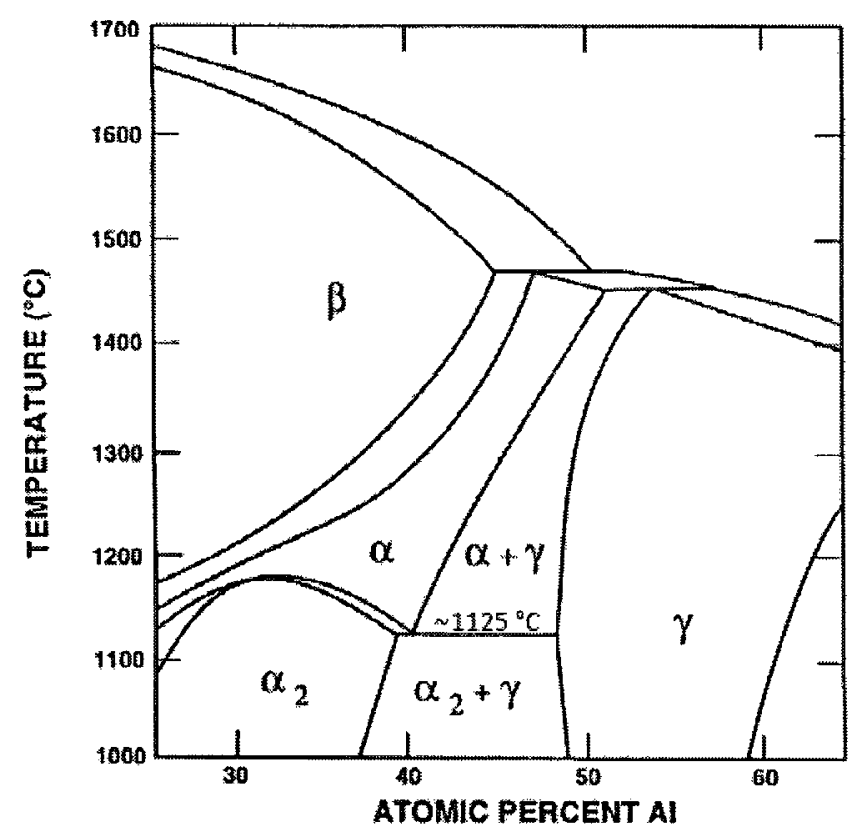

Figure 6. Binary Ti-Al phase diagram [29].

\subsubsection{Microstructures}

There are 4 typical microstructures which can be distinguished in TiAl alloys: fully lamellar (FL), near lamellar (NL), duplex (D), and near gamma (NG). Each is characterized by the volume fraction of lamellar colonies and equiaxed gamma grains. These microstructures can all be achieved through different solidification conditions, thermal treatments and alloy compositions [14,28]. An example of each type of microstructure can be seen in Figure 7. The fully lamellar microstructure consists of grains of lamellar colonies with alternating layers of $\gamma-\mathrm{TiAl}$ and $\alpha_{2}-\mathrm{Ti}_{3} \mathrm{Al}$ with orientation relationship $\{111\}_{\gamma} \|(0001)_{\alpha_{2}}$ and $\left.<1 \overline{1} 1\right]_{\gamma} \|<11 \overline{2}>_{\alpha_{2}}$ as shown in Figure 8 [28]. The grains are typically greater than $500 \mu \mathrm{m}$ in diameter $[14,17]$. In general, alloys with aluminum content less than 52 at.\% that are heat treated in the single phase gamma 
region form this microstructure [14]. The duplex structure is a mixture of lamellar colonies and equiaxed gamma grains with a typical grain size between 10 and $35 \mu \mathrm{m}$ $[14,17]$. A near lamellar microstructure consists of mostly lamellar colonies with some equiaxed gamma grains at the grain boundaries.

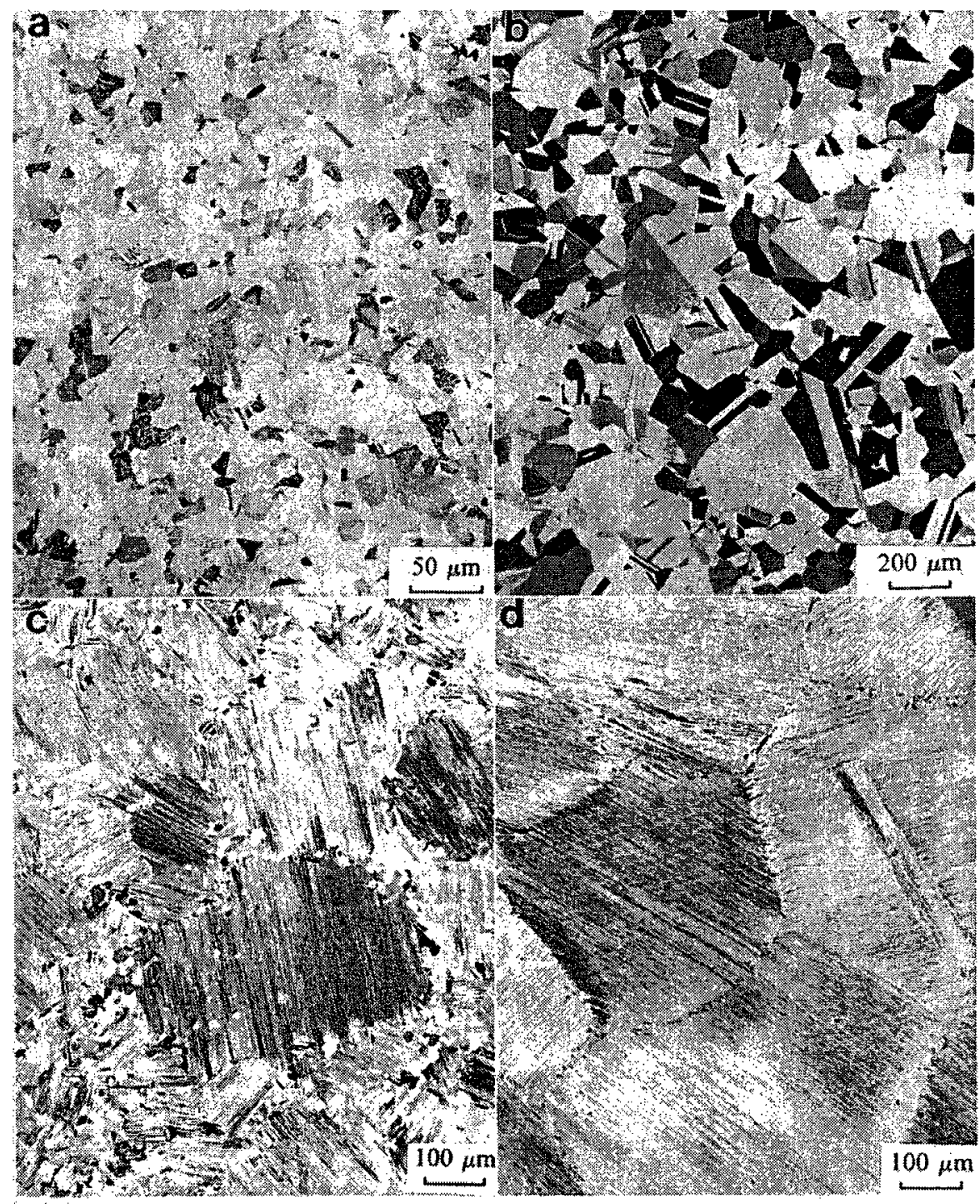

Figure 7. The four typical microstructures of $\gamma$-TiAl: a) Duplex (D) b) Near Gamma (NG) c) Near Lamellar (NL) and d) Fully Lamellar (FL) [30]. 


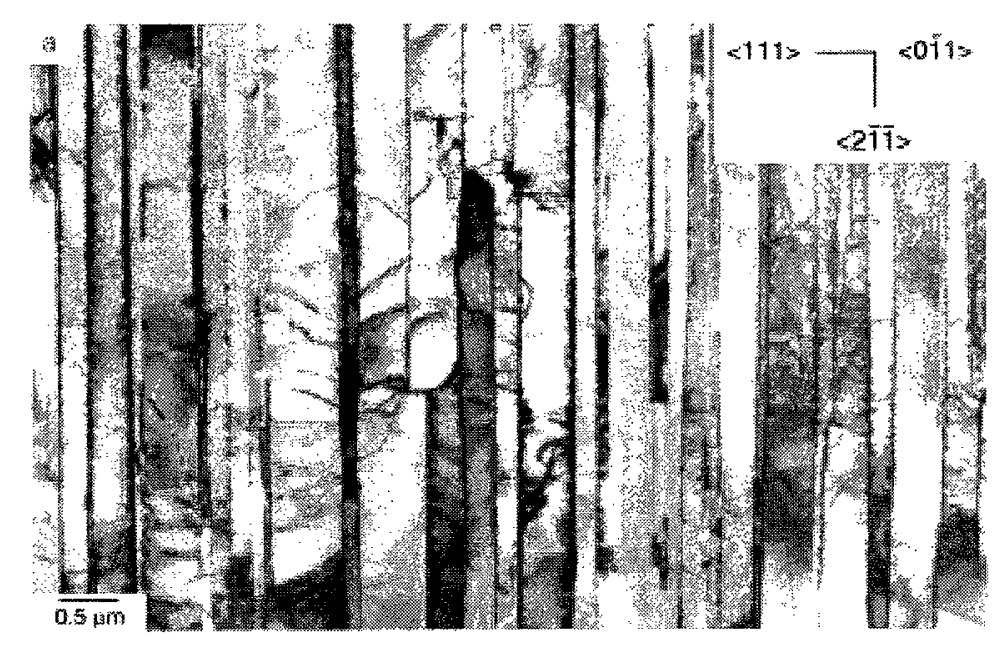

Figure 8. The lamellar structure of $\gamma$-TiAl $[28]$.

The microstructure that is formed depends highly on the heat treatment temperature and the cooling rate. If a TiAl alloy is cooled relatively quickly from the $\alpha$ phase field the resulting microstructure is typically a fully lamellar structure [3]. At slightly slower cooling rates a near lamellar structure is formed [3]. The slower cooling rate allows for coarsening of some of gamma lamellae into equiaxed grains [31]. Gamma grains can also form in the aluminum rich interdendritic zones [31]. Heat treating just below the $\alpha$ transus can also result in a near lamellar structure [32]. A duplex structure is typically formed by heat treating in the $\alpha+\gamma$ phase field where upon cooling, the structure transforms into the duplex structure consisting of lamellar grains and single phase gamma grains [31,33]. Figure 9 shows specific treatment temperatures that can be used to form the four different microstructures. 


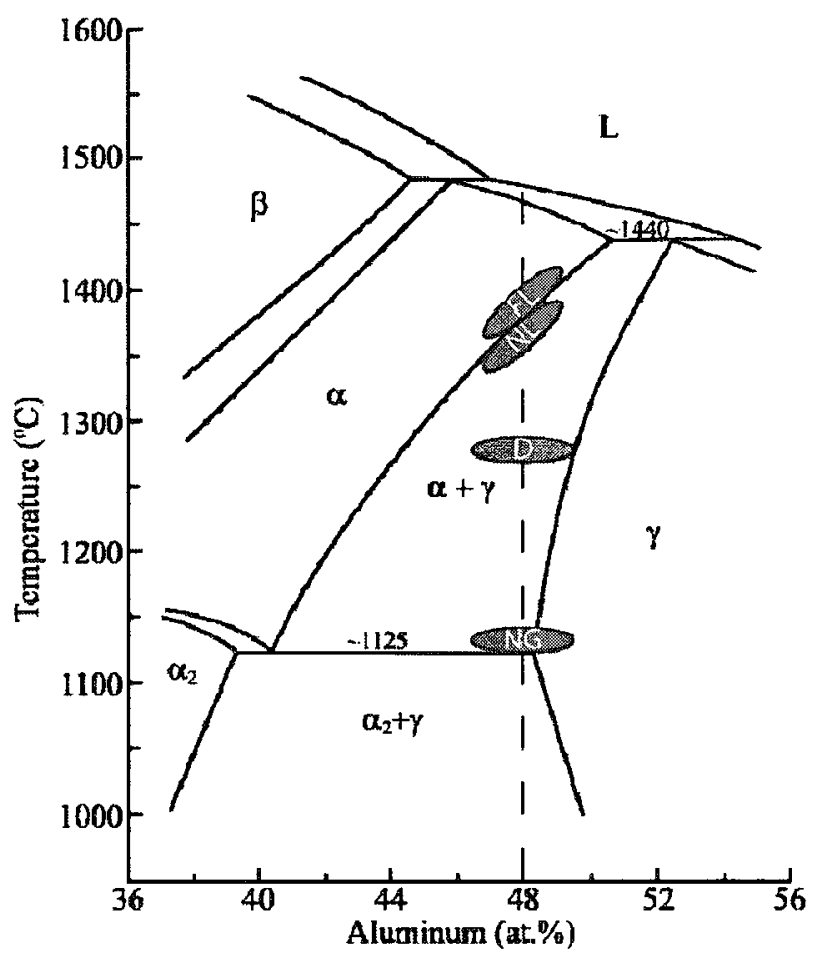

Figure 9. Binary phase diagram from [14] with heat treatment temperatures used to develop particular microstructures marked; FL: Fully Lamellar, NL: Nearly Lamellar, D: Duplex, NG: Near Gamma [32].

\subsubsection{Mechanical Properties}

The mechanical properties of gamma TiAl Alloys are strongly affected by their microstructure. Each given microstructures has their advantages and disadvantages resulting in inevitable trade-offs with respect to their mechanical properties. A given structure may be beneficial for some properties but unfavorable for others. The microstructural dependence of mechanical properties of gamma TiAl alloys will be discussed among various measures of mechanical behavior including ductility, fracture toughness, strength and creep properties. 


\subsubsection{Ductility}

The poor ductility of gamma TiAl, especially at low temperatures, has always been their short fall. In general, most intermetallic compounds exhibit brittle behavior at low temperatures and gamma TiAl alloys are no exception [14]. The ductility is highly sensitive to microstructure. A duplex microstructure has much better room temperature ductility than the other microstructures, as shown in Figure 10 and Table 1 . The best ductility is found for compositions with $48 \mathrm{at} \% \mathrm{Al}$ that have been heat treated near the center of the $\alpha+\gamma$ phase field to allow for equal volume fractions of each phase as shown in Figure 11 [14]. The ductility of the duplex phase is largely attributed to the size scale of its microstructure with grain sizes much smaller than NG, FL or NL. The ductility of any of these microstructures will tend to decrease with increasing grain size. For example, a study found that the ductility of a FL microstructure decreased from $2.0 \%$ to $0.2 \%$ when the grain size increased from 250 to $2600 \mu \mathrm{m}$ [34]. In large grained FL structures, cracking precedes general yielding which results in non-uniform yielding and subsequently low strains to failure. Figure 12 shows the fracture strain dependence on both grain size and grain size distribution. The low ductility is also largely attributed to the combined effect of low cohesion strength, insufficient deformation modes and low dislocation mobility [28]. 

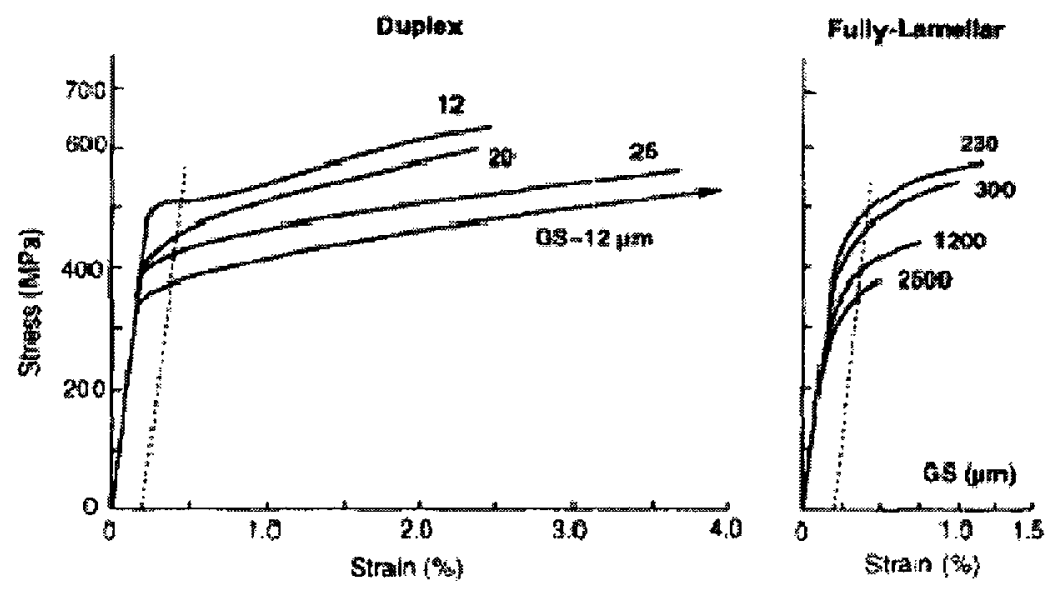

Figure 10. Room temperature stress-strain curves of a TiAl alloy with either a duplex or fully lamellar microstructures for various grain sizes [34].

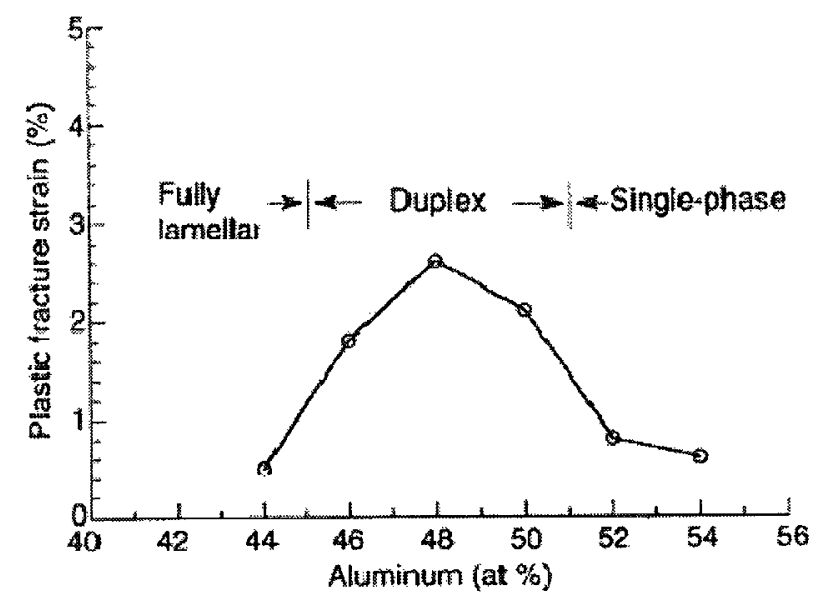

Figure 11. Room temperature ductility of binary TiAl at various aluminum Al concentrations [14].

Table 1. Mechanical Property dependence on microstructure of a Ti-46.5Al-2.5V-1Cr Alloy [21].

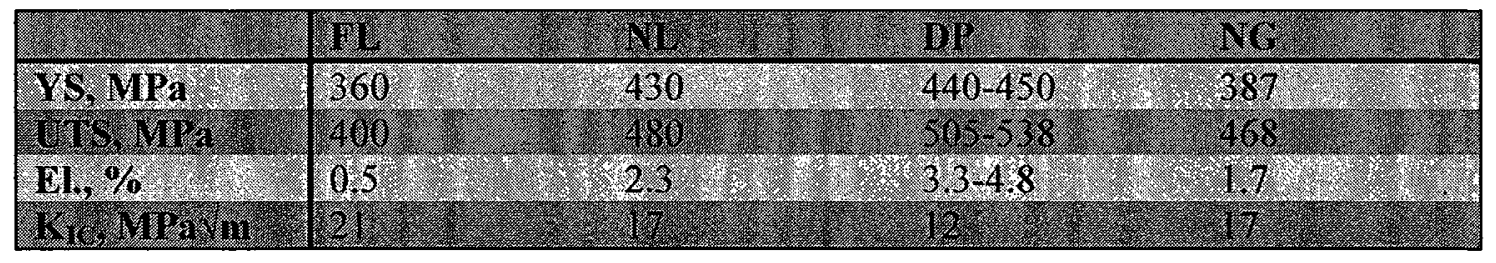



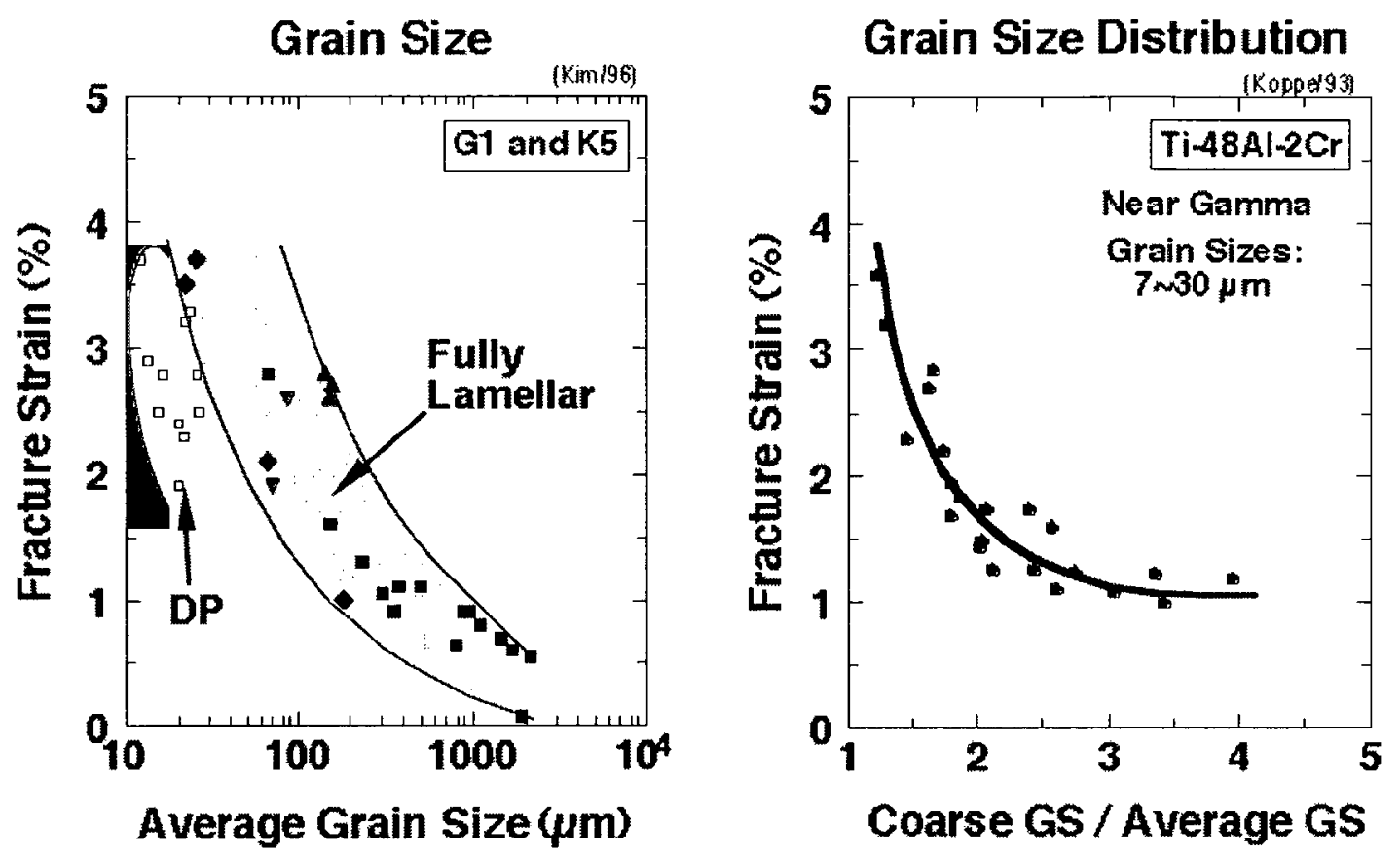

Figure 12. The effect of grain size on fracture strain [18].

\subsubsection{Fracture Toughness}

The fracture toughness of gamma TiAl is also very dependent on the microstructure. As illustrated in Table 1, the fracture toughness is highest for a fully lamellar structure and lowest for the fine grain duplex structure. The lamellar structure is most effective for toughening when the crack front is perpendicular to the lamellae allowing the $\alpha_{2}$ layers to provide resistance to crack propagation [14]

The effect of grain size is opposite to that for ductility, meaning larger scale microstructures have a higher toughness than small scale microstructures resulting in an 
inverse relationship with the ductility [14,34]. Figure 13 shows this inverse relationship for the lamellar structures.

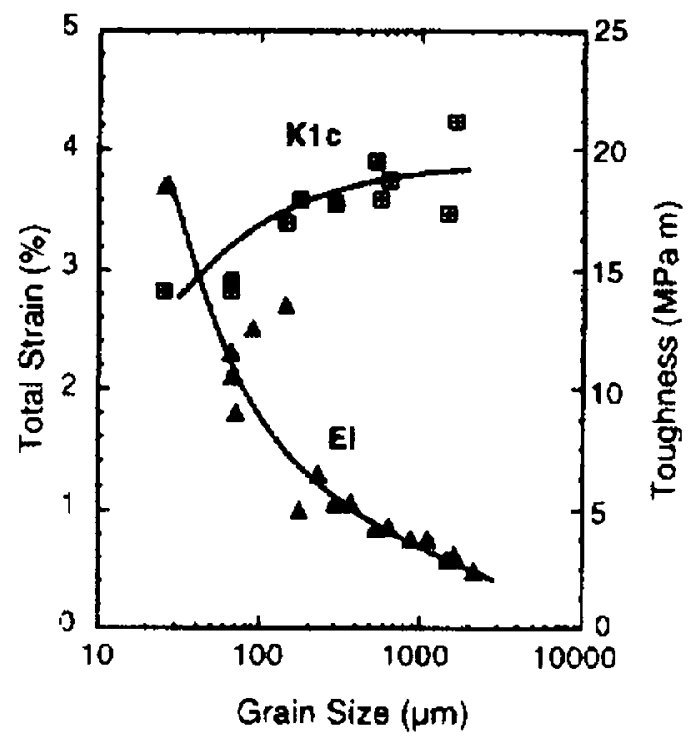

Figure 13. The relationship between fracture toughness and elongation of the lamellar microstructures $[34]$.

\subsubsection{Strength}

The strength of a TiAl alloys is largely influenced by both composition and microstructure. A dramatic increase in the strength can be achieved with addition of appropriate alloying elements. Additions of $\mathrm{Nb}, \mathrm{Cr}, \mathrm{Mo}, \mathrm{Mn}, \mathrm{Ta}$, and $\mathrm{V}$ provide varying degrees of solid solution strengthening (see section 2.1.4). Precipitation strengthening can be achieved with additions of $\mathrm{C}$ and $\mathrm{W}$ and through appropriate heat treatments (see section 2.1.4). Furthermore, the strength can be increased by reducing the aluminum content. However, this will also reduce the ductility and oxidation resistance of the alloy [28]. 
Similar to both ductility and fracture toughness, the strength is also dependent on the grain size. The strength of gamma TiAl with a given microstructure can be determined based on the Hall-Petch relationship, as show in Figure 14. For a lamellar structure, the yield strength is a function of the grain size, the lamellar spacing, and the anisotropic flow stress behavior [18,34]. Taking all these factors into account, the Hall-Petch relationship for a fully lamellar structure can be expressed.

$$
\begin{aligned}
& \sigma_{y}=\sigma_{o}+k_{F L} d^{-1 / 2} \\
& k_{F L}=\alpha k_{d}\left(k_{d} \approx 1 M P a \sqrt{m}\right) \\
& \alpha=f\left(\tau_{H} * / \tau_{S} *\right)=f\left(\lambda, \alpha_{2} / \gamma\right)
\end{aligned}
$$

Where $\tau_{\mathrm{H}}{ }^{*}$ and $\tau_{\mathrm{S}} *$ are the resolved shear stress in the "easy" and "hard" slip systems respectively, and the anisotropy factor $\alpha$ is a measure of the anisotropy of strength of the lamellar grains and is a function of the lamellar spacing $(\lambda)$ and the $\alpha_{2} / \gamma$ phase ratio. The value of $\alpha$ typically ranges from about 1.0 for large lamellar spacing to 2.5 for extremely fine lamellar spacing [18]. As indicated in Figure 14, the strength increases for decreasing grain size and lamellar spacing. 


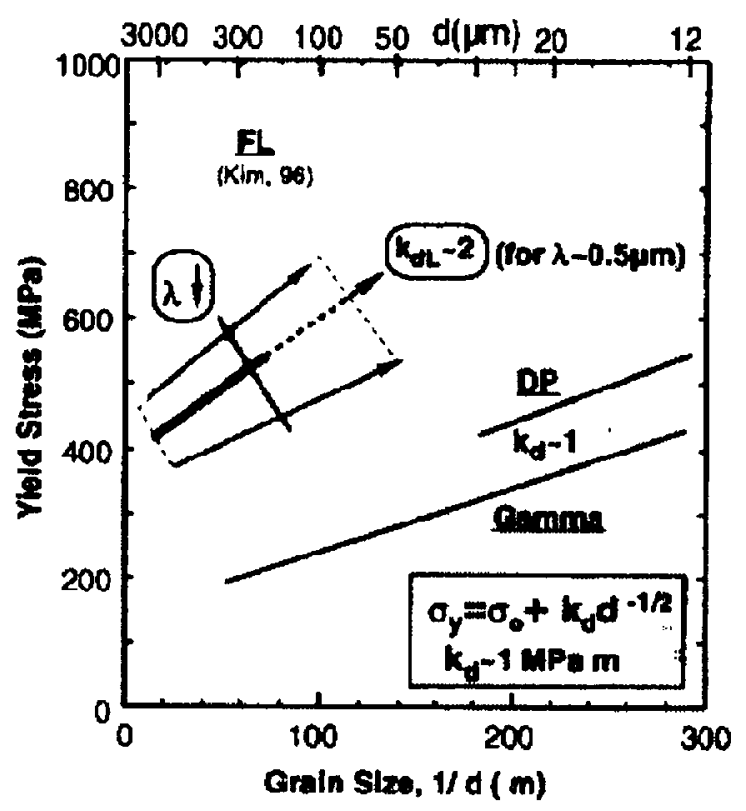

Figure 14. Hall-Petch relationship for gamma TiAl with various microstructures [34].

\subsubsection{Creep Behavior}

The creep behavior and high temperature properties of gamma TiAl alloys depend largely on the microstructure. A fully lamellar microstructure provides significantly more creep resistance than a duplex structure as illustrated in Figure 15, which compares the creep behavior of single phase $\mathrm{Ti}-52 \mathrm{Al}$ and a two phase $\mathrm{Ti}-48 \mathrm{Al}$ tested at $800{ }^{\circ} \mathrm{C}$ and $69 \mathrm{MPa}$ [33]. In fact, the Ti-48Al alloy with the fully lamellar structure continued for more than 3000 hours without any indication of tertiary creep [33]. The reduced primary and steady state creep rates of a fully lamellar structure is mainly attributed to its large grain size and because the lamellar interfaces hinder dislocation motion [14,35]. Another factor that influences the creep behavior is grain boundary morphology [21]. A serrated grain boundary that limits grain boundary sliding during creep will result in superior high 
temperature properties [21]. Tungsten rich $\beta$ precipitates at the lamellar interfaces can also be used to significantly improve the primary creep behavior by further hindering dislocation motion in the lamellae as well as by reducing the emission of dislocations from the lamellar interfaces $[15,35,36,37]$. Furthermore, limiting the grain boundaries that are perpendicular to the direction of applied stress can also improve creep properties. This can be achieved through a directional solidification process, which results in columnar grains that run the length of the component oriented along the direction of applied stress [29]. Alloying additions such as W, Mo, Nb, Cr, C, and Si can also be used to improve the creep properties [35]. The creep mechanism during primary creep of alloys with lamellar microstructures is the emission of dislocations from the interfaces [28]. The creep mechanisms during secondary creep vary for stress and temperature. At high stress and temperature dynamic recrystalization is the creep mechanism [28]. For intermediate stress and temperature the creep mechanisms include order twinning, dislocation glide and dislocation climb [28]. 


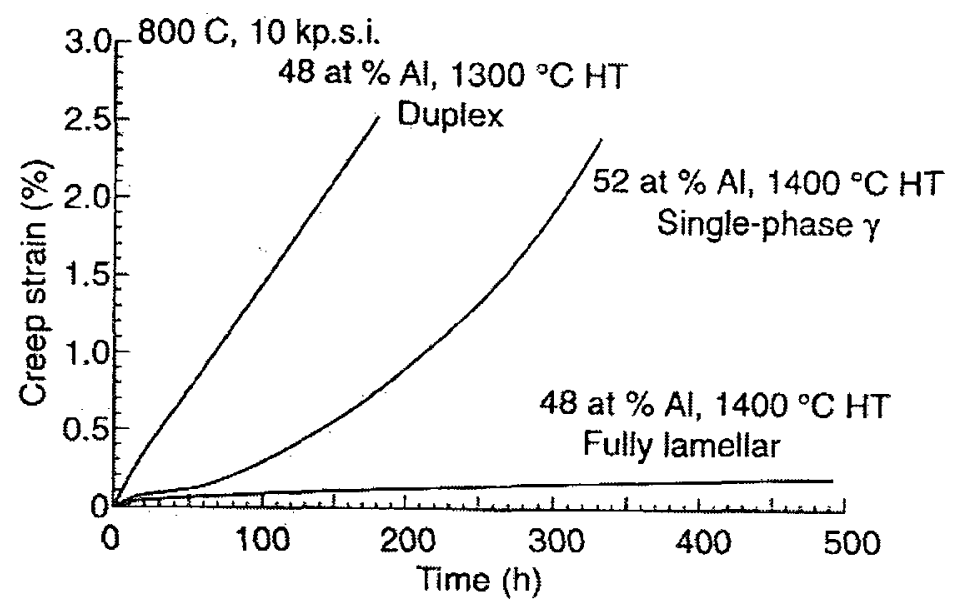

Figure 15. Creep behavior for TiAl alloys with various microstructures tested at $800{ }^{\circ} \mathrm{C}$ and $69 \mathrm{MPa}$ $[33$.

\subsubsection{Alloying}

The reduction in slip modes in both the ordered $\alpha$ and $\gamma$ phases is largely responsible for the brittle nature of TiAl alloys. Alloying can reduce the restrictions on the slip modes, as well as slow down the kinetics of the ordering. Furthermore, alloying can introduce the $\beta$ phase as a ductile phase, which can resist the growth of microcracks propagating through the $\alpha_{2}$ and $\gamma$ phases [4]. With the addition of appropriate alloying additions the phase boundaries of the binary Ti-Al system can be shifted in order to allow for different equilibrium phases at certain Al concentration. This is illustrated in Figure 16 for some widely used alloying elements. Phase boundary shift is one of the most important roles of alloying in TiAl alloys [3]. Alloying can also change the transformation behavior of the material during heat treatment, which allows for a greater degree of control of the final microstructure [4]. However, there is no evidence to indicate that alloying can directly 
affect the inherent crystal plasticity of either the $\alpha_{2}$ or $\gamma$ phases [4]. There are a number of alloying additions that are relevant to the Ti-Al system. Many are discussed in this section.

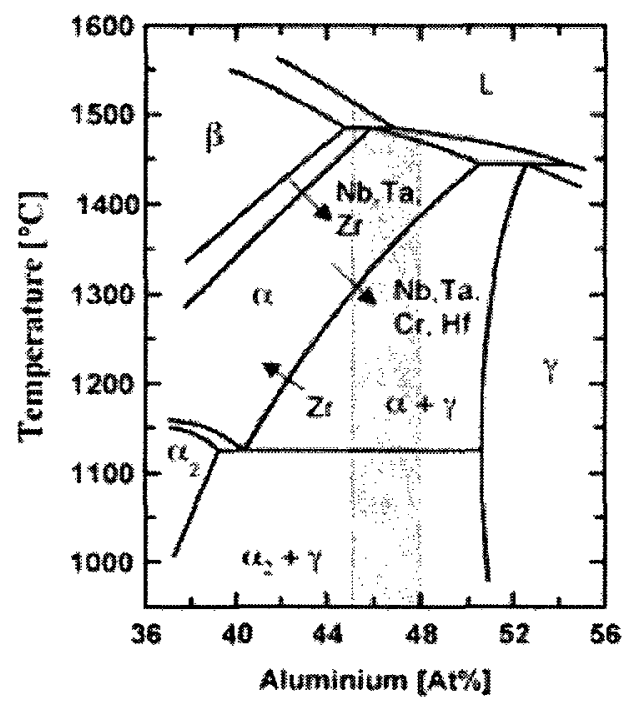

Figure 16. Phase boundary shift in the binary Ti-Al system from alloying additions [17].

\subsubsection{Aluminum}

The aluminum (Al) content is the most important consideration in the design of a TiAl alloy composition. Most gamma TiAl alloys have $\mathrm{Al}$ concentrations in the range of 45-50 at.\% [14]. The $\mathrm{Al}$ concentration has a significant effect on the solidification and the solid state equilibrium of the phases, as well as on the microstructures and mechanical properties [14]. The $\gamma$ phase is more stable in Al rich alloys and the $\alpha$ phase is more stable in $\mathrm{Al}$ lean alloys. The $\mathrm{Al}$ concentration also governs the primary and secondary solidification phases and therefore governs some as-cast mechanical properties (discussed 
in section 2.1.5.1). At lower $\mathrm{Al}$ (below 46 at.\%) the primary solidification phase is $\beta$ and the cast structure tends to be equiaxed grains. At higher $\mathrm{Al}$ concentrations the primary solidification phase is $\alpha$ and the cast structure tends to be large columnar lamellar grains [14]. As a result the as-cast fracture toughness is directly related to the $\mathrm{Al}$ concentration, as shown in Figure 17a. The strength of a TiAl alloy is also directly related to the $\mathrm{Al}$ content. Lower $\mathrm{Al}$ concentrations tend to result in increased strength, as shown in Figure $17 \mathrm{~b}$ [14]. In addition, the $\mathrm{Al}$ concentration also largely influences what microstructures can be formed, therefore affecting the mechanical properties (discussed in section 2.1.3). With appropriate heat treatments, an alloy with over 52 at.\% $\mathrm{Al}$ will tend to have a single phase gamma microstructure, an alloy with $48-50$ at.\% $\mathrm{Al}$ will tend to have a duplex microstructure, and an alloy with less than 48 at.\% Al can have a fully lamellar, near lamellar or duplex microstructure [14].

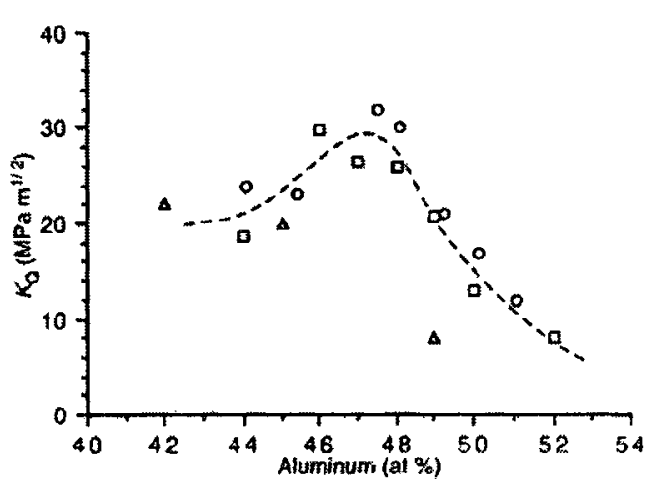

a)

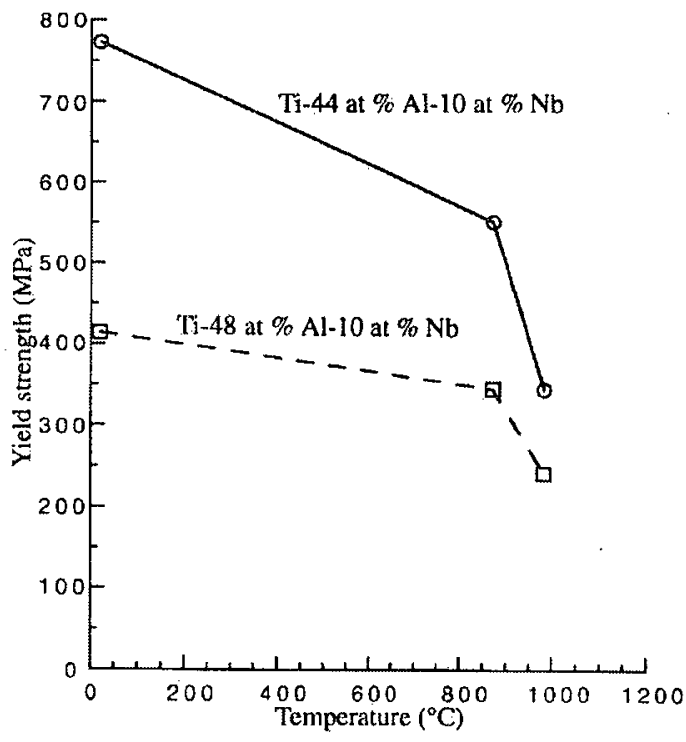

b)

Figure 17. The effect of aluminum content on a) the fracture toughness of as-cast binary alloys, and b) the strength of high $\mathrm{Nb}$ alloys for various temperatures [14]. 


\subsubsection{Niobium}

Niobium $(\mathrm{Nb})$ is a widely used alloying addition and is particularly important for improving the oxidation resistance of the material. A significant improvement in oxidation resistance can be seen with additions up to about 7.5 at. $\%[3,19]$. The oxidation resistance tends to improve linearly with the amount of $\mathrm{Nb}$ added [14]. $\mathrm{Nb}$ additions can also significantly strengthen the material through solid solution strengthening $[3,17,28]$. Furthermore, additions of $\mathrm{Nb}$ increases the anisotropy of the lattice structure resulting in further strengthening [19]. $\mathrm{Nb}$ also improves the high temperature mechanical properties by slowing diffusion $[14,38]$. Nb has also been shown to refine the microstructure [28]. Because $\mathrm{Nb}$ is soluble in TiAl it can be added in substantial amounts, however, with additions greater than 15 at. \% the toughness is reduced and some amount of the sigma $(\sigma)$ phase begins to form [19]. Additionally, the density of the material increases with the amount of $\mathrm{Nb}$ added. For example, an alloy containing 10 at. $\% \mathrm{Nb}$ is 1.1 times heavier than one that does not contain $\mathrm{Nb}[19]$. Another detrimental effect of $\mathrm{Nb}$ additions is that it embrittles the gamma phase and therefore lowers the ductility of the material [19,39]. Other alloying additions are therefore necessary to improve the forgability of high $\mathrm{Nb}$ alloys [19,39]. Another effect of adding $\mathrm{Nb}$ can be seen in Figure 16, where $\mathrm{Nb}$ shifts the phase boundaries and acts as a $\beta$ stabilizer. 


\subsubsection{Boron}

Boron (B) additions are very widely used for grain refinement and to stabilize the microstructure, as shown in Figure $18[3,4,17,28]$. Grain refinement is achieved through the formation of $\mathrm{TiB}_{2}$ particles, which refine the lamellar colonies and also act as barriers for grain growth at high temperatures $[4,17]$. However, B additions can result in larger lamellar spacing [4]. Boron can also reduce the ductility through the formation of excess borides [39].
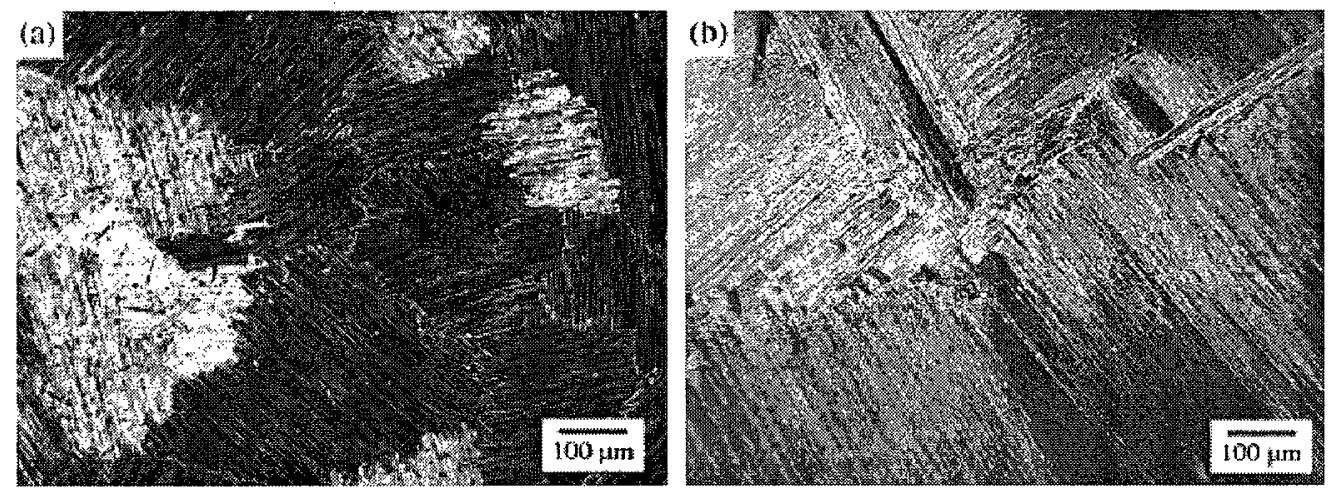

Figure 18. The effect of Boron on grain size; (a) Ti-48Al-2Cr-2Nb-1B and (b) Ti-48-2Cr-2Nb [3].

\subsubsection{Chromium, Manganese, Molybdenum, Vanadium}

Chromium (Cr), manganese (Mn), molybdenum (Mo) and vanadium (V) additions improve the ductility for materials with a duplex or two phase microstructure $[14,28]$. $\mathrm{Cr}$ can improve the oxidation resistance at concentrations above 8 at. \%. However, it can also be detrimental to the oxidation resistance at concentrations less than 4 at.\% [14]. Mo can provide some oxidation resistance [14]. Solid solution strengthening can be achieved 
with additions of $\mathrm{Cr}, \mathrm{Mo}, \mathrm{Mn}$, and $\mathrm{V}$ with concentrations between $0.6-1$ at. \% [28]. All of these elements are also $\beta$ stabilizers [40].

\subsubsection{Tungsten}

Tungsten (W) can be effectively used to increase the creep resistance through the formation of $\beta$ particles at the grain boundaries and lamellar interfaces $[14,15,32,35]$. Additionally, tungsten can provide some oxidation resistance and increased strength $[14,39]$. Tungsten is also a $\beta$ stabilizer [36].

\subsubsection{Carbon}

Additions of Carbon (C) have been shown to increase the creep resistance and high temperature strength of TiAl alloys $[18,21,28]$. The creep rate is reduced by providing dislocation drag, and the increased strength comes from the formation of $\mathrm{Ti}_{3} \mathrm{AlC}$ perovskite precipitates $[14,18]$. These precipitates provide a strong resistance to dislocation glide due to their large coherency stresses and mismatch with the gamma matrix [14].

\subsubsection{Tantalum, Phosphorous, Silicon, Yttrium}

Tantalum (Ta), phosphorous (P), silicon (Si) and yttrium (Y) all provide some oxidation resistance [14]. Phosphorous decreases the oxidation rate at concentrations as low as 0.1 at. \%. Silicon forms an $\mathrm{SiO}_{2}$ layer that helps reduce the infusion of oxygen. Yttrium improves the adhesion of surface oxides [14]. Silicon also increases creep resistance 
through the formation of $\mathrm{Ti}_{5} \mathrm{Si}_{3}$, which stabilizes the lamellar structure [14]. Tantalum increases the creep resistance by slowing down diffusion [14]. Furthermore, Tantalum provides solid solution strengthening with additions between $0.6-1$ at.\% [28].

\subsubsection{Nitrogen and Oxygen}

Both Nitrogen $(\mathrm{N})$ and Oxygen $(\mathrm{O})$ increase the strength but reduce the ductility of gamma TiAl $[3,14]$. Nitrogen can improve the creep resistance by providing dislocation drag [14]. Nominal oxygen levels are typically between 500-1000 ppm but can be lower since the $\alpha_{2}$ phase will absorb oxygen, which will strengthen it but also lowers its ductility $[3,14]$.

\subsubsection{Processing}

One of the main reasons why introducing TiAl alloys into the aerospace industry has been so troublesome is the difficulty associated with processing them to their final shape in a cost effective and efficient way [3]. There has been a significant amount of effort in developing processing technologies to allow structural parts to be made having a promising balance of mechanical properties. Casting, wrought (ingot metallurgy), and powder metallurgy processing routes have been developed for particular compositions and applications with varying degrees of success. However, even if the desired microstructure and mechanical properties can be achieved at a research level, the cost and statistical success of full-scale production of the TiAl components must also be considered. The ongoing production of TiAl LPT blades for the GEnx engine by means 
of investment casting has proven that full-scale production of TiAl components is economically feasible. With expansions to some of their plants, GE is expected to produce 50,000 blades per year by 2010 [41].

Figure 19 shows several possible processing routes for TiAl alloys. In this section casting, wrought and PM processing will be reviewed. However, the focus will be on powder metallurgy processing since it is more pertinent to the research topic.

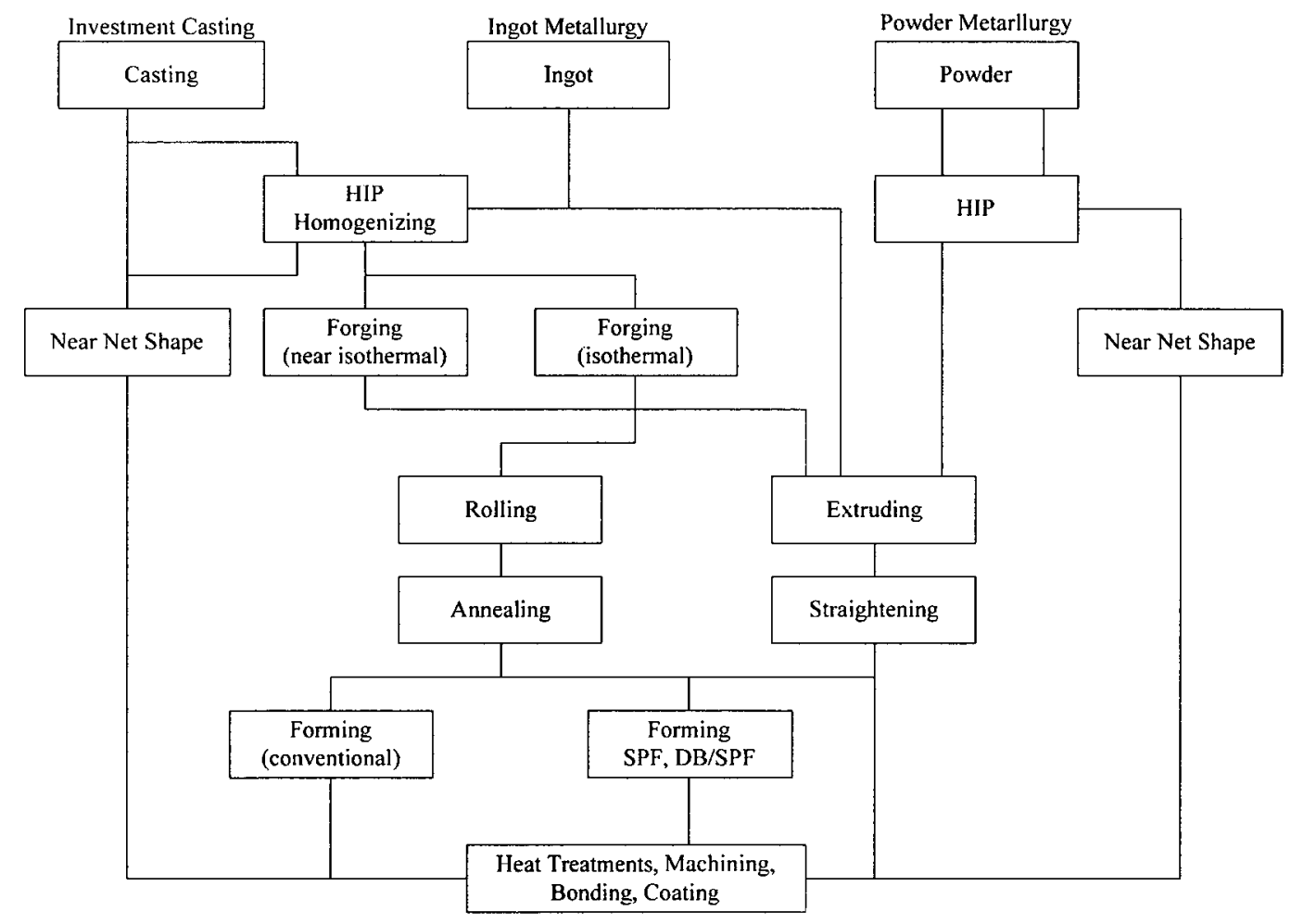

Figure 19. Typical processing routes for gam ma TiAl alloys [42]. 


\subsubsection{Casting Processes}

Casting is the most economical way of producing TiAl components for research purposes $[3,12]$. Investment casting is a well established process for the production of complex TiAl parts [3]. One of the main issues with casting these materials is the high reactivity of molten TiAl. This issue can be managed with the use of cold wall crucibles. However, cold wall crucibles are thermally inefficient and require preheating of the molds to allow improved filling. For these reasons, slow cooling is difficult to avoid, which results in large $\alpha$ grains and therefore long lamellae [3]. Large lamellar grains can result in low ductility, a large scatter in properties, pre-yield cracking and can also act as fatigue crack initiation sites [3]. Dimples, and the associated porosity, in cast components is also a major problem leading to a reject rate as high as $80 \%$, which inevitably increases the cost of production [3]. To mitigate the formation of porosity, casting is typically followed by hot isostatic pressing (HIP), as show in Figure 19.

In casting gamma TiAl alloys there are a number of possible cast structures that can be obtained at different aluminum levels. As seen in the phase diagram in Figure 6, there are 3 primary solidifying phases and two peritectic reactions. As a result of these peritectic reactions, significant segregation of the aluminum and the formation of unstable phases is very difficult to avoid [14,43]. For example, during the solidification of a stoichiometric composition the primary solidification phase is $\alpha-\mathrm{Ti}_{3} \mathrm{Al}$ and aluminum is therefore rejected into the interdendritic zones, while refractory alloying elements, particularly those that stabilize the $\beta$ phase, become concentrated in the dentritic 
core [43]. The formation of secondary gamma phase occurs preferentially at the locations of high aluminum content resulting in a highly segregated cast structure [14]. Figure 20 shows the $\gamma$-phase volume fraction as a function of the aluminum concentration. The $\gamma$-TiAl phase will only solidify as a primary phase in alloys containing more than 55 at.\% aluminum. In alloys with less than 49 at.\% aluminum the primary solidification phase is $\beta$, which is metastable at room temperature.

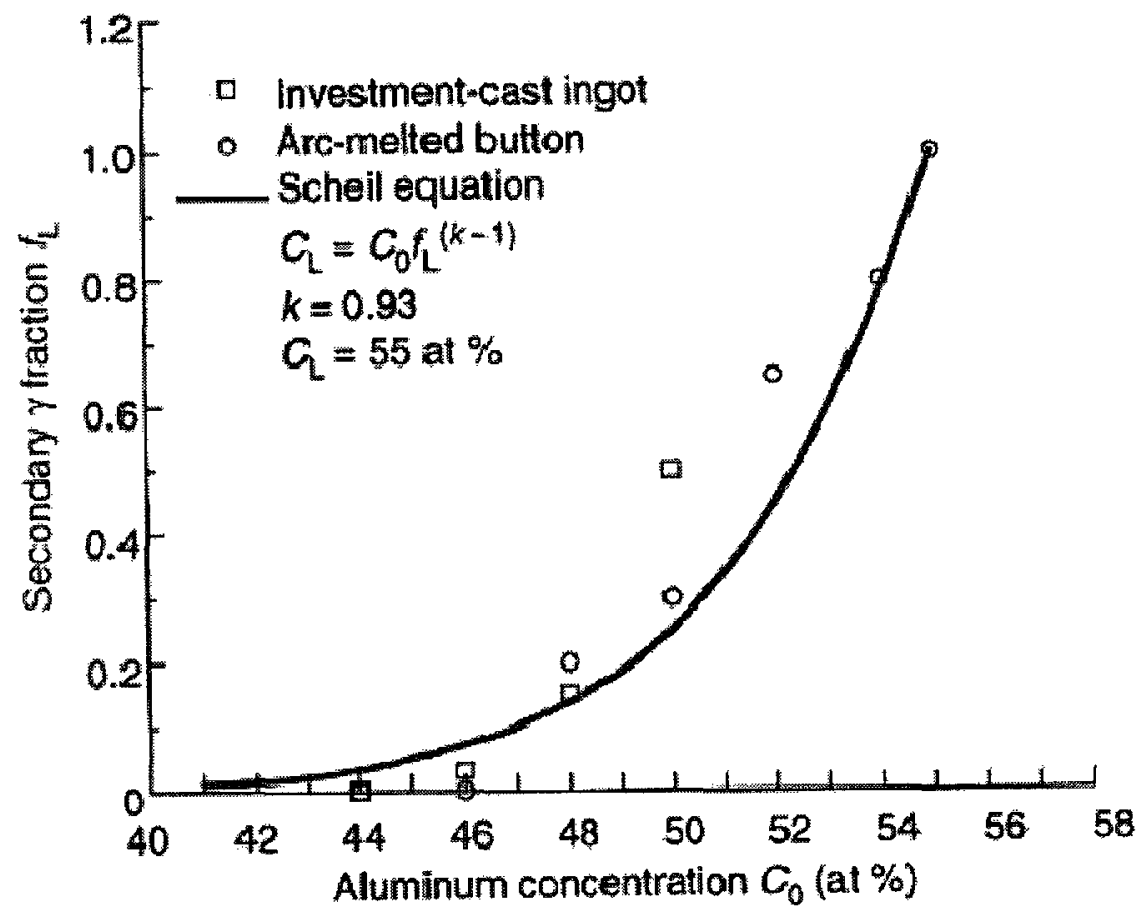

Figure 20. The volume fraction of secondary gamma-phase as a function of the Al concentration [14].

Other challenges in casting include misrun, which occurs when the superheat is too low, surface shrinkage due to entrapped bubbles, shrinkage during HIP'ing, and hottearing and cracking due to the mold restraint during solidification and cooling [5]. In order to eliminate some of these problems new investment casting processes have been 
investigated, including: centrifugal, tilt and counter gravity [5]. With centrifugal investment casting complete filling of the mold is possible; however, the presence of turbulence creates other challenges. The other two techniques have less turbulent filling of the mold. These three investment casting techniques have been used successfully to produce gamma TiAl valves for automotive engines [5].

Directional solidification casting techniques, with the use of a Bridgman furnace, can provide excellent high temperature properties through careful control of the microstructure [29,35]. Directional solidification can be used to produce columnar fully lamellar grains that are oriented in the direction of applied load by carefully controlling the temperature gradients during solidification. As a result, the creep behavior is significantly improved since grain boundaries that are perpendicular to the loading direction, which act as weak points at high temperature, are eliminated [29]. The lack of transverse grain boundaries also mitigates the effects of diffusion creep [29].

\subsubsection{Wrought Processes}

Wrought processing is a promising processing route for TiAl alloys. A broad range of microstructure can be developed with the added benefit of a refined microstructure, as compared to those produced though casting processes [28]. As mentioned previously, a more refined microstructure results in improved ductility and strength. Additionally, hot working is an effective way of increasing the uniformity of the microstructure [39]. However, not unlike casting, wrought processing also has the problem of macro- and 
microsegregation during the production of the ingot, once again due to the presence of the peritectic reactions during solidification [28]. Nevertheless, multistep hot working has been show to help alleviate that problem $[12,28]$.

Typical wrought processing of gamma TiAl alloys includes canned hot extrusion, isothermal forging, or canned non-isothermal forging of a cast ingot into a near net shape component, which is subsequently machined to its final dimensions. This can be followed by a heat treatment to obtain the desired final microstructure. This process is illustrated in Figure 19. This processing route has been used to produce HPC blades and resulted in a very homogeneous lamellar microstructure with an average colony size of $130 \mu \mathrm{m}$ [28]. In general, the hot ductility of gamma TiAl is very poor and is highly dependent on the strain rate and temperature, which gives rise to a certain flow stress in the material [28]. In order to achieve crack free forging a critical tensile stress in the workpiece must not be exceeded. This critical stress is typically in the range of 200-500 MPa depending on the alloy composition and the microstructure [28]. Therefore, ideally, forging should be done at moderate strain rates $<10^{-1} \mathrm{~s}^{-1}$ and at isothermal conditions. Strain rates below $10^{-2} \mathrm{~s}^{-1}$ were found to provide optimum microstructural homogeneity [28]. However, careful control of the temperature is essential, where temperature losses can result in cracking. Canning is one way to control the temperature. Canned hot extrusion can be done at higher strain rates and is typically done at temperatures above $1250{ }^{\circ} \mathrm{C}$ [28]. 
In both hot extrusion and isothermal forging the use of a can is known to significantly improve their success. Cans are typically made from a conventional Ti alloy or an austenitic stainless steel [28]. The can design should be such that the flow stress in the billet and the can during deformation are as close as possible as to avoid nonuniformities and cracking [28]. The thickness of the can and the thermal insulation between the can and the billet are important considerations for a proper can design [28]. With the use of a properly designed can, a significant reduction in forging temperature is possible and the achievable height reduction in a one step forging process increased [28].

The presence of the $\beta$ phase has also been shown to significantly improve the hot workability of TiAl alloys $[18,43,44,45]$. In wrought processing of alloys containing the $\beta$ phase the ingot is heated into the $\alpha+\beta$ phase field and subsequently forged. This process can be done in generally available facilities, therefore the cost reduction can be substantial [44]. Furthermore, the $\beta$ phase can also considerably improve the machinablity $[18,45]$. The effects of the $\beta$ phase and beta gamma alloys will be discussed further in section 2.2 .

\subsubsection{Powder Metallurgy (PM)}

Powder metallurgy (PM) is a very attractive processing route for TiAl since a high degree of chemical homogeneity can be achieved while avoiding macrosegregation [46]. Furthermore, PM can be used as a near net shape process, which limits both the wasted material and the subsequent machining to the final shape. It has been shown that room 
and elevated temperature properties of fully lamellar PM TiAl alloys are superior to those made by ingot metallurgy. In fact, superplastic behavior has been observed in PM TiAl that contains the $\beta$ phase and a fine-grained two phase $\left(\gamma\right.$ and $\left.\alpha_{2}\right)$ duplex microstructure [47].

\subsection{Powder Atomization Techniques}

There are a number of difficulties associated with the production of gamma TiAl alloy powders. Firstly, the melting temperature of these alloys is relatively high $\left(\sim 1450^{\circ} \mathrm{C}\right)$. Secondly, the molten TiAl is highly reactive and will react with almost any crucible material. Thirdly, the molten TiAl, as well as the hot TiAl particles, and even room temperature TiAl powder particles, are very susceptible to the absorption of oxygen, nitrogen and carbon if exposed to air. As a result of these difficulties, the production of TiAl powders is limited to specialized techniques such as crucible-free or cold crucible techniques. An example of a commonly used crucible-free technique is Electrode Induction Melting Gas Atomization (EIGA). Plasma Melting Induction Guided Gas Atomization (PIGA) is an example of a commonly used cold crucible technique [17].

In EIGA a pre-alloyed rod is fed into a conical induction coil, as show in Figure 21. The induction coil melts the tip of the rod and the subsequent liquid droplets fall into the center of an argon gas nozzle where it is atomized. The melt rate can be controlled by the power in the induction coil and the feed rate of the rod. The rod also rotates slowly (around $5 \mathrm{rpm}$ ) in order to maintain symmetric melting of the tip. Up to $50 \mathrm{~kg} / \mathrm{hr}$ of 
powder can be produced using this technique [17]. Some advantages of this technique can be attributed to the small volume of molten metal present, which results in small power requirements as well as increased safety. However, a disadvantage is the required used of a pre-alloyed rod. Any segregation along the length of the rod would result in a chemically heterogeneous powder [17].

PIGA is a technique that was specifically developed for $\mathrm{Ti}$ and $\mathrm{Ti}$ alloys and is shown schematically in Figure 22. A He-operated plasma torch is used to maintain a melt bath that is contained in a water-cooled copper crucible. An induction coil heated watercooled copper funnel placed at the bottom of the crucible guides the melt stream into the center of an argon gas nozzle where it is atomized. A melt flow rate up to $250 \mathrm{~kg} / \mathrm{hr}$ can be achieved using this technique. A drawback to PIGA is the higher electrical power requirements needed in order to maintain a much larger volume of molten metal than in EIGA. Furthermore, the large volume of molten metal requires a higher degree of safety precautions. However, the melt bath associated with PIGA maintains a chemically homogeneous source for the melt stream and the subsequent powder [17]. 


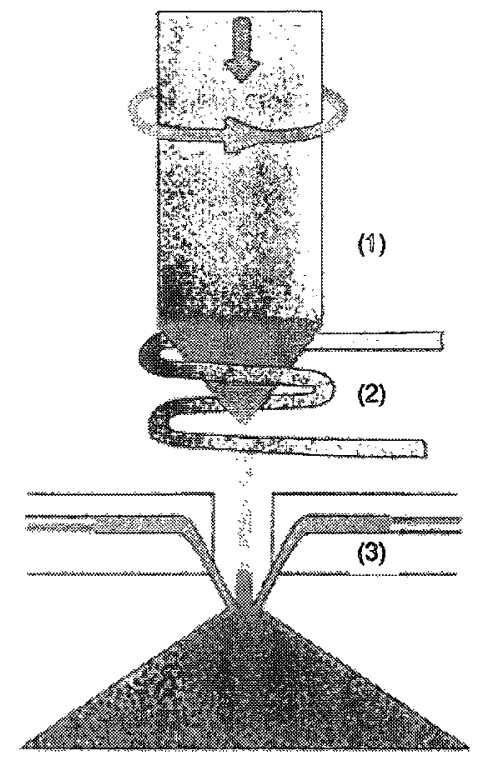

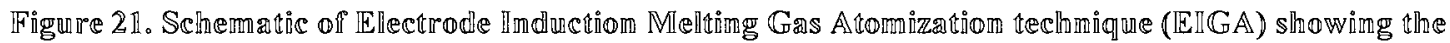
(1) electrode, (2) indluction coil, and (3) gas mozzle [17].

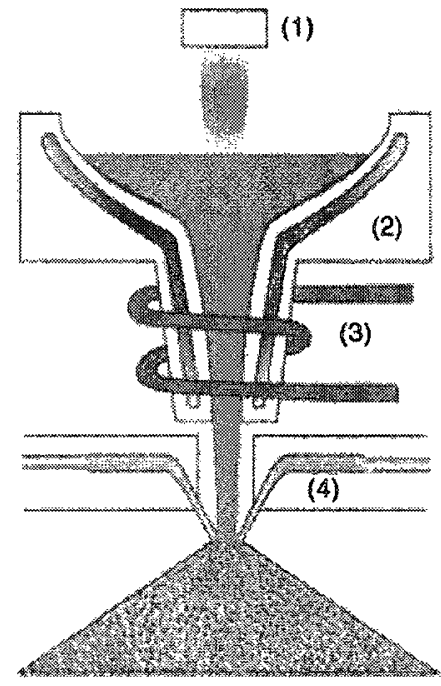

Fingure 22. Schematic of Plasma Meltiong Gas A tromization technionue (PIGA) showimg the (1) plasma

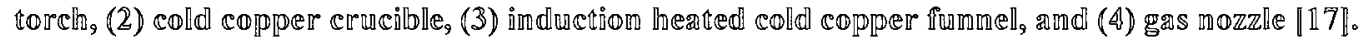




\subsection{Properties of Gamma TiAl Powders}

The microstructural quality of a component made using a powder metallurgical process is highly dependent of the powder properties prior to consolidation. The quality of a gamma TiAl powder can be quantified and controlled by the powder size and distribution, the level of impurities within the powder particles, the amount of closed pores containing the atomization gas, and the cooling rate of the powder particles after atomization. Careful control of these parameters can guarantee a high quality powder as well as a superior microstructure in the final consolidated part [17]. Ideally, the powder particles should be chemically and microstructurally homogeneous, therefore resulting in a compact with limited micro- and macrosegregation. Furthermore, the oxygen and nitrogen levels in the particles should be kept as low as possible. The powder particles should also be as small as possible in order to obtain a very small grain size once the powder is consolidated.

\section{Powder Size Distribution}

The powder size and distribution depends highly on several parameters. Firstly, the properties of the melt, such as density, temperature, viscosity, and surface tension, can influence the quality of the powder. Secondly, the atomizing gas flow, which is dependent on the type of atomization gas, as well as the nozzle geometry and the gas velocity and pressure, can influence the powder quality. 
The shape of the powder particles produced using the aforementioned atomization techniques is almost always spherical regardless of their size. Figure 23 is an SEM image of a PIGA-powder with spherical particles having diameters ranging from $20-90 \mu \mathrm{m}$. Figure 24 shows typical powder size distribution for both PIGA and EIGA. Nearly all the powder particles produced using these techniques are less than $180 \mu \mathrm{m}$, which is well within the $0-250 \mu \mathrm{m}$ acceptable size range for hot isostatic pressing (HIP) consolidation [17]. EIGA does, however, produce significantly smaller powder particles than PIGA $(\sim 55 \mu \mathrm{m}$ vrs $\sim 75 \mu \mathrm{m})$. This is mainly due the EIGAs thinner melt stream diameter as well as a smaller gas nozzle diameter [17].

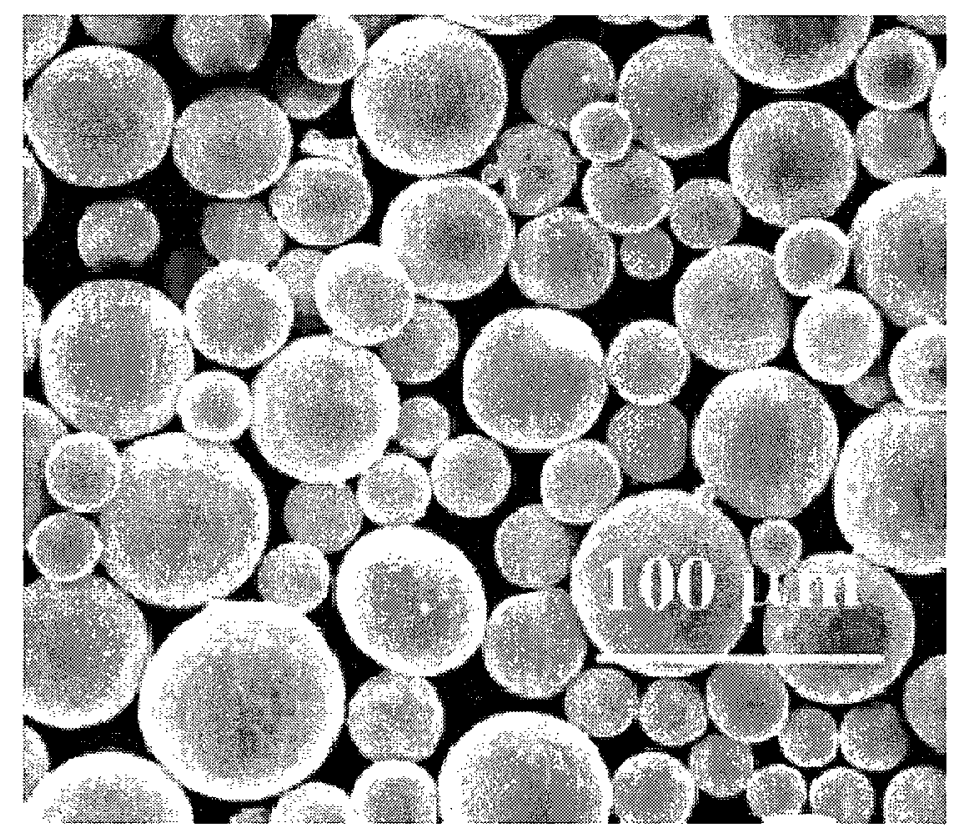

Figure 23. SEM image of Ar gas atomized Ti-50Al-2Nb alloy powder [17]. 


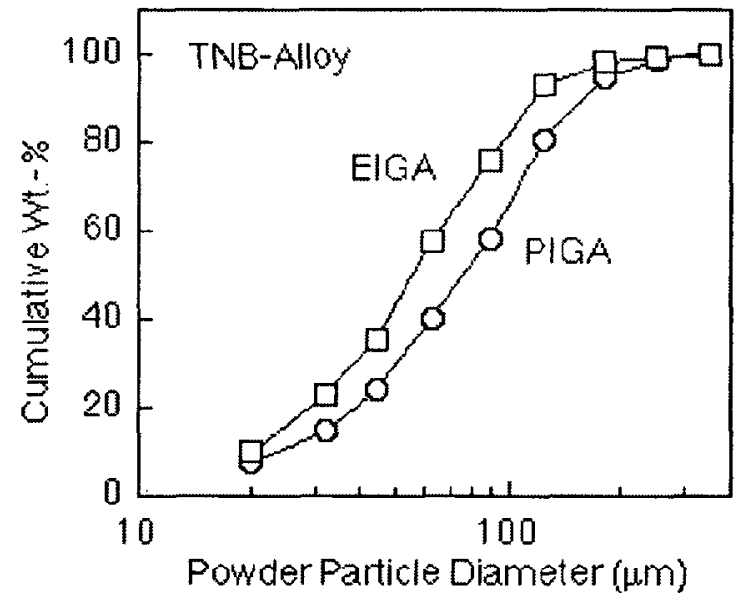

Figure 24. Powder particle size distribution of Ti-46Al-9Nb powders atomized using EIGA or PIGA techniques [17].

\section{Impurities}

The mechanical properties of a component made through powder metallurgy can be greatly degraded if there were impurities in the powder particles prior to consolidation. Oxygen and nitrogen are some of the more detrimental impurities in TiAl powders. Oxygen levels between 1050 and 1600 ppm have been found to significantly decrease the plastic fracture elongation [17]. Furthermore, oxide and nitride layers on the powder particles can make consolidation or sintering process very difficult. An oxide layer on the particles also impedes the grain growth during annealing [48]. Therefore, it is essential to maintain an inert gas environment within the atomization facility and to mitigate any exposure of the TiAl powders to air during handling. 
A study was done to evaluate the increase in oxygen and nitrogen levels when a gamma TiAl powder with a composition of Ti-45Al-7.5 Nb was exposed air between $3 \mathrm{~min}$ and 9 hours. For two different particle size fractions $(20-32 \mu \mathrm{m}$ and $45-60 \mu \mathrm{m})$ it can be seen in Figure 25 that oxygen levels increase steadily. The nitrogen level, however, was found to remain constant. The rate of oxygen absorption is also dependent on the alloy composition. Although a large oxygen content can be very detrimental, small amounts of oxygen absorption is unavoidable. For example, if the gamma TiAl powder is filled into cans under argon and subsequently HIPed, the oxygen level in the consolidated component would still be in the range of $400 \mathrm{ppm}$. However, this level of oxygen content is well within a safe margin [17].

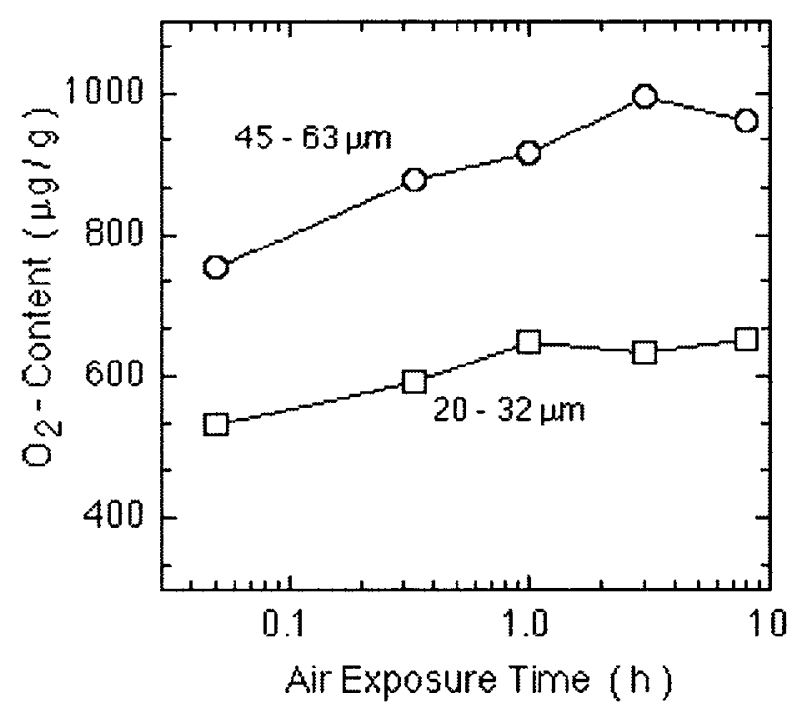

Figure 25. Increase in oxygen concentrations in Ti-45Al-7.5Nb for two different powder particle size distributions when exposed to air [17]. 


\section{Argon Gas in TiAl Powder}

The formation of closed pores, which contain the atomization gas (typically argon), during the atomization process is unavoidable. Entrapped argon in the powder particles cannot be removed through compaction. Therefore, it is essential to minimize the amount of entrapped argon as much as possible. During the HIP process the pores shrink. However subsequent thermal treatments can cause thermally induced porosity (TIP). The amount of trapped argon in the powder particles is primarily influenced by the atomization technique that is used, where EIGA results in higher argon levels than PIGA. The argon level is also influenced by the particle size where smaller particles tend to have lower amounts of argon. The use of different atomization gases such as He does not resolve the issue. In fact, the TIP due to entrapped He was found to be worse than it is with Ar. Atomization techniques that utilize a vacuum would resolve the problem, however the cooling rate is much lower, which would have a detrimental effect on the

quality of the powder particles. Furthermore, in a vacuum environment there is also the possibility of aluminum evaporation $[17,48]$

\section{Effect of Cooling Rate}

One of the main advantages associated with powder metallurgy is the ability to cool the particle very quickly. As a result of the high cooling rates, a high level of microstructural and chemical homogeneity can be achieved. Figure 26 shows the powder particles cooling rates as a function of their diameter and the type of gas used to atomize them. 
The use of helium as the atomization gas results in the highest cooling rates. The cooling rate using argon is approximately a factor of 4 lower and Vacuum is approximately a factor of 50 lower than argon. The cooling rate also increases for decreasing particle size.

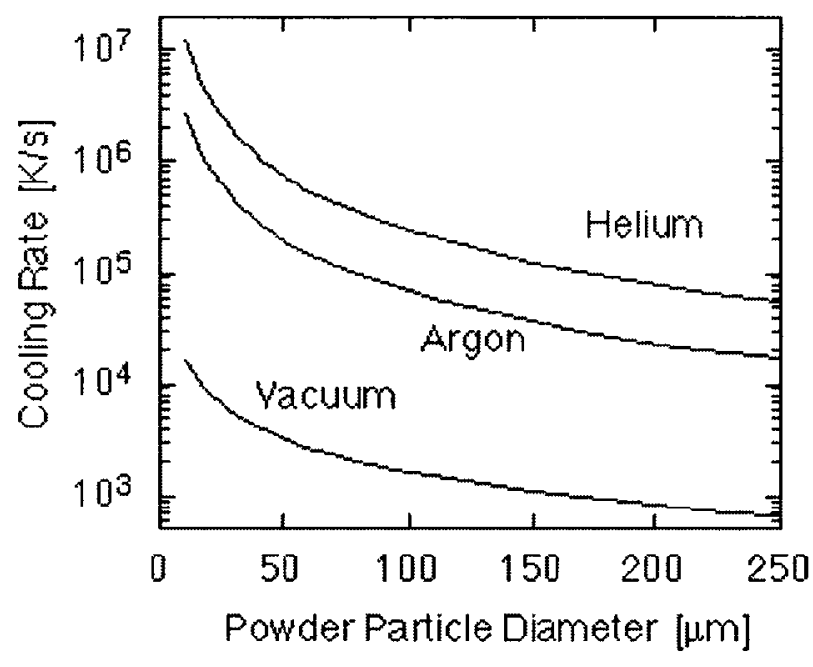

Figure 26. Cooling rates for Ti-49Al powder particles at $1750 \mathrm{~K}$ with various atomization gases [17].

The cooling rate can have a profound effect on the microstructure and phase distribution. In rapidly solidified TiAl powder metastable phases can be formed. The nature of these phases depends greatly on the composition of the powder as well as the cooling rate. For compositions less than 49 at. $\% \mathrm{Al}$ the $\beta$ phase is the primary nucleating phase. Higher undercooling results in a larger fraction of metastable $\beta$ phase, which subsequently transforms into the $\alpha$ phase upon further cooling. If the cooling rate is sufficiently high, the $\alpha \rightarrow \alpha+\gamma$ transformation can be halted [49]. This results in a higher fraction of $\alpha_{2}$ in the final microstructure, at the expense of the $\gamma$-phase. Furthermore, the 
cooling rate is highly dependent on the size of the powder particles. Therefore, smaller particles, which cool faster, will have a larger fraction of $\alpha_{2}$. This trend is illustrated in Table $2[50]$.

Table 2. The phase volume fractions for varying powder particle size range [50]

\begin{tabular}{|c|c|c|c|c|}
\hline \multirow{2}{*}{$\begin{array}{c}\text { POWDER } \\
\text { MICROSTRUCTURE }\end{array}$} & \multicolumn{4}{|c|}{ POWDER PARTICLE SIZE RANGE } \\
\cline { 2 - 5 } & $<44 \mu \mathrm{m}$ & $44-63 \mu \mathrm{m}$ & $63-88 \mu \mathrm{m}$ & $88-150 \mu \mathrm{m}$ \\
\hline Single phase $\alpha_{2}$ & $30 \%$ & $13 \%$ & $3-5 \%$ & $<1 \%$ \\
Dual phase $\alpha_{2}+\gamma$ & $69 \%$ & $85 \%$ & $93 \%$ & $95 \%$ \\
Single phase $\gamma$ & $<1 \%$ & $1-2 \%$ & $2-4 \%$ & $3-5 \%$ \\
\hline
\end{tabular}

\subsection{Hot-Isostatic-Pressing (HIP) of TiAl Powders}

Hot isostatic pressing (HIP) is a very common method used by industry for consolidating TiAl powders. Full density is achieved through a combination of high temperature (1000$\left.1300{ }^{\circ} \mathrm{C}\right)$, high pressure $(150-200 \mathrm{MPa})$ and time $(2-4$ hours $)$ [17]. Under these conditions, consolidation occurs through a combination of volume or boundary diffusion, as well as creep or plastic yielding [51,52]. However, the dominant densification mechanism varies for different compositions and HIP parameters. The HIP parameters are chosen based on achieving full density and obtaining the desired post-HIP microstructure. Further microstructural changes can be made through subsequent heat treatments. 
The optimum HIP parameters are dependent on the properties of the powder. Namely, the size distribution, morphology and composition of the powder particles are important in considering the HIP pressure, temperature and time. The general effect for most gamma TiAl alloys is that a longer HIP time or higher HIP temperature will improve the density of the final material [54]. However, it is not possible to eliminate all the porosity during the HIP process [17,52].

\subsection{Effect of HIP Conditions on Microstructure}

The HIP parameters can, to a large degree, control the final microstructure of the consolidated material. It is desirable to produce a compact with as fine a microstructure as possible. This can be achieved by either reducing the HIP temperature, by using a powder with a fine particle size, with the addition of appropriate alloying elements, or by increasing the HIP pressure $[17,53]$.

Depending on the intended application of the alloy, changes in HIP conditions can be utilized to obtain the desired microstructure, and therefore the desired mechanical behavior. Near- $\gamma$, duplex, near lamellar, or a fully lamellar microstructures are achievable $[17,53]$. As mentioned in section 2.1.2, the fine grained duplex structure has superior room temperature strength and ductility whereas the coarse grained fully lamellar structure has improved high temperature creep resistance, fracture toughness and impact resistance [53]. Furthermore, a more refined lamellar structure has improved room temperature strength and ductility without a significant adverse effect on the fracture 
toughness [53]. With all this in mind, careful consideration of the HIP conditions must be made in order to achieve a post-HIP microstructure such that subsequent thermomechanical treatments can be easily used to obtain the desired final microstructure.

\section{HIP Temperature}

The HIP temperature has a significant influence on the microstructure. The HIP temperature governs the phase field in which the consolidation is occurring and therefore governs the phase transformations that take place. Furthermore, the temperature also governs the transformation kinetics. HIP that takes place in the $\alpha$-phase field is largely controlled by the $\gamma \rightarrow \alpha$ interface growth velocity, which is controlled by the interface reaction involving either uniform atomic detachment (uad) or a screw dislocation (sd). These growth rates can be defined by the following equations [53]:

$$
\begin{aligned}
& V_{\text {uad }}=\frac{d r}{d t}=A_{1} K_{1}\left[1-\frac{C_{I}}{C_{I}(r)}\right] \\
& V_{\text {sd }}=\frac{d r}{d t}=A_{2} K_{2}\left[1-\frac{C_{I}}{C_{l}(r)}\right]
\end{aligned}
$$

where $A_{1}$ and $A_{2}$ are constants, $r$ is the radius of the dissolving $\gamma$ particle, $C_{1}$ and $C_{1}(r)$ are the equilibrium and actual $\mathrm{Al}$ contents in the $\alpha$-phase at the $\alpha / \gamma$ interfaces. $\mathrm{K}_{1}$ and $\mathrm{K}_{2}$ are given by the equations:

$$
\begin{aligned}
& K_{1} \propto T \exp \left(-\frac{Q_{1}}{R T}\right) \\
& K_{2} \propto T^{2} \exp \left(-\frac{Q_{2}}{R T}\right)
\end{aligned}
$$


where $Q_{1}$ and $Q_{2}$ are the activation energy barriers.

At higher temperatures, the kinetics of the $\gamma \rightarrow \alpha$ dissolution increases resulting in a higher fraction of the $\alpha$-phase, which upon cooling transforms into the lamellar structure through the diffusion controlled eutectoid transformation $\alpha \rightarrow \alpha_{2}+\gamma$ [53]. Therefore, a higher degree of superheat above the $\alpha$ transus during HIP will result in a larger fraction of lamellar grains in the post-HIP microstructure. Increasing the HIP-temperature also increases the uniformity of the post-HIP microstructure by provoking the development of $\gamma$-grains in a duplex structure and lamellar grains in a near lamellar structure [53]. However, an increase in HIP-temperature does not necessarily guarantee compositional homogeneity, especially if there are alloying elements with low diffusivity such as tungsten. Segregation that is originally present in the atomized particles is difficult to alleviate. Furthermore, a higher HIP temperature will result in a more complete densification, however, the rate of grain growth will be higher.

The HIP temperature also influences the grain size. The effects of the HIP temperature and powder particle size on the grain size in the consolidated material have been studied [17]. Three TiAl powder each having different particle size ranges $(20-45$, $45-125,180-355 \mu \mathrm{m})$ were each compacted at 3 different temperatures $(1000,1150$, $1300^{\circ} \mathrm{C}$ ). In each case the resulting microstructure was near- $\gamma$. It was found that the HIP temperature had a significant effect on the resulting average $\gamma$ grain size where the effect of the powder particle size was minimal in comparison. This trend is illustrated in Figure 
27. From an economic perspective, the use of coarser powders is beneficial since there is no disadvantage with respect to grain size. However, the drawback to decreasing the HIP temperature is the increased difficulty associated with reaching full density [54]. Figure 28 shows a study done on an alloy with composition $\mathrm{Ti}-45 \mathrm{Al}-9(\mathrm{Nb}, \mathrm{W}, \mathrm{B})$. The results indicate that at lower HIP temperatures the degree of densification was lower. The full density of this alloy was $4.3 \mathrm{~g} / \mathrm{cm}^{3}[54]$.

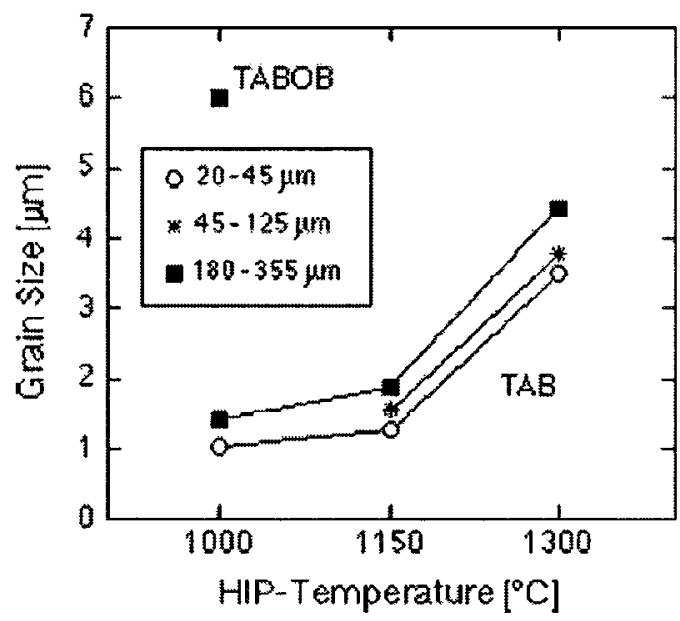

Figure 27. The effects of HIP temperature and powder particle size on grain size [17].

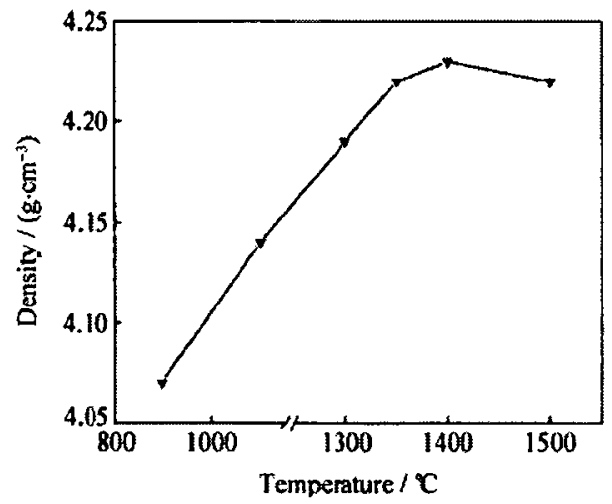

Figure 28. Compact Density versus the HIP temperature [54]. 


\section{HIP Pressure}

The HIP-pressure can also have a significant effect on the microstructure. The pressure applied during the HIP process had been found to reduce the rate of $\gamma \rightarrow \alpha$ dissolution. The hydrostatic pressure increases the activation energy barriers $Q_{1}$ and $Q_{2}$ in equations 6 and 7 , thereby slowing the dissolution rate by reducing the coefficients $K_{1}$ and $K_{2}$ in equations 4 and 5 . Therefore an increased hydrostatic pressure can suppress the formation of the $\alpha$ grains, which would subsequently form lamellar grains upon cooling, resulting in predominantly equiaxed or duplex structures. The HIP-pressure also influences the size scale of the microstructure, where higher pressures will result in a more refined microstructure [53].

\section{HIP Time}

An increase HIP time allows more time for the dissolution of $\gamma \rightarrow \alpha$ therefore resulting in a more developed lamellar structure. Longer HIP-time also results in higher microstructural and compositional homogeneity [53]. However, a longer HIP time can also lead to more grain growth.

\subsubsection{Summary}

Gamma TiAl alloys have excellent potential for use in gas turbine engines due to their low density, good high temperature properties, and high modulus. Gamma TiAl alloys are two phase alloys consisting of $\gamma-\mathrm{TiAl}$ and $\alpha_{2}-\mathrm{TiAl}_{3}$ with the $\gamma$ phase accounting for $80-95 \%$ of the material by volume. With alloying additions, the $\beta$ and $\sigma$ phases can also 
be stable in gamma TiAl alloys. There are four typical microstructures that form in gamma TiAl alloys: near gamma, duplex, near lamellar, and fully lamellar. Each is characterized by the fraction of equiaxed $\gamma$ grains and lamellar colonies, which consists of alternating layers of $\gamma$ and $\alpha_{2}$ phase. These microstructures can be formed through different heat treatments. The mechanical properties of gamma TiAl alloys are highly dependent on their microstructure. A fully lamellar structure offers the best fracture toughness and high temperature properties and a duplex structure offers the best ductility and tensile strength, due to its fine grain structure. However, the downfall of gamma TiAl alloys has always been its room temperature ductility, which is typically only $\sim 1 \%$. The ordered nature of the intermetallic compounds formed between titanium and aluminum reduces deformation modes giving $\mathrm{TiAl}$ alloy their excellent strength, but also leads to a very low ductility and fracture toughness, even at high temperatures.

As a result of the brittle nature of gamma TiAl alloys, wrought processing and machining using conventional methods is very difficult and expensive. Casting is the most widely used processing method, however, gamma TiAl alloys solidify through a peritectic reaction that results in significant compositional segregation, large grains, anisotropic properties, porosity and hot cracking. Powder metallurgy processing reduces the compositional segregation as a result of the extremely fast cooling rates associated with the gas atomization process used to produce the powder. Furthermore, new types of TiAl alloys with lower aluminum content $(<44$ at.\% $\mathrm{Al})$ and $\beta$ stabilizing alloying additions $(\mathrm{Nb}, \mathrm{Mo}, \mathrm{Mn}, \mathrm{V}, \mathrm{Cr}, \mathrm{W}$, etc.) solidify through the $\beta$ phase and avoid the 
peritectic reaction. Additionally, these new alloys utilize the $\beta$ phase to improve their hot workability and machinability.

\subsection{Beta Gamma Alloys}

Gamma TiAl alloys are an attractive material for use in gas turbine engines. They possess excellent high temperature properties with the added benefit of a low density. However, wrought processing of these materials is very challenging as a result of their brittle nature. Forging, extruding, as well as machining, of gamma TiAl alloys cannot be done conventionally and therefore the processing costs are very high. Recent research has been focused on enhancing the ductility of these alloys through significant alloying additions as well as microstructural control, but with only limited success. Attention has now been placed on the development of a new class of alloys called beta gamma TiAl alloys, which utilize finely dispersed $\beta$ phase throughout the microstructure to improve their hot workability and machinability $[18,40,55]$. Beta gamma TiAl alloys have compositions in the range of Ti-(40-45)Al-(2-7) Nb-(1-10)(Mn,Cr,V,Mo) [16].

The $\beta$ phase has a bcc structure and can exist in either an ordered (B2) or disordered (A2) state. Very little is known about the deformation of either the ordered or disordered $\beta$ phase when it coexists with $\gamma$ and $\alpha_{2}$, however, it can be assumed that deformation occurs on the $<111>\{110\}$ slip system as is usually observed for bec materials [43]. At elevated temperature the $\beta$ phase is much softer than both the $\gamma$ or $\alpha_{2}$ phases and as a result is much more easily deformed [40]. Additionally, the $\beta$ phase can act as a 
lubricating layer for the other phases during deformation therefore significantly improving the hot workability of the alloy even with only small volume fractions of the $\beta$ phase present in the microstructure [40]. As a result, beta gamma TiAl has been shown to have superior hot workability and machinability than conventional gamma TiAl alloys $[18,45,55]$.

With the addition of significant amounts of $\beta$ stabilizers, beta gamma alloys solidify through a $\beta$ solidification process, therefore avoiding the detrimental effects of the peritectic solidification that conventional gamma TiAl alloys must undergo (illustrated in Figure 29). Peritectic solidification typically results in several undesirable features, including large grains, segregation, anisotropy, porosity and hot cracking [55].

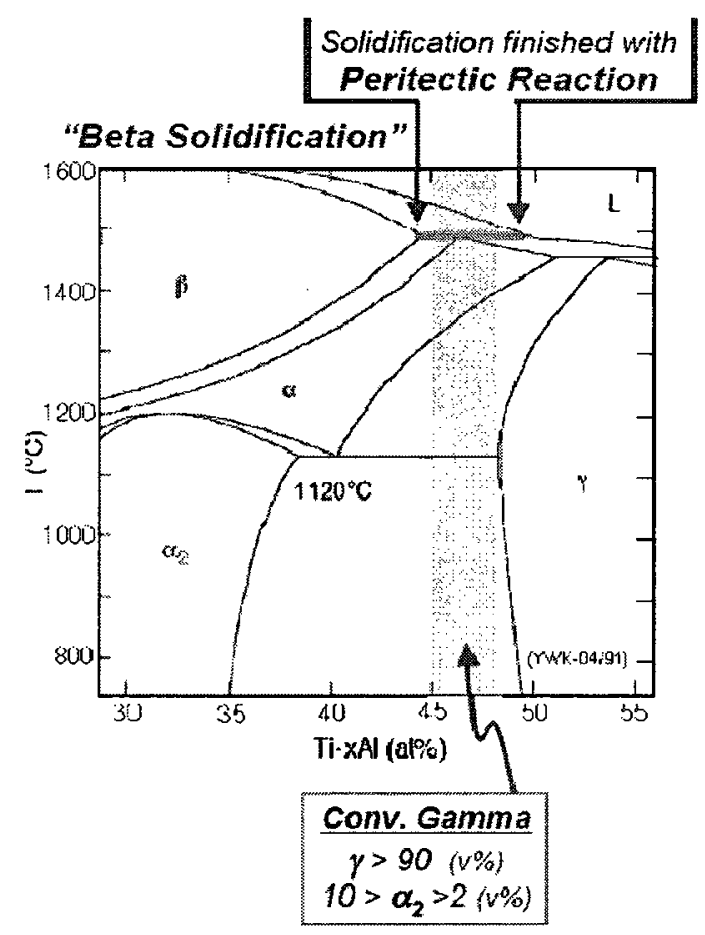

Figure 29. $\beta$ solidification versus solidification with peritectic reaction [55]. 
Though the solidification of beta gamma TiAl avoids the peritectic reaction, $\beta$ solidification can result in a higher volume fraction of the brittle $\alpha_{2}$ than is observed in conventional gamma TiAl alloys. Careful consideration of the alloy composition must be made in order to shift the $\gamma$ and $\alpha_{2}+\gamma$ phase boundaries to the Ti side as to avoid excess formation of the $\alpha_{2}$ phase [55].

\subsubsection{Typical Microstructures}

Beta gamma TiAl can have a variety of microstructures, which are determined by the composition and processing parameters. The distribution and volume fraction of each phase are mostly controlled by the composition, more specifically the aluminum content and the effective amount of $\beta$ stabilizing alloying additions. Figure 30 shows the transformation pathways for three different beta gamma TiAl alloy groups $\mathrm{A}, \mathrm{B}$, and $\mathrm{C}$. Conventional gamma alloys, $\mathrm{G}$, are also shown on the modified ternary diagram. Each transformation pathway results in two or three phase alloys. 


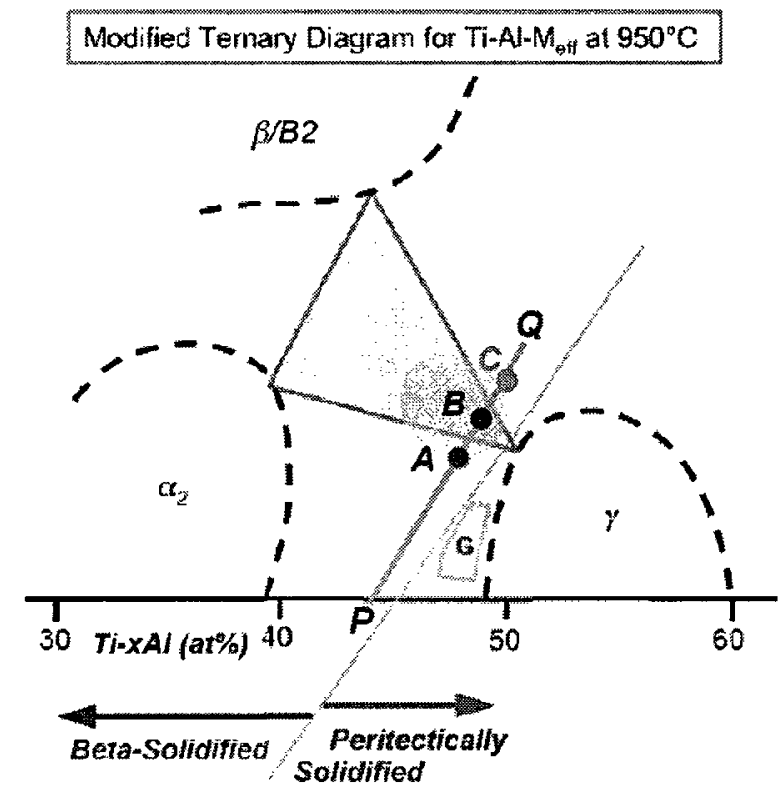

Quasi-Isopleth of Ti-44AI-XM

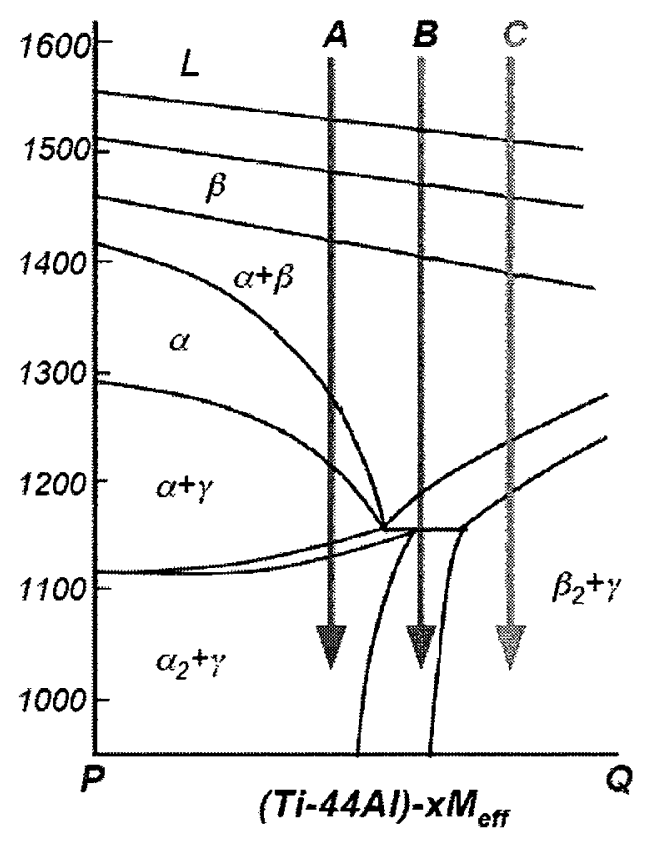

Figure 30. Beta gamma TiAl alloy groups [55].

As shown in Figure 31, the as-cast microstructure of alloy A resembles that of conventional gamma alloys that has been $\beta$ solidified to a two-phase field $\left(\gamma+\alpha_{2}\right)$ containing small lamellar colonies and approximately 1.5 vol. $\% \beta$ phase. If alloy $A$ is HIP'ed following casting, the microstructure changes to a near lamellar structure with slightly larger grain size and 2.0 vol. $\% \beta$ phase. The cast + HIP microstructure of alloy $B$ is a three phase alloy $\left(\gamma+\alpha_{2}+\beta\right)$ containing a near lamellar structure with approximately 14 vol. $\% \beta$ phase. Alloy $C$ has two phase field $(\gamma+\beta)$ microstructure. The constituent phases of a given alloy composition can be determined based on the niobium equivalent, which demonstrates the effective amount of $\beta$ stabilizer. Table 3 shows the niobium equivalents that are typical for each alloy group. 

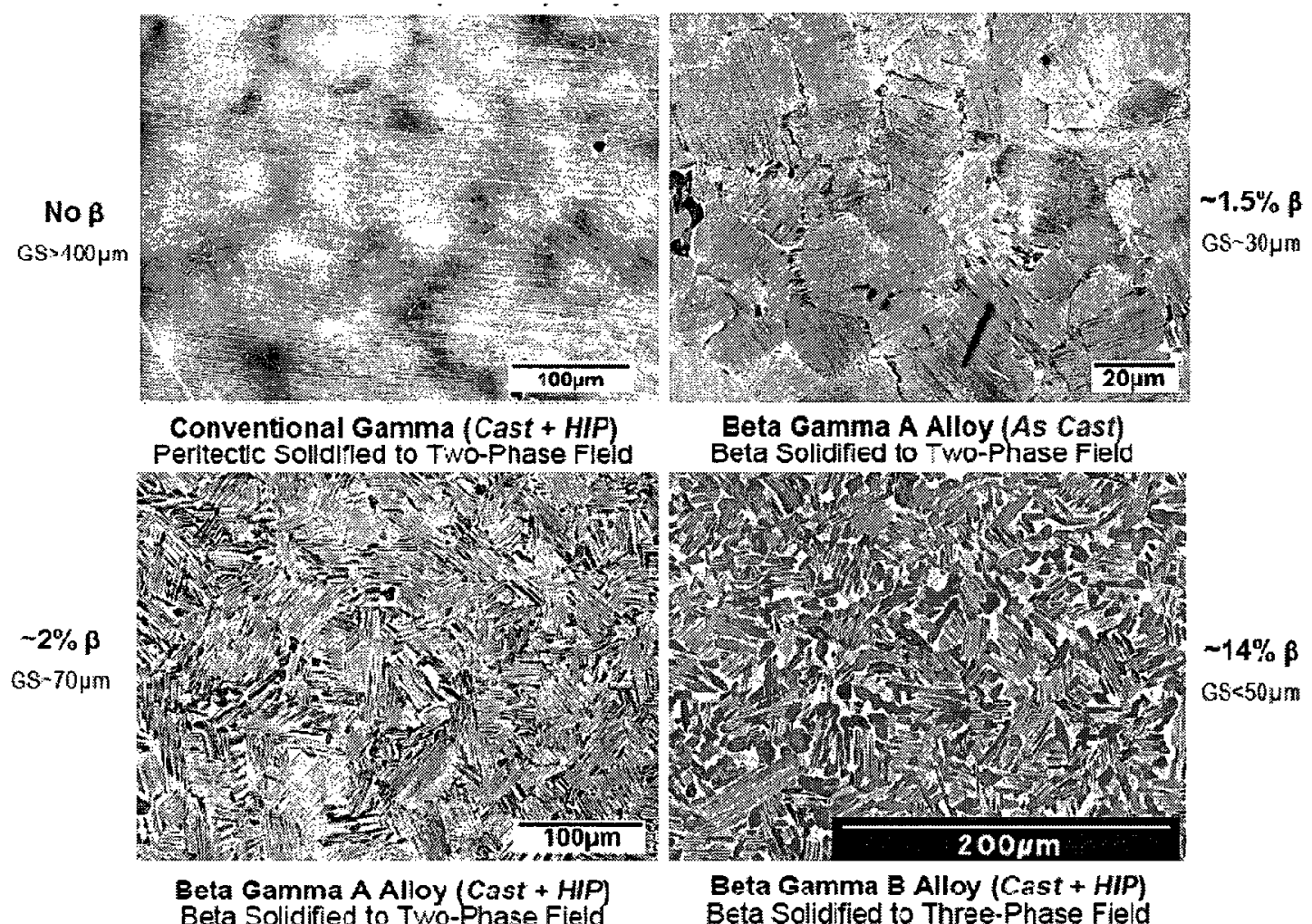

Beta Gamma B Alloy (Cast + HIP)

Beta Solidified to Two-Phase Field

Beta Solidified to Three-Phase Field

Figure 31. Typical microstructures of as-cast and cast+HIP beta gamma alloys [55].

Table 3. Beta gamma TiAl alloy groups and their phase fields [55].

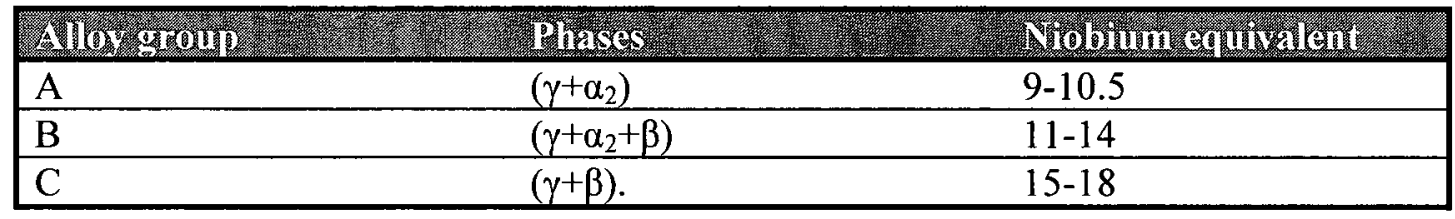

The microstructure can be further enhanced through forging and aging. Figure 32 shows the microstructure of a three phase alloy (alloy B) that has been forged and aged $\left(900^{\circ} \mathrm{C} / 24 \mathrm{hrs}\right)$. The resulting microstructure is a very fine grained three phase structure with phase fractions of $75 \% \gamma, 9 \% \alpha_{2}$, and $16 \% \beta$. 

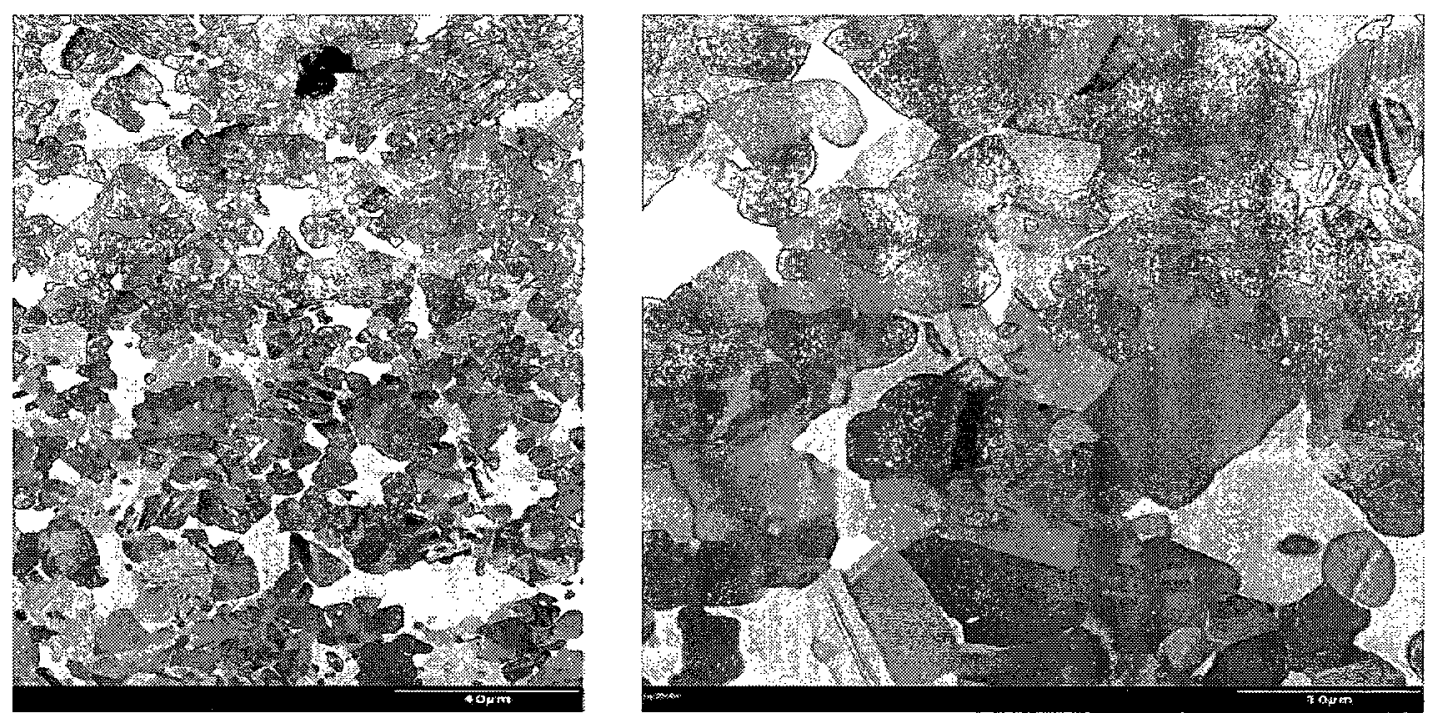

Figure 32. Forged and aged $\left(900^{\circ} \mathrm{C} / 24 \mathrm{hrs}\right)$ beta gamma TiAl alloy containing $75 \% \gamma, 9 \% \alpha_{2}$, and $16 \%$ B [55].

Another three phase alloy with a composition (Ti-42Al-xNb-3V) that has been forged $(70 \%)$ and aged $\left(1100{ }^{\circ} \mathrm{C} / 17 \mathrm{hrs} /\right.$ Furnace cool $)$ is shown in Figure 33. The resulting microstructure is again a very fine grained (GS $<7.4 \mu \mathrm{m})$ three phase structure with phase fractions of $83 \% \gamma, 14 \% \alpha_{2}$, and $4 \% \beta$. Furthermore, Figure 34 shows an alloy composition that has been forged at $1300^{\circ} \mathrm{C}$ and aged $\left(1200^{\circ} \mathrm{C} / 2 \mathrm{hrs}\right)$ with a resulting microstructure consisting of lamellar colonies, equiaxed $\gamma$ grains and equiaxed $\beta$ grains $[45]$. 


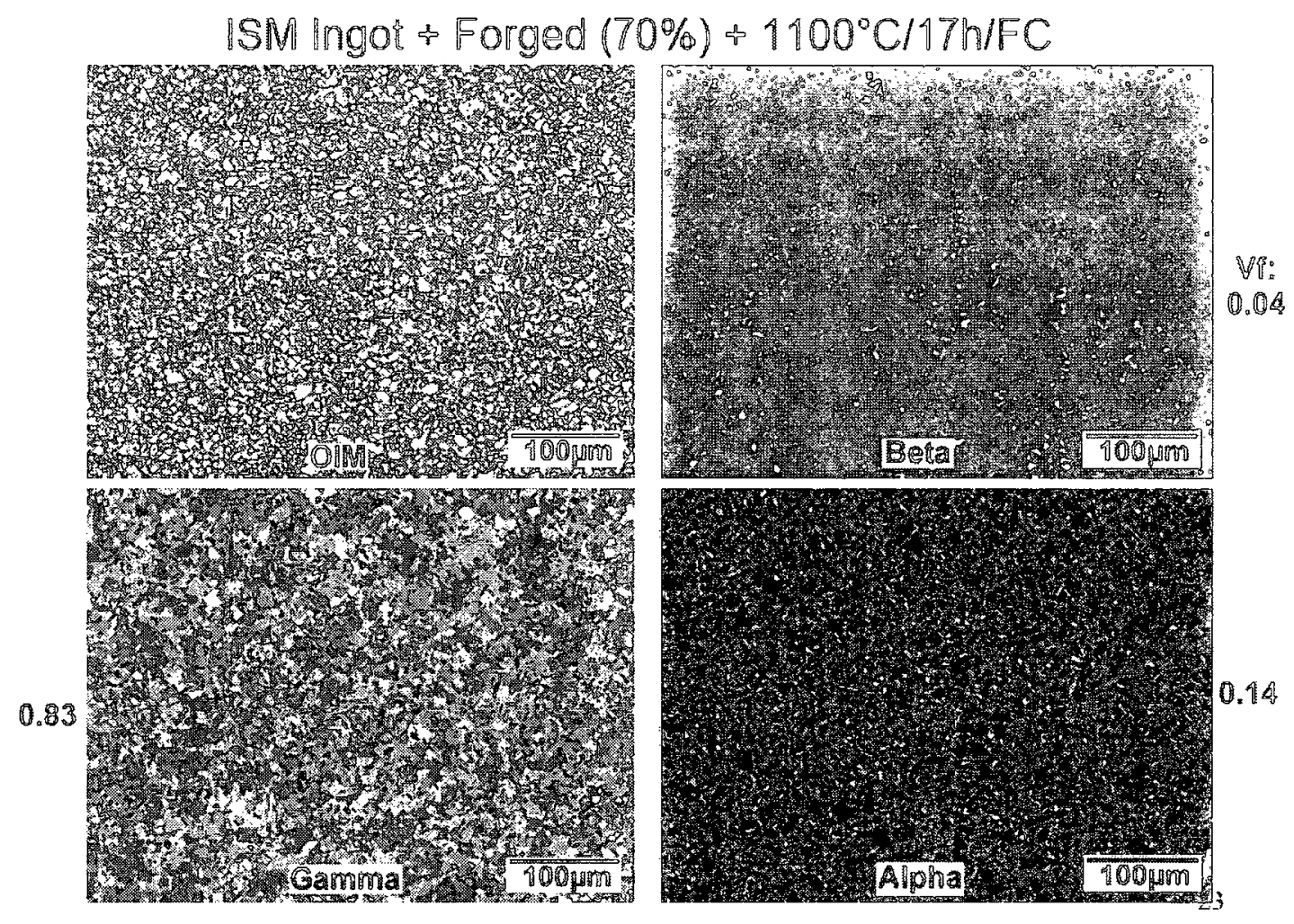

Fignre 33. Forged (70\%) and aged (11B0\%C/R7/FC) beta gamma TiAl Alloy with composition Ti $42 A \|-x \mathbb{N} b-3 \mathbb{V} \llbracket 18 \rrbracket$ 。

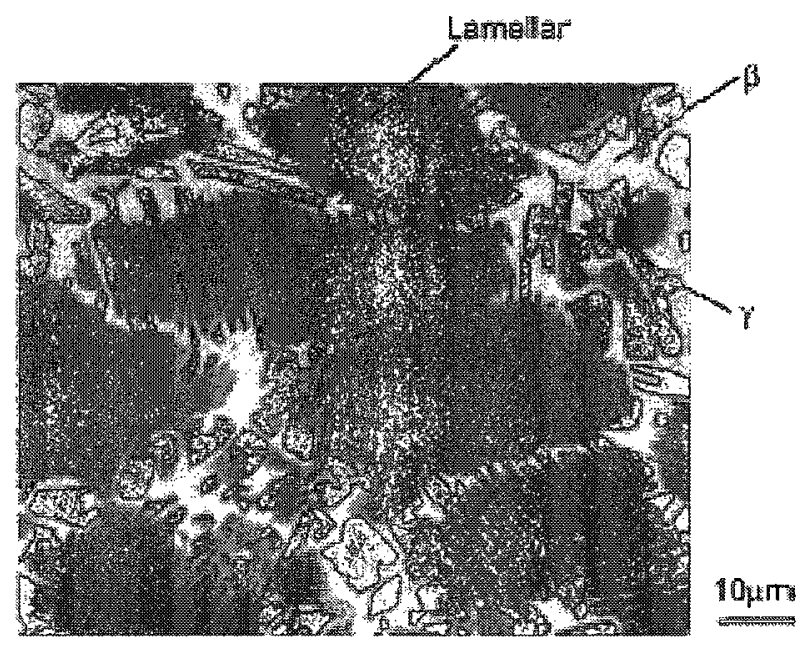

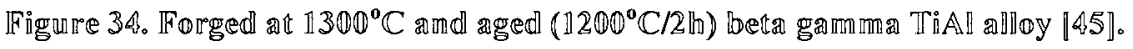


It is clear that a wide variety of microstructures are possible for beta gamma TiAl. Additionally, the microstructural scale tends to be significantly smaller and the compositional homogeneity much higher than that of conventional gamma TiAl alloys $[55]$.

\subsubsection{Mechanical Properties}

The mechanical properties of beta gamma TiAl alloys are comparable to those of conventional gamma TiAl alloys. However, the presence of the $\beta$ phase limits their high temperature capability. Figure 35 shows the potential range of stresses and temperatures at which beta gamma TiAl alloys can be used in comparison to other widely used aerospace materials.

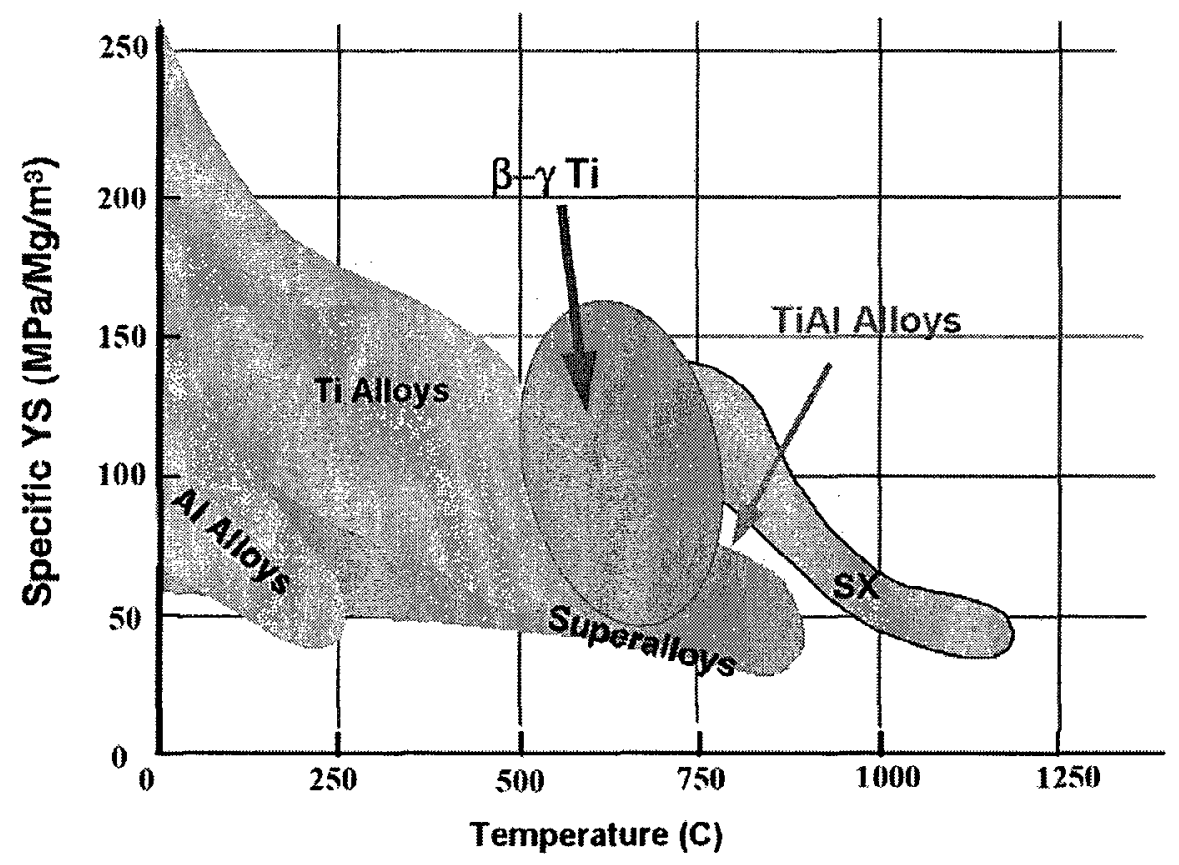

Figure 35. Strength and Temperature domains of various aerospace materials [18]. 
Similar to gamma alloys, the mechanical properties of beta gamma alloys are highly sensitive to their microstructure. Unfortunately, since beta gamma alloys are relatively new, the amount of literature on their mechanical properties is limited. Some analysis has been done on a wrought processed beta gamma alloy with a three phase microstructure containing lamellar colonies, equiaxed $\gamma$, and equiaxed $\beta$, as seen in Figure 36. The lamellar colonies account for $71.6 \%$ of the area fraction and have an average grain size of $9.0 \mu \mathrm{m}$ and an interlamellar spacing of $40 \mathrm{~nm}$. As a result of the very fine microstructure the alloy exhibited excellent tensile strength, as would be expected according to the HallPetch relationship [56]. The tensile properties of this alloy at various temperatures can be seen in Table 4 . The tensile strength begins to decline rapidly beyond $700{ }^{\circ} \mathrm{C}$ due to the presence of the $\beta$ phase, which becomes soft at elevated temperatures [56]. Though it may be detrimental to the elevated temperature strength, it is this feature of beta gamma alloys that significantly improves their hot workability. As a result of the soft nature of the $\beta$ phase at elevated temperatures, as well as the very fine microstructure, the creep life is much lower than conventional gamma TiAl alloys [56]. Efforts are now being made to remove the $\beta$ phase from the microstructure following hot working in order to improve the high temperature properties $[55,56,57]$. The $\beta$ phase has also been shown to significantly improve the ductility, but does not give any obvious improvement in damage tolerance $[18,40,58]$. The fracture toughness of the wrought processed Ti-42Al-10V was satisfactory with an absorption energy of $5 \mathrm{~J} / \mathrm{cm}^{2}$ in a Charpy impact test [56]. 


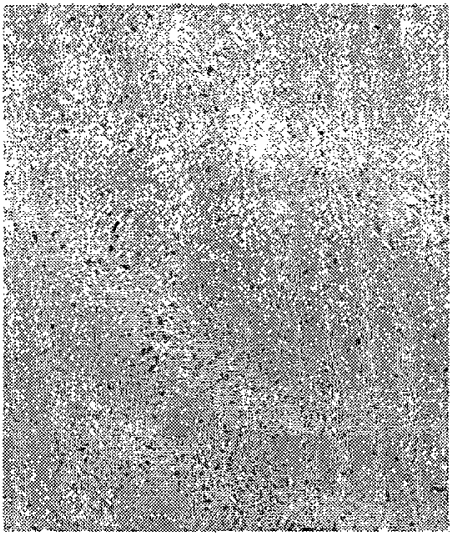

$100 \mu \mathrm{m}$

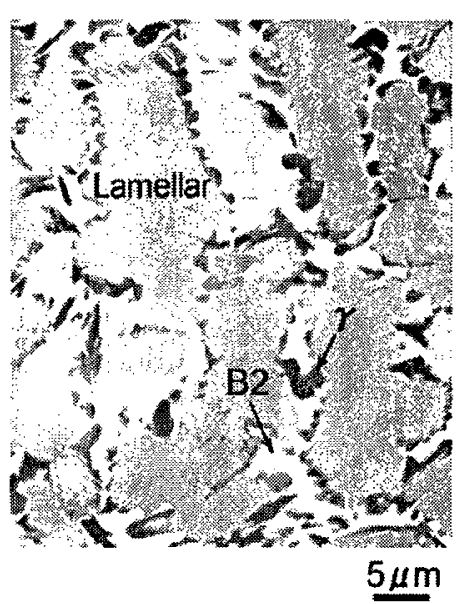

(b)

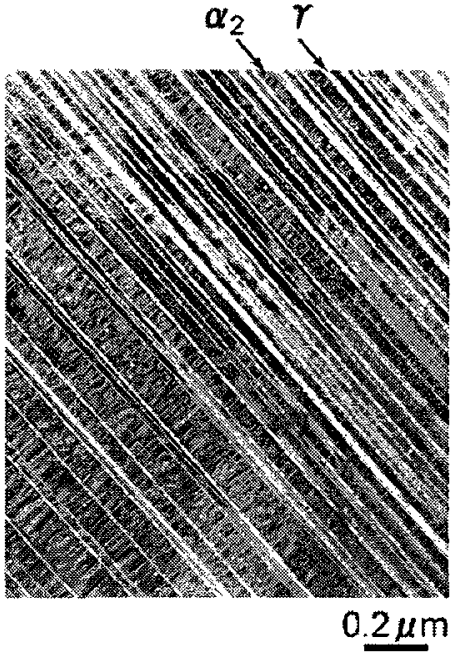

(c)

Figure 36. Microstructure of wrought processed Ti-42Al-10 V, (a) optical micrograph, (b) back scattering electron image, (c) TEM image [56].

Table 4. Tensile Properties of wrought processes Ti-42Al-10V [56]

\begin{tabular}{|l|l|l|l|}
\hline Temperature $\left({ }^{\circ} \mathrm{C}\right)$ & Yield strength $(\mathrm{MPa})$ & UTS $(\mathrm{MPa})$ & Elongation $(\%)$ \\
\hline 25 & 1265 & 1334 & 0.35 \\
\hline 500 & 1049 & 1385 & 1.2 \\
\hline 700 & 655 & 1236 & 2.1 \\
\hline
\end{tabular}

\subsubsection{Processing}

The processability of beta gamma alloys is intrinsic in their design. Essentially, the purpose of these alloys is to improve hot workability, machinability, and reduce the cost of processing $[44,55,57]$. Beta gamma alloys can be processed using conventional ingot/wrought processing methods, where conventional gamma alloys cannot. Figure 37 shows some typical processing routes for beta gamma alloys. 


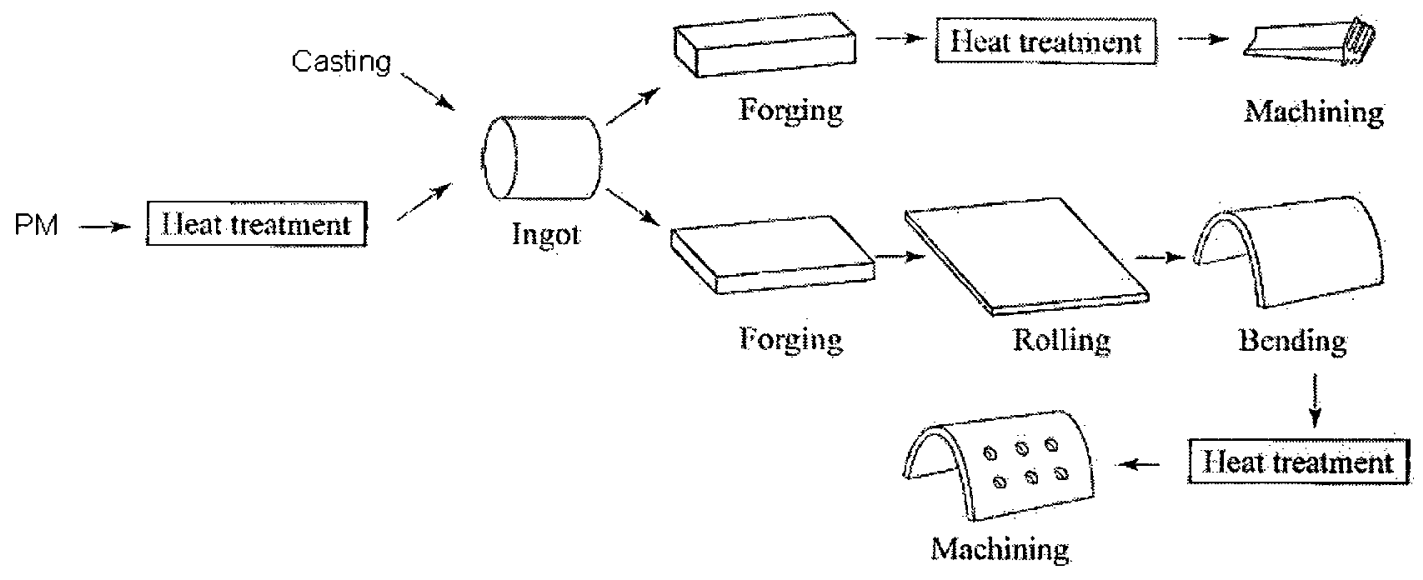

Figure 37. Typical processing routes for beta gamma TiAl alloys [44].

\subsubsection{Ingot Production}

One of the major downfalls of wrought processing conventional gamma TiAl is the amount of micro- and macrosegregation in the ingot as a result of solidification through a peritectic reaction. However, as discussed in section 2.2 , beta gamma alloys solidify though $\beta$ solidification, therefore avoiding the peritectic reaction and drastically reducing both of micro- and macrosegregation [18]. This reduced segregation leads to more uniform flow stress during hot working.

When producing beta gamma ingots for wrought processing it is important to consider both the volume fraction, as well as the morphology of the $\beta$ phase. It has been shown that forging becomes easier when the volume fraction of $\beta$ phase is largest [40]. Furthermore, an ingot with fine homogeneously dispersed $\beta$ particles in the matrix has been shown to be significantly better than an ingot with coarse $\beta$ particles that are not 
finely dispersed [40]. In an ingot with coarse $\beta$ particles, deformation during forging or extrusion is concentrated in the $\beta$ phase and therefore causes flow localization [40].

Beta gamma TiAl ingots have been cast successfully having a uniform distribution of $\beta$ phase $[18,55]$. Examples are shown in Figure 31. However, similar to gamma TiAl alloys, casting beta gamma alloy can still lead to a textured microstructure, which results in anisotropic properties, therefore making wrought processing more difficult [43]. Beta gamma TiAl Ingots could also be produced using a powder metallurgy process, which would results in ingots with no texturing that are compositionally very homogeneous and result in very fine microstructures [17]. These microstructural features could lead to significantly improved hot workability. The powders can be produced and consolidated using methods discussed in section 2.1.5.3.

\subsubsection{Hot Working}

Conventional forging and extrusion of gamma TiAl alloys has been shown to be very difficult. Wrought processing gamma TiAl alloys is typically limited to isothermal canned forging which required expensive machinery. However, with the addition of the $\beta$ phase the hot workability of beta gamma TiAl alloys is significantly improved, making forging and extrusion in generally available facilities possible, therefore significantly reducing the cost [44]. As mentioned in previous sections, the $\beta$ phase has a low yield strength at high temperatures, therefore it carries most of the deformation during hot 
working [43]. The $\beta$ phase also acts as a lubrication layer for other phases during deformation [40].

Not unlike gamma TiAl alloys, the success of a given forging or extrusion process is dependent on the strain rate and temperature at which the process is conducted. The best formability is achieved at the temperature and strain rate at which the material dissipates the power most efficiently [40]. The processing map in Figure 38 shows the power dissipation efficiency for different temperatures and strain rates of an alloy with the composition Ti-42Al-6Nb-3Mn-0.2B.

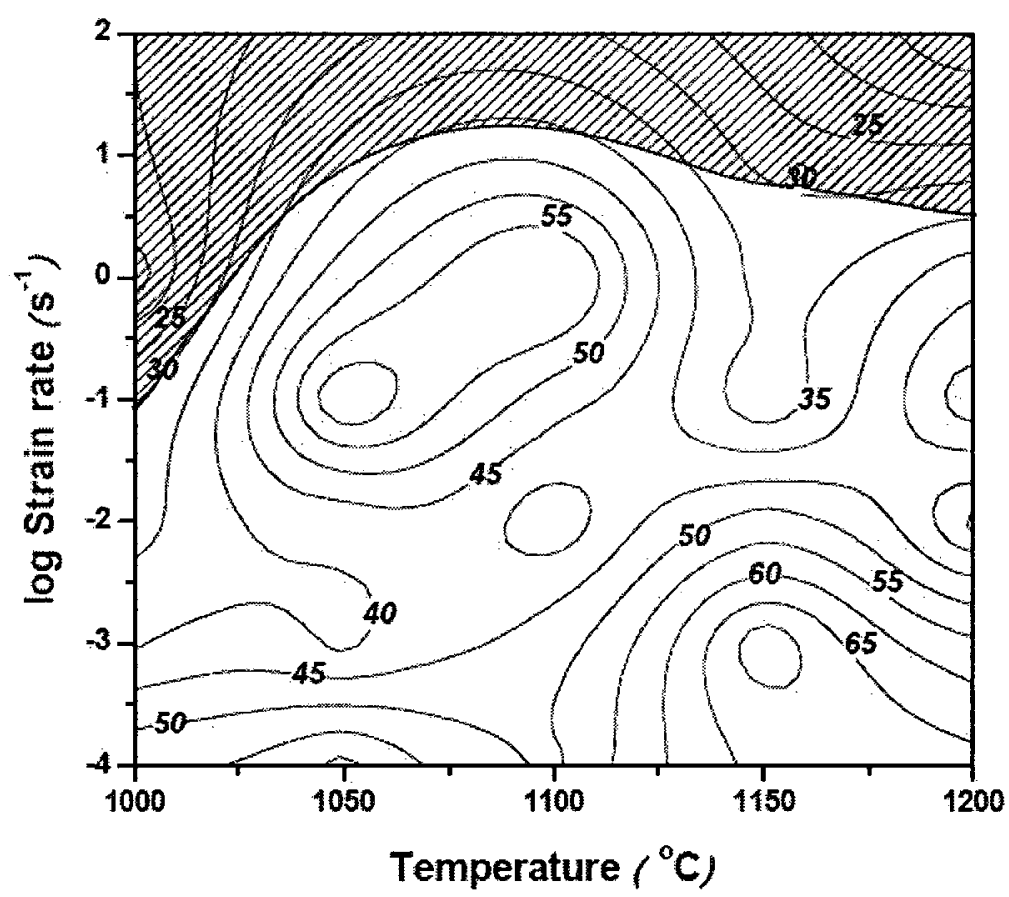

Figure 38. Processing efficiency map for a beta gamma TiAl alloy with the composition Ti-42A]-6Nb-3Mn-0.2B $(\varepsilon=0.06)[40]$. 
The best processing temperature is when the volume fraction of $\beta$ is highest, while still being finely dispersed in the matrix (ie. not coarse-grained). At lower temperatures the volume fraction of $\beta$ phase is too low, and at higher temperatures the morphology of the $\beta$ phase changes to coarse $\beta$ grains which cause localized deformation [40].

It has been found that for both conventional gamma TiAl alloys and beta gamma TiAl alloys, lower strain rates reduce the flow stress in the material, therefore reducing the likelihood of crack formation [28]. Furthermore, at lower strain rates the microstructural features, such as lamellae, are less affected. Figure 39 shows the microstructure of a beta gamma TiAl alloys forged at various strain rates. It can be seen that after high strain rate deformation $\left(1 \mathrm{~s}^{-1}\right)$ the lamellae are bent or kinked. After an intermediate strain rate deformation $\left(10^{-1} \mathrm{~s}^{-1}\right)$, the lamellae are fragmented. After a low strain rate deformation $\left(10^{-2} \mathrm{~s}^{-1}\right)$, the lamellae are still intact [40].
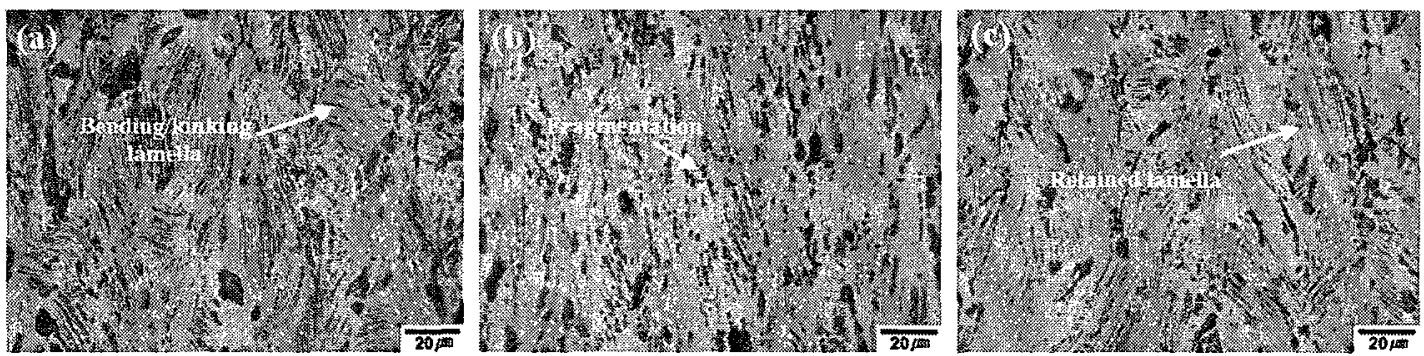

Figure 39. Microstructure of beta gamma TiAl alloy forged at $1050^{\circ} \mathrm{C}$ : (a) $1 / \mathrm{s}$ (b) $10^{-1} / \mathrm{s}$ (c) $10^{-2} / \mathrm{s}[40]$.

The room temperature volume fraction of the $\beta$ phase is the most significant indication of the hot workability of a beta gamma TiAl alloy. Figure 40 and Figure 41 
show the as-forged pancake of two beta gamma alloys having $3 \%$ and $14 \%$ volume fraction $\beta$. It can be seen that a small increase in room temperature $\beta$ phase volume fraction significantly improves the forgability of the alloy. It has been shown that only a $10 \%$ volume fraction of $\beta$ phase is required for conventional forging [16].

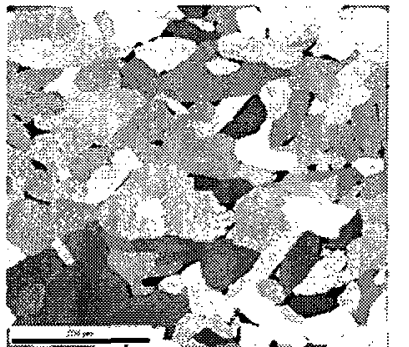

OIM Image $(\alpha+\beta)$

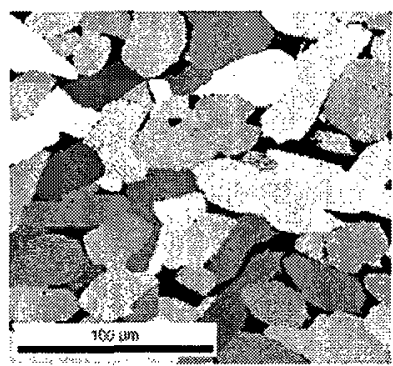

OIM Image $(\alpha+\beta)$

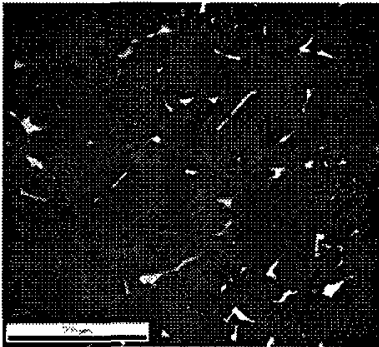

Beta Distribution (3\%)

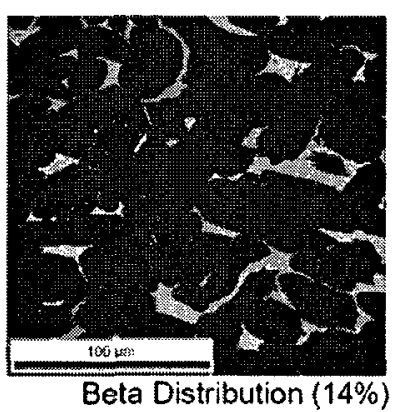

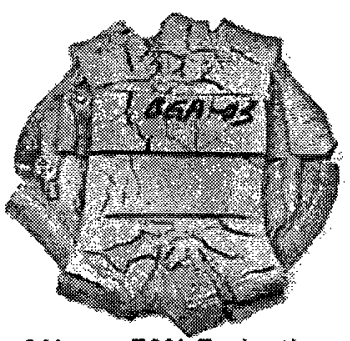

30 ipm - 70\% Reduction

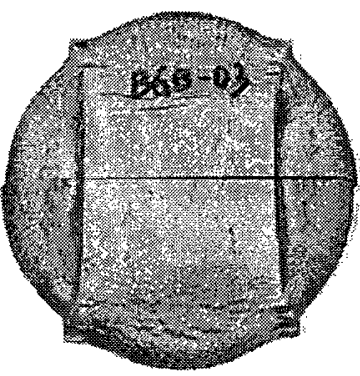

Figure 40. The effect of the $\beta$ phase on forging at $1300^{\circ} \mathrm{C}[18]$.
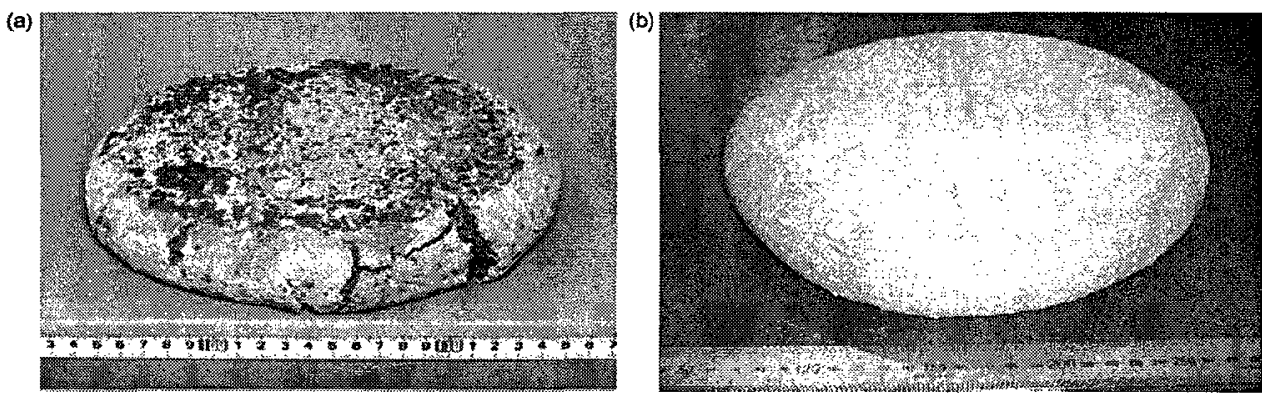

Figure 41. Hot forged samples of a) a conventional TiAl alloy and b) a TiAl alloy containing the $\beta$ phase [45]. 


\subsubsection{Machining}

The $\beta$ phase in beta gamma TiAl alloys has been shown to significantly improve machinability. As shown in Figure 42, TiAl alloys without $\beta$ phase tend to have particulate turnings when machined, where alloys with $\beta$ phase tend to have curled turnings when machined. It has been verified that industrial machining processes of beta gamma TiAl alloys is possible and that components with complex configurations could be made through hot forging followed by machining [45].

(a)
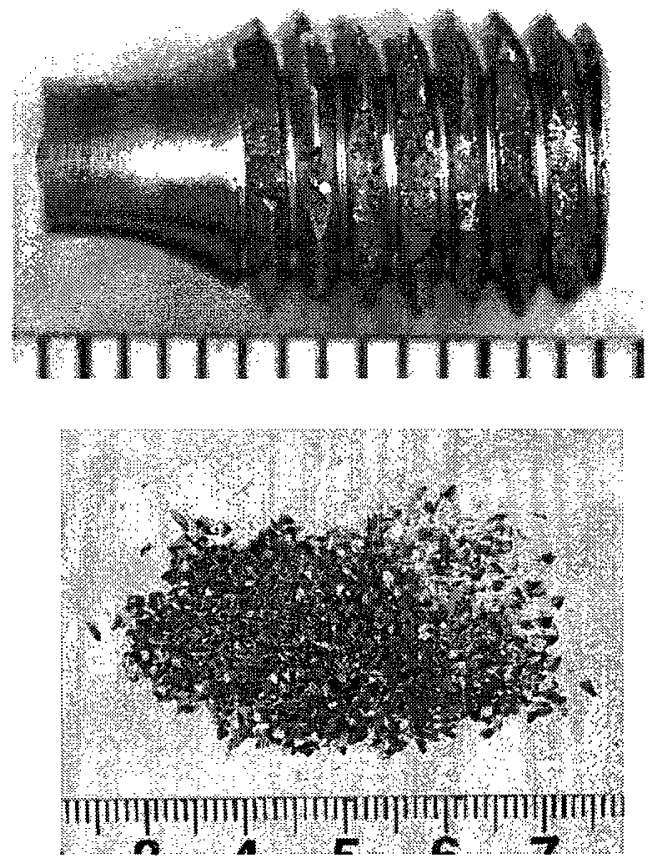

(b)
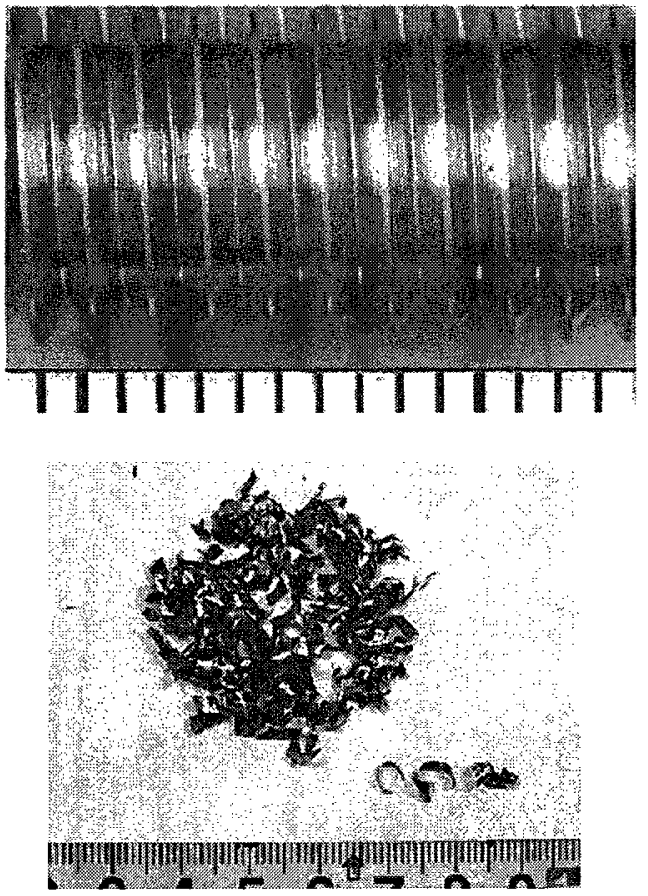

Figure 42. Improved machinability of beta gamma TiAl alloys. Shows a) particulate turnings of a TiAl alloy with no $\beta$ phase and $b$ ) curled turnings of a TiAl alloy with approximately $25 \% \beta$ phase [45]. 


\subsubsection{Summary}

Beta gamma alloys are a new class of TiAl alloys with compositions existing within the range of Ti-(40-45)Al-(2-7) Nb-(1-10)(Mn, Cr, V,Mo). The $\beta$ stabilizing elements such as $\mathrm{Nb}, \mathrm{Mn}, \mathrm{Cr}, \mathrm{V}$ and $\mathrm{Mo}$, in conjunction with the low $\mathrm{Al}$ content, stabilized the $\beta$ phase to room temperature. The stable $\beta$ phase has been shown to significantly improve the hot workability and machinability of the alloy. The degree to which the hot workability and machinability are improved depends largely on the volume fraction and morphology of the $\beta$ phase, where a higher amount of evenly distributed fine $\beta$ grains throughout the microstructure shows the most improvement. At elevated temperatures the $\beta$ phase becomes softer than the surrounding $\gamma$ and $\alpha$ phases and therefore carries most of the deformation during hot working. The $\beta$ phase has also been shown to act as a lubricating layer for other phases during deformation. Further, the large amount of $\beta$ stabilizing elements and the low aluminum content results in an alloy that solidifies through the $\beta$ phase and avoids the detrimental effects of the peritectic solidification that conventional TiAl alloys must undergo. These detrimental effects include segregation, large grains, anisotropic properties, porosity and hot cracking

There are three different beta gamma alloy groups, which are classified based on the constituent phases at room temperature. In order of increasing amount of $\beta$ stabilizing alloying additions, beta gamma alloys can be classified as a two phase $\left(\gamma+\alpha_{2}\right)$ alloy, a three phase $\left(\gamma+\alpha_{2}+\beta\right)$ alloy, or a two phase $(\gamma+\beta)$ alloy. Through thermal treatments, near gamma, duplex, near lamellar and fully lamellar microstructures are possible, with the 
added benefit of a finer microstructural scale as compared to conventional gamma TiAl alloys.

The processing routes of beta gamma alloys typically consists of producing an ingot through casting or powder metallurgy, followed by one or several wrought processing steps and/or thermal treatments, and finished by conventional machining. Most of the research to date has been directed at ingot production through casting. However, powder metallurgy could result even higher compositional homogeneity, highly isotropic properties, and a more refined microstructural scale, which would further improve the hot workability.

The mechanical properties of beta gamma alloys are comparable to those of gamma TiAl alloys. However, the presence of the $\beta$ phase limits their high temperature capabilities. As a result of the soft nature of the $\beta$ phase at elevated temperatures, as well as the very fine microstructure, the creep life is much lower than that conventional gamma TiAl alloys. In order to improve the creep properties of beta gamma alloys, heat treatments must be used to remove as much of the $\beta$ phase as possible following the hot working and machining processes. Furthermore, heat treatments could potentially be used to precipitate fine $\beta$ particles at the lamellar interfaces, which have been shown to significantly improve the primary creep resistance of conventional gamma TiAl alloys. 


\section{Thesis Objective}

Poor workability, poor machinability, and high processing costs have hindered the widespread use of gamma TiAl alloys. These downfalls have limited the size and complexity of the components that can be made with TiAl alloys. However, recently introduced beta gamma TiAl alloys utilize evenly distributed $\beta$ phase throughout the microstructure to significantly improve the hot workability and machinability. Previous research has focused on the development of cast beta gamma TiAl Alloys [16,55], whereas this project will investigate the benefits of powder metallurgy (PM) processing of beta gamma TiAl Alloys. Powder metallurgy has been shown to result in very fine microstructures and improved compositional homogeneity, which are very beneficial for wrought processing. The objective of the research is to develop the processing conditions for two beta gamma TiAl powder alloys by systematically evaluating the effects of the HIP parameters and heat treatment conditions on their microstructure.

The two pre-alloyed beta gamma TiAl powder alloys that will be studied in this project have nominal compositions of TiAl-4Nb-3Mn and TiAl-2Nb-2Mo. The tasks of the project include:

- Optimize the HIP conditions (temperature, pressure, time, and cooling rate) for the selected beta gamma alloy powders to achieve a fine microstructure with as much evenly dispersed $\beta$ phase as possible (ideal for hot working). 
- Develop a solution heat treatment for each alloy that can be used to remove the $\beta$ phase and result in a fully lamellar microstructure (ideal for high temperature applications).

- Develop an aging heat treatment for each alloy that would precipitate fine $\beta$ particles at the lamellar interfaces in order to improve the primary creep resistance (improved high temperature properties)

Figure 43 shows the proposed processing route for the two beta gamma alloys, including when the HIP, solution heat treatment, and aging heat treatment would be utilized.

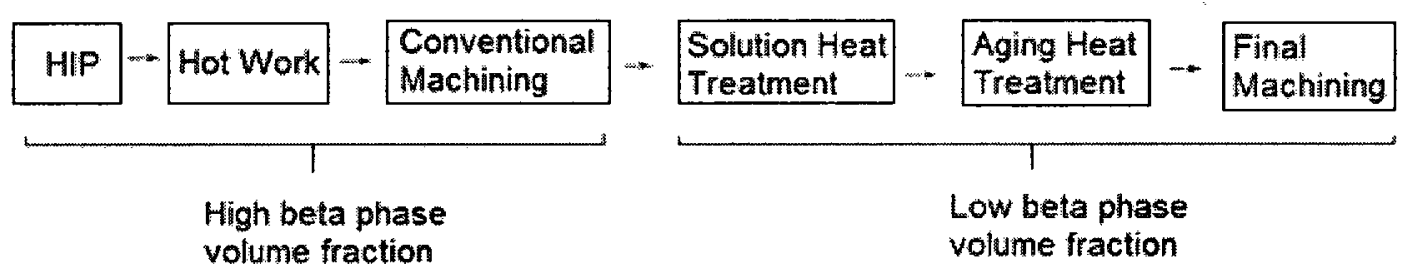

Figure 43. The proposed processing route for the beta gamma alloys.

Qualitative and quantitative microstructural characterization through optical, scanning electron microscopy (SEM) and scanning transmission electron microscopy (STEM) will be utilized to evaluate the powder metallurgy processing conditions. Further analysis using differential scanning calorimetry (DSC), x-ray diffraction (XRD), and microhardness testing will also aid in the development and evaluation of the processing conditions. The results of this research will establish a foundation for powder metallurgy processed beta gamma TiAl alloys and perhaps improve the ability to produce larger, more complex components. 


\section{Experimental Procedure}

In this project the processing conditions of pre-alloyed beta gamma TiAl powders were developed. The powder alloys were consolidated through a hot isostatic pressing (HIP) process. The effects of the HIP conditions on the microstructures of the alloys were explored with the purpose of developing a HIP process that resulted in microstructures ideal for further thermal-mechanical processing. Differential scanning calorimetry (DSC) of the as-HIP'ed alloys was then conducted to determine important phase transformation temperatures. In addition, X-ray diffraction (XRD) analysis was done on several samples quenched from various temperatures in order to gain an understanding of the phases that are present at higher temperatures. Utilizing the DSC and XRD results, thermal treatments were investigated in order to generate microstructures ideal for high temperature applications. A solution heat treatment was developed to generate a homogenous fully lamellar microstructure and an aging heat treatment was used to precipitate $\beta$ particles at the lamellar interfaces to improve creep properties $[15,35]$. Following each heat treatment, the microhardness of the lamellar grains was measured. The microstructural characterization was done using optical, scanning electron, and scanning transmission electron microscopes. The detailed procedures are described in the following sections. 


\subsection{Materials}

Processing conditions were developed for two beta gamma TiAl alloys. The alloys had nominal compositions in atomic percent of TiAl-4Nb-3Mn (G1) and TiAl-2Nb-2Mo (G2). The -35 mesh gas atomized pre-alloyed powders were supplied by Crucible Research and were stored in an argon atmosphere to minimize exposure to oxygen and nitrogen. The size of the powder particles of alloy G1 ranged between 100 and $200 \mu \mathrm{m}$ with an average size of $150 \mu \mathrm{m}$. Alloy G2 had smaller powder particle with a range between 40 and $90 \mu \mathrm{m}$ and an average of $70 \mu \mathrm{m}$.

\subsection{Hot Isostatic Pressing}

The hot isostatic pressing (HIP) process consisted of several steps. The first was to prepare stainless steel tubes that would encapsulate the powder alloys. The second step was to fill the stainless steel tubes with the powder alloys and seal them under a vacuum. The sealed tubes were then submitted to the HIP technician with the specified HIP conditions.

\subsubsection{Tube Preparation}

The $304 \mathrm{~L}$ stainless steel tubes used to vacuum encapsulate the powder alloys during the HIP process had an outer diameter of $5 / 8$ inches and a wall thickness of 0.035 inches. The tubes were cut to roughly 13 inches lengths. One end of each tube was then crimped using a hydraulic crimper (Figure 44) then tungsten inert gas (TIG) welded to provide a 
vacuum seal. The tubes were then filled with approximately 6 inches of alloy powder. The filled tubes were then evacuated to $1.0 \times 10^{-5}$ mbar on an Edwards High Vacuum vapour diffusion pump, heated to a temperature of $230^{\circ} \mathrm{C}$, and held for 3 days (Figure 46). The tubes were crimped, cut, and TIG welded closed while still under vacuum. The sealed tubes are shown in Figure 47.

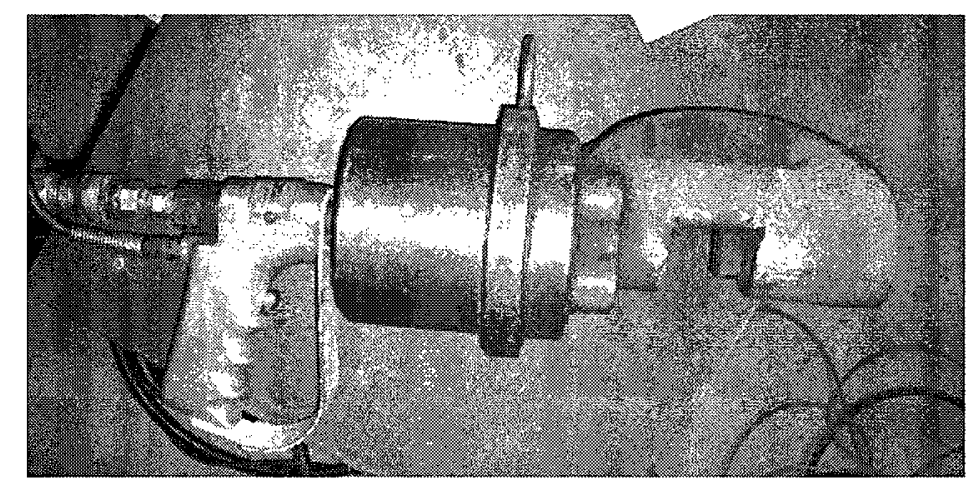

Figure 44. Hydraulic crimper used to crimp the stainless steel tubes.

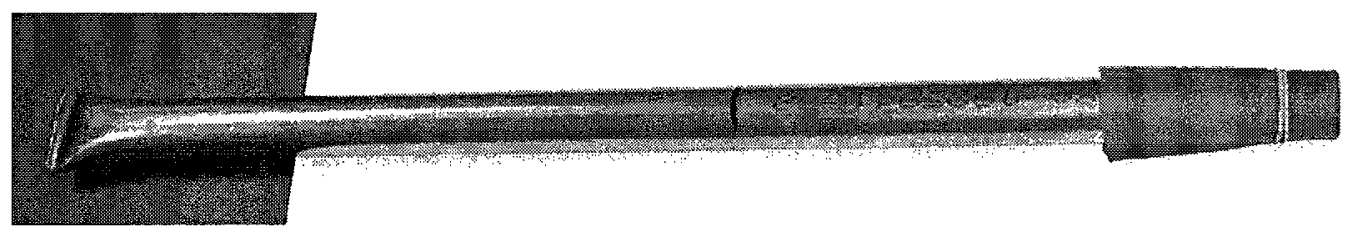

Figure 45. A Stainless steel tube filled with powder, ready for vacuum encapsulation. 


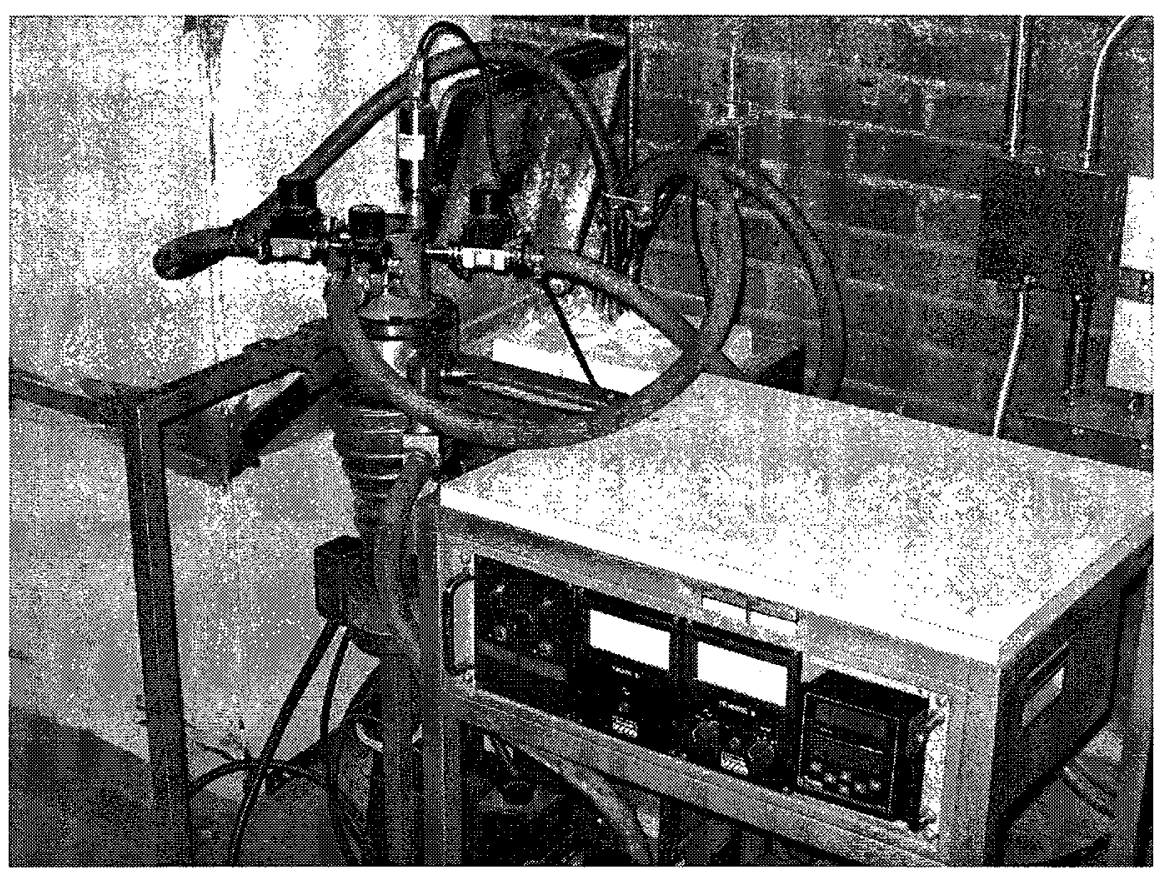

Figure 46. Tubes filled with alloy powders connected to the diffusion pump at a pressure of $1 \times 10^{-5}$ mbar, and in a furnace at $230^{\circ} \mathrm{C}$.

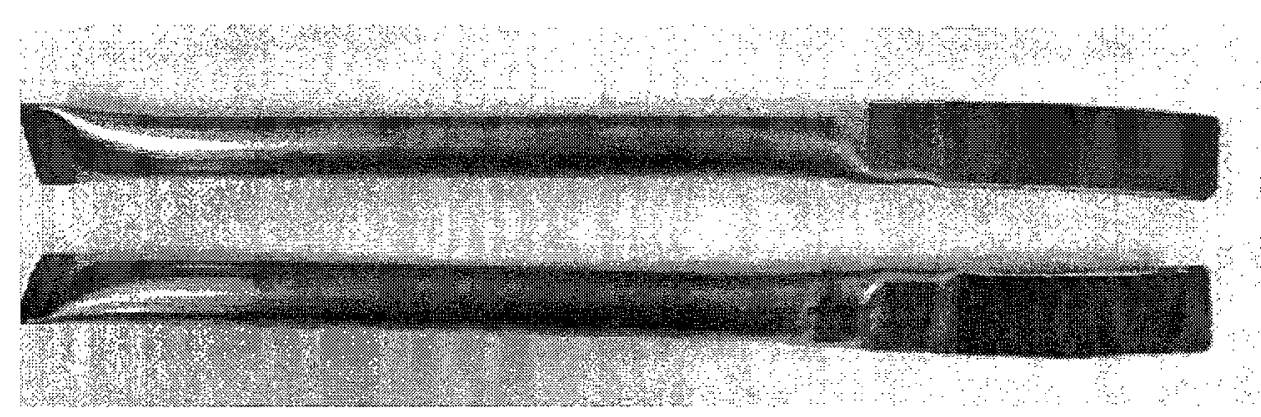

Figure 47. The sealed tubes ready for hot isostatic pressing.

\subsubsection{HIP Processes}

The HIP conditions are based on four parameters: the temperature, the pressure, the duration, and the cooling rate. The HIP conditions that were investigated are summarized in Table 5. The initial HIP trials (HIP trials 1, 2, and 3) were to investigate the effects of 
the cooling rate on the microstructure of the alloys. Further HIP trials (HIP trails 4, 5, 6, Step HIP 1, Step HIP 2 ) were conducted to optimize the as-HIP'ed microstructures by varying the temperature and durations of the HIP process. After HIP'ing, the crimped ends of the consolidated bars were removed using a Buehler abrasive saw. The bars were then de-canned on a lath at the Carleton University machine shop. The de-canned TiAl bars were then sectioned into several 1 inch pieces for heat treatment trials. The hot isostatic press that was used can be seen in Figure 48.

Table 5. The HIP conditions used to consolidate the powder alloys.

\begin{tabular}{|c|c|c|}
\hline HIP Trial & HIP Condition $\left({ }^{\circ} \mathrm{C} / \mathrm{MPa} / \mathrm{Hours}\right)$ & Cooling rate $\left({ }^{\circ} \mathrm{C} / \mathrm{min}\right)$ \\
\hline 10.11 .2 & $1250 / 200 / 2$ & furnace cool \\
\hline 2 & $1250 / 200 / 2$ & 8.5 (from 1250 to $1000^{\circ} \mathrm{C}$ \\
\hline 3 & 1250120012 & 3.0 (rom 1250 to $800^{\circ} \mathrm{C}$ ) \\
\hline 4 & $1200 / 200 / 2$ & furnace cool \\
\hline 3 & $201200 / 200 / 4$ & furmace cool \\
\hline 6 & $1300 / 200 / 2$ & furnace cool \\
\hline Step HIP 1 & $1250 / 20011+1200 / 200 / 2$ & funace cool \\
\hline Step HIP 2 & $1250 / 200 / 1+1100 / 200 / 2$ & furnace cool \\
\hline
\end{tabular}

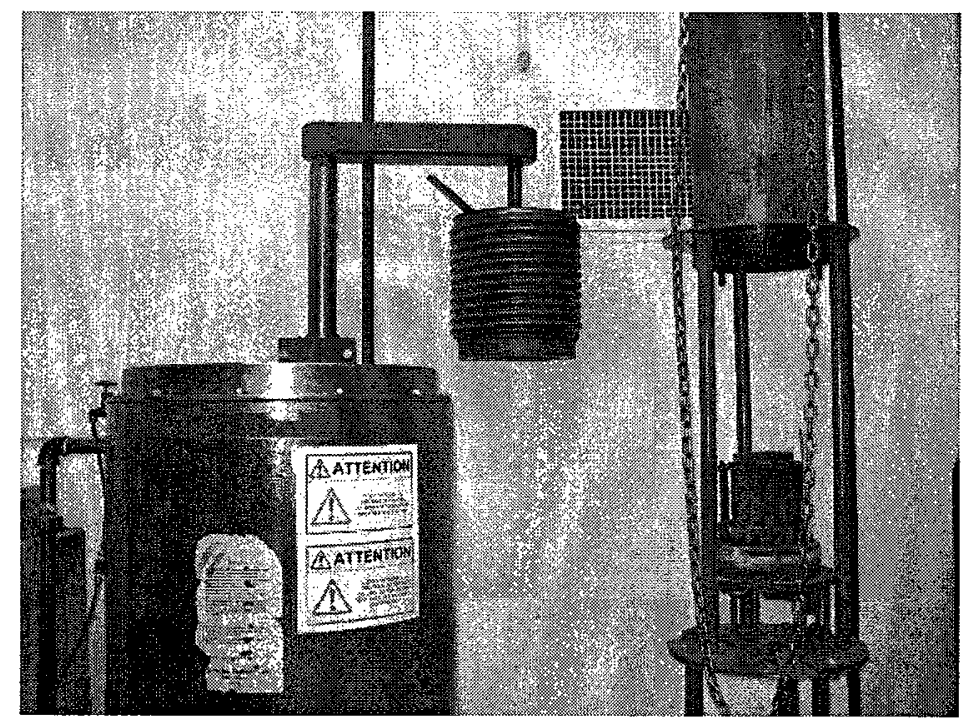

Figure 48. The hot isostatic press used to consolidate the powders. 


\subsection{Differential Scanning Calorimetry (DSC)}

In order to determine the approximate temperature of the $\alpha$ transus of each alloy, Differential scanning calorimetry (DSC) of the As-HIP'ed alloys was conducted. A Netzsch 404C DSC was used, as shown in Figure 49. Firstly, a temperature calibration curve had to be generated by measuring the melting temperature of several pure substances. Secondly, the crucibles were baked out and a baseline DSC signal was measured for the empty crucibles. Thirdly, the DSC signal of the as-HIP'ed TiAl samples were measured in conjunction with the temperature calibration curve and the crucible baseline correction curve.

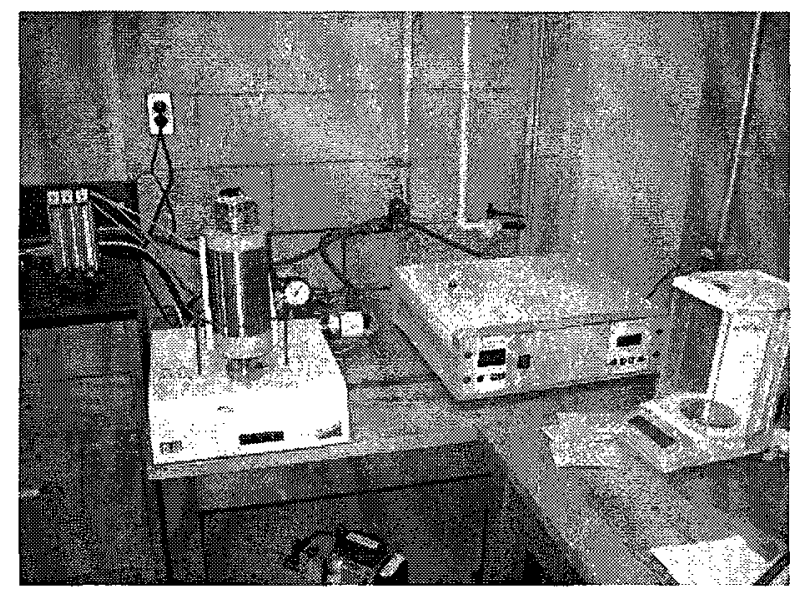

Figure 49. Netzsch 404C differential scanning calorimeter.

\subsubsection{Calibration}

Temperature calibration of the DSC was essential in order to acquire accurate temperature readings during DSC experiments. Based on the melting temperature of 
several pure substances a calibration curve can be developed over the range of temperatures desired. For this project, the melting points of small samples of gold, silver, and nickel were measured using the DSC and compared to theoretical values.

Each sample was approximately $20 \mathrm{mg}$ and was placed in an yttria crucible with $15 \mathrm{mg}$ of yttria powder in the bottom and $10 \mathrm{mg}$ of yttria powder covering the sample. The yttria reference crucible was filled with $20 \mathrm{mg}$ of yttria powder. A small piece of titanium foil was placed on top of the yttria powder in the crucible during the cobalt DSC calibration run in order to reduce the oxidation.

An example of a temperature program used for the calibration experiments can be seen in Figure 50. The experimental melting temperature that was used to compare to the theoretical melting point was the average melting temperatures measured through the two melting cycles. The onset of the peak in the DSC signal was used as the experimental melting temperature. 


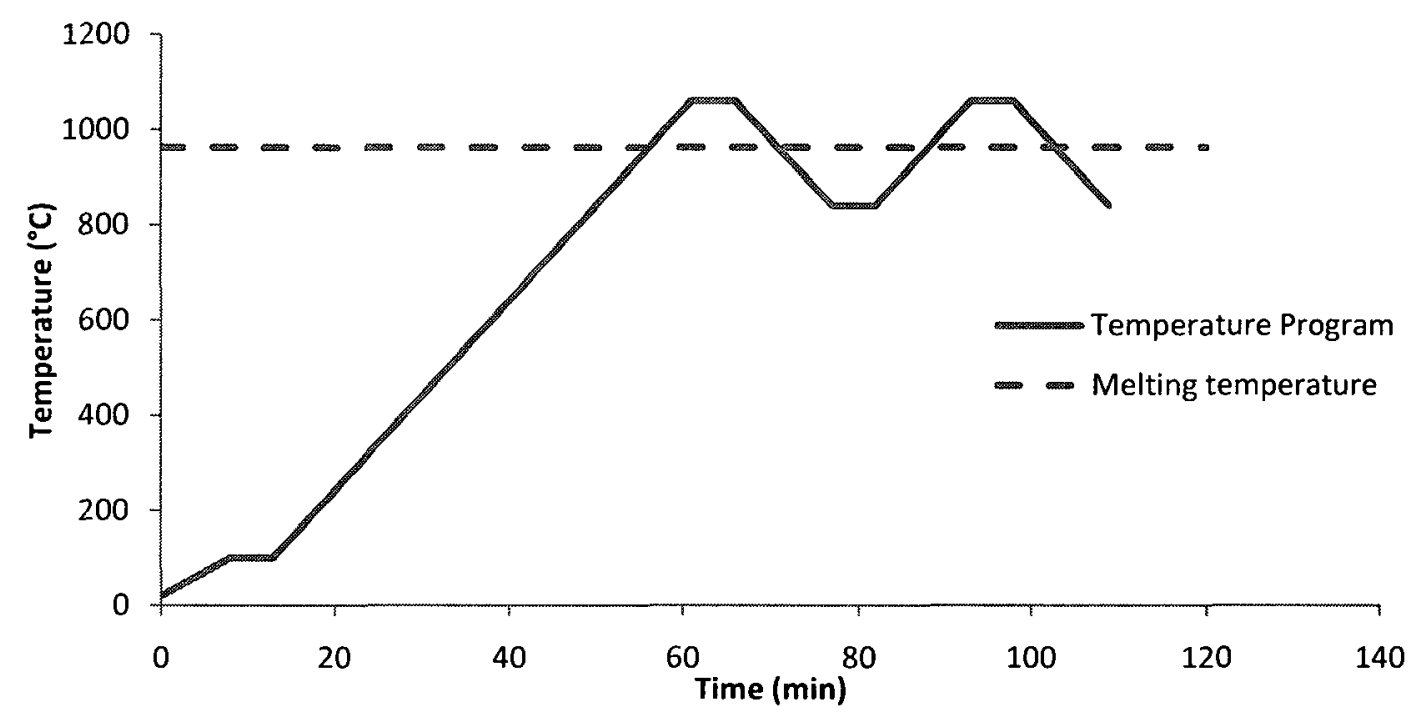

Figure 50. DSC calibration temperature program for silver.

\subsubsection{DSC Runs}

In order to ensure that the DSC results were not affected by the crucibles, Both the sample and reference crucibles were baked out to a temperature of $1500{ }^{\circ} \mathrm{C}$ for 20 minutes. Furthermore, a baseline DSC run of the empty yttria crucibles was conducted to determine the DSC signal from the sample crucible alone. This signal can then be subtracted from the DSC results to isolate the DSC signal from the sample. During the baseline run, the sample crucible was filled with $25 \mathrm{mg}$ of yttria powder and the reference crucible was filled with $20 \mathrm{mg}$ of yttria powder. The crucibles were then run through the sample temperature program shown in Figure 51. The DSC output signal was saved as a baseline correction file and could be applied directly to the sample DSC runs. A sample of each alloy weighing approximately $20 \mathrm{mg}$ was cut from the as-HIP'ed bars and was then placed in the yttria sample crucible with $15 \mathrm{mg}$ of yttria powder beneath it and 
$10 \mathrm{mg}$ of yttria powder covering it. Each sample was then run through the temperature program shown in Figure 51.

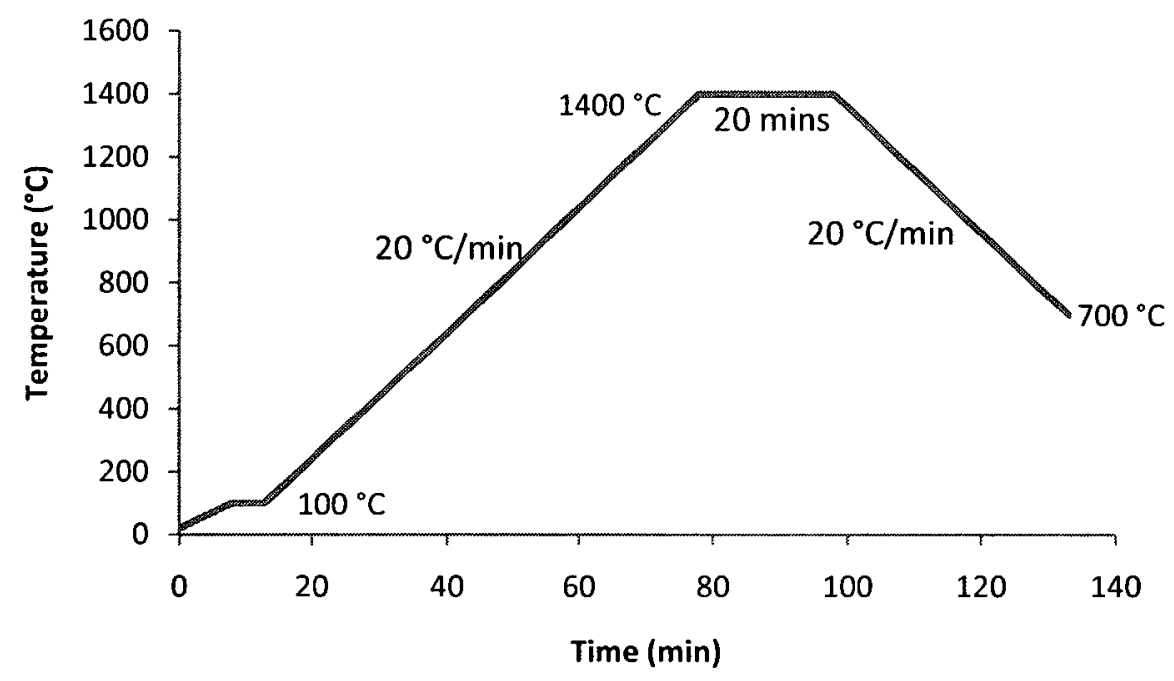

Figure 51. The Temperature program used for the baseline and Sample DSC runs.

\subsection{X-Ray Diffraction (XRD) Analysis}

$\mathrm{XRD}$ analysis was done in order to gain a better understanding of the phases present in each alloy at temperatures close to the $\alpha$ transus. As-HIP'ed samples of each alloy were held for 1 hour at the temperatures shown in Table 2 and Table 3, then water quenched. The samples that were used were HIP'ed at $1250^{\circ} \mathrm{C}$ for 2 hours at $200 \mathrm{MPa}$ followed by a furnace cool. Following polishing, the samples were submitted to an XRD technician for analysis on a Bruker AXS D8 Advance system $\theta-\theta$ powder diffractometer, equipped with a $\mathrm{Cu}$ tube and a Vantec position-sensitive detector with radial Soller slits. 
Table 6. Temperatures for XRD analysis for alloy G1.

\begin{tabular}{cc}
\hline Trial & $\begin{array}{c}\text { Quench } \\
\text { Temperature }\left({ }^{\circ} \mathbf{C}\right)\end{array}$ \\
\hline 1 & 1170 \\
\hline 2 & 1230 \\
\hline 3 & 1285 \\
4 & 1350 \\
\hline
\end{tabular}

Table 7. Temperatures for XRD analysis for alloy G2.

\begin{tabular}{cc}
\hline Trial & $\begin{array}{c}\text { Quench } \\
\text { Temperature }\left({ }^{\circ} \mathrm{C}\right)\end{array}$ \\
\hline 1 & 1200 \\
\hline 2 & 1240 \\
3 & 1270 \\
\hline 4 & 1300 \\
5 & 1350 \\
\hline
\end{tabular}

\subsection{Heat Treatments}

A solution heat treatment process (step cooled solution heat treatment, SCSHT) was developed for both alloys in order to acquire a homogeneous fully lamellar microstructure. The solution heat treated samples were then aged at various temperatures and durations in order to precipitate $\beta$ phase particles at the lamellar interfaces. All heat treatments were conducted in air in a Lindburg/Blue $M$ box furnace (model \#: BF51333C) shown in Figure 52. Small 1 inch samples of the de-canned as-HIP'ed bars were cut using a Buehler abrasive saw. 


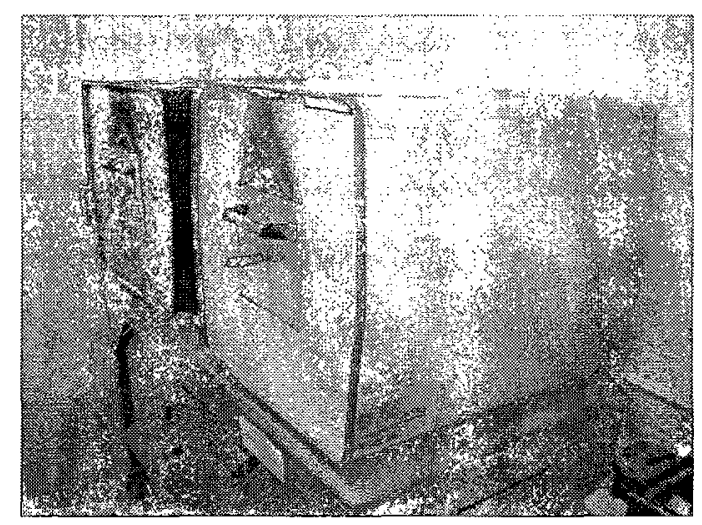

Figure 52. Lindburg/blue $M$ box furnace used for heat treatments.

\subsubsection{Step Cooled Solution Heat Treatments (SCSHT)}

Table 8 shows a summary of the step cooled solution heat treatment trials. The samples were held at a temperature of $1400{ }^{\circ} \mathrm{C}$ for 40 minutes in air. During the step cooling process, the samples were furnace cooled $\left(11^{\circ} \mathrm{C} / \mathrm{min}\right)$ to a transition temperature $T_{\mathrm{F} / \mathrm{A}}$ then removed from the furnace and air cooled to room temperature, as shown in Figure 53. The optimal solution heat treatment process was developed by varying the step cool transition temperature, $T_{F / A}$, between 1270 and $1290{ }^{\circ} \mathrm{C}$. This type of cooling pathway was used to develop the desired fully lamellar microstructure. If the samples were air cooled from $1400{ }^{\circ} \mathrm{C}$, too much $\beta$ phase would be retained to room temperature and massively transformed or equiaxed $\gamma$ would form at the prior $\alpha$ grain boundaries. If the samples were furnace cooled from $1400^{\circ} \mathrm{C}$, the $\gamma$ lamellae would coarsen to eventually form full $\gamma$ grains.

Table 8. Step cooled solution heat treatment conditions for both G1 and G2.

\begin{tabular}{llll}
\hline Temperature & Duration & Transition temperature $\left(\mathbf{T}_{\mathrm{F} / \mathrm{A}}\right)$ \\
\hline $1400^{\circ} \mathrm{C}$ & 40 mins & $1270^{\circ} \mathrm{C}$ & $1280^{\circ} \mathrm{C}$ \\
\hline
\end{tabular}




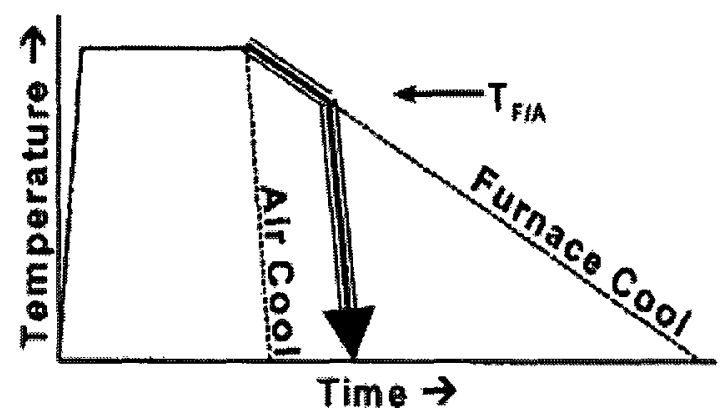

Figure 53. Step cooling during the solution heat treatment process.

\subsubsection{Aging Heat Treatments}

Table 9 and Table 10 show a summary of the isothermal aging conditions investigated for G1 and G2, respectively. The aging temperatures were varied between $800{ }^{\circ} \mathrm{C}$ and $950^{\circ} \mathrm{C}$ and the durations were varied between 6 and 96 hours. All samples were air cooled to room temperature.

Table 9. Aging heat treatments for alloy $G 1$.

\begin{tabular}{|cc}
\hline $\begin{array}{c}\text { Temperature } \\
\left({ }^{\circ} \mathbf{C}\right)\end{array}$ & $\begin{array}{c}\text { Duration } \\
(\mathbf{h r s})\end{array}$ \\
\hline $\mathbf{8 0 0}$ & 6 \\
$\mathbf{8 0 0}$ & 24 \\
900 & 24 \\
9900 & 96 \\
\hline 900 & 6 \\
\hline 950 & 24 \\
\hline 950 & \\
\hline
\end{tabular}

Table 10. Aging heat treatments for alloy G2

\begin{tabular}{cc|}
\hline $\begin{array}{c}\text { Temperature } \\
\left({ }^{\circ} \mathrm{C}\right)\end{array}$ & $\begin{array}{c}\text { Duration } \\
(\mathbf{h r s})\end{array}$ \\
\hline $\mathbf{8 0 0}$ & 6 \\
$\mathbf{8 0 0}$ & 24 \\
$\mathbf{9 0 0}$ & 6 \\
$\mathbf{9 0 0}$ & 24 \\
\hline 900 & 96 \\
\hline $\mathbf{9 5 0}$ & 6 \\
\hline 950 & 24 \\
\hline
\end{tabular}




\subsubsection{Microhardness Testing}

Microhardness testing using a LECO LM247AT microhardness tester (Figure 54) was done for all heat treatment conditions. Ten micro indentations were made in the center of lamellar grains of lightly etched optical samples with a force of 300 grams and a dwell time of 13 seconds. The ten indentations were made at various locations on the sample, including near the center and near the edges.

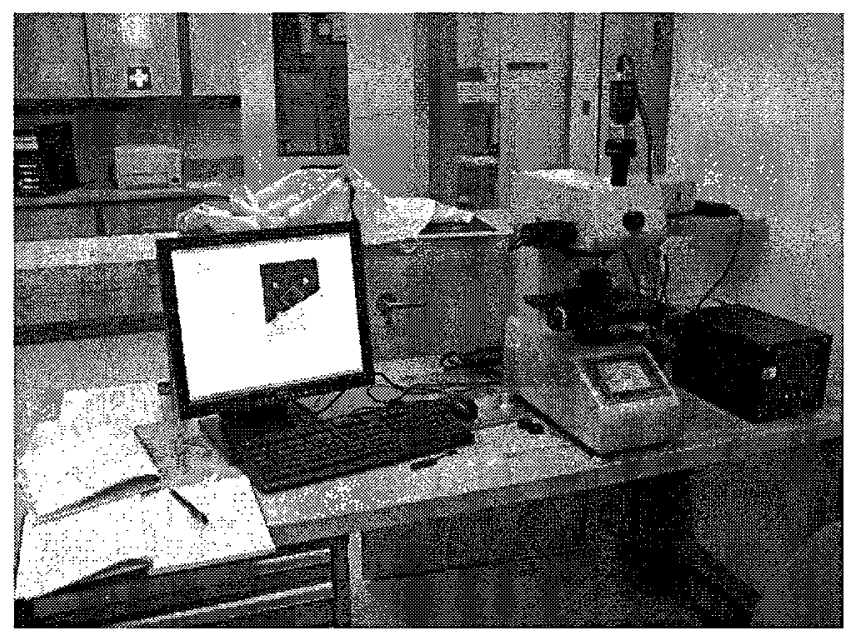

Figure 54. LECO LM247AT microhardness testers used for microhardness testing.

\subsection{Microstructural Analysis}

Microstructural analysis and characterization was the means of evaluating the processing conditions being investigated. This section outlines the sample preparations and the microstructural analysis techniques that were used in the project. 


\subsubsection{Sample Preparation}

Following each processing condition (HIP, solution heat treatment, aging), $1 / 4$ inch thick pieces were cut from the samples for optical and SEM analysis. The optical samples were mounted in Bakelite and were mechanically polished with 400 to 1200 grit sandpaper using the polishing wheel shown in Figure 55. Final polishing was done using a ferric oxide solution for 10 minutes followed by a colloidal silica suspension for 7 minutes, producing a mirror finish. The samples were then etched with the TiAl etchant shown in Table 11 in order to reveal the microstructure for optical observation.

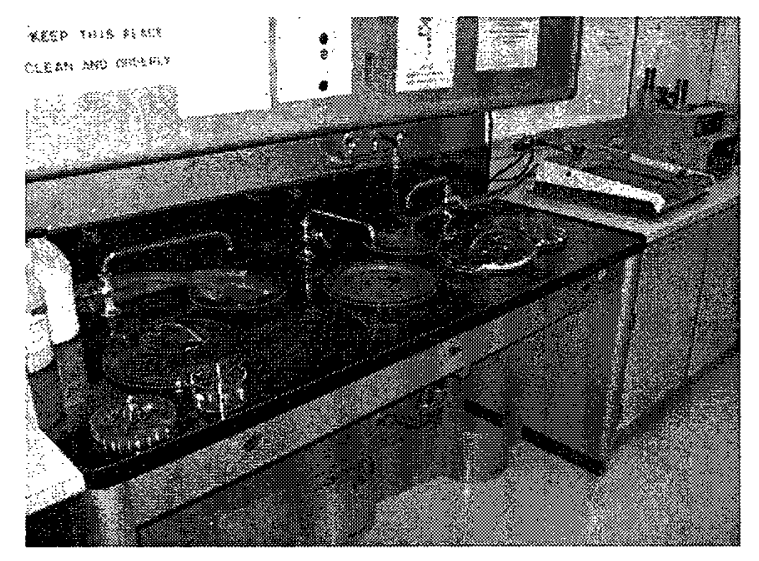

Figure 55. Polishing wheel used for mechanical polishing of samples

Table 11. TiAl etchant.

\begin{tabular}{ll}
\hline Volume $(\mathrm{mL})$ & Chemical \\
\hline 25 & Glucose \\
\hline 12 & Water \\
12 & Nitric Acid \\
1 & Hydrofluoric Acid \\
\hline
\end{tabular}


The SEM samples were prepared by mechanically polishing to 600 grit then electrochemically polishing for 3 minutes at 30 Volts in an acid solution at $-45^{\circ} \mathrm{C}$. The composition of the acid solution is shown in Table 12. Figure 56 shows the electrochemical polishing setup.

Table 12. Electrochemical polishing solution.

\begin{tabular}{ll}
\hline Chemical & Percentage (\%) \\
\hline Methanol & 64 \\
Butanol & 31 \\
Perchloric aeid & 5 \\
\hline
\end{tabular}
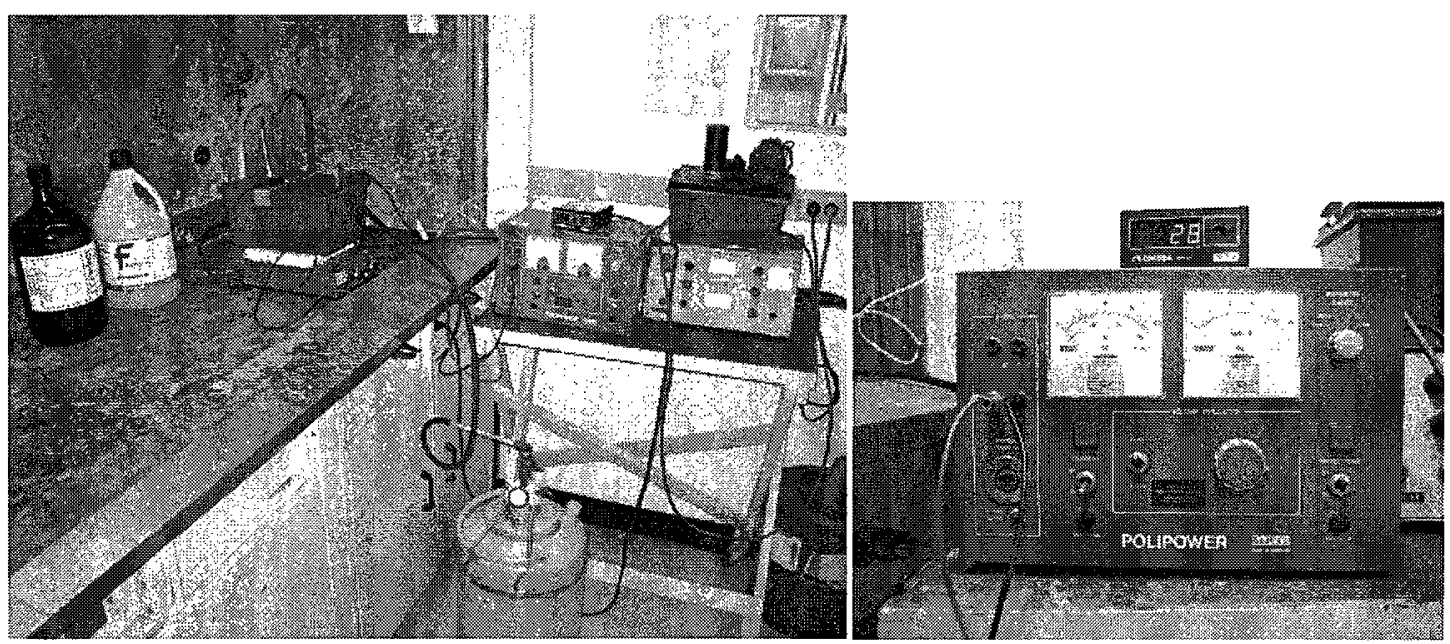

Figure 56. Electrochemical polishing setup.

Samples for scanning transmission electron microscopy (STEM) were prepared by first cutting $0.4 \mathrm{~mm}$ thick slices off the as-HIP'ed or heat treated samples using a Buehler IsoMet 2000 cutter with a diamond wafering blade (Figure 57). A slice was then glued to a brass holder (Figure 58a) with superglue and mechanically polished to roughly half its original thickness using 320 grit followed by 600 grit sand paper. The superglue was then dissolved in acetone. The sample was then re-glued to the brass holder with the un- 
polished side exposed and was mechanically polished using 320 grit followed by 600 grit sand paper until the slice was approximately $40 \mu \mathrm{m}$ thick. Using the puncher shown in Figure $58 \mathrm{~b}$, approximately eight $3 \mathrm{~mm}$ diameter disks were punched from each slice, as shown in Figure 59. The discs were then further reduced in thickness using a Struers Tenupol - 3 twin jet polisher (Figure 60) and the acid solution shown in Table 12. The twin jet polishing parameters are shown in Table 13.

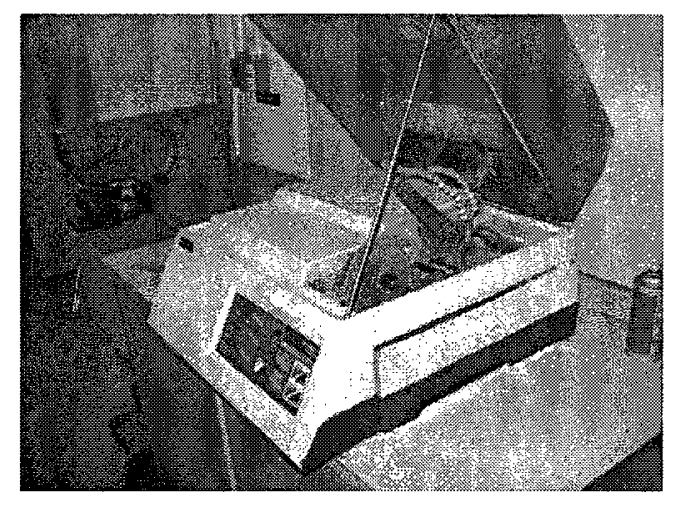

Figure 57. Buehler IsoMet 2000 cutter used to cut slices for TEM samples.

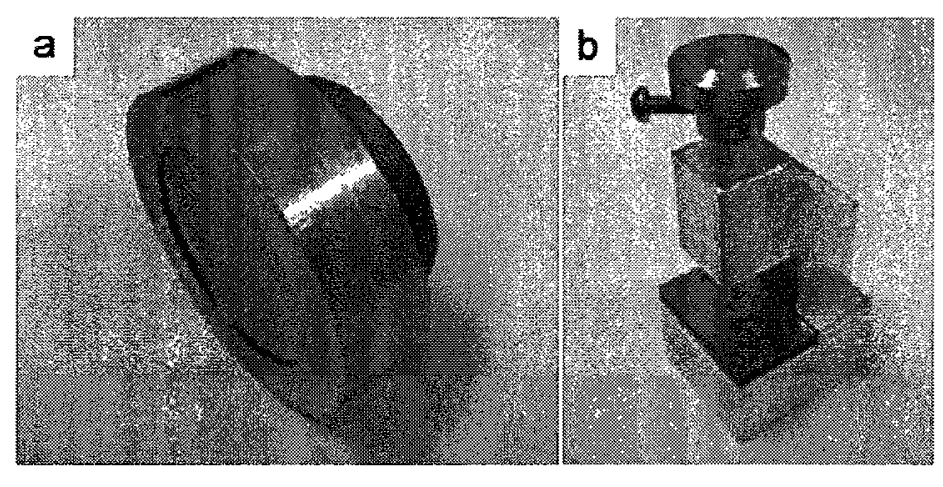

Figure 58. a) Brass holder used for mechanical polishing of slices used for TEM samples, and b) Puncher used to punch $3 \mathrm{~mm}$ diameter TEM samples from the mechanically polished slices. 

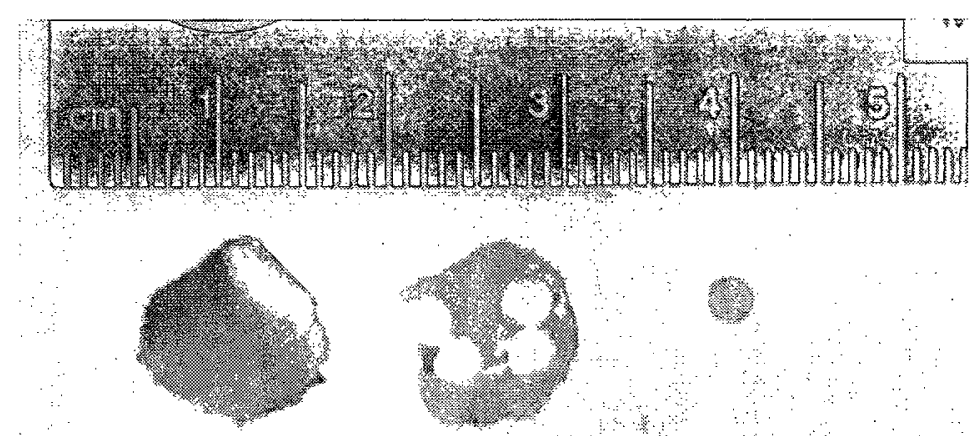

Figere 59. TRM sample.
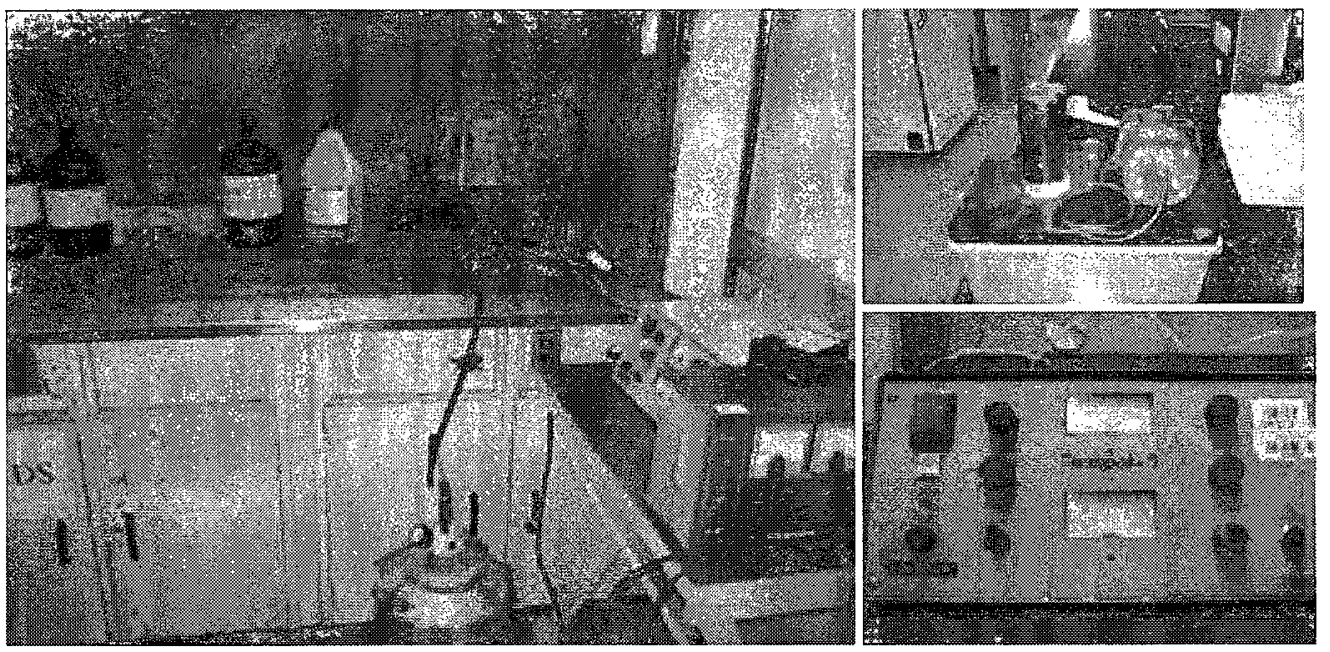

Figure 60. Twin-Jet polishing setup and power supply.

Table 13. Twin jet polishing parameters。

\begin{tabular}{lc}
\hline Temperature & -45 to $-50^{\circ} \mathrm{C}$ \\
Voltage & $15 \mathrm{~V}$ \\
Current & $20-30 \mathrm{~mA}$ \\
Flow Rate & 7 \\
Photo Sensitivity & 0.5 \\
\hline
\end{tabular}




\subsubsection{Microstructural Analysis Techniques}

Optical microscopy (OM) was conducted using an Olympus PMG-3 optical microscope equipped with a CCD camera, as shown in Figure 61. Optical micrographs were acquired using Quartz PCI image software. Magnifications of 5x to $100 \mathrm{x}$ were possible.

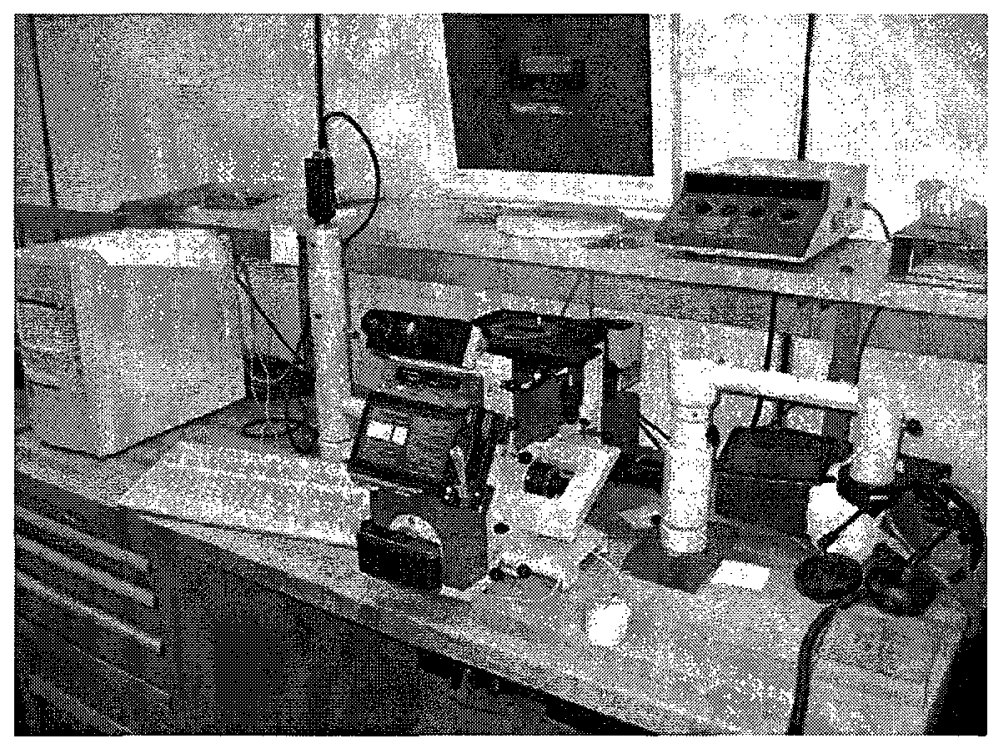

Figure 61. Olympus PMG-3 optical microscope equipped with CCD.

Scanning electron microscopy (SEM) was conducted using a Philips XL30S FEG equipped with an energy dispersive spectroscopy (EDS) system from Pheonics systems (Figure 62). Backscattered electron (BSE) images were acquired using a beam size of 5 with an accelerating voltage of $20 \mathrm{kV}$. 


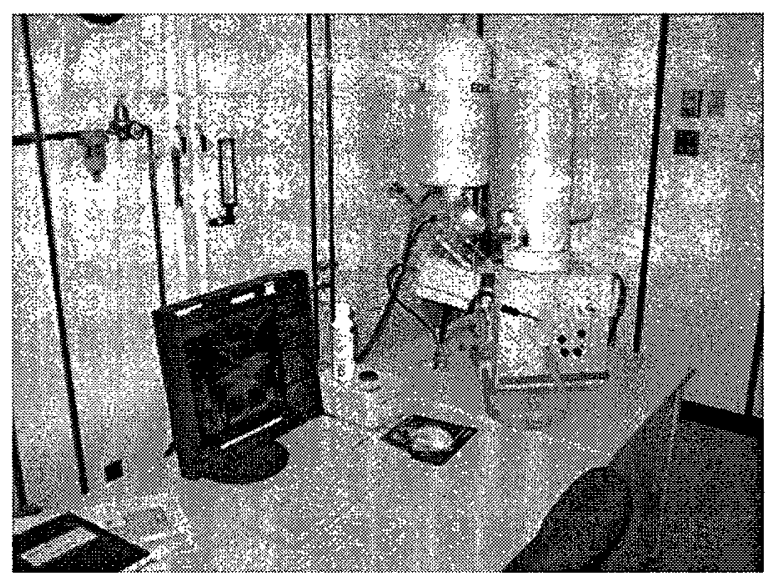

Figure 62. Philips XL30S FEG scanning electron microscope equipped with an EDAX from Pheonics systems.

Scanning Transmission Electron Microscopy (STEM) analysis was conducted using a Jeol JEM-2100F field emission electron microscope (Figure 63) under transmission and scanning transmission modes. Various STEM modes such as bright field, dark field, and angular dark field were utilized at the accelerating voltage of $200 \mathrm{kV}$.

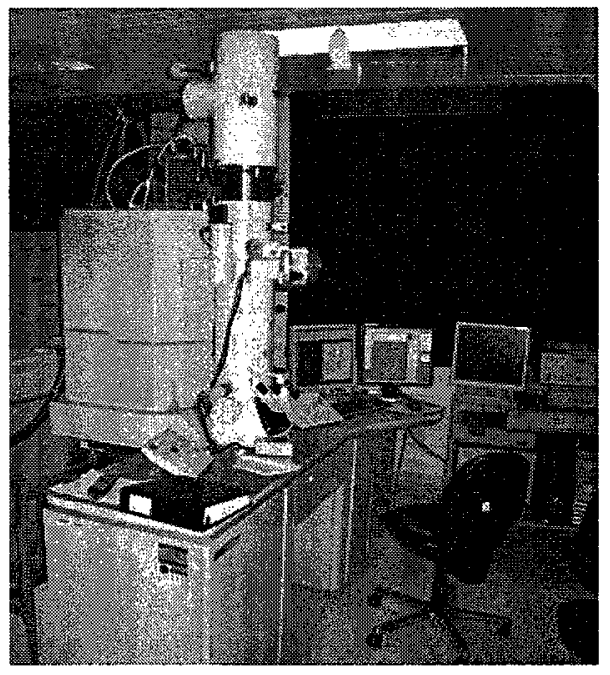

Figure 63. Jeol JEM-2100F field emission electron microscope. 
The volume fraction of the $\beta$ phase in the alloys was measured using Photoshop. The threshold tool was used to isolate the white $\beta$ phase in the BSE images, as shown in Figure 64. A histogram within Photoshop indicates the percentage of white pixels in the image. The $\beta$ phase volume fraction for a given set of HIP conditions was taken as the average from at least ten BSE images having magnifications ranging from $2000 \mathrm{x}$ to $8000 x$

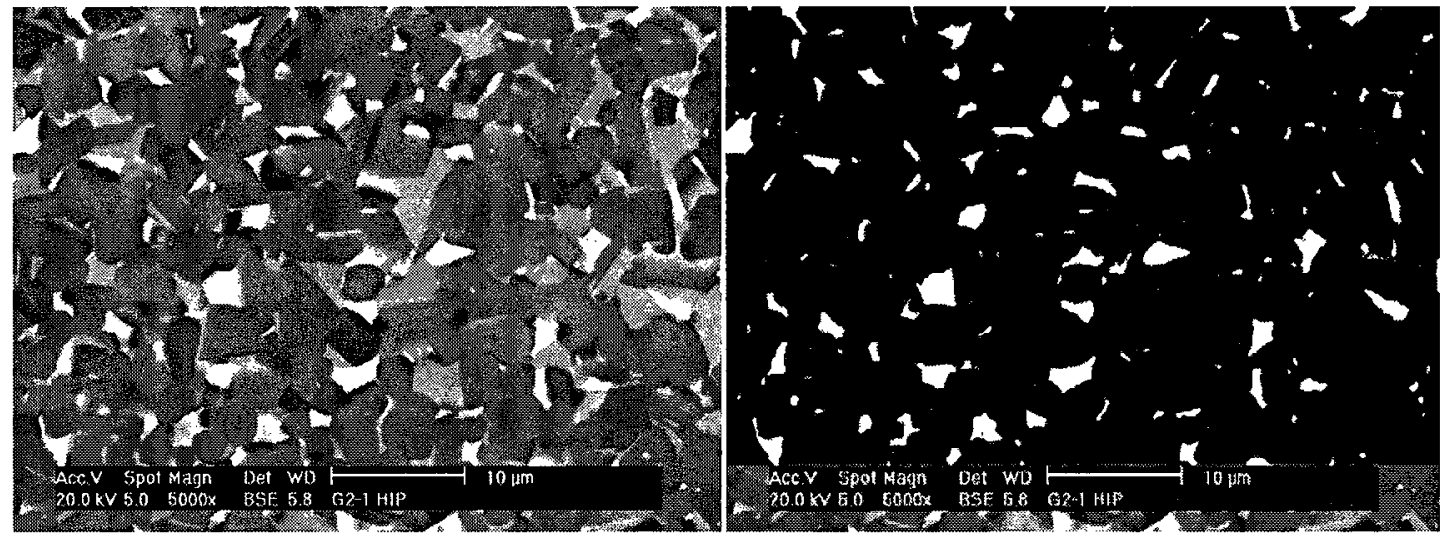

Figure 64. Threshold tool in Photoshop used to determine the $\beta$ phase volume fraction. 


\section{Results and Discussion}

The following section contains the results obtained throughout the project. The interpretation and discussion of the results are also presented. This section includes an analysis of the atomized powder particles, the hot isostatic pressing results, phase transformation analysis, and the step cooled and aging heat treatment results, which includes microhardness analysis.

\subsection{The Microstructure of the Gas Atomized Powders}

The microstructures of the powder particles of alloy G1 and G2 can be seen in Figure 65 and Figure 66, respectively. There is a clear dendritic structure in both alloy powders, showing primary equiaxed dendrites separated by interdendritic zones. SEM-EDS of alloy G1 showed that the interdendritic zones were slightly rich in $\mathrm{Al}$ and $\mathrm{Mn}$, and slightly depleted in $\mathrm{Ti}$ and $\mathrm{Nb}$, as seen in Figure 67. Alloy G2 had interdendritic zones rich in $\mathrm{Al}$ and depleted in $\mathrm{Ti}, \mathrm{Nb}$ and $\mathrm{Mo}$, as seen in Figure 68. The chemical homogeneity between the dendritic core and interdendritic zone is very high as compared to that of a cast gamma TiAl alloy [18]. This chemical homogeneity can be attributed to the extremely fast cooling rates associated with gas atomization, as well as to nonperitectic solidification through the $\beta$ phase.

In both alloy powders, a white phase with a vein morphology is visible throughout the dendrites. The white phase in alloy G2 showed no detectable difference in 
composition due to the limited resolution of the SEM, as seen in Figure 68. However, the white phase in alloy $\mathrm{G} 1$, which is more pronounced than it is in alloy G2, was rich in Ti and $\mathrm{Mn}$ and depleted in $\mathrm{Al}$, as seen in Figure 69.
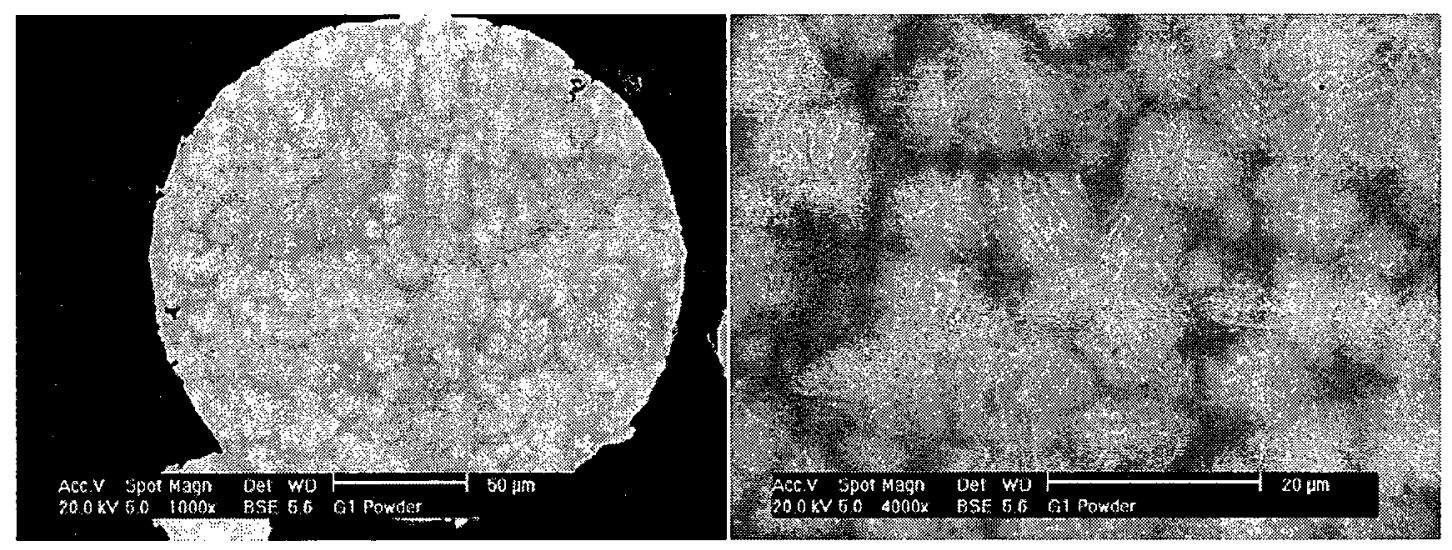

Figure 65. The microstructure of the alloy $\mathrm{G1}$ gas atomized powder particles.

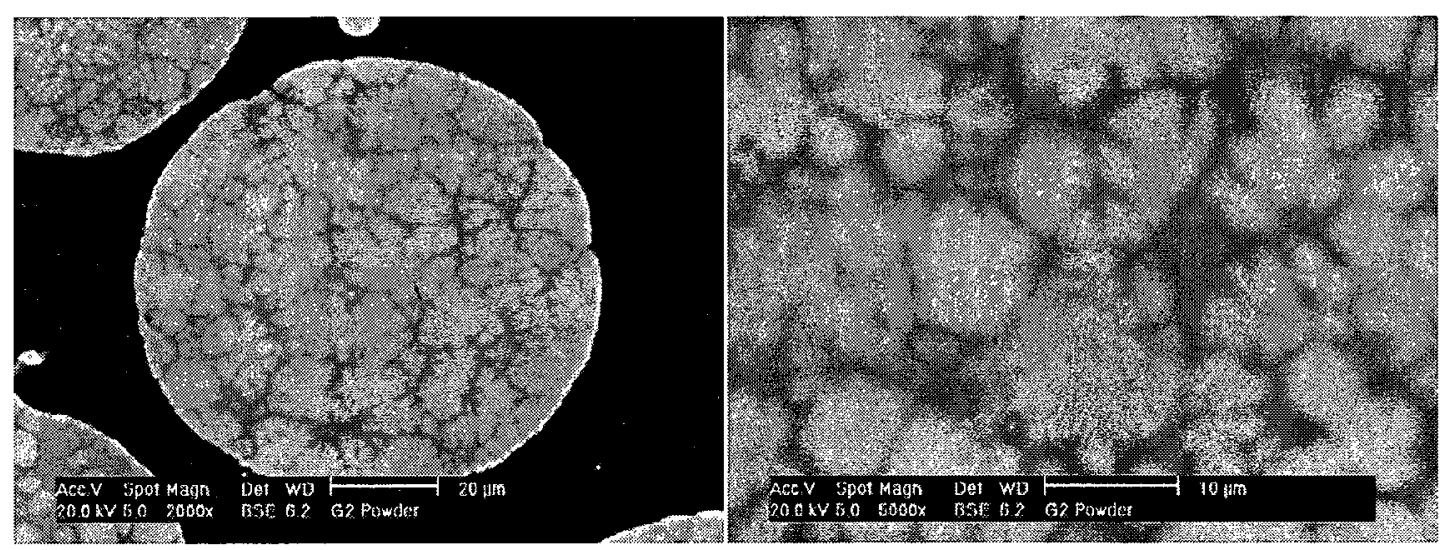

Figure 66. The microstructure of the alloy $\mathbf{G} 2$ gas atomized powder particles. 

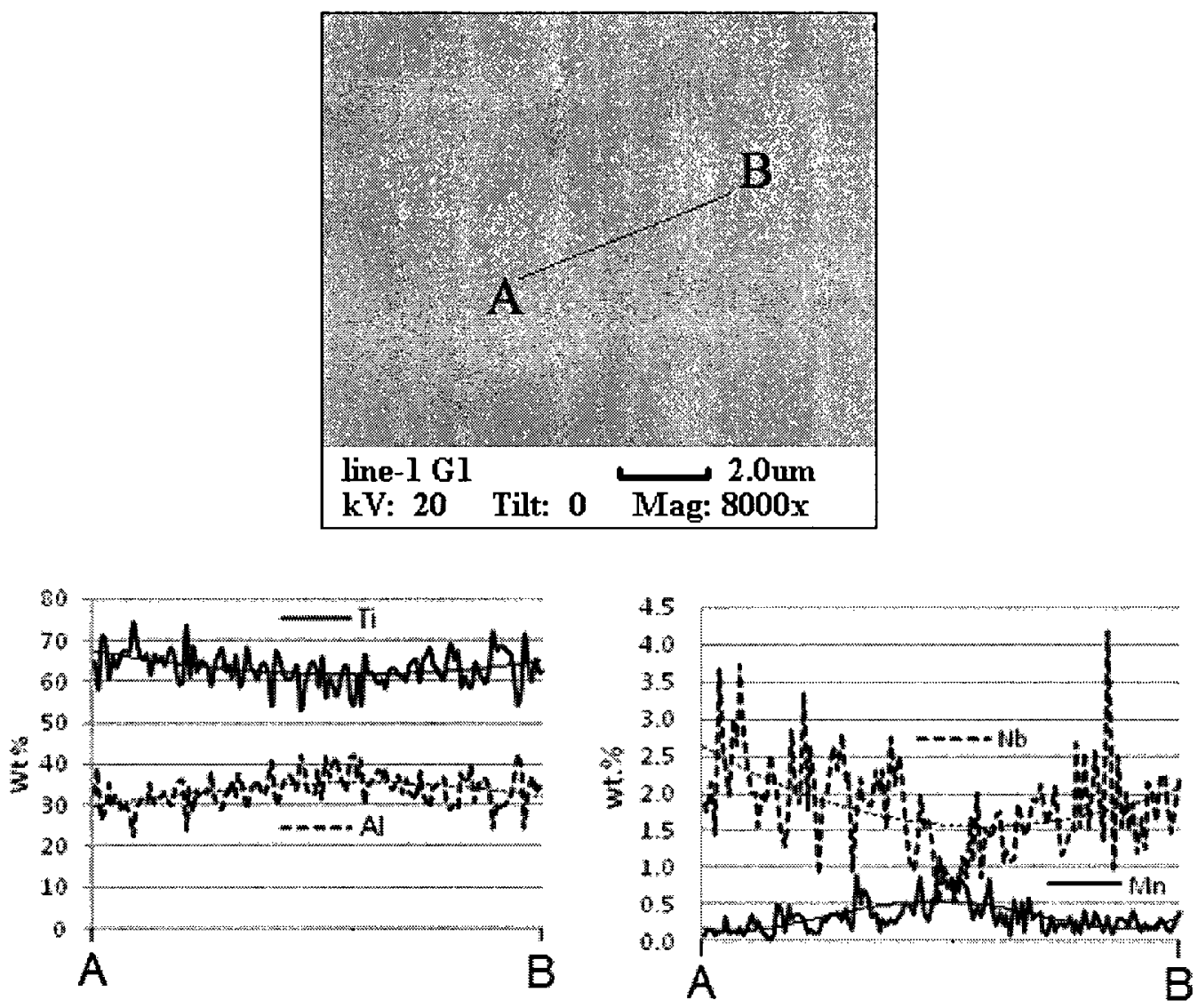

Figure 67. SEM-EDS line scan across the interdendritic zone of the gas atomized powder of alloy G1. 


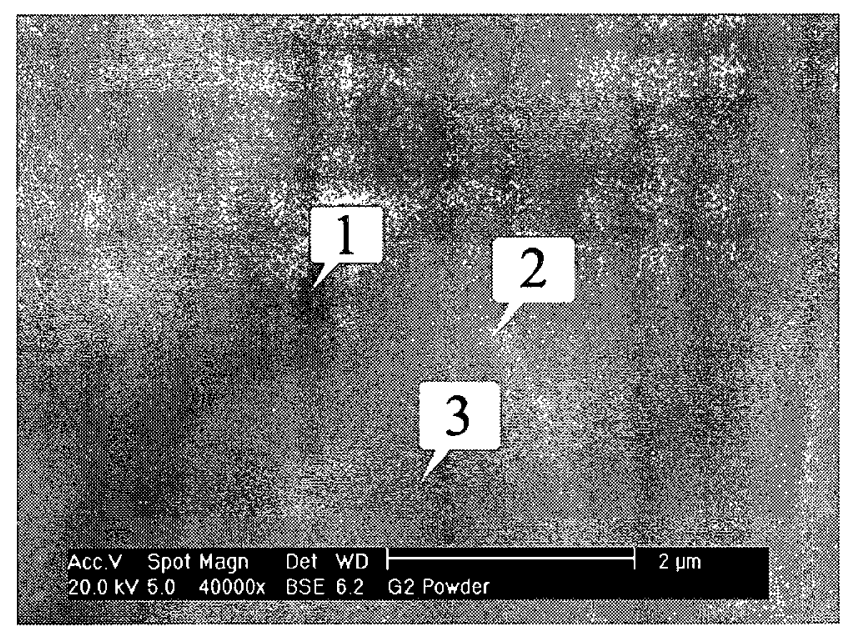

\begin{tabular}{|c|c|c|c|}
\hline & tero & $\mathrm{Nb}$ & Min \\
\hline 1. & $46.83: 50.04$ & 1.63 & 1.50 \\
\hline 2 & 486017.70 & 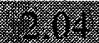 & \\
\hline 3 & $48.70 \div 47.14$ & 206 & 2.14 \\
\hline
\end{tabular}

Figure 68. SEM-EDS point analysis of the powder of alloy G2. Spot analyses 1 is in the interdendritic region and spot analysis 3 is in the dendritic core. Spot analysis 2 is in the white phase with a vein morphology.

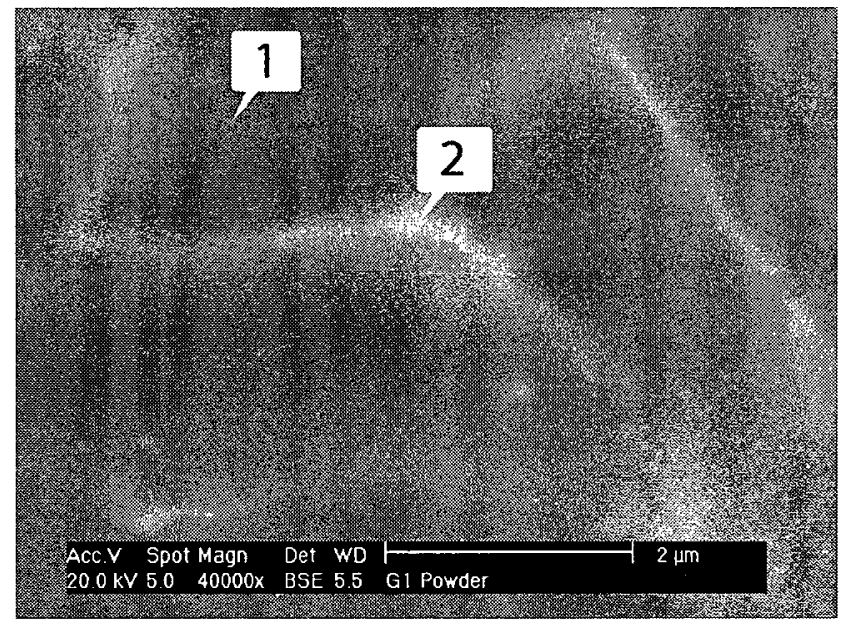

\begin{tabular}{|c|c|c|}
\hline & & (1) \\
\hline 1. & $45.71 ?-47.26$ & \\
\hline & & \\
\hline
\end{tabular}

Figure 69. SEM-EDS point analysis of the powder of alloy G1. Spot analysis 1 is in the dendritic core and spot analysis 2 is in the white phase with a vein morphology. 


\subsection{Hot Isostatic Pressing (HIP)}

The typical as-HIP'ed microstructure of alloys G1 and G2 can be seen in Figure 70 and

Figure 71 , respectively. Alloy G1 was found to have a two phase near- $\gamma$ microstructure consisting mostly of $\gamma$ grains (dark grey phase) with a small amount of $\alpha_{2}$ grains (light grey phase). Only a very small amount of $\beta$ phase (white phase) could be found in the asHIP'ed G1 alloy. Alloy G2 was found to have a three phase near- $\gamma$ microstructure consisting of $\gamma$ grains, a small amount of $\alpha_{2}$ grains, and a small amount of $\beta$ grains.

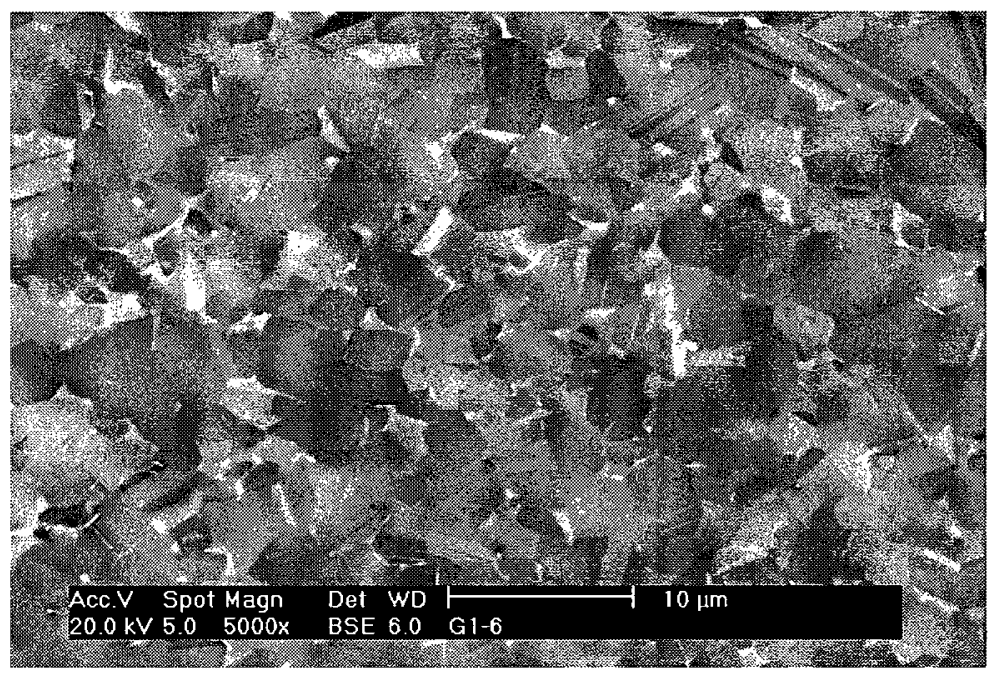

Figure 70. As-HIP'ed microstructure of alloy G1 showing a two phase near- $\gamma$ microstructure with $\gamma$ grains (dark gray), $\alpha_{2}$ grains (light gray). This sample was HIP'ed at $1250^{\circ} \mathrm{C} / 200 \mathrm{MPa} / 2$ hours. 


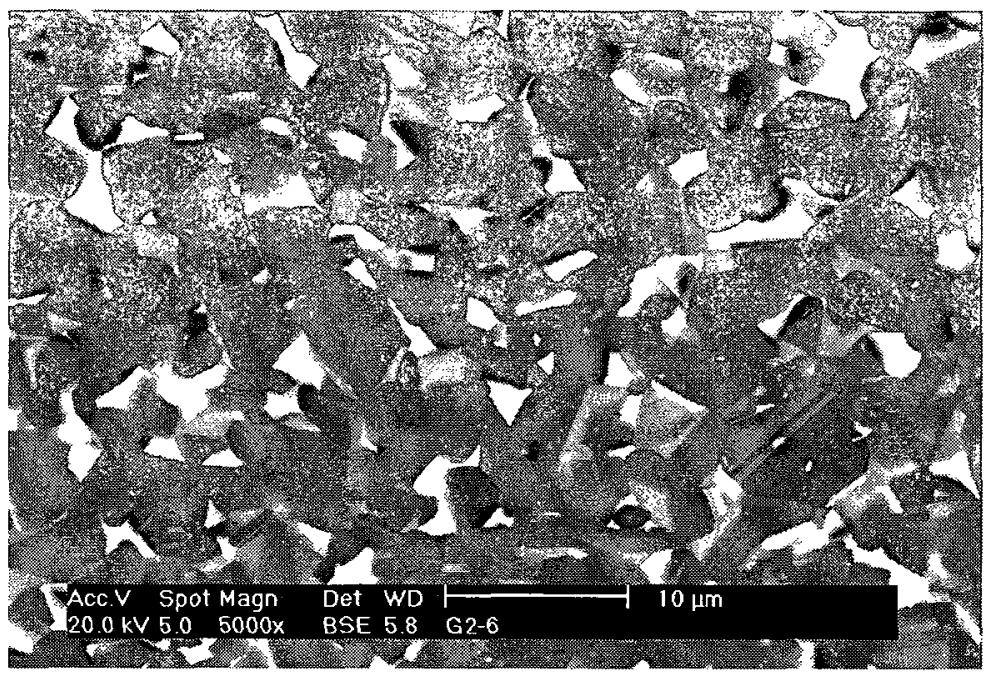

Figure 71. As-HIP'ed microstructure of alloy G2 showing a three phase near- $\gamma$ microstructure with $\gamma$ grains (dark gray), $\alpha_{2}$ grains (light gray), and $\beta$ grains (white). This sample was HIP'ed at 1250 ${ }^{\circ} \mathrm{C} / 200 \mathrm{MPa} / 2$ hours.

The much greater stability of the $\beta$ phase in alloy $\mathrm{G} 2$ can be attributed to the different $\beta$ stabilizing alloying additions. Alloy Gl utilizes 4 at.\% $\mathrm{Nb}$ and 3 at.\% $\mathrm{Mn}$ to stabilize the $\beta$ phase, whereas alloy G2 utilizes 2 at.\% Nb and 2 at.\% Mo. It has been found that the $\beta$ forming effectiveness of Mo is significantly higher than that of $\mathrm{Nb}$ and $\mathrm{Mn}$ [59]. The $\beta$ forming effectiveness of different alloying additions can be described in terms of a niobium equivalent, as seen in Table 14 [59]. These $\mathrm{Nb}$ equivalents can then be used to determine the overall $\beta$ forming effectiveness of a given composition, as seen in Table 15. A lower aluminum content also stabilizes $\beta$ phase. However, both alloys G1 and G2 have roughly the same amount of aluminum. 
Table 14. The $\beta$ forming effectiveness of $M n$ and Mo in terms of a niobium equivalent [59].

\begin{tabular}{cc}
\hline Element & Nb equivalent \\
\hline $\mathrm{Nb}$ & 1.0 \\
$\mathrm{Mn}$ & 2.2 \\
\hline $\mathrm{Mo}$ & 6.4 \\
\hline
\end{tabular}

Table 15. The $\beta$ forming effectiveness of alloys $G 1$ and G2 in terms of a niobium equivalent.

\begin{tabular}{cc}
\hline Alloy & Nb equivalent \\
\hline G1 & 10.6 \\
\hline G2 & 14.8 \\
\hline
\end{tabular}

Alloy $\mathrm{Gl}: 4 \mathrm{Nb}+3 \mathrm{Mn}=4 \mathrm{Nb}+3 *(2.2 * \mathrm{Nb})=10.6 \mathrm{Nb}$

Alloy G2: $2 \mathrm{Nb}+2 \mathrm{Mo}=2 \mathrm{Nb}+2 *(6.4 * \mathrm{Nb})=14.8 \mathrm{Nb}$

As shown in Table 3 of section 2.2, the room temperature equilibrium phases of an alloy can be determined based on the $\mathrm{Nb}$ equivalent of $\beta$ stabilizing alloying additions. Alloy $\mathrm{Gl}$, with a $\mathrm{Nb}$ equivalent of 10.6 , falls closest to a two phase $\left(\gamma+\alpha_{2}\right)$ alloy group. Alloy $\mathrm{G} 2$, with a $\mathrm{Nb}$ equivalent of 14.8 , falls between the three phase $\left(\gamma+\alpha_{2}+\beta\right)$ alloy group and the two phase $(\gamma+\beta)$ alloy group. Since there is clearly three different phases in the as-HIP'ed microstructure of alloy G2, shown in Figure 71, it must be a three phase $\left(\gamma+\alpha_{2}+\beta\right)$ alloy. The resulting as-HIP'ed microstructures of alloy G1, shown in Figure 70, also appears to coincide with its respective theoretical alloy groups, as there is a negligible amount of $\beta$ phase. This leads to the conclusion that the composition of alloy G1 is flawed, since the alloy was designed to contain a similar amount of $\beta$ phase as alloy G2. The designer of the alloy indicated that the resulting composition of alloy G1 (TiAl$4 \mathrm{Nb}-3 \mathrm{Mn}$ ) did not match that of the alloy design as a result of difficulties associated with alloy compositional control during the atomization process [60]. It was particularly 
difficult to control the aluminum content and it is likely that the alloy G1 was supposed to have less aluminum in order to more effectively stabilize the $\beta$ phase [60].

\subsubsection{Phase Analysis}

STEM-EDS point analysis showed that the white phase in G1 (Figure 72a) was rich in Ti, $\mathrm{Nb}$, and $\mathrm{Mn}$, and that the white phase in G2 (Figure 72b) was rich in $\mathrm{Ti}, \mathrm{Nb}$, and $\mathrm{Mo}$. These phases are likely to be $\beta$-phase since in previous studies phases that were rich in $\mathrm{Ti}$ and $\beta$-stabilizing elements, such as $\mathrm{W}, \mathrm{Nb}, \mathrm{Mo}$, and $\mathrm{Mn}$, were identified as $\beta$-phases $[4,7,10,12,13]$.

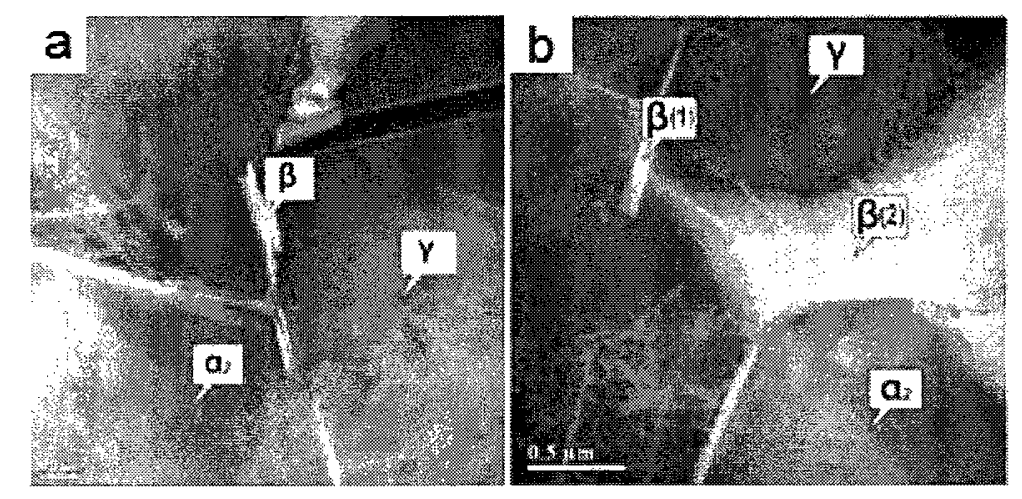

Figure 72. Angular dark field-TEM micrographs of alloy a) G1, and b) G2 HIP'ed at $1250^{\circ} \mathrm{C}$ with a cooling rate of $8.5^{\circ} \mathrm{C} / \mathrm{min}$. The $\beta$-phase in $\mathrm{G} 1$ is rich in $\mathrm{Ti}, \mathrm{Nb}$, and $\mathrm{Mn}$. The $\beta$-phase in $\mathrm{G} 2$ is rich in $\mathrm{Ti}, \mathrm{Nb}$, and Mo.

Table 16. TEM-EDS of G1 (all in at. \%).

\begin{tabular}{ccccc}
\hline Al & Ti & Mn & Nb \\
\hline$\gamma^{2}$ & 45.30 & 47.66 & 2.95 & 4.09 \\
$\boldsymbol{\alpha}_{2}$ & 32.63 & 59.97 & 3.33 & 4.06 \\
\hline $\boldsymbol{B}$ & 27.58 & 59.50 & 5.73 & 7.19 \\
\hline
\end{tabular}


Table 17. TEM-EDS of G2 (all in at. \%).

\begin{tabular}{lcccc}
\hline & Al & Ti & Nb & Mo \\
\hline$\gamma$ & 37.41 & 5973 & 2.87 & $\mathbf{0 . 0 0}$ \\
$\boldsymbol{\alpha}_{2}$ & 36.66 & 58.93 & 2.96 & 1.45 \\
$\boldsymbol{\beta}(\mathbf{1})$ & 23.01 & 63.33 & 3.15 & $\mathbf{1 0 . 5 1}$ \\
$\boldsymbol{\beta}(\mathbf{2})$ & 19.05 & 72.02 & 4.46 & 4.48 \\
\hline
\end{tabular}

\subsubsection{Effect of the Cooling Rate on $\beta$ Phase Volume Fraction}

Figure 73 shows the resulting microstructures of both alloys for various cooling rates from HIP'ing at $1250^{\circ} \mathrm{C}$ and $200 \mathrm{MPa}$ for 2 hours. Both alloys exhibited very fine grain $(\sim 5 \mu \mathrm{m})$ near- $\gamma$ microstructures with small amounts of $\alpha_{2}$ (light gray) and $\beta$ phases (white). It was found that the cooling rate (in the range of 3.0 to $17.5^{\circ} \mathrm{C} / \mathrm{min}$ ) had a negligible effect on the volume fraction of $\beta$ phase in both alloys. As seen in Figure 74, alloy $\mathrm{G} 1$ contained $\sim 1.0$ vol. $\% \beta$ phase and alloy $\mathrm{G} 2$ contained $\sim 6.5$ vol. $\% \beta$ phase, for all three different cooling rates. However, the cooling rate was found to have an effect on the morphology of the $\beta$-phase in G1. A slow cooling rate resulted in fine needle-shaped precipitates (white arrows in Figure 73). Faster cooling rates resulted in larger $\beta$ particles (black arrows) and the formation of the $\beta$ phase at the $\gamma / \alpha_{2}$ grain boundaries (grey arrows). However, it is unclear whether the precipitates indicated by the black and white arrows are actually Ti-boride or Ti-carbide particles. 


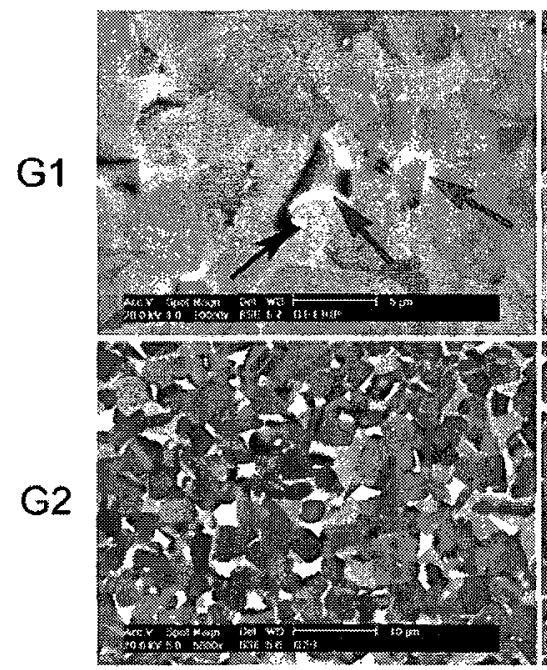

$17.5^{\circ} \mathrm{C} / \mathrm{min}$

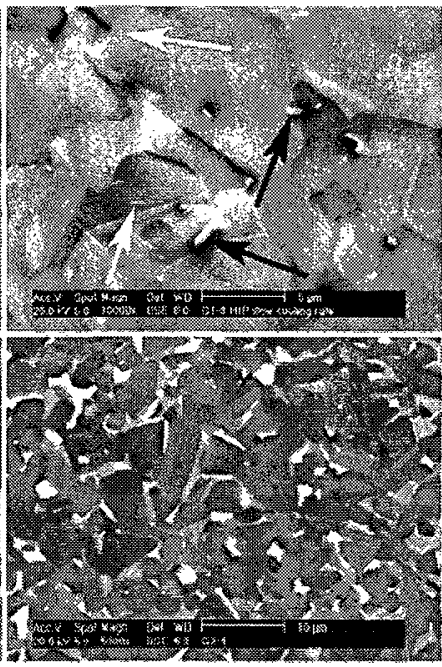

$8.5^{\circ} \mathrm{C} / \mathrm{min}$

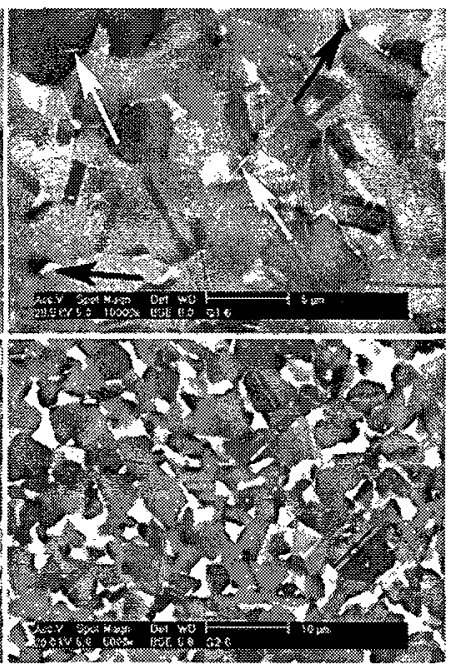

$3.0^{\circ} \mathrm{C} / \mathrm{min}$

Figure 73. BSE images of the microstructures of alloys $\mathrm{G1}$ and $\mathrm{G} 2$ resulting from $\mathrm{HIP}$ at a temperature of $1250^{\circ} \mathrm{C}$ with cooling rates between $3.0^{\circ} \mathrm{C} / \mathrm{min}$ and $17.5^{\circ} \mathrm{C} / \mathrm{min}\left(\alpha_{2}\right.$-phase appears as light gray, $\beta$-phase appears as white). The images for $G 1$ and $G 2$ are at $10,000 x$ and $5,000 x$ magnification, respectively.

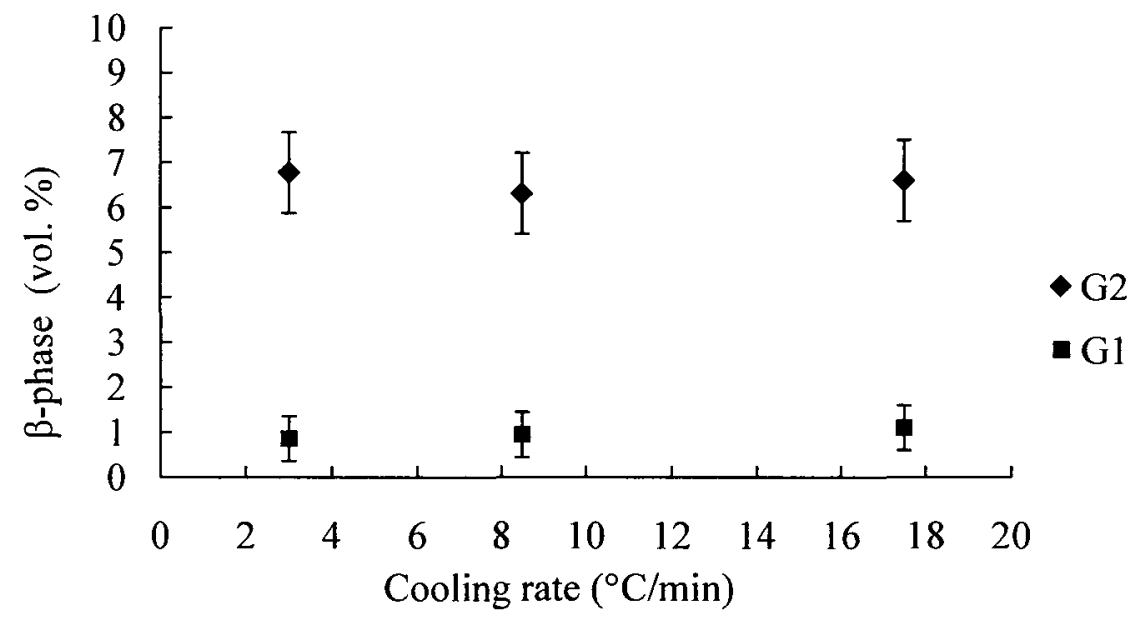

Figure 74. Plot showing the volume fraction of $\beta$-phase for various cooling rates. Samples were HIP'ed at $1250^{\circ} \mathrm{C}$. 


\subsubsection{Effect of HIP Temperature and Duration on $\beta$ Phase Volume Fraction}

Figure 75 shows the microstructures of both alloys resulting from various HIP temperatures. The microstructure in Gl was not significantly affected by a reduction in HIP temperature to $1200^{\circ} \mathrm{C}$. The volume fraction of the $\beta$ phase did not change. This result further supports that alloy G1 is a two phase $\gamma+\alpha$ alloy. Due to the very low amount of $\beta$ phase in alloy Gl in the as-HIP'ed conditions, it does not appear as suitable as alloy G2 for hot working or machining.

However, it was found that the HIP temperature did have a significant effect on the microstructure of alloy G2, as seen in Figure 75 and Figure 76. Reducing the HIP temperature to $1200{ }^{\circ} \mathrm{C}$ resulted in a very fine grain $(-2 \mu \mathrm{m})$ near- $\gamma$ microstructure with an increase in the $\beta$ phase volume fraction to 9.4 vol.\%. However, there were small regions of slightly coarser grain size $(\sim 4 \mu \mathrm{m})$ distributed throughout the microstructure, as shown in Figure 77. Nevertheless, the resulting microstructure, having a very small grain size in addition to a high amount of $\beta$ phase, would have very good hot workability [61]. In studies done by Clemens et al. [61,62], it was found that a similar alloy containing $\sim 7.5$ vol. $\% \beta$ phase had very good hot workability. In the same study, it was also found that the flow stress in the material during hot working was directly related to the $\beta$ phase volume fraction. As seen in Figure $78 \mathrm{~b}$, the flow stress is at a maximum at a hot working temperature that correspond to the minimum $\beta$ phase volume fraction $\left(\sim 1260^{\circ} \mathrm{C}\right)$. Hot working temperatures higher or lower than $1260{ }^{\circ} \mathrm{C}$ have higher amounts of $\beta$ phase and consequently the flow stress is reduced. Furthermore, not unlike gamma TiAl alloys, the flow stress was highly affected by the strain rate. A forging test 
of the alloy in this study showed excellent hot workability, as seen in Figure 79. Alloy G2 HIP'ed at $1200{ }^{\circ} \mathrm{C}$ contained more $\beta$ phase and had a more refined microstructure than the alloys studied by Clemens. Therefore, it can be assumed that hot workability of alloy G2 HIP'ed at $1200{ }^{\circ} \mathrm{C}$ would be comparable, if not superior. However, it would still be beneficial to increase the volume fraction of the $\beta$ phase to further improve the hot workability.

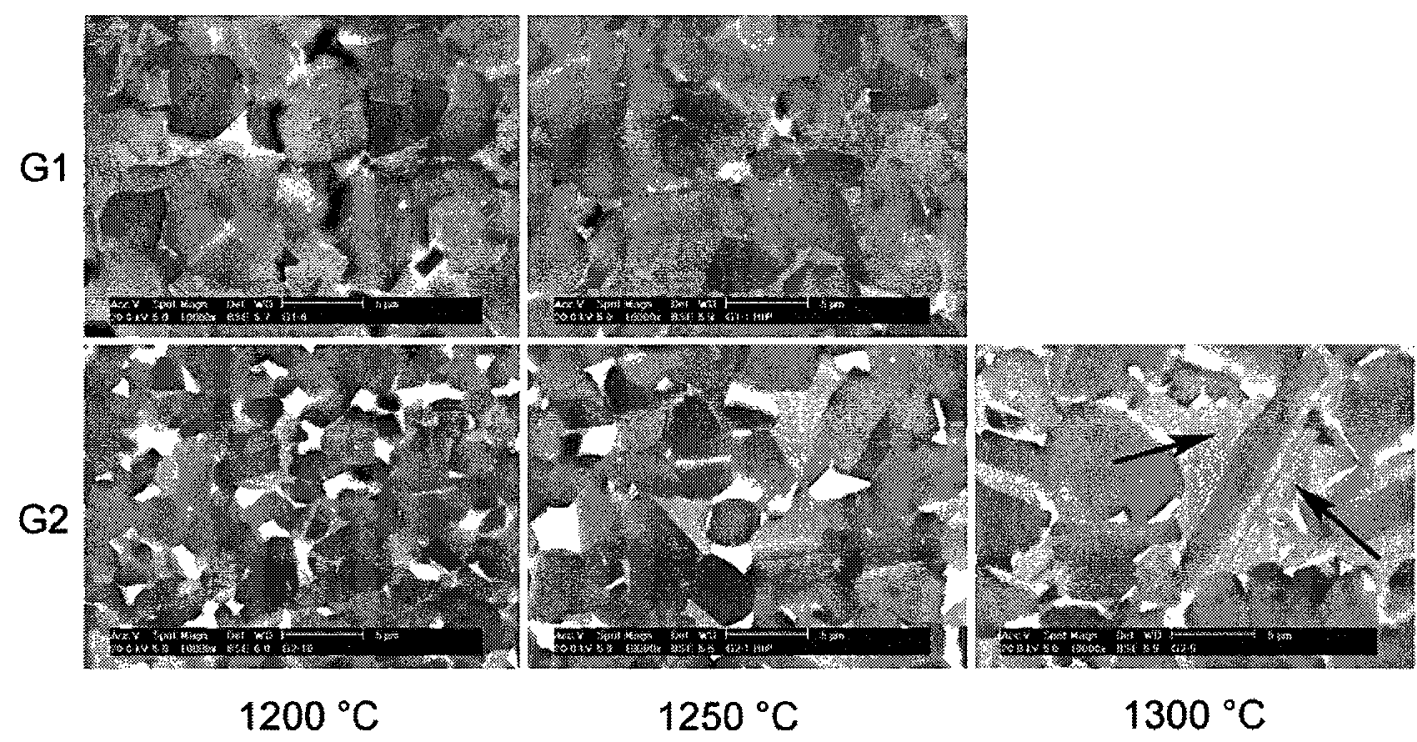

Figure 75. BSE images of the microstructures of alloys $\mathrm{G} 1$ and $\mathrm{G} 2$ resulting from $\mathrm{HIP}$ at temperatures between $1200{ }^{\circ} \mathrm{C}$ and $1300{ }^{\circ} \mathrm{C}$ with a cooling rate of $17.5^{\circ} \mathrm{C}\left(\alpha_{2}\right.$-phase appears as light gray, $\beta$-phase appears as white). The images for both $G 1$ and $G 2$ are at $10,000 x$ magnification. 


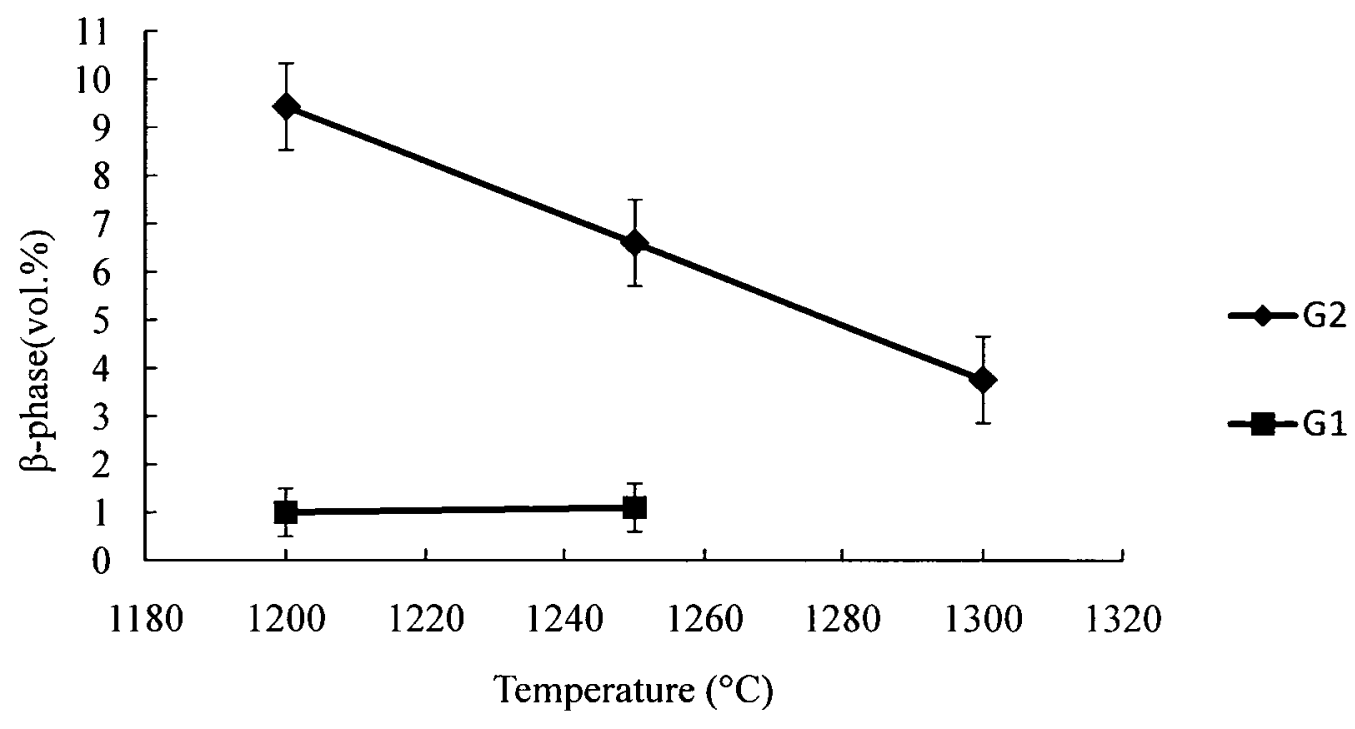

Figure 76. Plot showing the volume fraction of $\beta$-phase in alloy $G 2$ for various HIP temperatures. Samples were cooled at a rate of $17.5^{\circ} \mathrm{C} / \mathrm{min}$.

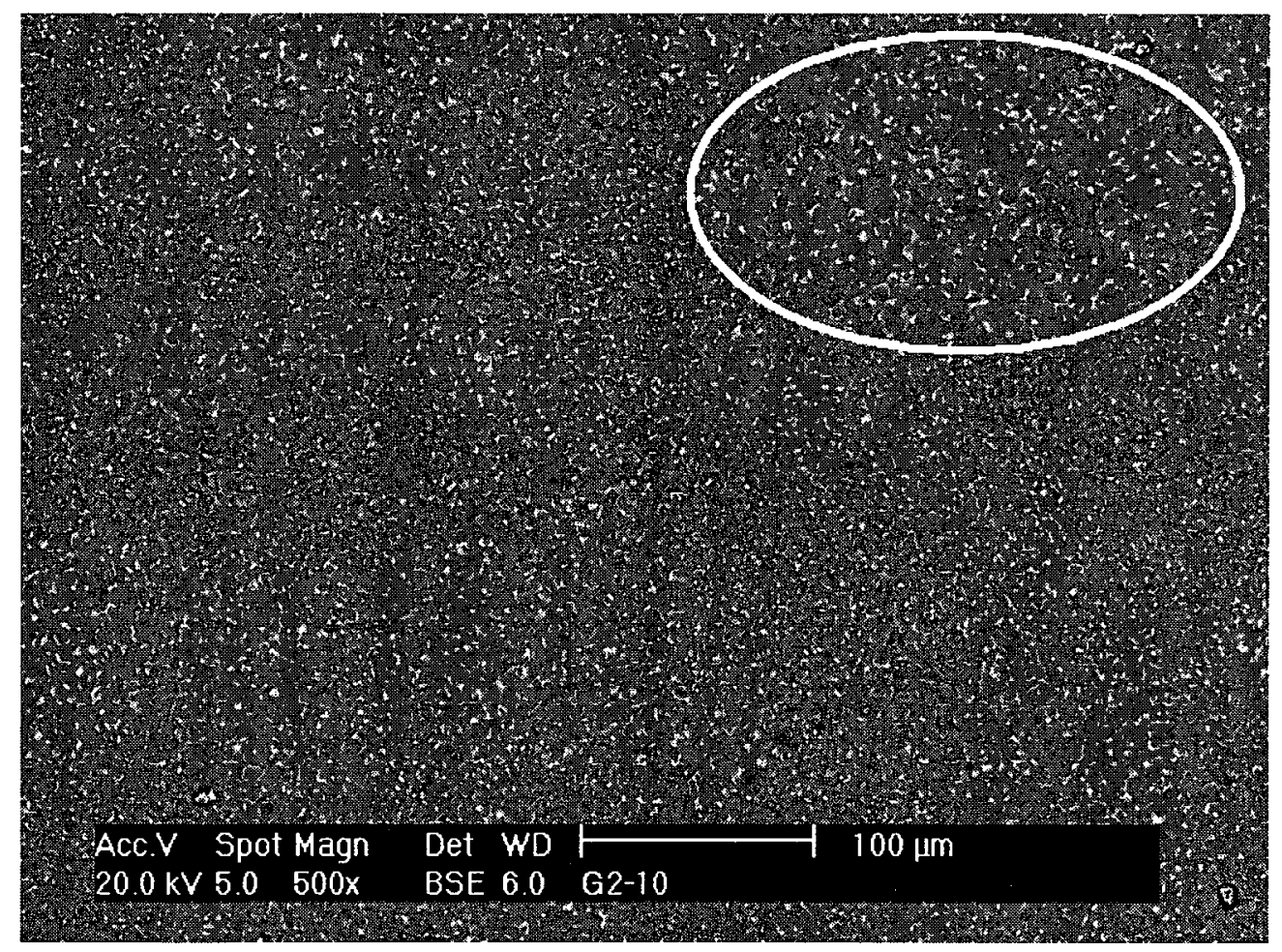

Figure 77. BSE micrograph of alloy G2 HIP'ed at 1200 for 2 hours showing some coarse grained regions (white circle). 


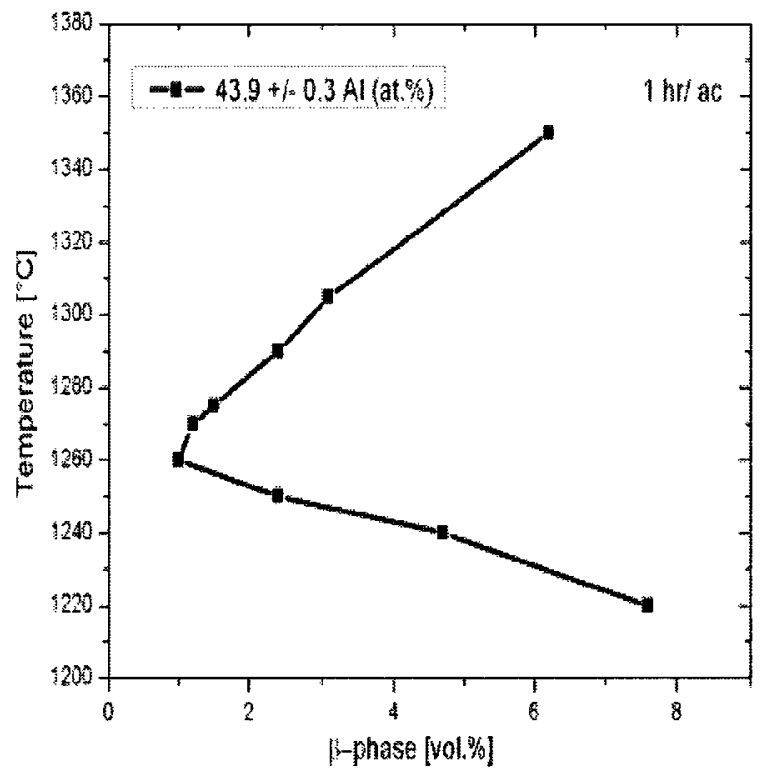

a)

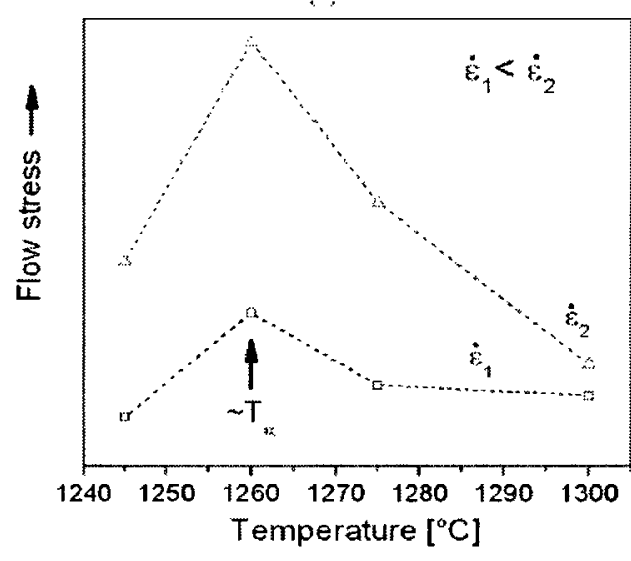

b)

Figure 78. The dependence of the a) $\beta$ phase volume fraction on annealing temperature (air cooling) and $b$ ) the flow stress on the hot working temperature and strain rate [62].

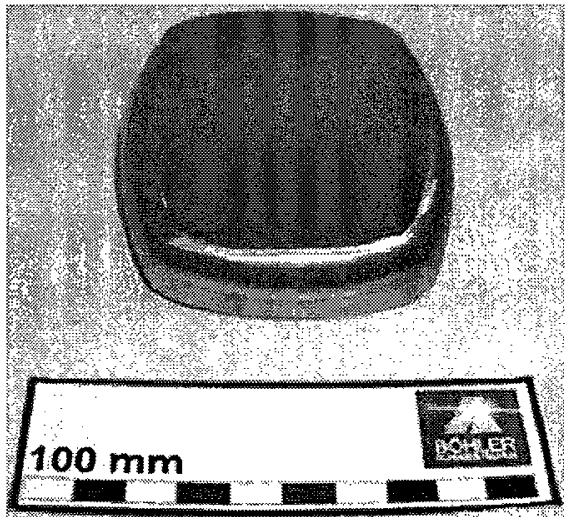

Figure 79. Forging test of $\mathrm{Ti}-43 \mathrm{Al}-4 \mathrm{Nb}-1 \mathrm{Mo}-0.1 \mathrm{~B}$, forged to an overall strain of 1.3 [61]

An increase in HIP temperature to $1300{ }^{\circ} \mathrm{C}$ resulted in the volume fraction of the $\beta$ and $\gamma$ phases to decrease while the volume fraction of the $\alpha_{2}$ phase increased, as shown in Figure 75, Figure 76, and Table 18. Furthermore, the grain size also increased to 
$\sim 7 \mu \mathrm{m}$ and a small amount of lamellae have formed (black arrows in Figure 75). These features are indicative of a HIP temperature near the $\alpha$ transus temperature. The $\alpha$ transus of a beta gamma alloy is typically below $1280^{\circ} \mathrm{C}$, which is significantly less than the HIP temperature of $1300^{\circ} \mathrm{C}[61,62]$. However, the HIP control temperature is measured outside the pressure cell of the HIP press. The control thermocouples are in direct line of sight of the heating elements and therefore are heated through radiation and convection. The inside of the pressure cell relies on conduction through the cell walls to heat the specimens. As a result, the HIP temperature may not accurately represent that actual temperature of the HIP specimens. It is likely that the actually temperature of the consolidating powder is slightly below the HIP press control temperatures. Therefore a HIP setting of $1300{ }^{\circ} \mathrm{C}$ may actually below the $\alpha$ transus temperature of the alloy, which explains the lack of transformation of $\alpha$ grains to lamellar colonies. A sufficient superheat above the $\alpha$ transus along with sufficiently fast cooling is required to form lamellar colonies [63].

As mentioned in section 2.1.5.3, the hydrostatic pressure associated with the HIP process suppresses the kinetics of the $\gamma \rightarrow \alpha$ dissolution [53]. It is possible that the higher HIP temperature of $1300^{\circ} \mathrm{C}$ was sufficiently high to overcome the retarding effects of the pressure and allow more $\gamma$ phase to dissolve into $\alpha$ phase, which explains the higher amount of $\alpha$ upon cooling to room temperature.

From the studies done by Clemens et al. $[61,62]$, it can be interpreted that the $\beta$ phase volume fraction would be a minimum if the HIP is conducted at the $\alpha$ transus 
temperature, since at that temperature the equilibrium $\beta$ phase volume fraction is at a local minimum. This characteristic is illustrated in Figure 80. These studies also suggest that the volume fraction of the $\beta$ phase will increase as the HIP temperature is reduced below the $\alpha$ transus temperature. It can be seen in Figure 76 that the volume fraction of the $\beta$ phase increases linearly as the HIP temperature is reduced below $1300^{\circ} \mathrm{C}$. Furthermore, according to Figure $78 \mathrm{a}$ and Figure 80, it can be predicted that the volume fraction of the $\beta$ phase will increase for HIP temperatures above $1300{ }^{\circ} \mathrm{C}$ [61]. The increased temperature would also result in a significant increase in the grain size and volume fraction of lamellar colonies [64]. As mentioned previously, the HIP temperature setting of $1300{ }^{\circ} \mathrm{C}$ likely represents a lower actual specimen temperature, which would more closely coincide with the results found by Clemens.

HIP'ing at $1300^{\circ} \mathrm{C}$ proved to be difficult as a result of the stainless steel canning material being very close to its melting temperature. In some samples small holes appeared in the stainless steel tubes resulting in a loss of vacuum and, consequently, incomplete consolidation. A canning material that can withstand higher temperatures is required in order to investigate any further increase in HIP temperature.

Table 18. Summary of phase fractions in G2 for various HIP conditions.

\begin{tabular}{|c|c|c|c|c|c|}
\hline Temperature $\left({ }^{\circ} \mathrm{C}\right)$ & Cooling Rate $\left({ }^{\circ} \mathrm{C} / \mathrm{min}\right)$ & $\beta(\%)$ & $\alpha(\%)$ & $\gamma(\%)$ & $\begin{array}{c}\text { Grain } \\
\text { Size }(\mu \mathrm{m})\end{array}$ \\
\hline 1200 & 175 & 9.4 & 10.3 & 80.3 & $2-2$ \\
\hline 1250 & 3.0 & 6.8 & 10.8 & 82.4 & 5 \\
\hline 1250 & 0 & 63. & 212.7 & 81.0 & 5 \\
\hline 1250 & 17.5 & 6.6 & 12.7 & 80.7 & 5 \\
\hline 1300 & 17.5 & 3.8 & 23.1 & 73.1 & $-\sqrt{7}$ \\
\hline
\end{tabular}




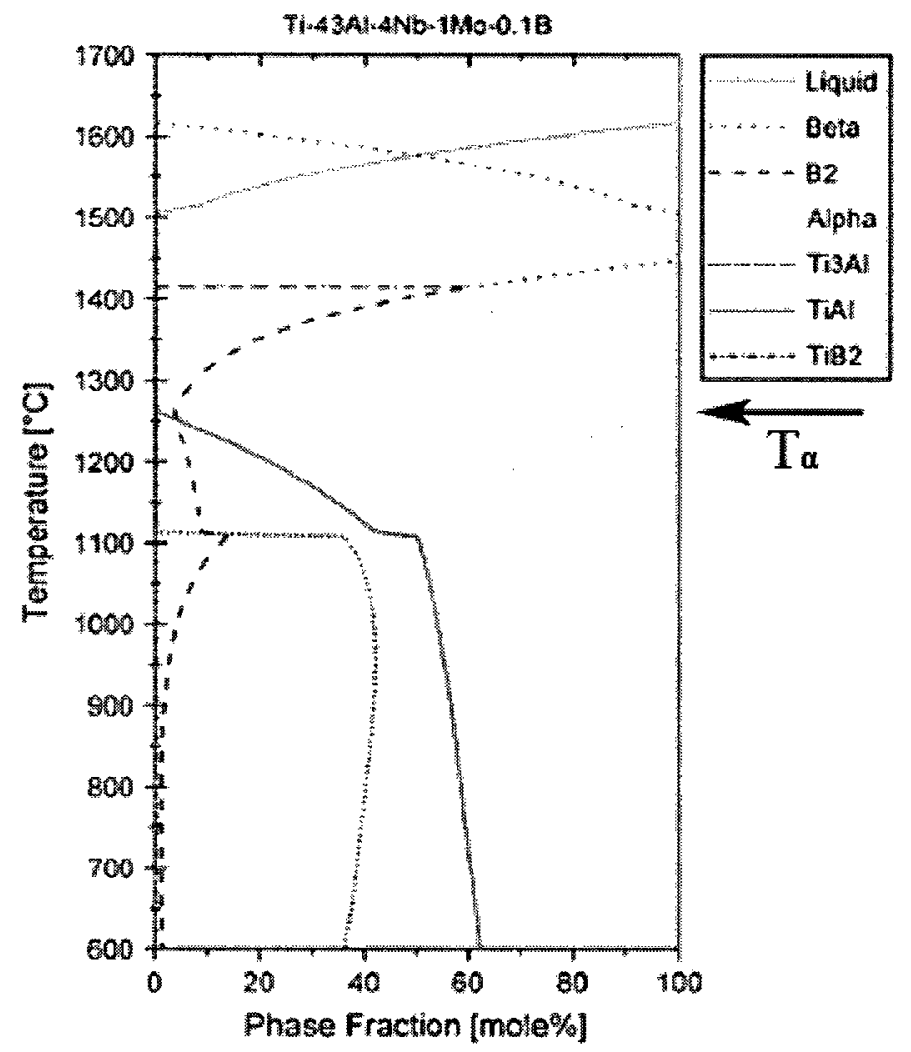

Figure 80. Calculated phase fractions of alloy with composition Ti-43Al-4Nb-1Mo-0.1B showing the local minimum in $\beta$ phase at the $\alpha$ transus temperature $\left.\left(T_{a}\right) \mid 61\right]$.

In an effort to increase the microstructure homogeneity of alloy G2 HIP'ed at $1200{ }^{\circ} \mathrm{C}$, the duration of the HIP process was increased to 4 hours. Figure 81 shows the microstructure of $\mathrm{G} 2$ HIP'ed at $1200{ }^{\circ} \mathrm{C}$ for 4 hours. It can be seen that the grain size homogeneity was not improved. There are still some areas of coarse grains, as indicated by the white circles. Therefore, in order to achieve good grain size homogeneity, the HIP temperature may have to be increased. However, at higher HIP temperatures, the $\beta$ phase volume fraction is lower. 


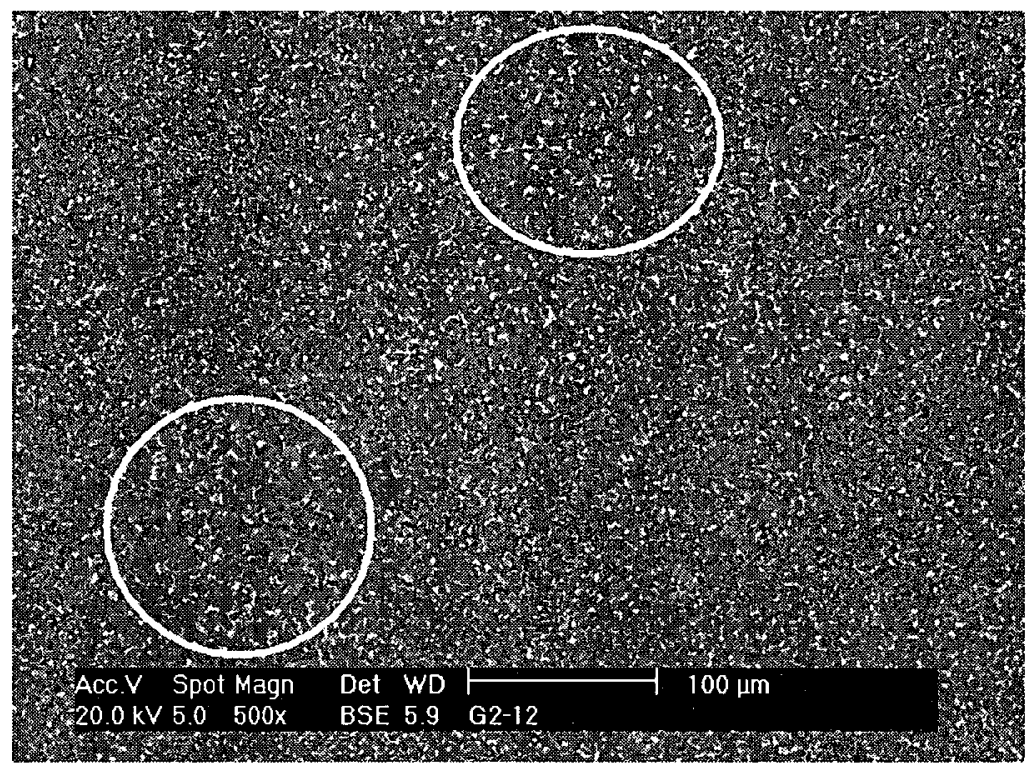

Figure 81. BSE image of alloy G2 HIP'ed at $1200^{\circ} \mathrm{C}$ for 4 hours, showing some coarse grained regions (white circles).

In an attempt to improve the grain size homogeneity throughout the microstructure while achieving a large $\beta$ phase volume fraction, a step-HIP process was developed. This process consisted of first HIP'ing at a temperature of $1250^{\circ} \mathrm{C}$ for 1 hour, followed by a furnace cool to a lower temperature $\left(1100^{\circ} \mathrm{C}\right.$ or $\left.1200^{\circ} \mathrm{C}\right)$ where the HIP process continued for an additional length of time (2-3 hours) before being furnace cooled to room temperature. The first HIP step at $1250{ }^{\circ} \mathrm{C}$ was to develop a homogeneous microstructure. The second lower temperature HIP step essentially acted as a heat treatment used to develop a higher $\beta$ phase fraction in the alloy. Figure 82 shows the microstructures resulting from both step-HIP consolidation processes. For both step-HIP processes, the $\beta$ phase volume fraction was maintained at the same level as the samples HIP'ed at $1200{ }^{\circ} \mathrm{C}(\sim 10$ vol.\%). However, there is still evidence of some coarse grained 
areas, but there is a slight improvement in grain size homogeneity as compared to the sample HIP'ed at 1200 for 4 hours.

It is possible that these coarse grained areas are related to the prior dendrite size of the powder particles. Large particles result in larger dendrites due to slightly lower cooling rates, which subsequently form larger grains [17]. Therefore the variation in grain size throughout the microstructure may be a result of variations in the powder particle size. The higher HIP temperatures, such as $1250^{\circ} \mathrm{C}$, would allow the fine grained areas to grow more closely in size to the coarse grained areas. As a result, the samples HIP'ed at $1250{ }^{\circ} \mathrm{C}$ for 2 hours (rather than only 1 hour) still result in the best grain size homogeneity. However, it is difficult to say whether a coarser, but more homogeneous microstructure, would result in better hot workability than a finer, slightly less homogenous microstructure. It is well know that a finer microstructure results in superior hot workability [62]. However, variations in grain sizes throughout a microstructure may result in anisotropic flow stresses during hot working. It is also possible that the variation of the grain size in these alloys is small enough so as to not affect the hot working properties. Hot working investigations are required in order to fully understand the effects of grain size on the hot workability of these alloys. 

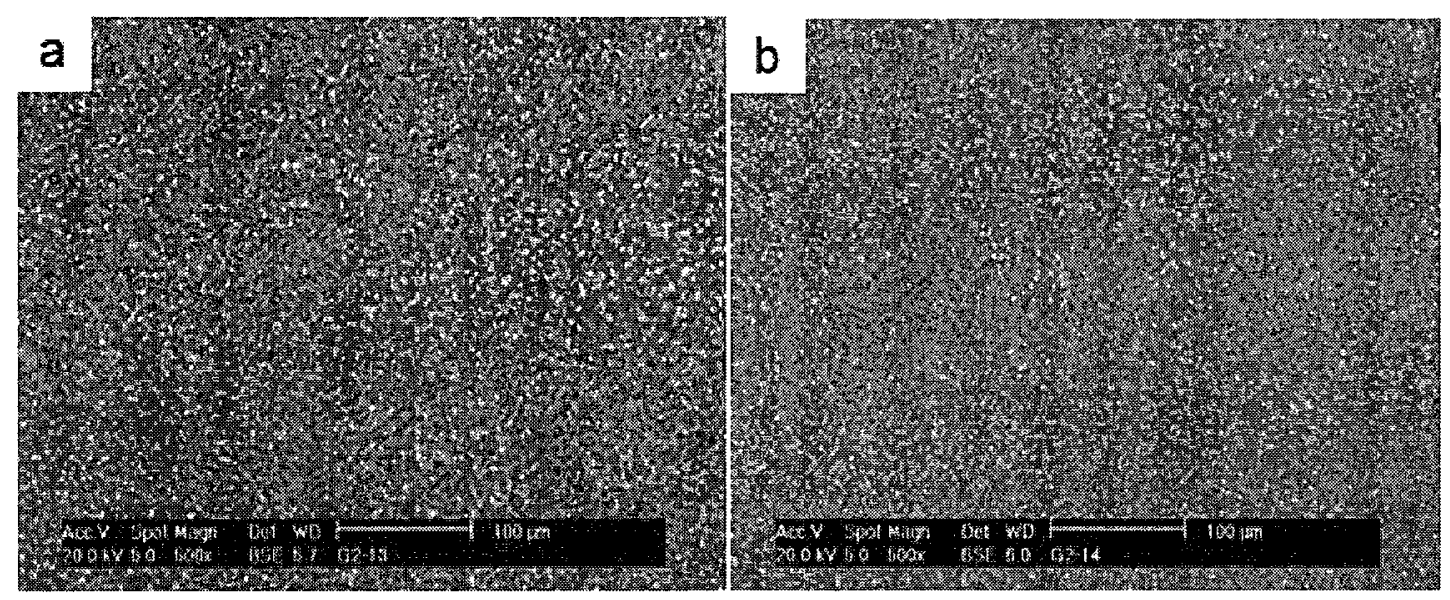

Figure 82. BSE images showing the microstructure of alloy G2 step-HIP'ed at a) $1250 / 1 \mathrm{hr}+$ $1200 / 2 \mathrm{hrs}$ and b) $1250 / 1 \mathrm{hr}+1100 / 3 \mathrm{hrs}$.

\subsubsection{Summary}

The goal of the HIP process was to develop a microstructure that would offer excellent hot workability. It has been shown that the most significant improvement in hot workability is achieved by introducing the $\beta$ phase into the microstructure. Beta gamma alloys are designed to contain a significant amount of $\beta$ phase at both room temperature and hot working temperatures.

Alloys G1 and G2 can be classified within theoretical beta gamma alloy groups based on the amount of $\beta$ stabilizing elements. The effective $\beta$ stabilizing alloying additions can be expressed as a niobium equivalent. Alloy G1 has a niobium equivalent of 10.6 and should theoretically fall within the two phase $\left(\gamma+\alpha_{2}\right)$ alloy group. The asHIP'ed microstructure of alloy Gl confirms its theoretical group since it contains $\gamma$ phase and $\alpha_{2}$ phase with only a very small amount of $\beta$ phase $(\sim 1 \%)$. However, it was later 
determined that the resulting composition of alloy G1 does not match that of the original design, leading to insufficient $\beta$ stabilizing alloying additions. Alloy G2 has a niobium equivalent of 14.8 and should fall within either the three phase $\left(\gamma+\alpha_{2}+\beta\right)$ or the two phase $(\gamma+\beta)$ alloy group. The as-HIP'ed microstructure of alloy G2 contained all three phases and therefore alloy G2 must fall within the three phase $\left(\gamma+\alpha_{2}+\beta\right)$ alloy group.

The effect of the HIP conditions on the microstructure, particularly the $\beta$ phase volume fraction, was investigated. It was found that the cooling rate from the HIP temperature did not have an effect on the volume fraction of the $\beta$ phase in both alloys. Furthermore, the HIP temperature did not appear to have an effect on the volume fraction of the $\beta$ phase in alloy $\mathrm{Gl}$. For both HIP temperatures of $1200^{\circ} \mathrm{C}$ and $1250^{\circ} \mathrm{C}$ there was only $\sim 1$ vol.\% $\beta$ in alloy G1. However, the HIP temperature did have an effect on alloy G2. There appeared to be a linear decrease in $\beta$ phase volume fraction when the HIP temperature was increase from $1200{ }^{\circ} \mathrm{C}$ to $1300{ }^{\circ} \mathrm{C}$. That is, at $1200{ }^{\circ} \mathrm{C}$ there was 9.5 vol. $\% \beta$, at $1250{ }^{\circ} \mathrm{C}$ there was 6.6 vol. $\% \beta$ and at $1300{ }^{\circ} \mathrm{C}$ there was 3.8 vol. $\% \beta$. However, at the lower HIP temperature of $1200^{\circ} \mathrm{C}$, there appeared to be some grain size inhomogeneities. The fine grained areas had an average grain size of $2 \mu \mathrm{m}$ and the coarse grained areas had an average grain size of $4 \mu \mathrm{m}$. When the HIP time was increased from 2 hours to 4 hours the problem was not alleviated. In an effort to achieve a homogeneous microstructure with as much $\beta$ phase as the $\mathrm{HIP}$ at $1200^{\circ} \mathrm{C}$, a step-HIP process was done. The step-HIP process consisted of HIP'ing at $1250^{\circ} \mathrm{C}$ for 1 hour then dropping the temperature to $1200{ }^{\circ} \mathrm{C}$ or $1100{ }^{\circ} \mathrm{C}$ where the sample was held for an additional $2-3$ 
hours. The resulting microstructures contained approximately the same amount of $\beta$ phase as the sample HIP'ed at $1200{ }^{\circ} \mathrm{C}(\sim 10$ vol.\%). However, the grain size inhomogeneity was not completely eliminated and the overall grain size was slightly larger compared to that of the samples HIP'ed at $1200^{\circ} \mathrm{C}$ for 2 and 4 hours $(2 \mu \mathrm{m}$ versus $4 \mu \mathrm{m})$. It is difficult to say whether the grain size inhomogeniety would be more detrimental than the increase in grain size. It is possible that the variation in grain size in the samples HIP'ed at $1200{ }^{\circ} \mathrm{C}$ is small enough as to not affect the hot workability. Hot working investigations are required to fully understand the effects of the grain sizes in these alloys.

Based on the HIP'ing results it can be concluded that alloy G1 is not ideal for hot working as a result of the limited amount of $\beta$ phase present in the microstructure. In contrast, alloy G2 HIP'ed at $1200{ }^{\circ} \mathrm{C}$ and both step-HIP processes results in microstructures that could offer excellent hot workability. The $\sim 10$ vol.\% $\beta$ phase that is evenly dispersed in the microstructure is enough to significantly improve the hot workability. Furthermore, the average grain size is very small with a range between $2 \mu \mathrm{m}$ and $4 \mu \mathrm{m}$ depending on the HIP process used. A fine microstructure has been shown to significantly improve the hot workability.

\subsection{Phase Transformation Analysis}

In order to design a set of heat treatment procedures for a given alloy it is very beneficial to know the phase transformation temperatures. The following section discusses the 
results of the differential scanning calorimetry (DSC) and $x$-ray diffraction (XRD) that was used to determine important phase transformation temperatures in alloys G1 and G2.

\subsubsection{Differential Scanning Calorimetry (DSC)}

The design of a post-HIP heat treatment process for beta gamma TiAl alloys is highly dependent on the phase transformation temperatures for a given alloy composition, in particular the $\alpha$ transus temperature $(\alpha+\gamma \rightarrow \alpha)$. There is no single phase alpha region in heavily $\beta$ stabilized beta gamma alloys (alloys B and C in Figure 30 in section 2.2.1), therefore, the $\gamma+\alpha+\beta \rightarrow \alpha+\beta$ transformation in these alloys is referred to as the $\alpha$ transus. The most effective way to determine the a transus temperature was through differential scanning calorimetry (DSC).

\subsubsection{Temperature Calibration}

The DSC was calibrated by comparing the experimentally measured melting points of pure metals with their theoretical melting points. The resulting DSC signals for two different melting cycles for silver, gold and nickel can be seen in Figure 83, Figure 84, and Figure 85, respectively. The experimental melting point, $\mathrm{T}_{\mathrm{exp}}$, was taken as the average onset temperature of the two DSC signal melting peaks. Table 19 shows the comparison of the theoretical and experimentally measured melting temperatures of the pure metals used for calibration. Figure 86 shows the temperature calibration curve determined using Netzsch Software. This curve was then applied to the DSC runs of alloys G1 and G2 to account for the error in the temperature measurements. 


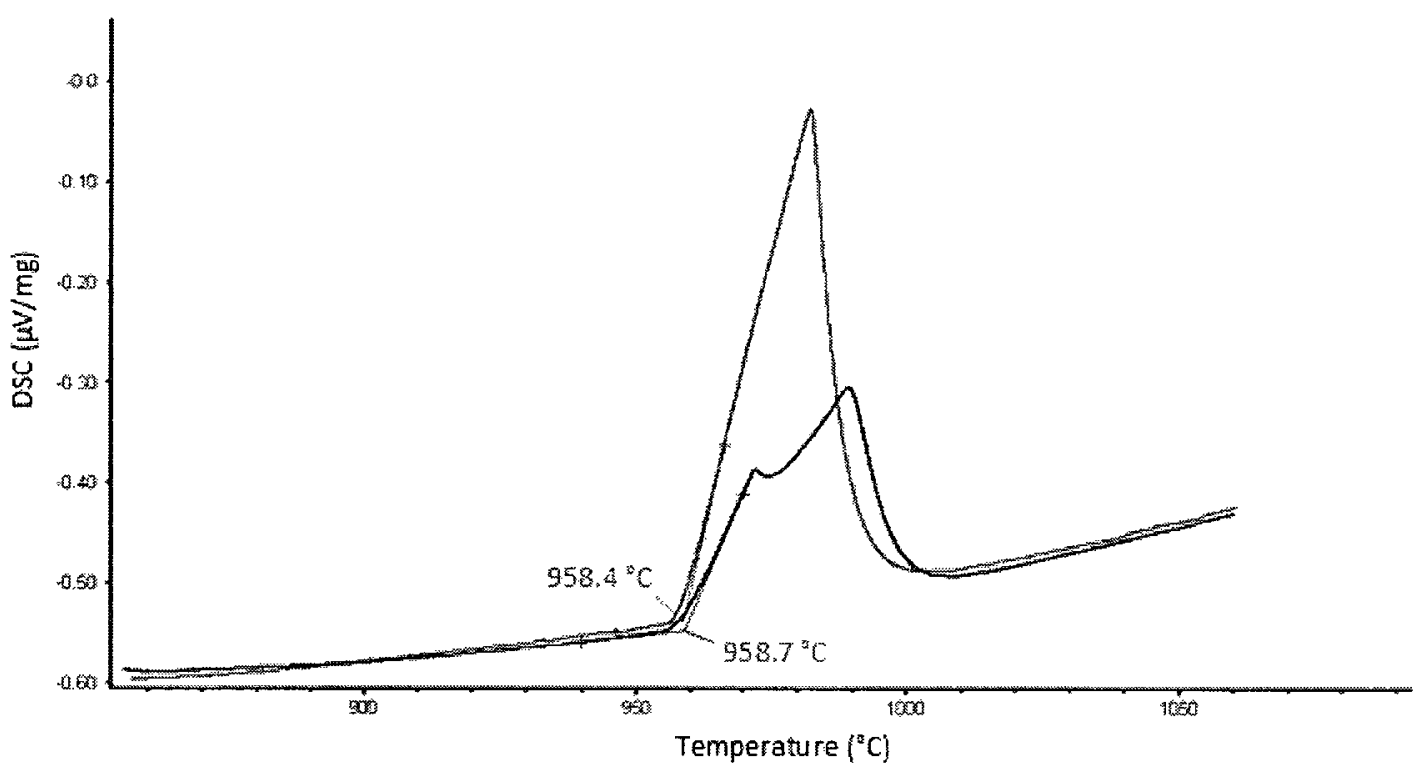

Figure 83. The DCS signal measured during two melting cycles of pure silver.

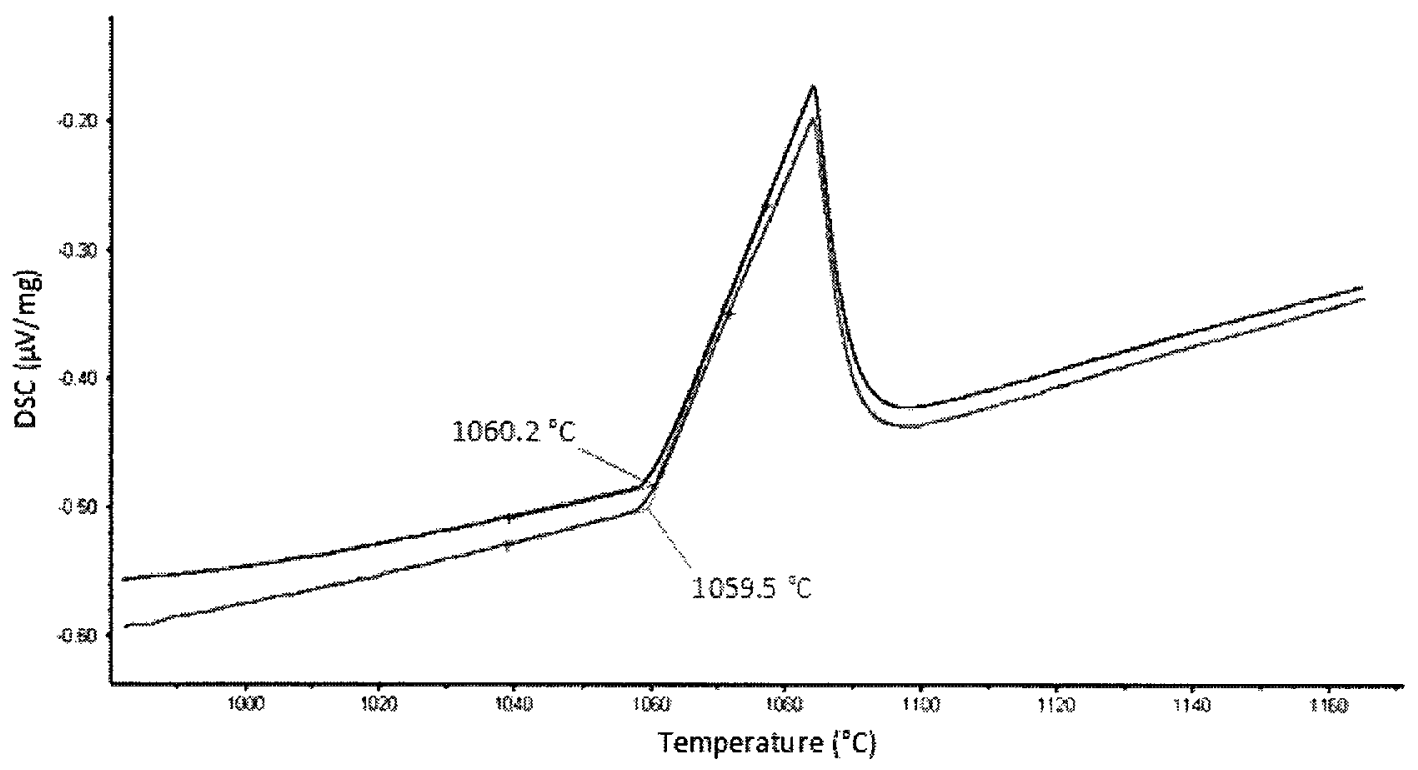

Figure 84. The DCS signal measured during two melting cycles of pure gold. 


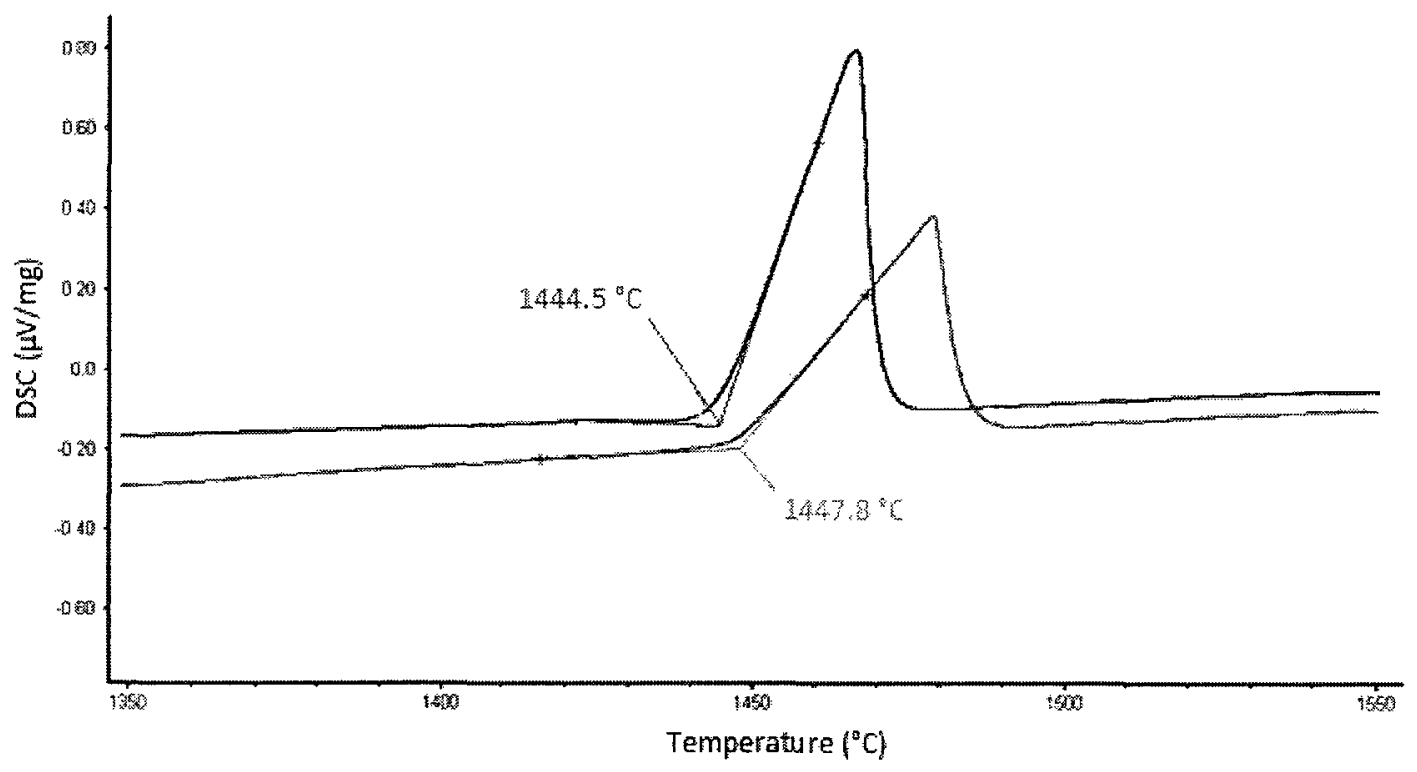

Figure 85. The DCS signal measured during two melting cycles of pure nickel.

Table 19. The Comparison of the measured experimental melting temperatures of pure metals to their theoretical melting temperatures.

\begin{tabular}{ccc}
\hline Material & $\begin{array}{c}\text { Theoretical melting } \\
\text { temperature }\left({ }^{\circ} \mathbf{C}\right)\end{array}$ & $\begin{array}{c}\text { Experimental melting } \\
\text { temperature }\left({ }^{\circ} \mathbf{C}\right)\end{array}$ \\
\hline $\begin{array}{c}\text { Silver } \\
\text { Gold }\end{array}$ & 961.8 & 958.6 \\
Nickel & 1064.2 & 1059.9 \\
\hline
\end{tabular}

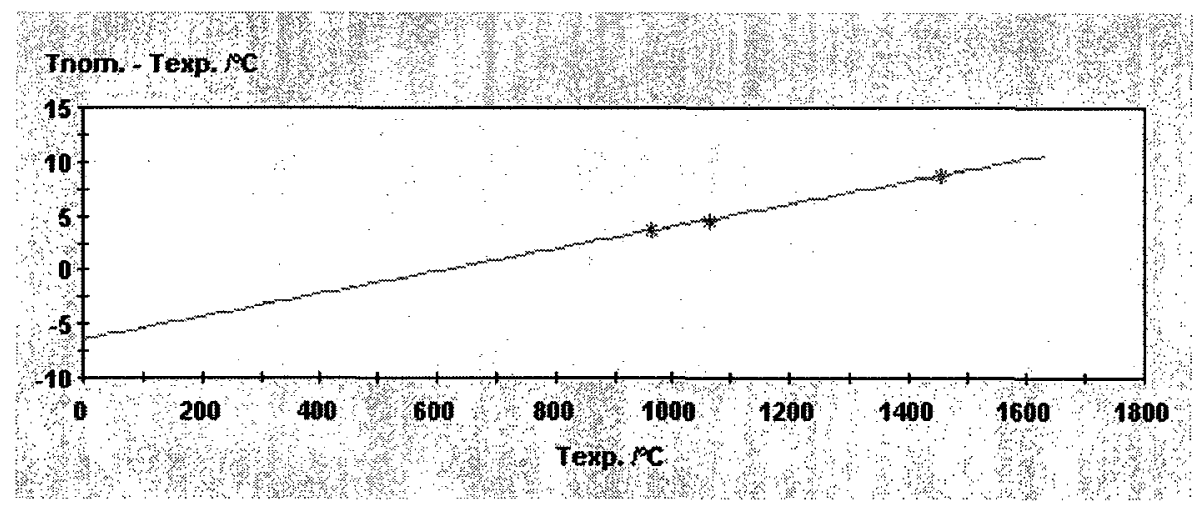

Figure 86. The temperature calibration curve used for the DSC runs of the TiAl samples. 


\subsubsection{DSC Analysis of As-HIP'ed Samples}

Figure 87 shows the DSC signal measured during the heating cycle of alloy G1. Significant phase changes are occurring between the temperatures of $1184{ }^{\circ} \mathrm{C}$ and 1325 ${ }^{\circ} \mathrm{C}$. Since alloy G1 does not contain a significant amount of $\beta$ stabilizers, it can be classified as a two phase $\gamma+\alpha_{2}$ alloy (alloy $\mathrm{A}$ in Figure 30 in section 2.2.1). It can be seen in this modified phase diagram (shown again in Figure 87) that alloy A undergoes a transformation from $\alpha+\gamma \rightarrow \alpha$ followed quickly by the transformation $\alpha \rightarrow \alpha+\beta$. These transformations coincide with the DSC signal. The onset of the first peak at $1184.4^{\circ} \mathrm{C}$ is likely the $\alpha+\gamma \rightarrow \alpha$ transformation, and the onset of the second peak at $1251.6^{\circ} \mathrm{C}$ is likely the $\alpha \rightarrow \alpha+\beta$ transformation.

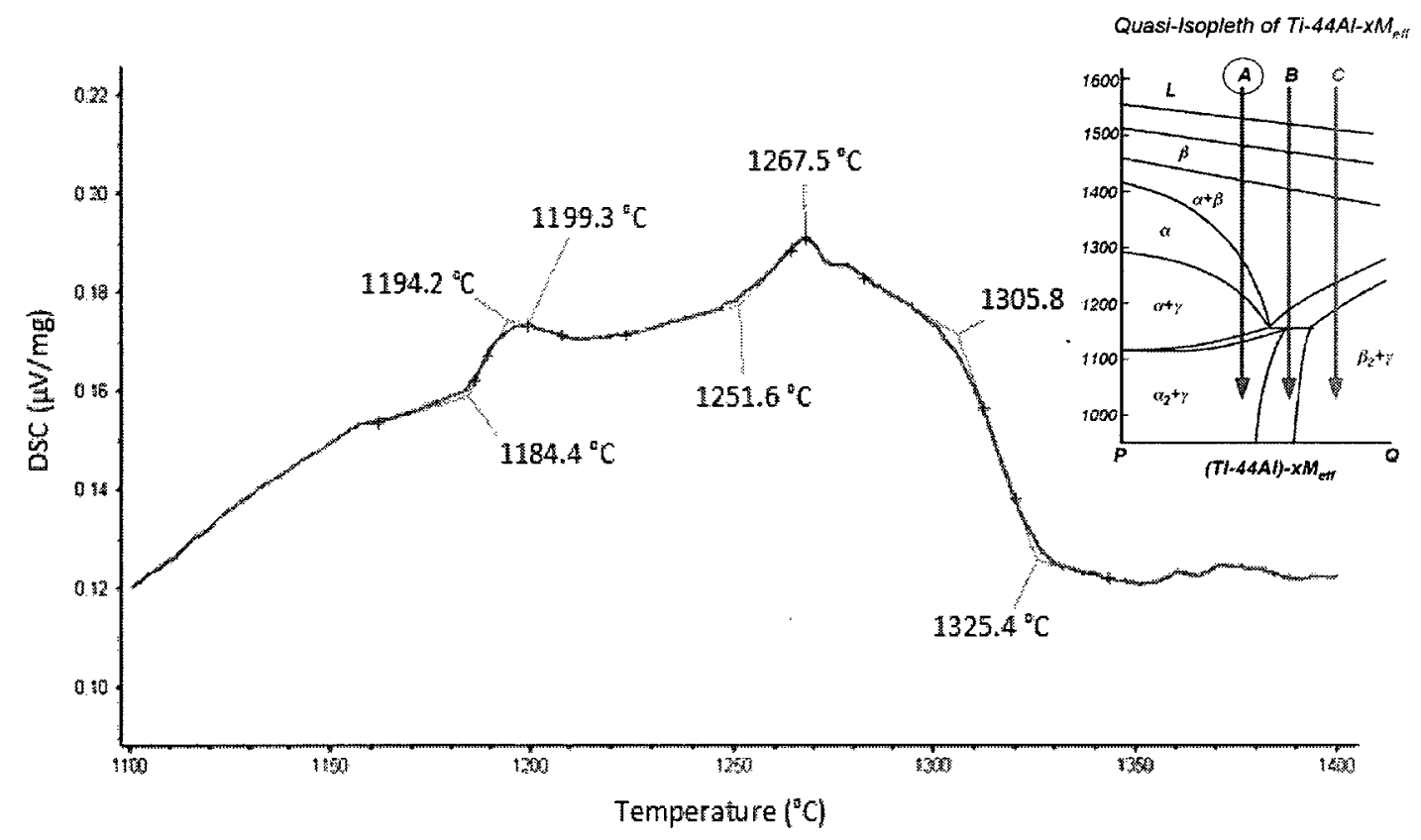

Figure 87. The DSC signal measured during the heating cycle of alloy G1. 
Figure 88 shows the DSC signal measured during the heating cycle of alloy G2. A significant phase change is occurring between the temperatures of $1211.5{ }^{\circ} \mathrm{C}$ and $1325.2^{\circ} \mathrm{C}$. Based on the amount of $\beta$ stabilizing elements that alloy $\mathrm{G} 2$ contains it is classified as a three phase $\gamma+\alpha+\beta$ alloy (Alloy B in Figure 30 in section 2.2.1). In these class of alloys, the $\alpha$ transus, or $\gamma+\alpha+\beta \rightarrow \alpha+\beta$ transformation, lies between the temperatures of $1150{ }^{\circ} \mathrm{C}$ and $1250^{\circ} \mathrm{C}$. Therefore it can be interpreted that the onset of the peak of the DSC signal at $1245.1{ }^{\circ} \mathrm{C}$ corresponds to the $\gamma+\alpha+\beta \rightarrow \alpha+\beta$ transformation temperature.

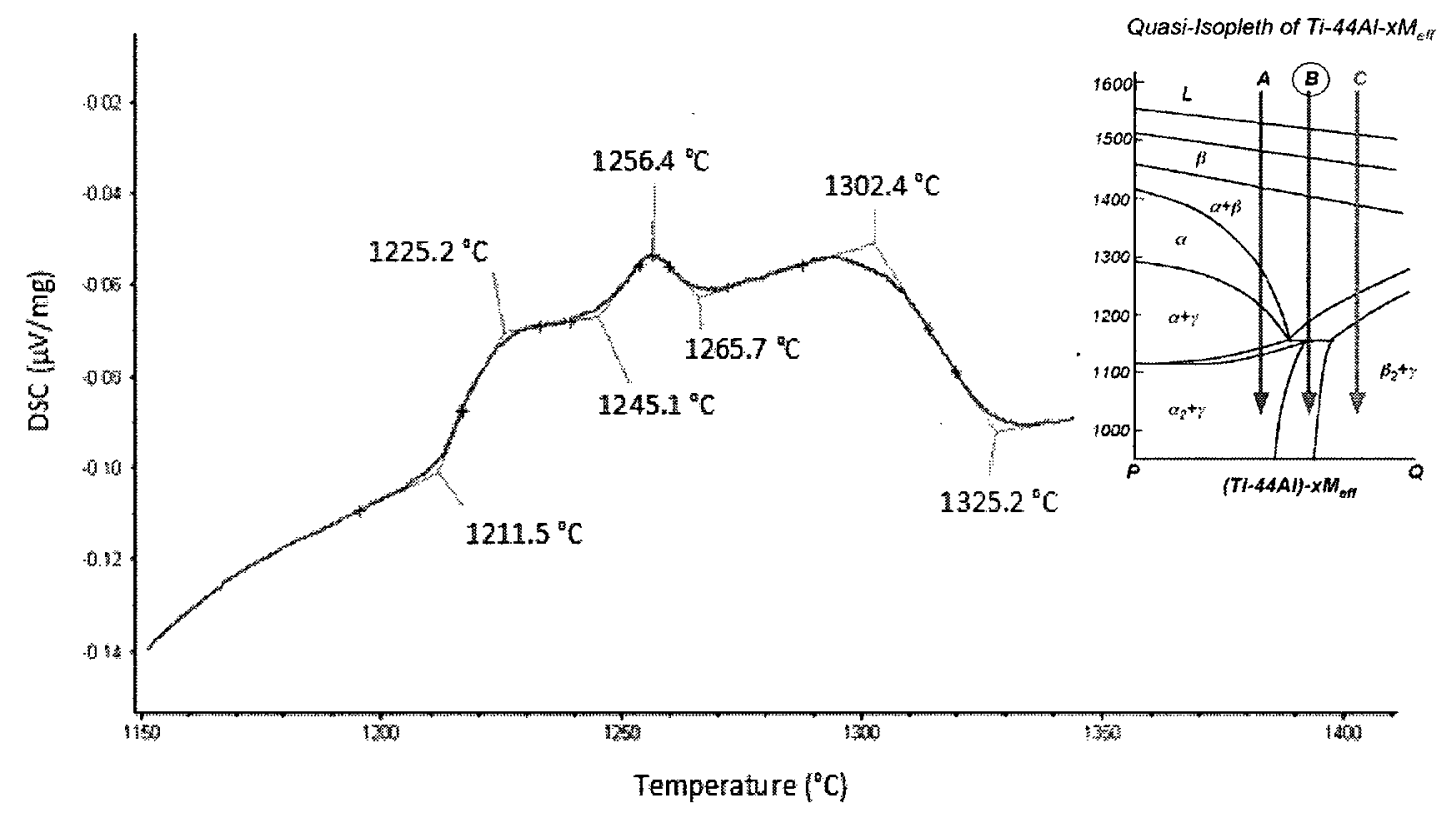

Figure 88. DSC signal measured during the heating cycle of alloy G2.

It is also important to consider the DSC signal during the cooling process, since it is more relevant to the solution heat treatment process that will be discussed in 
section 4.5.1. Figure 89 and Figure 90 show the DSC signal measured during the cooling cycles of alloy G1 and G2, respectively. For alloy G1, there is only one peak that occurs during the cooling process. It is possible that since the $\alpha \rightarrow \alpha+\gamma$ transformation temperature is very close to the $\alpha+\beta \rightarrow \alpha$, only one peak is measured by the DSC. The onset of the $\alpha+\beta \rightarrow \alpha$ transformation is at $1238.7^{\circ} \mathrm{C}$. For alloy G2, the onset of the $\alpha+\beta$ $\rightarrow \gamma+\alpha+\beta$ transformation is at $1235.6^{\circ} \mathrm{C}$.

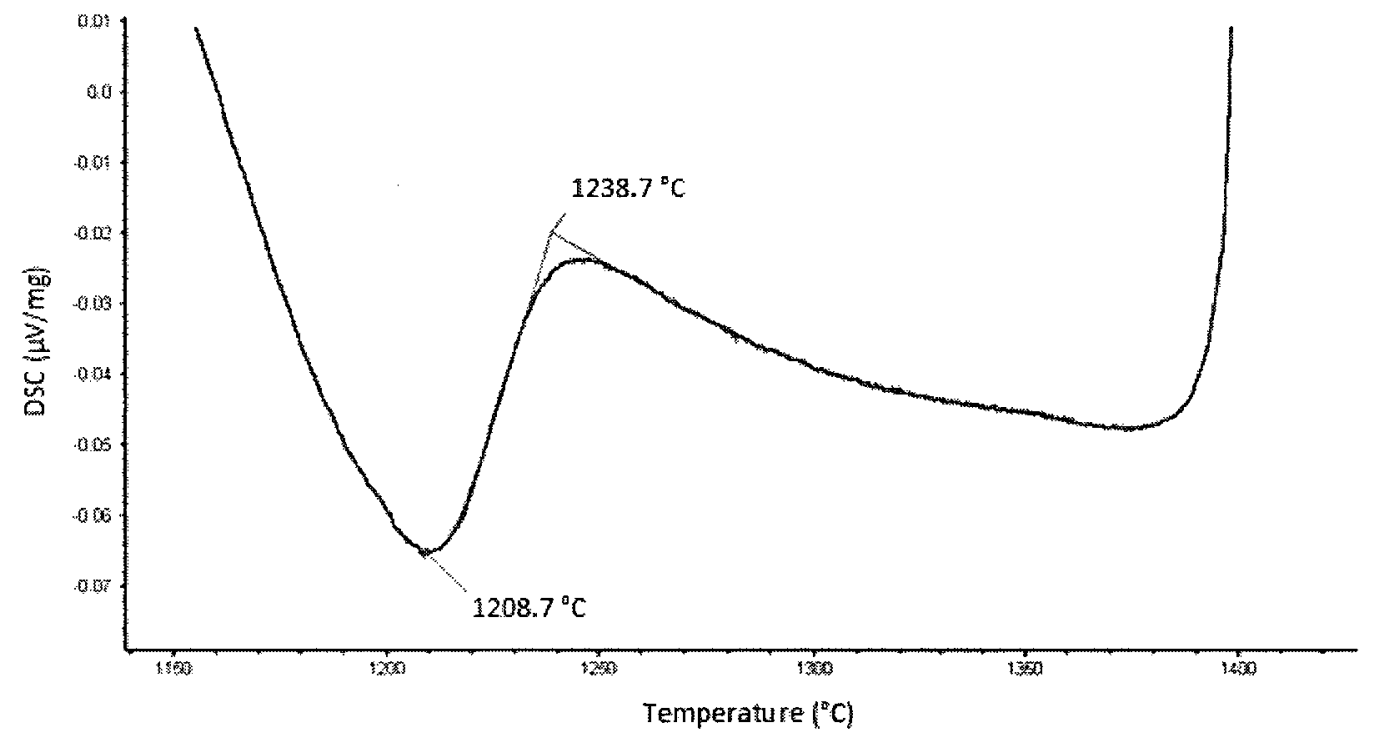

Figure 89. DSC signal measured during the cooling cycle of alloy G1. 


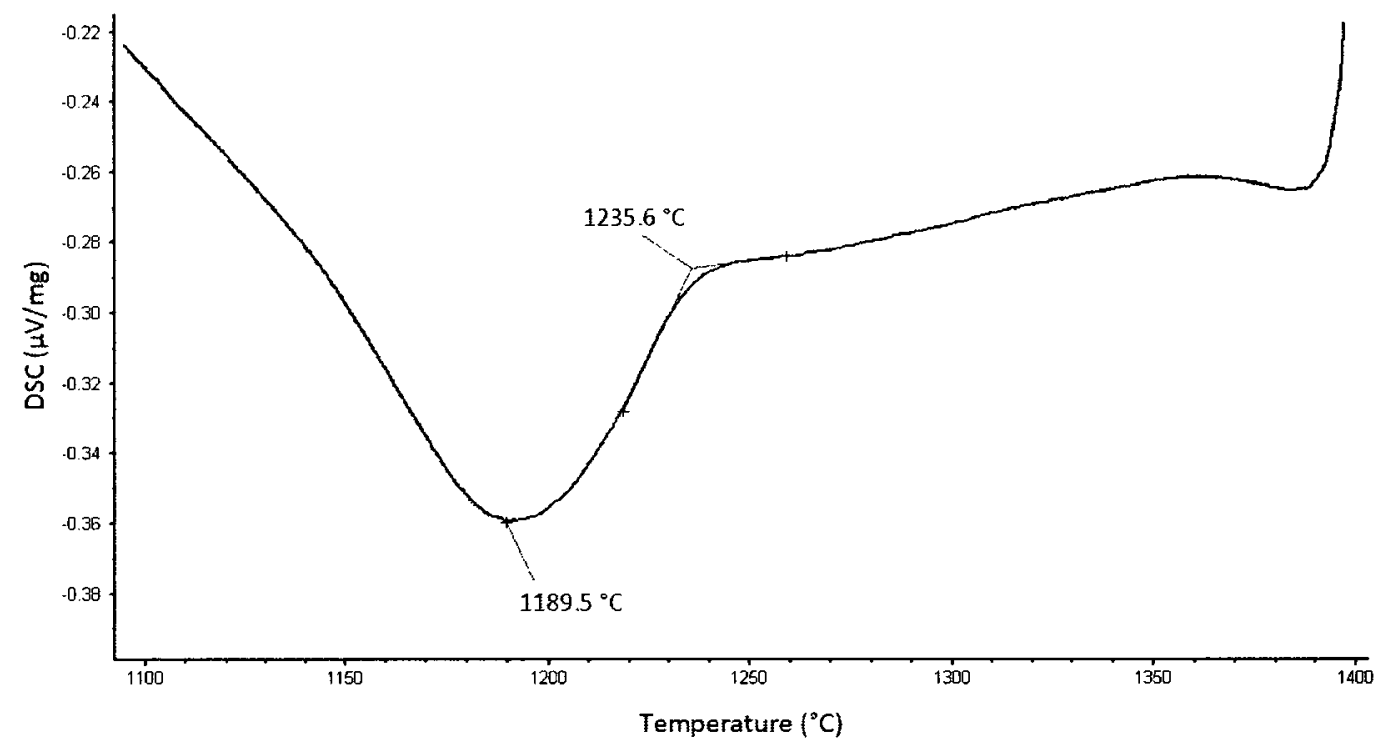

Figure 90. DSC signal measured during the cooling cycle of alloy G2.

\subsubsection{X-Ray diffraction (XRD) Analysis}

In order to verify the DSC results from section 5.3.1, x-ray diffraction (XRD) analysis of samples water quenched from various temperatures was done. The peaks were identified using the XRD analysis of a similar alloy done by Munoz-Morris [65]. Figure 91 shows the resulting XRD patterns of the alloy G1 samples. The XRD pattern of the sample quenched from $1170{ }^{\circ} \mathrm{C}$ shows that the alloy is within an $\alpha+\gamma$ two phase field at that temperature. Only a very small amount of $\beta$ was detected. Keeping in consideration the DSC results in Figure $87,1170{ }^{\circ} \mathrm{C}$ lies before the $\alpha+\gamma \rightarrow \alpha$ phase transformation temperature of $1184.4^{\circ} \mathrm{C}$, therefore also suggesting that at that temperature alloy $\mathrm{G} 1$ is in the $\alpha+\gamma$ two phase field. 
Increasing the temperature to $1230^{\circ} \mathrm{C}$, the XRD pattern shows a large increase in $\alpha$ phase with a significant decrease in $\gamma$ phase, which suggest that at that temperature alloy G1 has surpassed the $\alpha+\gamma \rightarrow \alpha$ transformation temperature and is within the single phase $\alpha$ region. The DSC results also suggest that the alloy is within the single phase $\alpha$ region at $1230^{\circ} \mathrm{C}$.

Further increasing the temperature to $1285{ }^{\circ} \mathrm{C}$, the $\mathrm{XRD}$ pattern shows a large increase in $\alpha$ phase, a small increase in $\beta$ phase, with negligible amount of $\gamma$ phase. The small amount of residual $\gamma$ phase is likely a result of some $\gamma$ nucleation during quenching. This result suggest that the $\alpha+\gamma \rightarrow \alpha$ phase transformation is complete and that the $\alpha \rightarrow \alpha+\beta$ phase transformation has just begun, meaning at $1285^{\circ} \mathrm{C}$ alloy G1 is within the $\alpha+\beta$ two phase field. The DSC results suggest that the $\alpha \rightarrow \alpha+\beta$ phase transformation temperature is $1251.6^{\circ} \mathrm{C}$, and at $1285^{\circ} \mathrm{C}$ alloy G1 would be within the $\alpha+\beta$ two phase field, therefore agreeing with the $\mathrm{XRD}$ results.

Increasing the temperature to $1350^{\circ} \mathrm{C}$, the $\mathrm{XRD}$ pattern shows a significant increase in $\beta$ phase, with the $\alpha$ phase accounting for the majority of the remaining structure. Again, the small amount of residual $\gamma$ phase is likely a result of some $\gamma$ nucleation during quenching. Therefore at $1350^{\circ} \mathrm{C}$ alloy G1 is well within the $\alpha+\beta$ two phase field. 


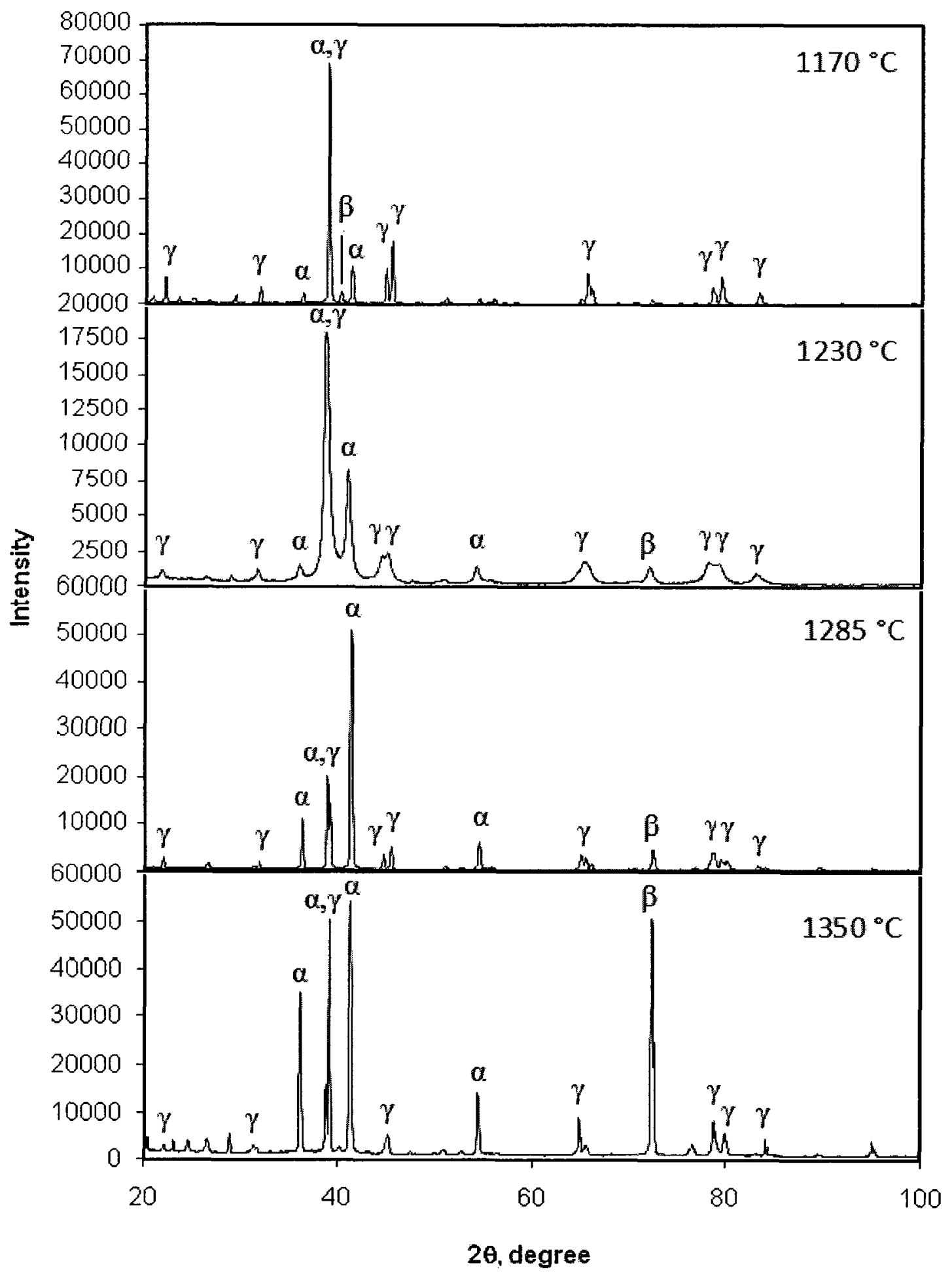

Figure 91. The XRD patterns of alloy G1 quenched from various temperatures. 
Figure 92 shows the resulting XRD patterns for alloy G2 quenched from various temperatures. The XRD pattern of alloy G2 at a temperature of $1200{ }^{\circ} \mathrm{C}$ shows that the constituent phases are $\gamma+\alpha+\beta$. The DSC results shown in Figure 88 in section 5.3.1.2 suggest that the $\gamma+\alpha+\beta \rightarrow \alpha+\beta$ transformation temperature is at $1245.1{ }^{\circ} \mathrm{C}$. Therefore at $1200{ }^{\circ} \mathrm{C}$ alloy $\mathrm{G} 2$ is in the $\gamma+\alpha+\beta$ three phase field, agreeing with the XRD results.

Increasing the temperature to $1240{ }^{\circ} \mathrm{C}$ shows an increase in the $\alpha$ phase and a decrease in both the $\gamma$ phase and $\beta$ phase.

At $1270{ }^{\circ} \mathrm{C}$, the $\mathrm{XRD}$ pattern shows a significant increase in $\alpha$ phase, with a negligible amount of $\gamma$ phase, indicating that alloy $\mathrm{G} 2$ is in the $\alpha+\beta$ two phase field at that temperature. The small amount residual $\gamma$ phase is likely the result of $\gamma$ nucleation during quenching. This result coincides with the DSC results since at $1270^{\circ} \mathrm{C}$ alloy $\mathrm{G} 2$ is above the $\gamma+\alpha+\beta \rightarrow \alpha+\beta$ transformation temperature of $1245.1^{\circ} \mathrm{C}$. A further increase in temperature to $1300^{\circ} \mathrm{C}$ shows very little change in the constituent phase fractions.

A further increase in temperature to $1350^{\circ} \mathrm{C}$ shows a large increase in $\beta$ phase, indicating that at that temperature alloy G2 is well within the $\alpha+\beta$ two phase field. The XRD patterns indicate that the most significant phase changes are occurring between the temperatures of $1200^{\circ} \mathrm{C}$ and $1270{ }^{\circ} \mathrm{C}$, therefore confirming the $\mathrm{DSC}$ results. 


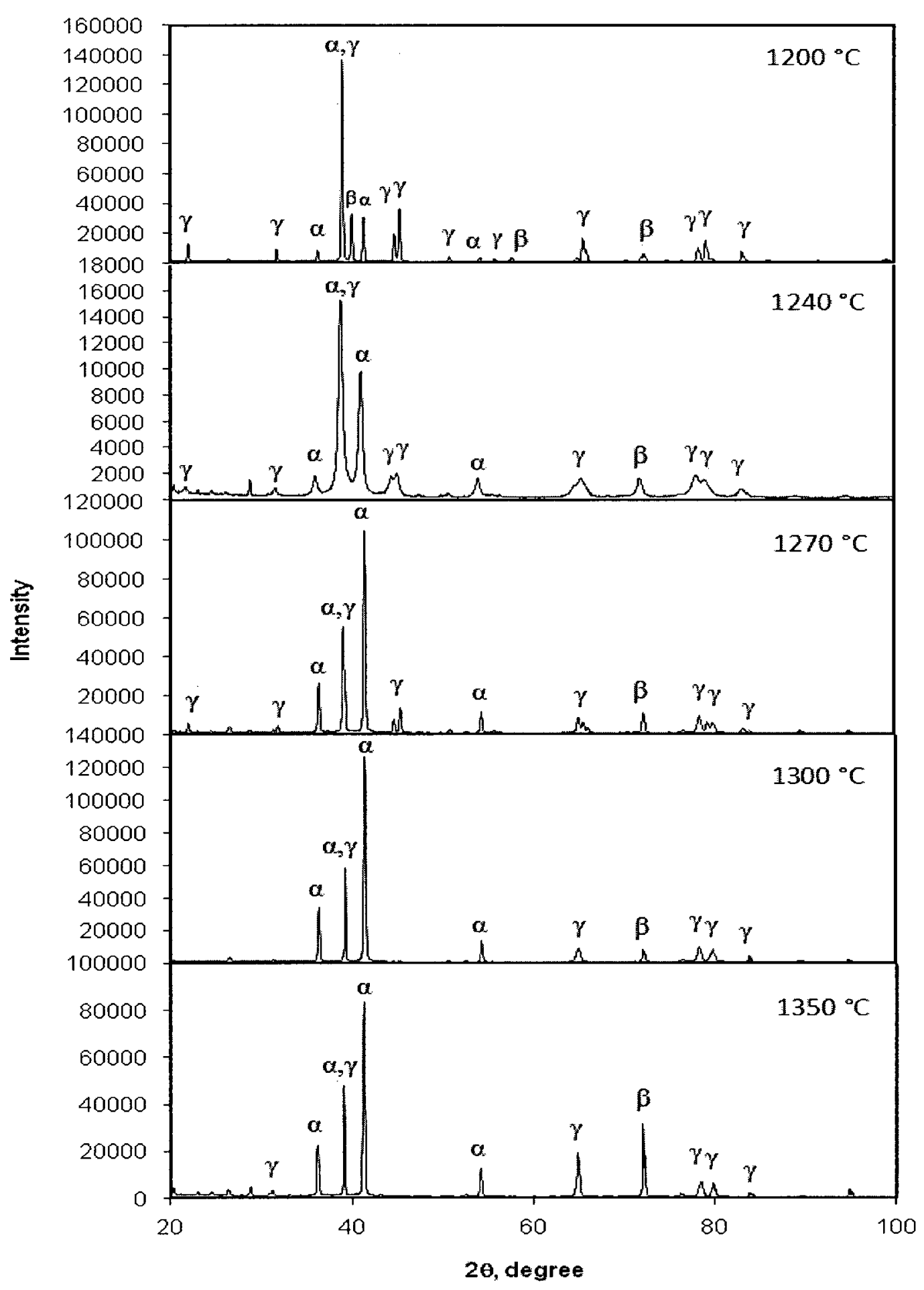

Figure 92. The XRD patterns of alloy G2 quenched from various temperatures. 


\subsubsection{Summary}

In designing a solution heat treatment process for a TiAl alloy, the most relevant phase transformation temperatures is the $\alpha$ transus. In the case of a three phase $\gamma+\alpha_{2}+\beta$ beta gamma alloy, such as alloy $\mathrm{G} 2$, the $\alpha$ transus is the $\alpha+\beta \rightarrow \gamma+\alpha+\beta$ phase transformation (during cooling). The transformation pathways of alloys G1 and G2 during cooling, including the $\alpha$ transus temperatures, are shown below.

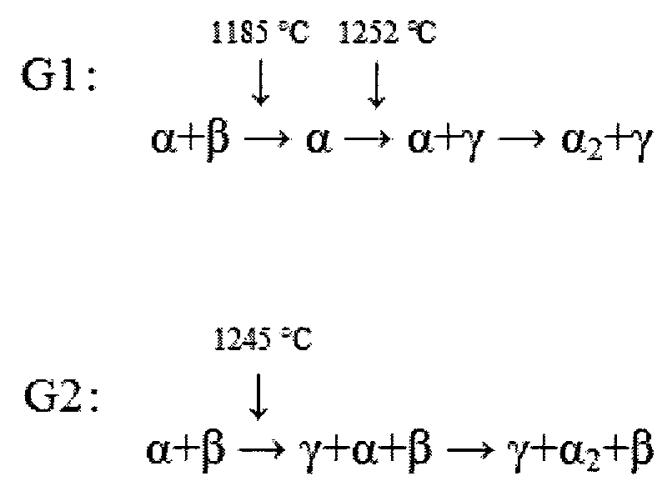

\subsection{Step Cooled Solution Heat Treatments (SCSHT)}

The large $\beta$ grains present in the as-HIP microstructure of alloy G2 would have a very detrimental effect on the high temperature properties of the alloys. The softening characteristics of the $\beta$ phase at high temperatures, which gives beta gamma TiAl alloys their excellent hot working behavior, also effectively reduces their high temperature mechanical properties [16]. Therefore, the microstructure containing the $\beta$ phase is only an intermediate microstructure used for wrought processing and machining to the desired part geometry. Following the wrought processing steps, the SCSHT would be used to remove as much of the $\beta$ phase as possible and develop a fully lamellar microstructure. 
The processing sequence of the powder alloys under investigation can be seen in Figure 93, which shows when the solution heat treatment would be applied

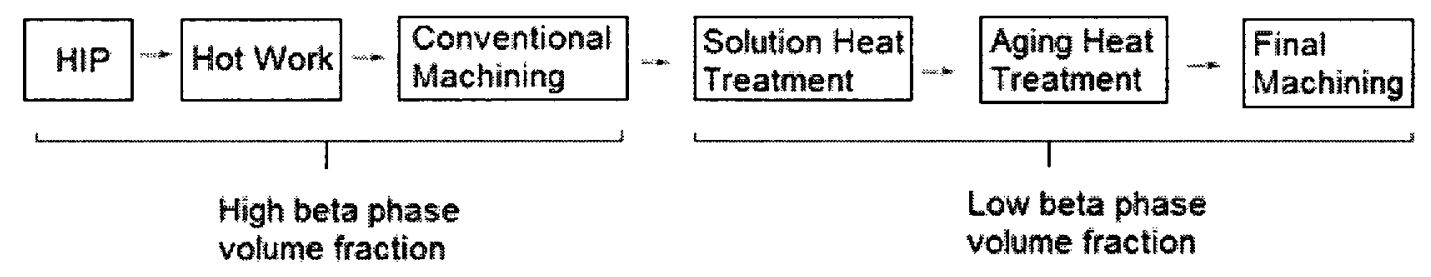

Figure 93. The proposed processing sequence for the powder beta gamma TiAl alloys.

Due to the large amount of $\beta$ stabilizing elements present in both alloys G1 and G2, the equilibrium phase diagram is significantly different than that of a conventional gamma TiAl alloys. As a result, the transformation pathways from the heat treatment temperature to room temperature are also expected to be very different. Figure 94 shows the equilibrium phases for a Ti-44Al alloy with varying amounts of $\beta$ stabilizing elements [55]. Group A alloys are two phase $\gamma+\alpha_{2}$ alloys. Group B alloys, which are three phase $\gamma+\alpha_{2}+\beta$ alloys, correspond to a typical beta gamma TiAl alloy [16]. Group C alloys are two phase $\gamma+\beta$ alloys. It can be seen that there is no single phase $\alpha$ region for heavily $\beta$ stabilized TiAl alloys (alloys B and C). Therefore it would likely be impossible to fully remove the $\beta$ phase from the $B$ and $C$ alloys while developing a fully lamellar microstructure through a solution heat treatment. 


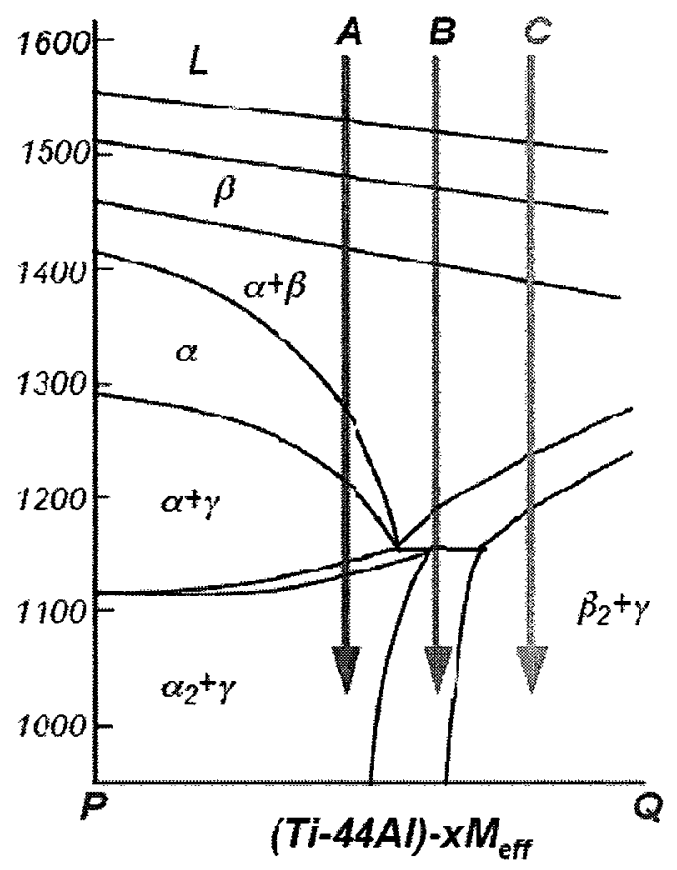

Figure 94. The equilibrium phase of a Ti-44Al alloy with the addition of varying amounts of $\beta$ stabilizing elements (xMeff) [55|.

The solution heat treatment temperature would have to be in the two phase $\alpha+\beta$ region. As the temperature is decreased towards the $\alpha$ transus (or three phase region), the equilibrium $\alpha$ phase fraction increases while that of the $\beta$ phase decreases [61]. It has also been shown in related studies of heavily $\beta$ stabilized alloys that the $\beta$ phase fraction is at a minimum at the $\alpha$ transus $[61,62]$. Therefore, in order to ensure that a minimum amount of $\beta$ phase is retained during the solution heat treatment, the cooling rate down to the $\alpha$ transus would have to be sufficiently slow as to allow for equilibrium amounts of $\alpha$ and $\beta$ phase to form in the course of the $\beta \rightarrow \alpha$ transformation. Upon further cooling the $\alpha$ phase would follow the transformation $\alpha \rightarrow \alpha+\gamma \rightarrow \alpha_{2}+\gamma$ to form lamellar colonies. Furthermore, the $\beta$ stabilizing elements segregate to the $\beta / \alpha$ interface boundaries during 
the $\beta \rightarrow \alpha$ transformation [61]. Therefore, the remaining $\beta$ phase would most likely be present at the lamellar colony boundaries following the solution heat treatment.

Based on the DSC and XRD analyses in sections 4.3 and 4.4, respectively, the $\alpha$ transus temperature of alloy Gl was determined to be approximately $1185^{\circ} \mathrm{C}$, and the $\alpha$ transus $(\gamma+\alpha+\beta \rightarrow \alpha+\beta$ transformation temperature) of alloy G2 was determined to be approximately $1245^{\circ} \mathrm{C}$. However, it was also determined that the onset of the phase transformations during cooling were somewhat different. During the cooling of alloy G1 at a rate of $20^{\circ} \mathrm{C} / \mathrm{min}$ the onset of the first phase transformation, $\alpha+\beta \rightarrow \alpha$, which was followed quickly by the $\alpha \rightarrow \gamma+\alpha$ transformatoin, was at $1238.5^{\circ} \mathrm{C}$. For alloy $\mathrm{G} 2$, the onset of the $\alpha+\beta \rightarrow \gamma+\alpha+\beta$ phase transformation was at $1235.6{ }^{\circ} \mathrm{C}$. A solution heat treatment temperature of $1400^{\circ} \mathrm{C}$ was chosen to ensure that the alloy was well within the $\alpha+\beta$ phase field. The duration of the solution heat treatment was chosen to be 40 minutes to allow for sufficient homogenization of the alloying elements since elements such as Mo and Mn have low diffusivity [61]. Following the 40 minute hold at $1400{ }^{\circ} \mathrm{C}$, the cooling was carefully controlled using a step cooling process that consisted of a furnace cool $\left(\sim 11^{\circ} \mathrm{C} / \mathrm{min}\right)$ to a predetermined transition temperature, $\mathrm{T}_{\mathrm{F} / \mathrm{A}}$, followed by air cooling to room temperature (see Figure 53 in section 4.5.1). This heat treatment is thus called a step cooled solution heat treatment (SCSHT). The effect of the furnace to air cooling transition temperature, $T_{F / A}$, is investigated in the following section. 


\subsubsection{Effect of the Furnace to Air Cooling Transition Temperature $\left(T_{F / A}\right)$}

In order to achieve the desired fully lamellar microstructure the cooling rate from the solution heat treatment temperature had to be carefully controlled. A sufficiently fast cooling rate is required in order to achieve a refined lamellar spacing, and avoid coarsening of the lamellae. However, a cooling rate that is too fast would result in a large degree of undercooling, which suppresses the $\alpha \rightarrow \alpha+\gamma$ transformation, and leads to the nucleation of massively transformed $\gamma$ grains, $\gamma_{\mathrm{M}}$, at the $\alpha$ grain boundaries [36]. The slow furnace cooling up to the transition temperature, $\mathrm{T}_{\mathrm{F} / \mathrm{A}}$, ensures that near equilibrium amounts of $\alpha$ and $\beta$ phases are present. Since the $\beta$ phase fraction is at a minimum at the $\alpha$ transus, air cooling from a temperature near the $\alpha$ transus would result in a minimum amount of $\beta$ phase in the final solution heat treated microstructure. Additionally, air cooling following a transition temperature that is near the $\alpha$ transus would reduce the degree of undercooling and therefore favor the formation of lamellar colonies and reduce the possible nucleation sites for massively transformed $\gamma$ [36]. The air cooling step also ensures that the fine fully lamellar microstructure is retained to room temperature. The effects of three different step cool transition temperatures $\left(1270{ }^{\circ} \mathrm{C}, 1280{ }^{\circ} \mathrm{C}\right.$ and $1290^{\circ} \mathrm{C}$ ) on the solution heat treated microstructure were investigated. All the solution heat treating trials were done using samples HIP'ed at $1250^{\circ} \mathrm{C}$ and $200 \mathrm{MPa}$ for 2 hours that were furnace cooled. 


\subsubsection{Alloy G1}

The microstructure of the SCSHT samples of alloy G1 are illustrated in Figure 95. The lamellar colony grain size ranged between 25 and $110 \mu \mathrm{m}$ with an average of $\sim 80 \mu \mathrm{m}$.

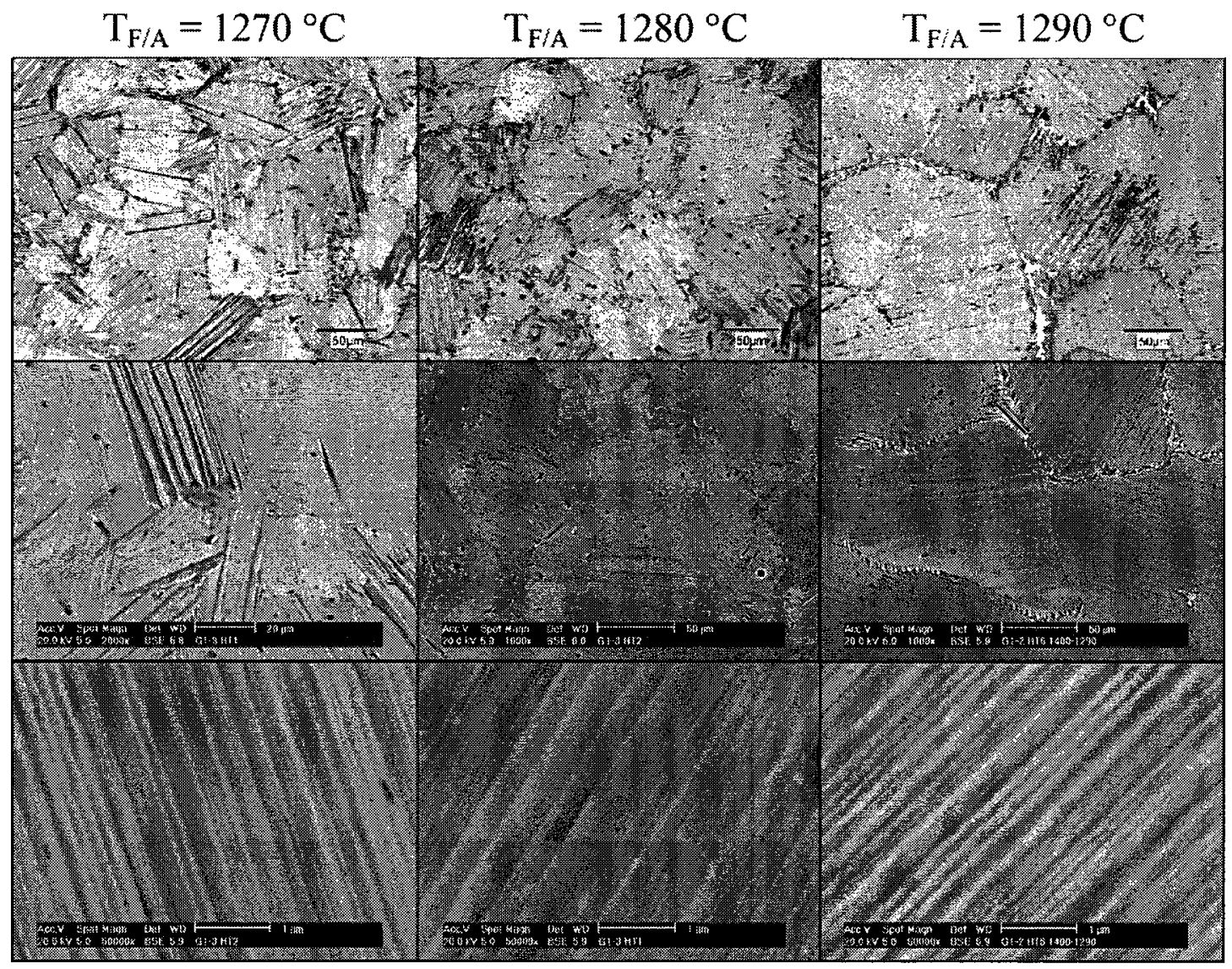

Figure 95. Optical and BSE micrographs showing the effect of the furnace to air cooling transition temperature on the microstructure of alloy $\mathrm{G} 1$.

With a transition temperature of $\mathrm{T}_{\mathrm{F} / \mathrm{A}}=1270{ }^{\circ} \mathrm{C}$ there is evidence of severe coarsening of the $\gamma$ lamellae as shown in Figure 96. Since the fast air cooling of the sample began from the $\alpha+\beta$ phase field, where the formation of the lamellae had not yet 
started, it is unclear how such significant coarsening of the $\gamma$ lamellae could occur. Nevertheless, these microstructural features are undesirable for high temperature applications. The lamellar colony grain boundaries were a mixture of planar and well interlocked. The well interlocked grain boundary morphology is thought to be a result of discontinuous coarsening of the lamellar colonies. Discontinuous coarsening is a process during which lamellae thicken and join together as they grow into adjacent grains, leading to irregular serrated grain boundaries [66].

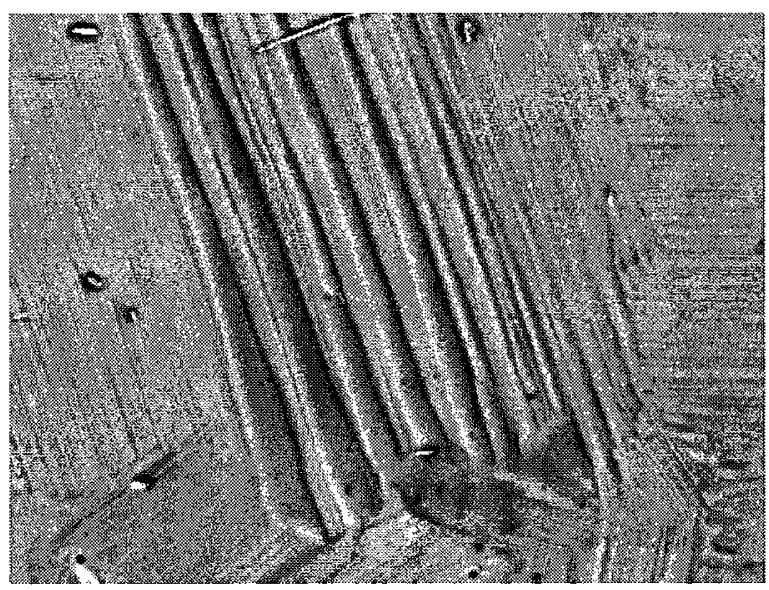

Figure 96. BSE micrograph of alloy $\mathrm{G1}$ solution heat treated with a step cool transition temperature of $T_{F / A}=1270{ }^{\circ} \mathrm{C}$ (enlarged from Figure 95), showing evidence of severe coarsening of the $\gamma$ lamellae.

The microstructure resulting from a transition temperature of $\mathrm{T}_{\mathrm{F} / \mathrm{A}}=1280^{\circ} \mathrm{C}$ showed no evidence of lamellar coarsening or the formation of massively transformed $\gamma$ phase. The grain boundary morphologies are also a mix of planar and well interlocked, as seen in Figure 97. However, less discontinuous coarsening was observed with a transition temperature of $T_{F / A}=1280^{\circ} \mathrm{C}$ than with a transition temperature of $T_{F / A}=1270{ }^{\circ} \mathrm{C}$. 


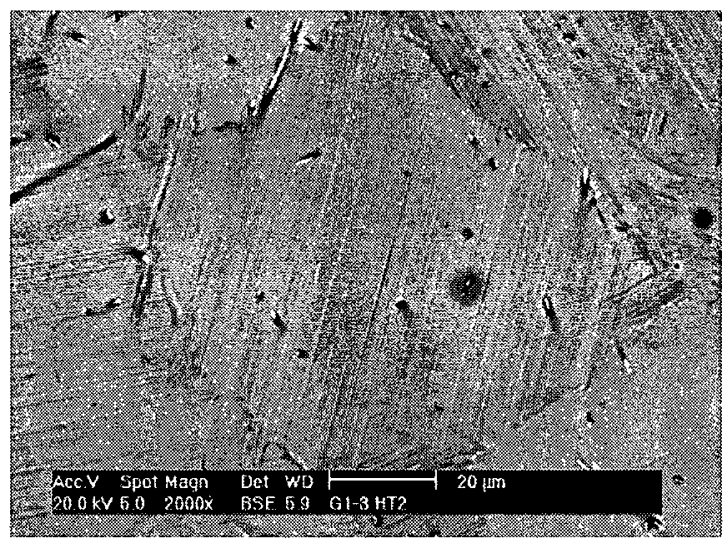

Figure 97. BSE image of alloy $G 1$ heat treated with a step cool transition temperature of $T_{F / A}=1280$ ${ }^{\circ} \mathrm{C}$, showing a mixture of planar and well interlocked grain boundary morphologies.

With a transition temperature of $\mathrm{T}_{\mathrm{F} / \mathrm{A}}=1290^{\circ} \mathrm{C}, \gamma$ and $\beta$ phase can be seen at the grain boundaries, as seen in Figure 98. The $\gamma$ phase could be massively transformed $\gamma$ phase, however further investigations would be required to properly identify the nature of the $\gamma$ phase at the colony boundaries. This type of grain boundary morphology is not ideal for high temperature properties since it would promote the formation of voids, which would coalesce to form cracks, and the large $\beta$ grains would become soft at high temperatures, therefore reducing the strength [15,35]. Furthermore, the precipitation of fine $\beta$ particles in subsequent aging heat treatments would be very difficult or impossible. The formation of the equiaxed (or massive) $\gamma$ phase at the grain boundaries is a result of air cooling from higher temperature, allowing for a large degree of undercooling before the completion of the $\alpha \rightarrow \alpha+\gamma$ transformation, therefore promoting the formation of these phases at the grain boundaries. The $\beta$ phase at the grain boundaries is likely a result of insufficient time for the $\beta \rightarrow \alpha$ transformation to reach the minimum equilibrium $\beta$ 
concentrations, which occurs at the $\alpha$ transus. Subsequent air cooling retains the $\beta$ phase to room temperature.

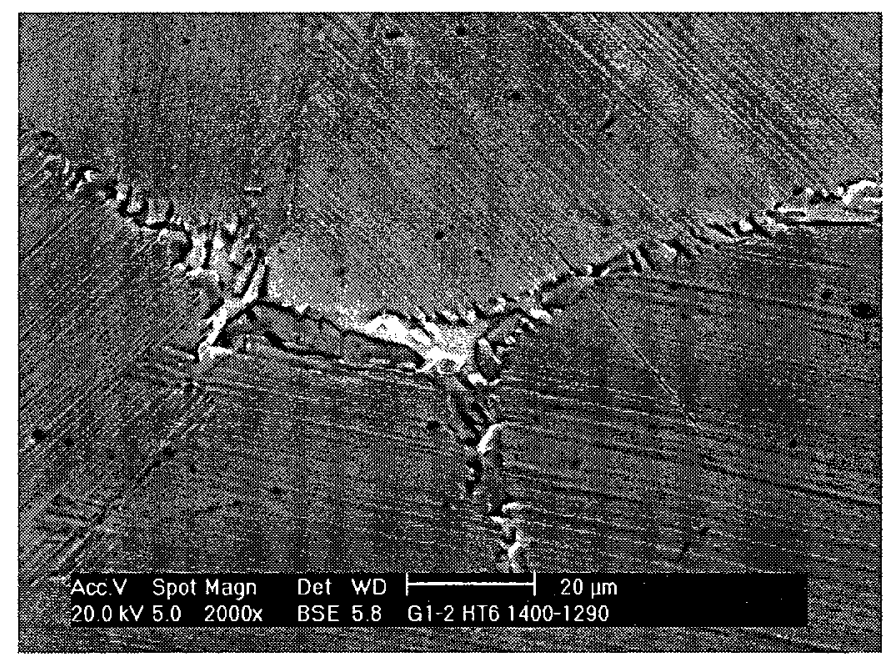

Figure 98. BSE image of alloy $G 1$ heat treated with a step cool transition temperature of $T_{F / A}=1290$ ${ }^{\circ} \mathrm{C}$, showing the formation of equiaxed $\gamma$ and $\beta$ phase at the grain boundaries.

From these results, it can be concluded that for alloy G1 a transition temperature of $\mathrm{T}_{\mathrm{F} / \mathrm{A}}=1280^{\circ} \mathrm{C}$ results in the best solution heat treated fully lamellar microstructure. This fully lamellar microstructure is also very fine (average lamellar colony size of $80 \mu \mathrm{m}$ ) and would offer good ductility compared to a more typical large grained ( $>500 \mu \mathrm{m})$ fully lamellar microstructure [14,34]. Furthermore, the average lamellar spacing that was measured at $0.04 \mu \mathrm{m}$ is very fine, as shown in Figure 99. It has been shown that a fine lamellar spacing significantly reduces both the primary creep strain and the secondary creep rate [69]. 


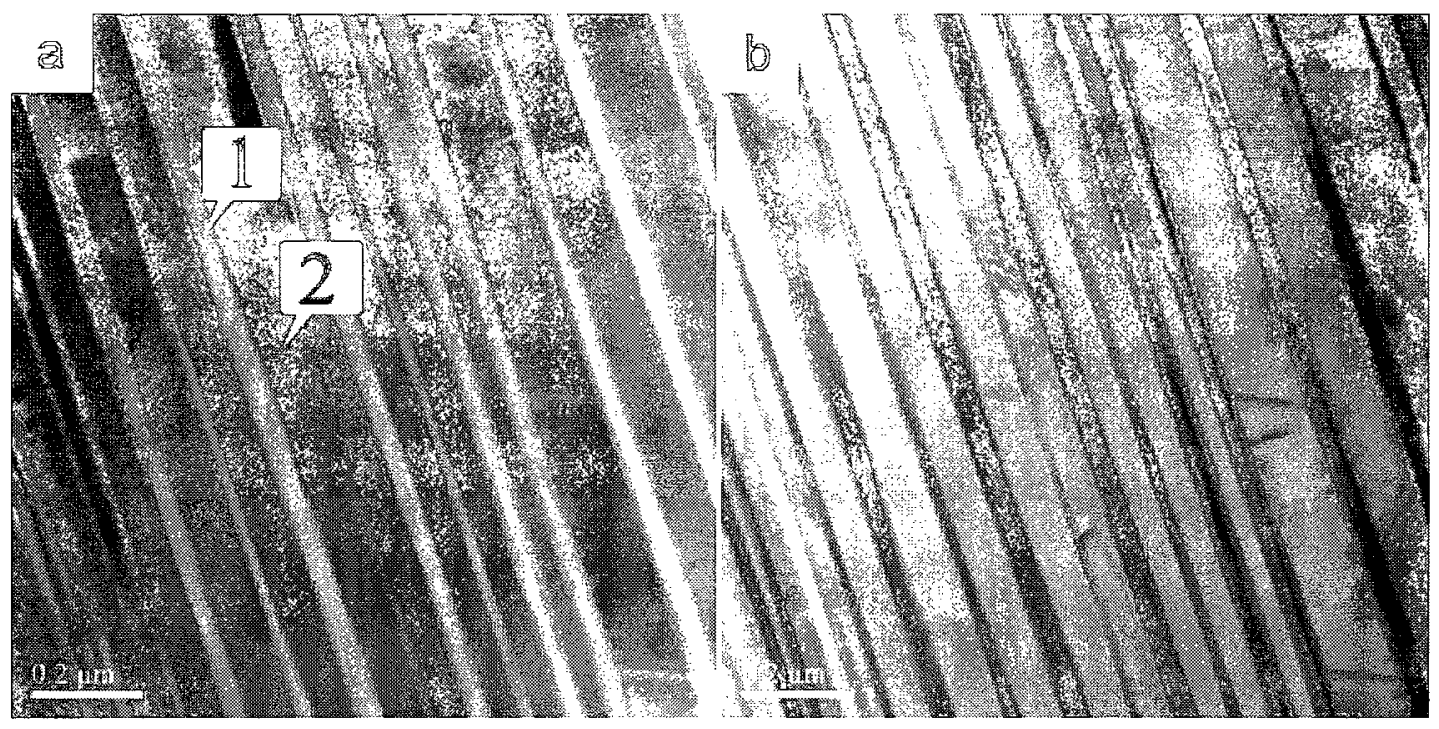

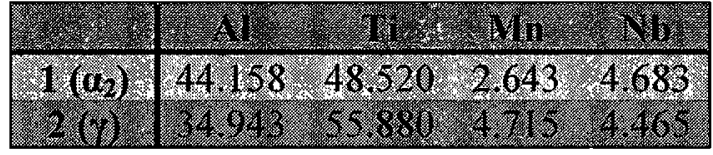

Figure 99. The a) angular dark field and b) bright field TEM images of alloy G1 solution heat treated with $T_{F / A}=1280{ }^{\circ} \mathrm{C}$. The bright contrast lamellae in the angular dark field imaged are $\alpha_{2}$ phase and the dark contrast lamellar are $\gamma$ phase.

\subsubsection{Alloy G2}

The microstructure of the SCSHT samples of alloy G2 are illustrated in Figure 100. The lamellar colony grain size ranged between 10 and $100 \mu \mathrm{m}$ with an average of $\sim 40 \mu \mathrm{m}$, which is much finer than the $\sim 80 \mu \mathrm{m}$ grain size of alloy Gl after the SCSHT. 


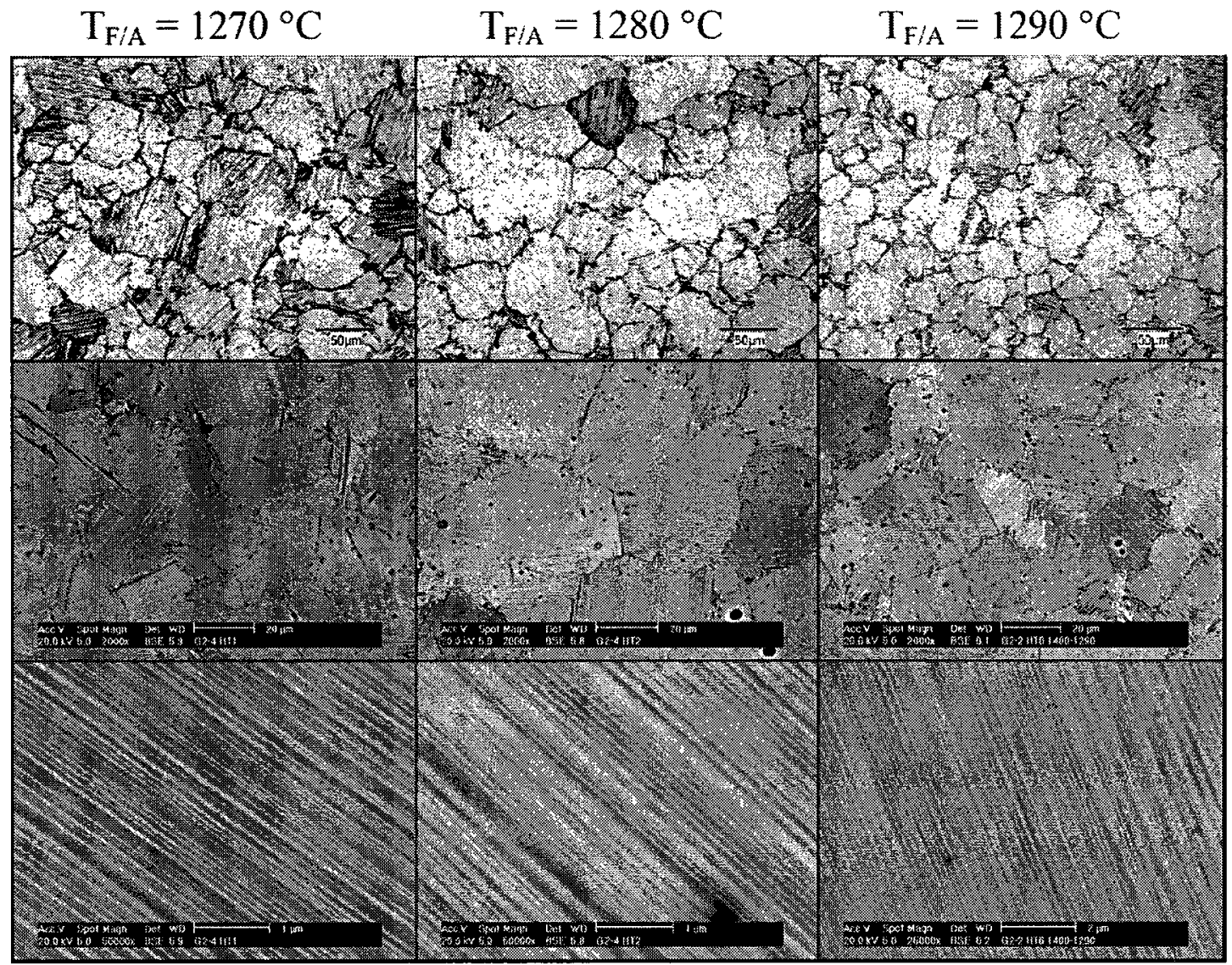

Figure 100. Optical and BSE micrographs showing the effect of the furnace to air cooling transition temperature on the microstructure of alloy $\mathbf{G 2}$.

Similar to alloy G1, alloy G2 shows evidence of coarsening of some of the $\gamma$ lamellae with a transition temperature of $\mathrm{T}_{\mathrm{F} / \mathrm{A}}=1270{ }^{\circ} \mathrm{C}$, as shown in Figure 101. These microstructural features would be likely to adversely affect the high temperature properties. Since the fast air cooling of the sample began from the $\alpha+\beta$ phase field, where the formation of the lamellae had not yet began, it is unclear how such significant coarsening of the $\gamma$ lamellae could occur. However, local variations in composition would cause the phase transformation temperatures to change. As shown in Figure 94, an 
increase in the amount of $\beta$ stabilizing elements increases the $\alpha+\beta \rightarrow \gamma+\alpha+\beta$ phase transformation temperature. The coarse lamellae appear to originate at the colony boundaries, and during the course of the furnace cooling stage, $\beta$ stabilizing elements segregate to the $\beta / \alpha$ interfaces, which subsequently become colony boundaries [61]. Therefore, these areas, which enriched in $\beta$ stabilizing elements, may have begun to form lamellae prior to the transition temperature of $1270{ }^{\circ} \mathrm{C}$, and further furnace cooling up to $1270^{\circ} \mathrm{C}$ would allow severe coarsening of the lamellae to occur.

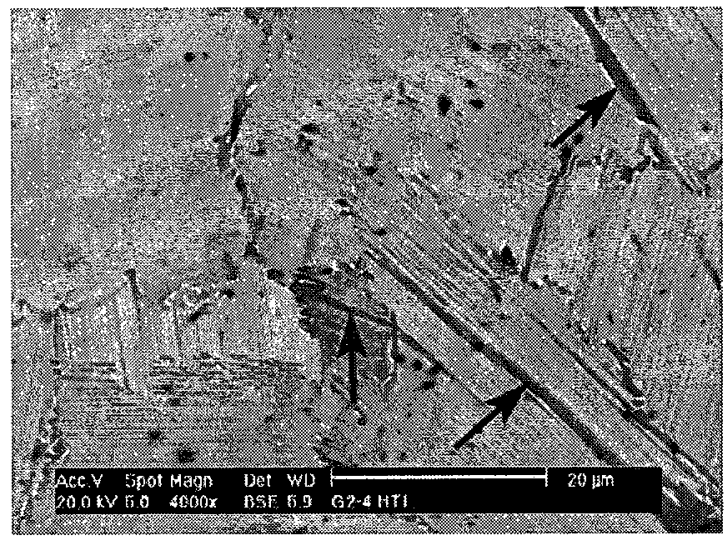

Figure 101. Alloy $\mathrm{G} 2$ solution heat treated with a step cool transition temperature of $T_{\mathrm{F} / \mathrm{A}}=1270^{\circ} \mathrm{C}$, showing evidence of coarsening of the $\gamma$ lamellae.

The lamellar colony grain boundaries were also a mixture of planar and well interlocked with a very small amount of fine $\beta$ particles. Since alloy G2 has a significant amount of $\beta$ stabilizing elements, which segregate to the grain boundaries during the $\beta \rightarrow \alpha$ transformation, it was expected that some $\beta$ would be present at the grain boundaries following the solution heat treatment. Completely eliminating the $\beta$ phase is not possible. However, the fine particle morphology would not be expected to 
detrimentally affect the high temperature properties. The well interlocked grain boundary morphology is a result of discontinuous coarsening of the lamellar colonies.

The microstructure resulting from a transition temperature of $\mathrm{T}_{\mathrm{F} / \mathrm{A}}=1280^{\circ} \mathrm{C}$ showed no evidence of lamellar coarsening or the formation of large $\gamma$ particles. The grain boundary morphologies are also a mix of planar and well interlocked with a very small amount of retained fine $\beta$ particles, as seen in Figure 102. However, less discontinuous coarsening was observed with a transition temperature of $\mathrm{T}_{\mathrm{F} / \mathrm{A}}=1280{ }^{\circ} \mathrm{C}$ than with a transition temperature of $\mathrm{T}_{\mathrm{F} / \mathrm{A}}=1270^{\circ} \mathrm{C}$.

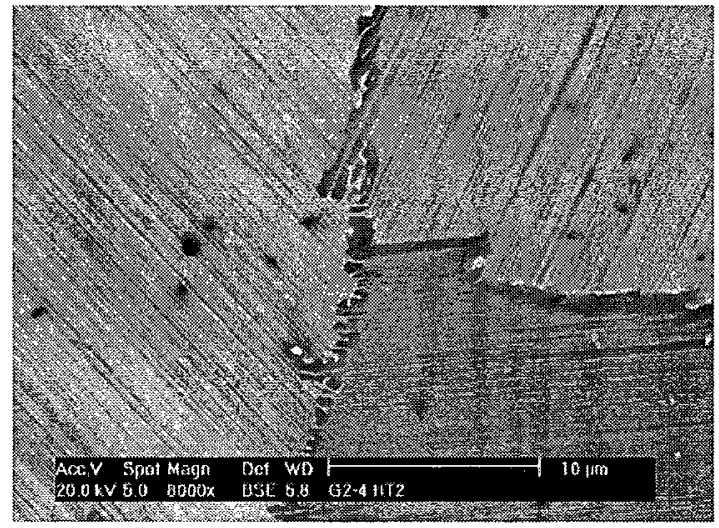

Figure 102. Alloy $\mathrm{G} 2$ heat treated with a step cool transition temperature of $\mathrm{TF} / \mathrm{A}=1280^{\circ} \mathrm{C}$.

With a transition temperature of $\mathrm{T}_{\mathrm{F} / \mathrm{A}}=1290^{\circ} \mathrm{C}, \gamma$ and $\beta$ phase can be seen at the grain boundaries, as shown in Figure 103. This type of grain boundary morphology is not ideal for high temperature properties since it would promote the formation of voids, which would coalesce to form cracks, and the large $\beta$ grains would become soft at high 
temperatures, therefore reducing the strength $[15,35]$. These $\beta$ grains would also likely coarsen during the aging heat treatments. Furthermore, the precipitation of fine $\beta$ particles at the grain boundaries in subsequent aging heat treatments would not be possible.

The formation of the $\gamma$ phase at the grain boundaries, which could possibly be massively transformed $\gamma$, is a result of air cooling from higher temperature, allowing for a large degree of undercooling before the completion of the $\alpha \rightarrow \alpha+\gamma$ transformation, therefore promoting the nucleation of $\gamma$ at the grain boundaries. The larger amount of $\beta$ phase at the grain boundaries is a result of insufficient time for the $\beta \rightarrow \alpha$ transformation to reach the minimum equilibrium $\beta$ concentrations, which occurs at the $\alpha$ transus. Subsequent air cooling retains the $\beta$ phase to room temperature.

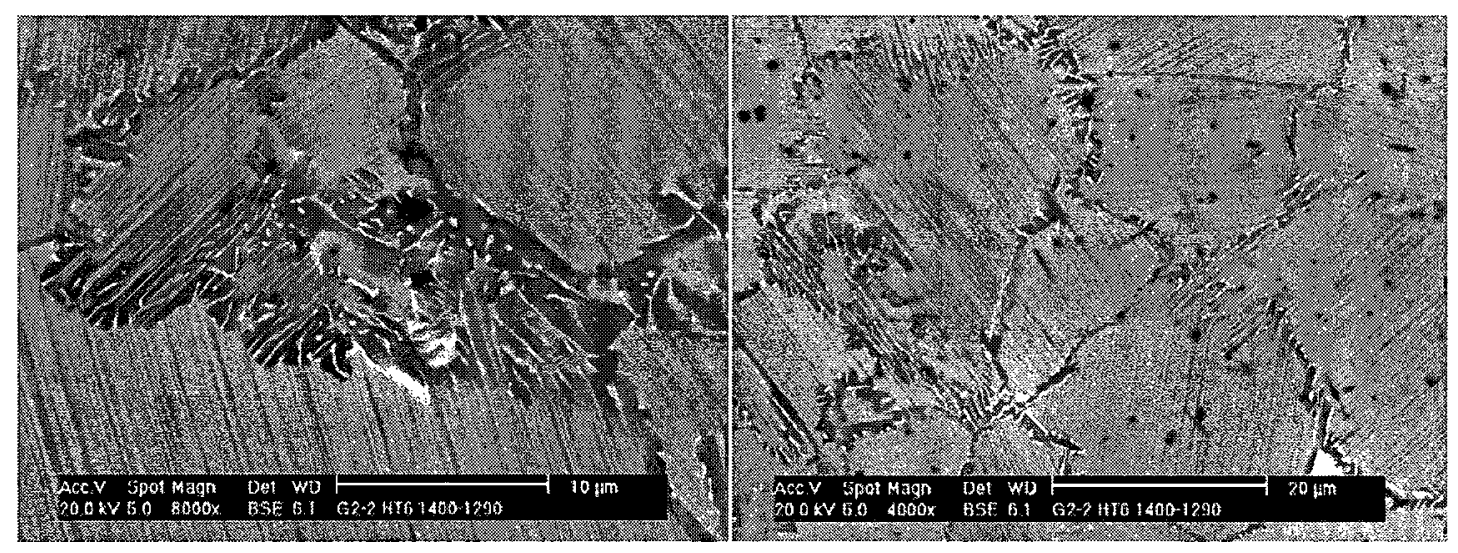

Figure 103. Alloy $\mathrm{G} 2$ heat treated with a step cool transition temperature of $T F / A=1290^{\circ} \mathrm{C}$, showing the formation of massive $\gamma$ and $\beta$ phases at the grain boundaries.

From these results, it can be concluded that for alloy G2 a transition temperature of $\mathrm{T}_{\mathrm{F} / \mathrm{A}}=1280{ }^{\circ} \mathrm{C}$ results in the best solution heat treated fully lamellar microstructure. This 
microstructure is very amenable to further aging heat treatments as a result of the limited amount of $\beta$ phase present. Furthermore, the very small average lamellar colony size of $40 \mu \mathrm{m}$ would result in significantly improved ductility over a more typical large grained $(>500 \mu \mathrm{m})$ lamellar microstructure [14,34]. Additionally, the average lamellar spacing that was measured at $0.04 \mu \mathrm{m}$ is very fine, as shown in Figure 104. As mentioned previously, it has been shown that a fine lamellar spacing significantly reduces the primary creep strain and the secondary creep rate [69]. Figure 104 also shows the EDS results, where the bright contrast lamellae in the bright field image are the $\gamma$ phase and the dark contrast lamellae are the $\alpha_{2}$ phase. The $\gamma$ lamellae were depleted in Mo while the $\alpha_{2}$ lamellae were rich in Mo, which is likely a result of a partitioning coefficient $\mathrm{k}_{\mathrm{a} / \mathrm{\gamma}}$ greater than 1.0.
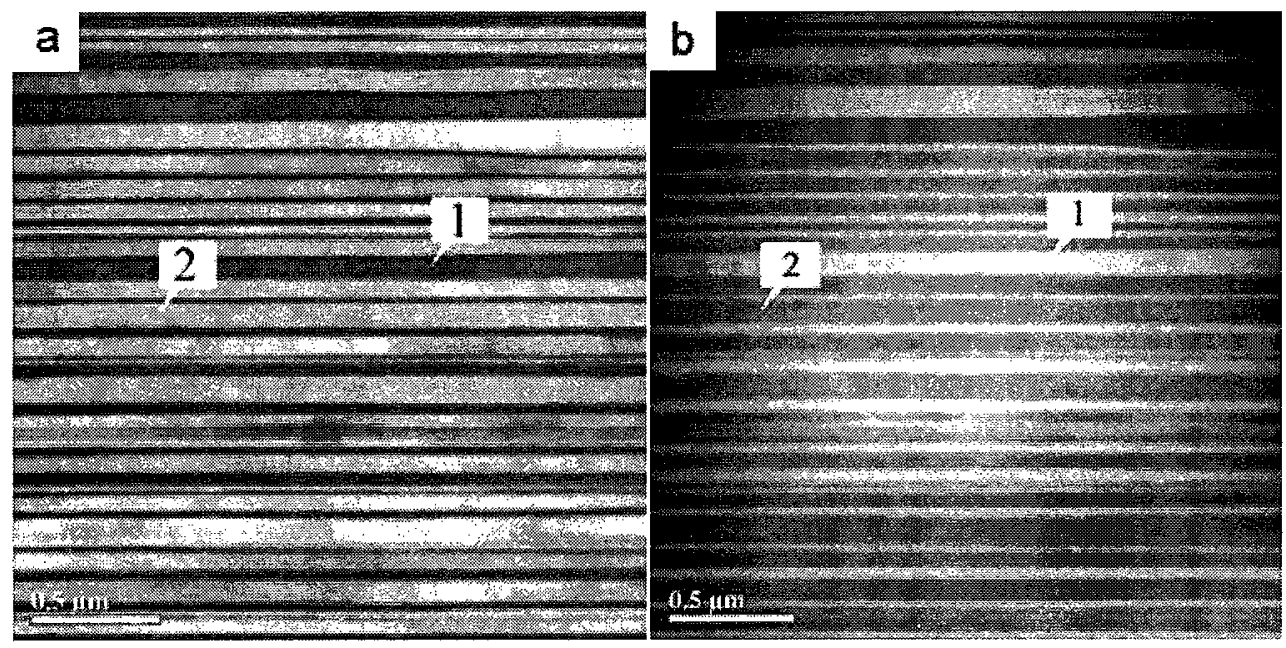

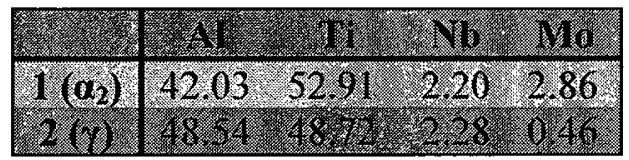

Figure 104. TEM images of $G 2$ solution heat treated with $T_{F / A}=1280^{\circ} \mathrm{C}$, showing EDS results (all in at.\%) in a) bright field and $b$ ) angular dark field modes. 


\subsubsection{Summary}

The purpose of the step cooled solution heat treatment was to develop a fine fully lamellar microstructure while removing as much of the $\beta$ phase as possible. The large $\beta$ grains in the as-HIP'ed microstructure of alloy G2 adversely affect the creep since the $\beta$ phase becomes soft at high temperatures. It is not possible to completely remove the $\beta$ phase from the microstructure of alloy G2 given the nature of a three phase $\left(\gamma+\alpha_{2}+\beta\right)$ beta gamma TiAl alloy, however the volume fraction of $\beta$ phase can be minimized by carefully controlling the cooling rates from the solution heat treatment temperature. It has been shown that the $\beta$ phase volume fraction is at a minimum at the $\alpha$ transus temperature (or $\alpha+\beta \rightarrow \gamma+\alpha+\beta$ transformation temperature). Therefore, furnace cooling down to a temperature near the $\alpha$ transus would allow for minimum equilibrium amounts of $\beta$ phase to be present, and subsequent air cooling would allow the formation of the fine lamellar structure. The effect of the furnace to air cooling transition temperature on the microstructure was investigated.

It was determined that a transition temperature of $1280^{\circ} \mathrm{C}$ resulted in the best fully lamellar microstructure for both alloys G1 and G2. There was no $\beta$ phase in alloy G1 and alloy $\mathrm{G} 2$ contained only very fine $\beta$ particles at the lamellar colony boundaries. The lower transition temperature of $1270^{\circ} \mathrm{C}$ resulted in severe coarsening of some of the $\gamma$ lamellae and the higher transition temperature of $1290^{\circ} \mathrm{C}$ resulted in a higher amount of retained $\beta$ phase at the lamellar colony boundaries. 
The very small average lamellar colony size in the solution heat treated microstructures of both alloys $(\mathrm{G} 1=80 \mu \mathrm{m}, \mathrm{G} 2=40 \mu \mathrm{m}$ ) would result in significantly improved ductility over a more typical large grained lamellar microstructure $(>500 \mu \mathrm{m})$. In addition, both alloys have very fine lamellar spacing $(\sim 0.04 \mu \mathrm{m})$, which would result in significantly improved creep resistance.

\subsection{Aging Heat Treatments}

The purpose of the aging heat treatments was to form fine $\beta$ precipitates at the lamellar interfaces in order to improve the high temperature properties. Fine lamellar interface $\beta$ precipitates have been shown to significantly improve the primary creep resistance of TiAl alloys with a fully lamellar microstructure [15,35]. In conventional TiAl alloys, which contain no interfacial precipitates, deformation of the microstructure during creep can be characterized by dislocations emanating from the lamellar interfaces, which subsequently glide along the $\gamma$ lamellae and pass through the lamellar interfaces [35]. However, in $\beta$ stabilized alloys, the fine interfacial $\beta$ precipitates that can be formed during aging hinder dislocation emission and block the motion of pre-existing dislocations during primary creep [35]. Additionally, interfacial precipitates have also been found to improve the tensile properties by hindering lamellar delamination [67].

All aging heat treatments were done on samples solution heat treated with a furnace to air cooling transition temperature of $\mathrm{T}_{\mathrm{F} / \mathrm{A}}=1280{ }^{\circ} \mathrm{C}$. The aging heat treatment temperatures were 800,900 and $950{ }^{\circ} \mathrm{C}$, with durations ranging from 6 to 96 hours. 
Figure 105 and Figure 106 show matrices of optical images illustrating the overall aged microstructures of alloy G1 and G2, respectively. Figure 107 and Figure 108 shows matrices of back scattered electron (BSE) images illustrating the grain boundary morphologies of alloys G1 and G2, respectively, resulting from the aging heat treatments. Figure 109 and Figure 110 show matrices of BSE images illustrating the lamellar structure of alloys G1 and G2, respectively, resulting from the aging heat treatments. 


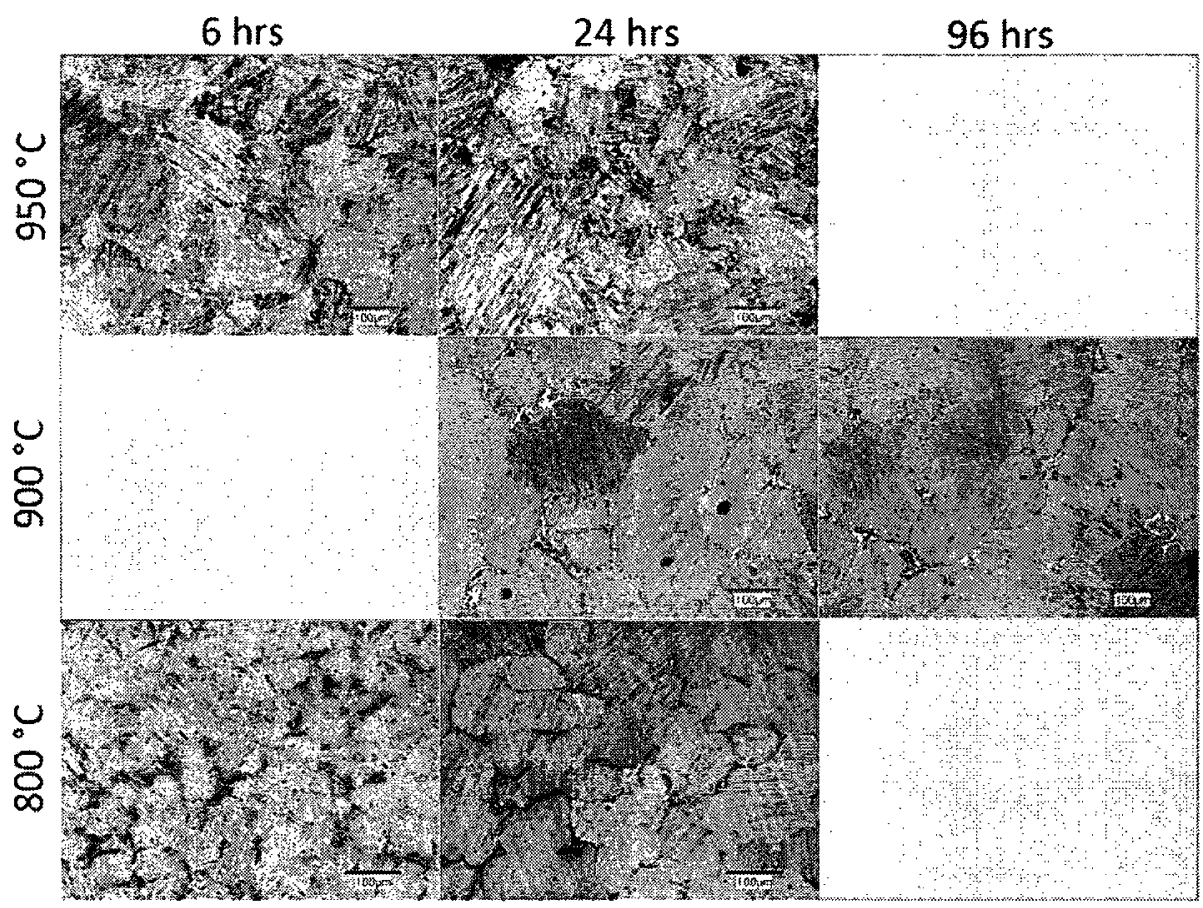

Figure 105. Optical micrographs showing the effect of the aging conditions on the overall microstructure of alloy $\mathbf{G 1}$ (all at the same magnification).

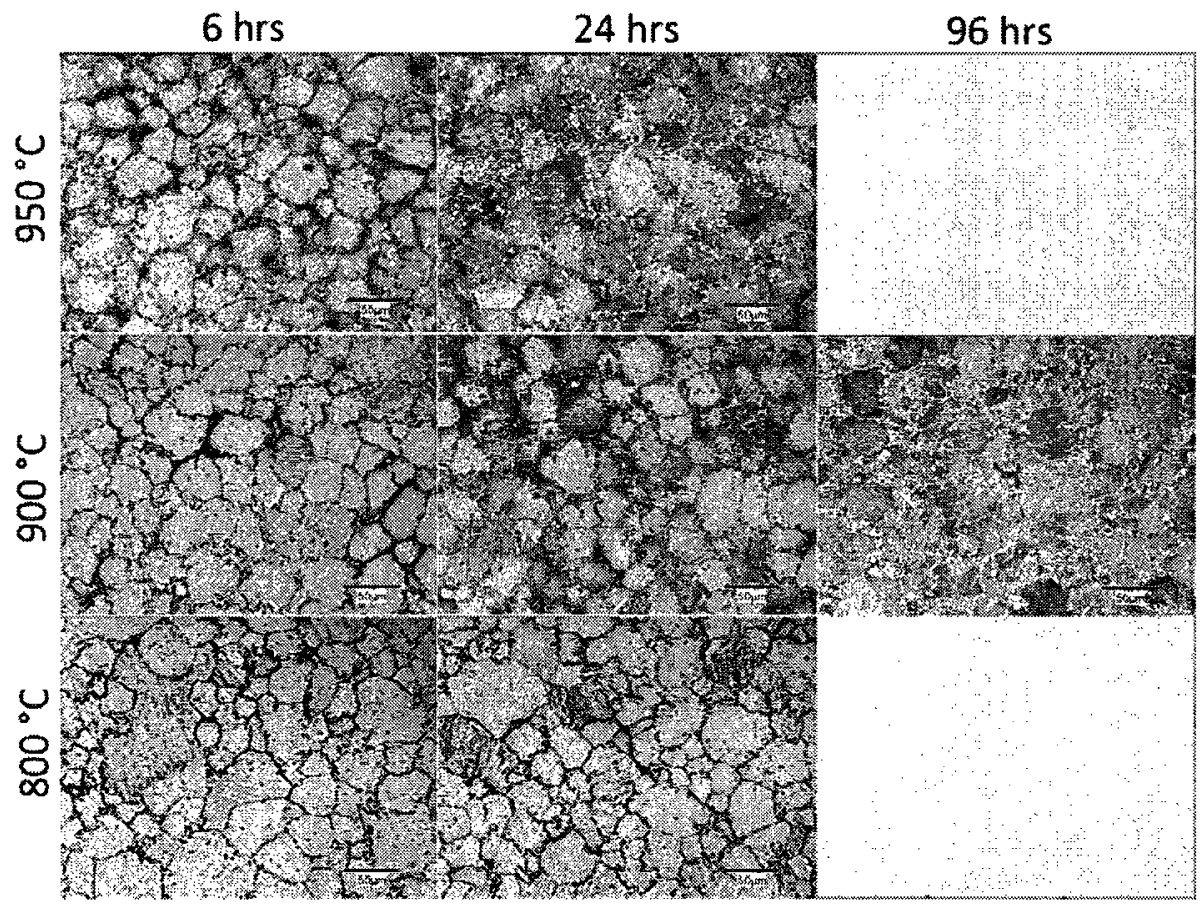

Figure 106. Optical micrographs showing the effect of the aging conditions on the overall microstructure of alloy $\mathbf{G} 2$ (all the same magnification). 


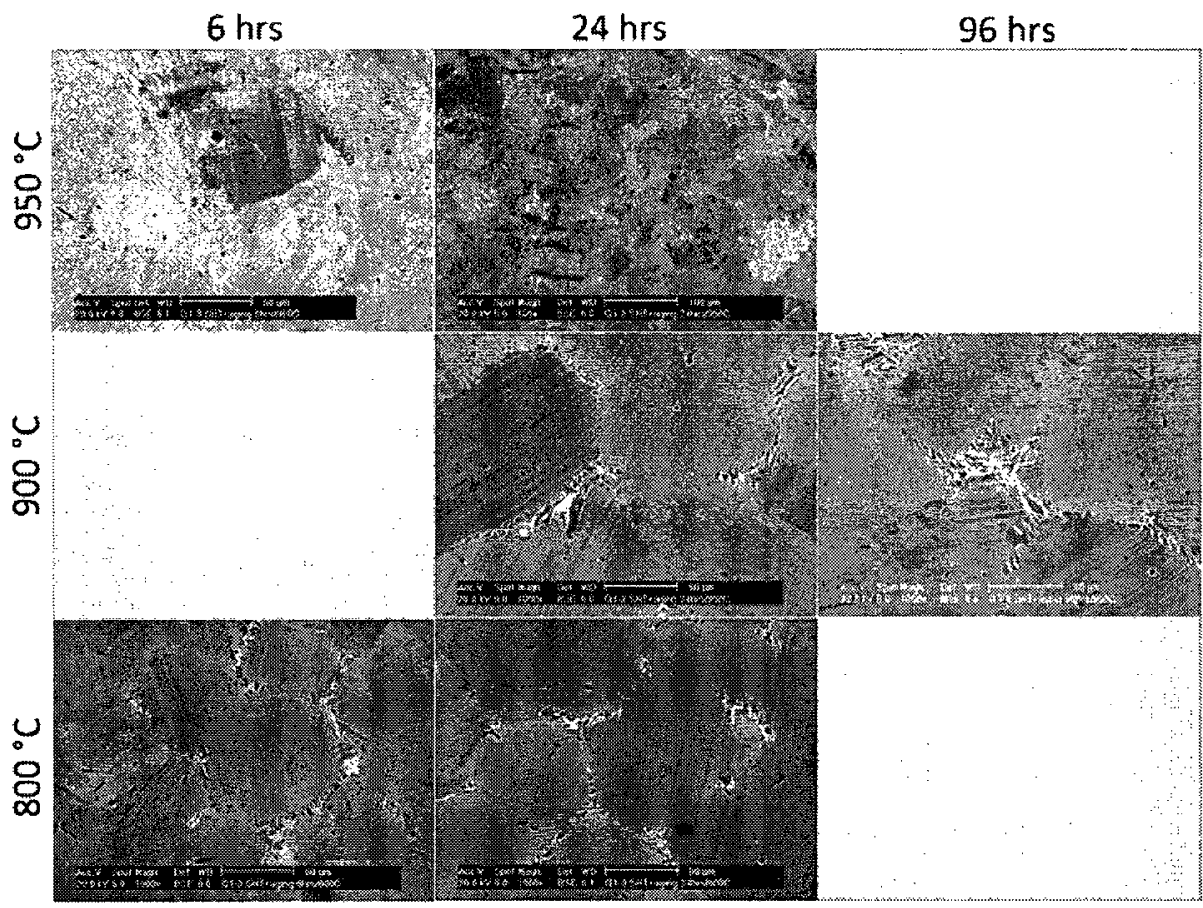

Figure 107. BSE images showing the effect of the aging conditions on the grain boundary morphology of alloy G1 (all at 1000x magnification).

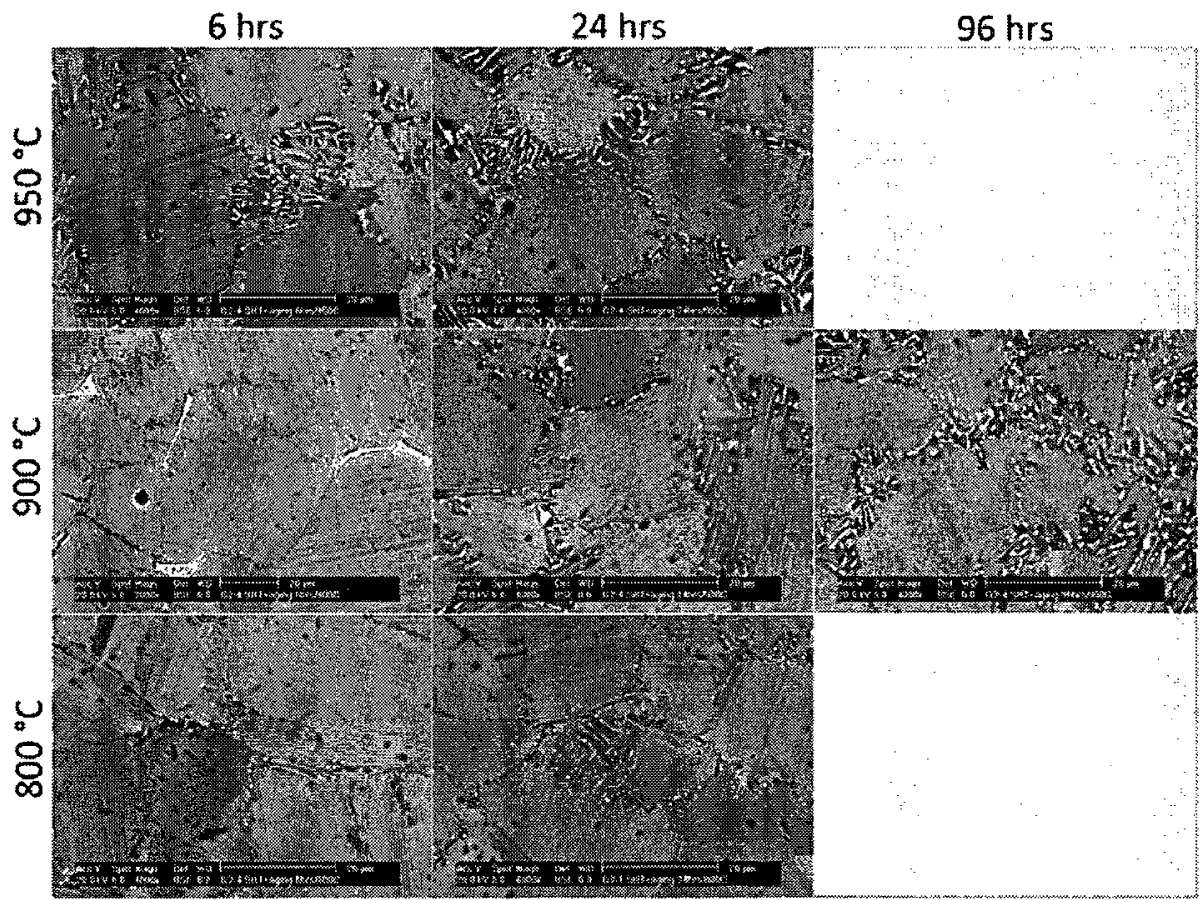

Figure 108. BSE images showing the effect of the aging conditions on the grain boundary morphology of alloy $\mathbf{G} 2$ (all at $4000 x$ magnification). 


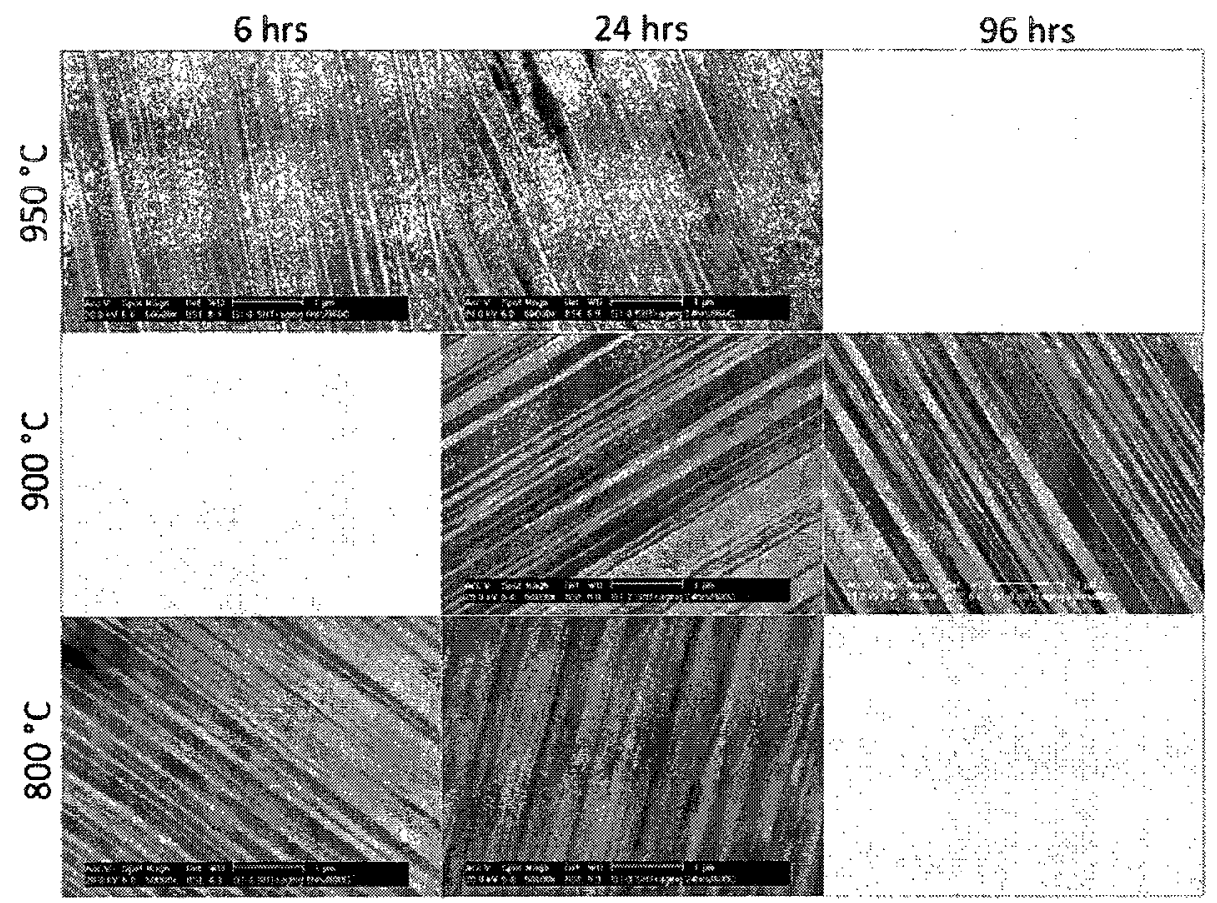

Figure 109. BSE images showing the effect of the aging conditions on the lamellae in alloy G1 (all at 50000x magnification).

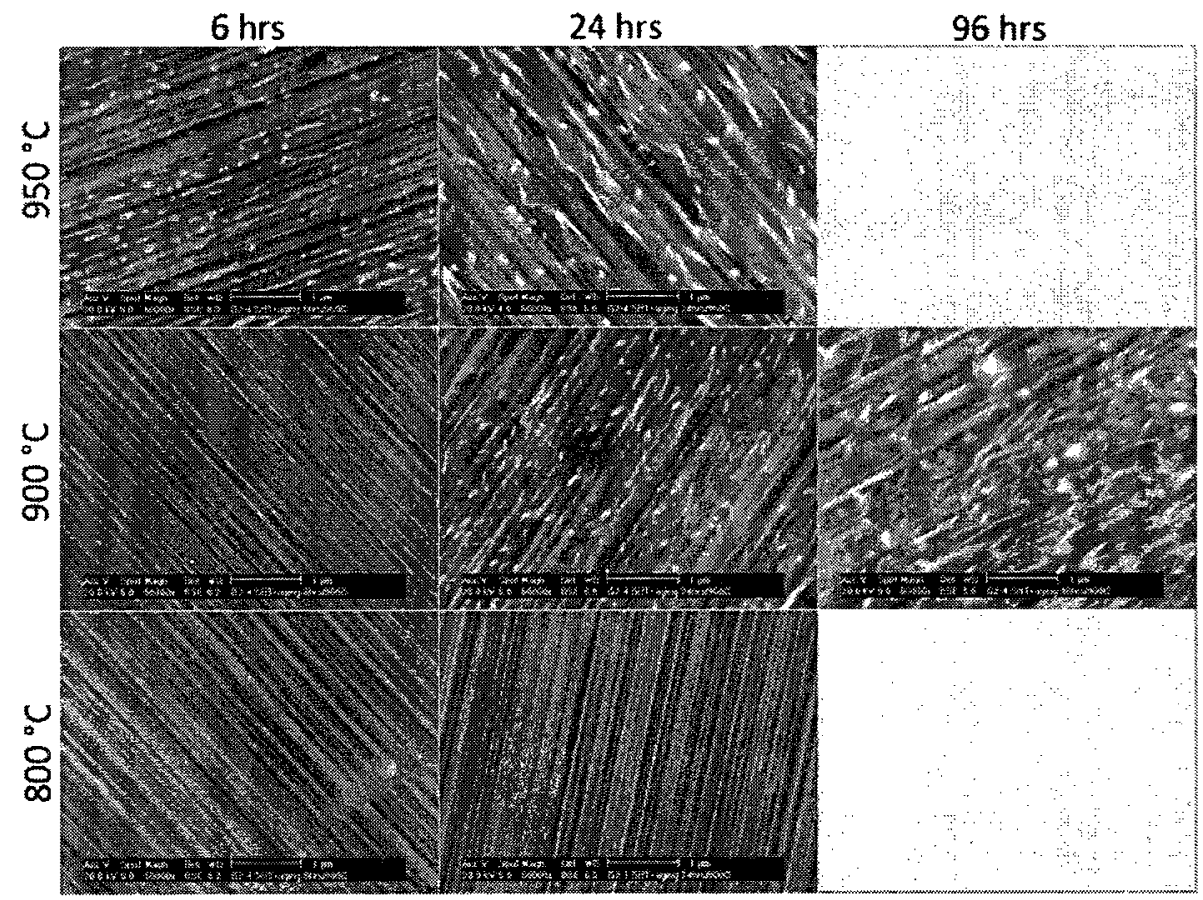

Figure 110. BSE images showing the effect of the aging conditions on the lamellae in alloy G2 (all at 50000x magnification). 


\subsubsection{Aging at $950^{\circ} \mathrm{C}$}

The first aging heat treatment trials were done at $950{ }^{\circ} \mathrm{C}$ for 6 and 24 hours. For both aging times, there was significant grain growth in alloy Gl. The lamellar colonies size ranged from $25 \mu \mathrm{m}$ to $300 \mu \mathrm{m}$, with an average of $150 \mu \mathrm{m}$. Therefore, the lamellar colony size nearly doubled during both the 6 and 24 hours aging heat treatments (average colony size of $\sim 80 \mu \mathrm{m}$ after SCSHT). The mechanism through which the lamellar colonies grew was through discontinuous coarsening, leading to well interlocked grain boundaries, as shown in Figure 111. There is also evidence of lamellar degradation. Figure 112 and Figure 113 show discontinuous $\alpha_{2}$ lamellae, which are the result of lamellar coarsening through the dissolution of the $\alpha_{2}$ lamellae into the $\gamma$ lamellae (black arrows). Furthermore, since the dissolution of the $\alpha_{2}$ lamellae is a time dependent diffusion controlled process, the lamellar structure is more degraded in the 24 hour aged sample than in the 6 hour aged sample. After aging for both 6 and 24 hour durations there was also no evidence of $\beta$ precipitation in alloy $\mathrm{Gl}$ at the colony boundaries or at the lamellar interfaces, as seen in Figure 107 and Figure 109.

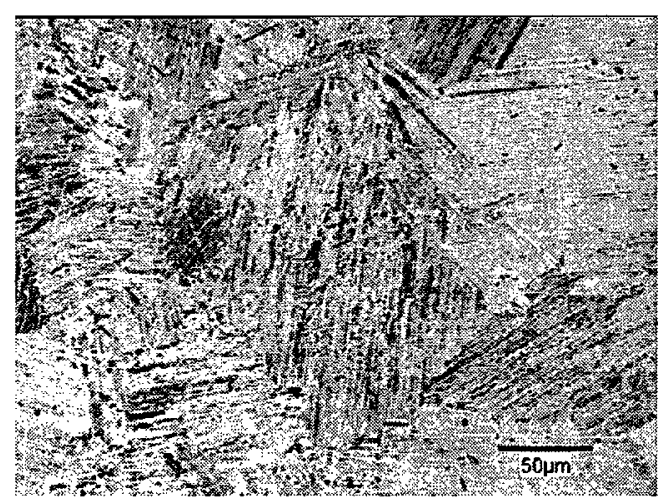

Figure 111. OM micrograph of alloy $\mathrm{G} 1$ aged at $950^{\circ} \mathrm{C}$ for 6 hours showing discontinuous coarsening. 


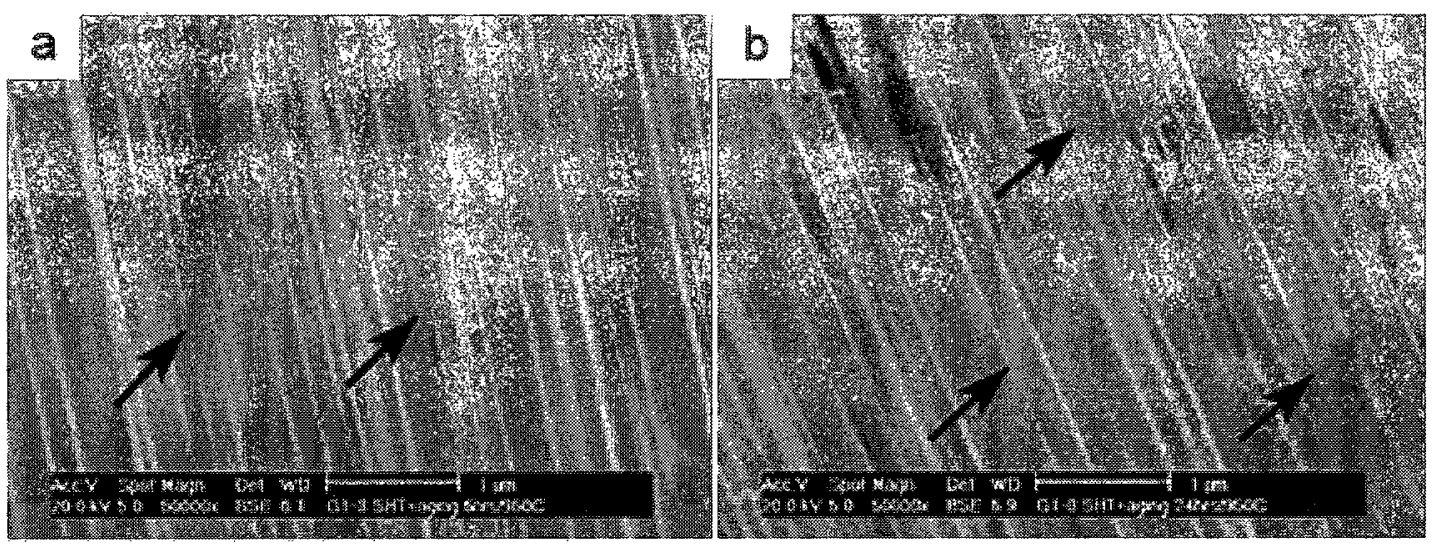

Figure 112. BSE images of alloy G1 aged at $950^{\circ} \mathrm{C}$ for a) 6 hours and b) 24 hours, showing the degraded lamellar structure cause by dissolution of the $\alpha_{2}$ lamellae.

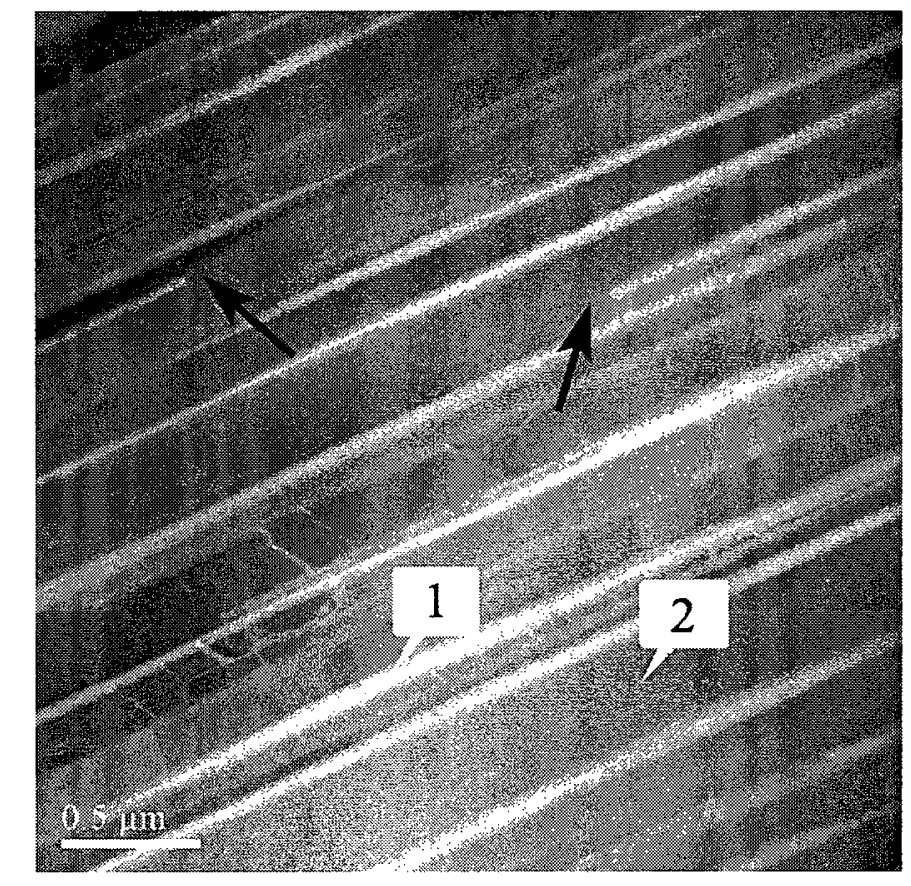

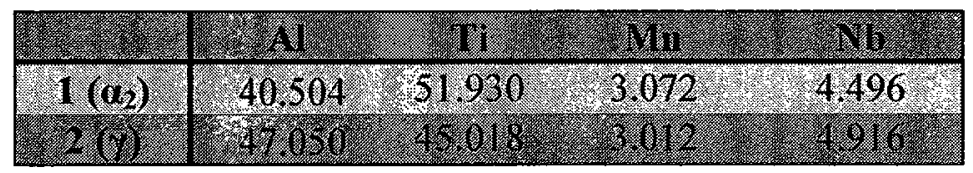

Figure 113. Angular dark field TEM image of alloy $\mathrm{G} 1$ aged at $950^{\circ} \mathrm{C}$ for 24 hours. The bright contrast lamellae are $\alpha_{2}$ and the dark contrast lamellae are $\gamma$. The black arrows indicate discontinuities of the $\alpha_{2}$ lamellae. 
In alloy $\mathrm{G} 2$, however, for both 6 and 24 hour aging times there was a significant amount precipitates at both the lamellar colony boundaries and at the lamellar interfaces, as seen in Figure 108 and Figure 110. STEM-EDS of these fine acicular-shaped precipitates, shown in Figure 114, indicated that they were rich in Ti and Mo. Based on previous research, these precipitates are thought to be the $\beta$ phase $[15,36]$. Similar $\beta$ precipitates in $\mathrm{TiAl}+\mathrm{W}$ alloys are known to form only at the $\alpha_{2} / \gamma$ interfaces at the expense of the $\alpha_{2}$ phase [15,36]. Figure 115 shows the edge-on lamellar structure of alloy $\mathrm{G} 2$ aged at $950{ }^{\circ} \mathrm{C}$ for 6 hours with $\beta$ precipitates having formed only in the $\alpha_{2}$ lamellae. The number of interfacial precipitates did not appear to increase when the aging time was increased from 6 to 24 hours. However, the size of the precipitates did increase substantially. Therefore, there was no further nucleation of interfacial precipitates following the first 6 hours of aging; there was only growth of the pre-existing interfacial precipitates. As mentioned previously, these interfacial $\beta$ precipitates have been shown to improve the primary creep resistance by acting as a barrier to dislocation motion. It has been shown that a larger amount of interfacial $\beta$ precipitates improves the primary creep resistance more effectively [15]. 


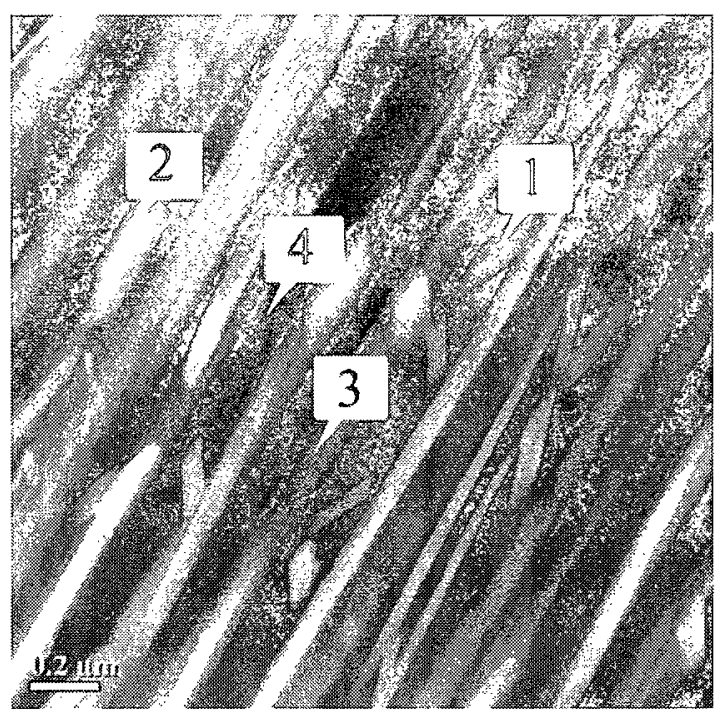

\begin{tabular}{|c|c|c|c|}
\hline & AI 11 & Whe & MT. \\
\hline $1(\beta)$ & $42.81 \quad 4900$ & 219 & 6.00 \\
\hline & $4.5 x$ & 2.11 & \\
\hline $3\left(a_{2}\right)$ & 42.69 & 2.87 & 16 \\
\hline $4(\sqrt{3})$ & $30.50=47.01$ & 2.39 & 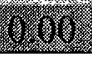 \\
\hline
\end{tabular}

Figure 114. Angular dark field TEM image of alloy G2 aged at $950^{\circ} \mathrm{C}$ for 24 hours with EDS analysis showing that the white precipitates are rich in $\mathrm{Ti}$ and $\mathrm{Mo}$, and are identified as the $\beta$ phase (all in at.\%). The light and dark lamellae are identified as $\alpha_{2}$ and $\gamma$ lamellae, respectivly.

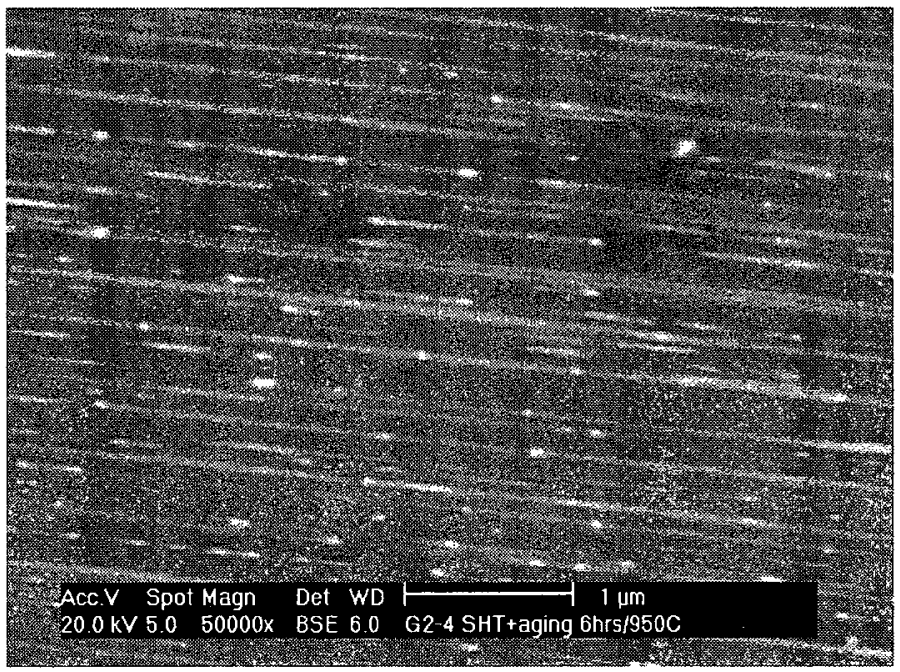

Figure 115. BSE micrograph of alloy $\mathrm{G2}$ aged at $950^{\circ} \mathrm{C}$ for 6 hours showing on-edge lamellar structure with interfacial $\beta$ precipitates formed in the $\alpha_{2}$ lamellae. 
The lamellar colony boundary precipitates were within a $\gamma$ matrix and were much larger and more globular than the interfacial precipitates, as seen in Figure 116. Those that were formed in the sample aged for 24 hours were much larger than those in the sample aged for 6 hours, as shown in Figure 108. Coarse intergranular $\beta$ precipitates have been found to adversely affect the creep properties by leading the early onset of tertiary creep [35]. These coarse precipitates act as nucleation sites for intergranular voids during creep. The voids form at lamellar colony boundaries transverse to the loading direction and coalesce to form crack, ultimately leading to failure $[15,35]$. Therefore, it is critical to the high temperature properties of the alloy that the intergranular $\beta$ precipitates be kept as small as possible.

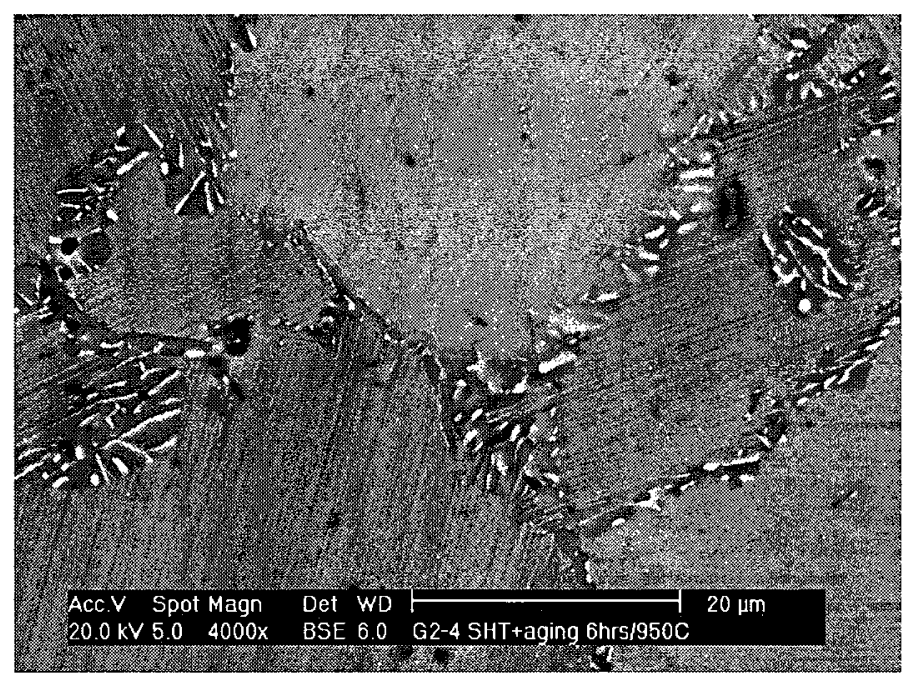

Figure 116. BSE micrograph of alloy $G 2$ aged at $950^{\circ} \mathrm{C}$ for 6 hours showing the $\beta$ phase precipitation at the lamellar colony boundaries.

In contrast to alloy G1, there was no evidence of grain growth in alloy G2 during the aging heat treatment. The average lamellar colony size remained the same as the prior 
SCSHT size of approximately $40 \mu \mathrm{m}$ in diameter. This result suggest that the intergranular $\beta$ precipitates, which only formed in alloy $\mathrm{G} 2$, effectively restricted the grain growth during aging. The mechanism through which these precipitates restrict grain growth can be explained as follows: The fast air cooling following the solution heat treatment results in a metastable fully lamellar microstructure where the interfacial energies are high. The additional energy input at elevated temperatures allows the microstructure to stabilize, which effectively acts as the driving force for microstructural changes during aging. At the lamellar colony boundaries of alloy G2, these high interfacial energies are lowered during aging by the nucleation of the $\beta$ phase rather than through discontinuous coarsening or the formation of equiaxed $\gamma$ grains [36]. In contrast, in alloy G1 there is an insufficient amount of $\beta$ stabilizing elements, therefore discontinuous coarsening is the more favorable mechanism in which to lower the high intergranular energies. Additionally, alloying additions of $\mathrm{Nb}$ and Mo have been found impede grain growth [68]. The resulting small lamellar colony size of alloy G2 would result in improved ductility and strength over more typical large grained ( $>500 \mu \mathrm{m})$ fully lamellar TiAl alloys [34].

Furthermore, the lamellae in alloy G2 appear to be much more stable, showing far less lamellar degradation through the dissolution of the $\alpha_{2}$ lamellae than what was observed in alloy Gl for the same aging conditions. Dissolution of the $\alpha_{2}$ lamellae is partially driven by the emission of interfacial dislocations [35]. However, in alloy G2 the interfacial $\beta$ precipitates hinders dislocation emission and motions thereby retaining the 
lamellar structure [35]. As a result, after aging at $950^{\circ} \mathrm{C}$ for 24 hours, the lamellar spacing is unchanged from that of the solution heat microstructure, which had a very fine spacing of $0.04 \mu \mathrm{m}$. A very fine lamellar spacing has been shown to significantly improve the primary and secondary creep resistance [69].

\subsubsection{Aging at $800^{\circ} \mathrm{C}$}

The next set of aging trials were done at $800{ }^{\circ} \mathrm{C}$ for durations of 6 and 24 hours in an effort to reduce the size and number of intergranular $\beta$ phase precipitates that were observed in alloy $\mathrm{G} 2$ aged at $950{ }^{\circ} \mathrm{C}$, while still precipitating the beneficial interfacial $\beta$ precipitates. The goal was also to minimize the grain growth in alloy Gl and investigate whether there was any stable $\beta$ phase at a lower temperature.

The $800^{\circ} \mathrm{C}$ aged samples of alloy G1 did in fact show some $\beta$ precipitation. Figure 117 shows how $\beta$ phase, as well as $\gamma$ phase, precipitated at the lamellar colony boundary triple points. In addition, Figure 118 shows the formation of very fine $\beta$ precipitates at the boundaries of two adjacent lamellar colonies. The $\beta$ precipitates at both locations in the microstructure were much larger in the 24 hour aged sample than they were in the 6 hour aged sample. The morphology of the $\beta$ phase at the colony boundary triple points, seen in Figure 117, would likely adversely affect the high temperature properties. Since some of the precipitates are relatively large, they lend themselves as possible void nucleation sites. The formation of these $\beta$ precipitates suggests that at $800{ }^{\circ} \mathrm{C}$ alloy $\mathrm{G} 1$ may lie slightly within the three phase $\left(\gamma+\alpha_{2}+\beta\right)$ region of the equilibrium phase diagram. 
However, at only $800{ }^{\circ} \mathrm{C}$, there is insufficient energy to form precipitates at the lamellar interfaces, as shown in Figure 109.

Nevertheless, the colony boundary precipitates may have had a positive effect on the stability of the average lamellar colony size. After 6 hours of aging there is negligible grain growth (still $\sim 80 \mu \mathrm{m}$ in diameter), and after 24 hours of aging there is only a small amount of grain growth to $\sim 110 \mu \mathrm{m}$. However, it is unclear whether the limited grain growth is a result of the lower aging temperature or the formation of the $\beta$ precipitates; it is likely a combination of both factors.
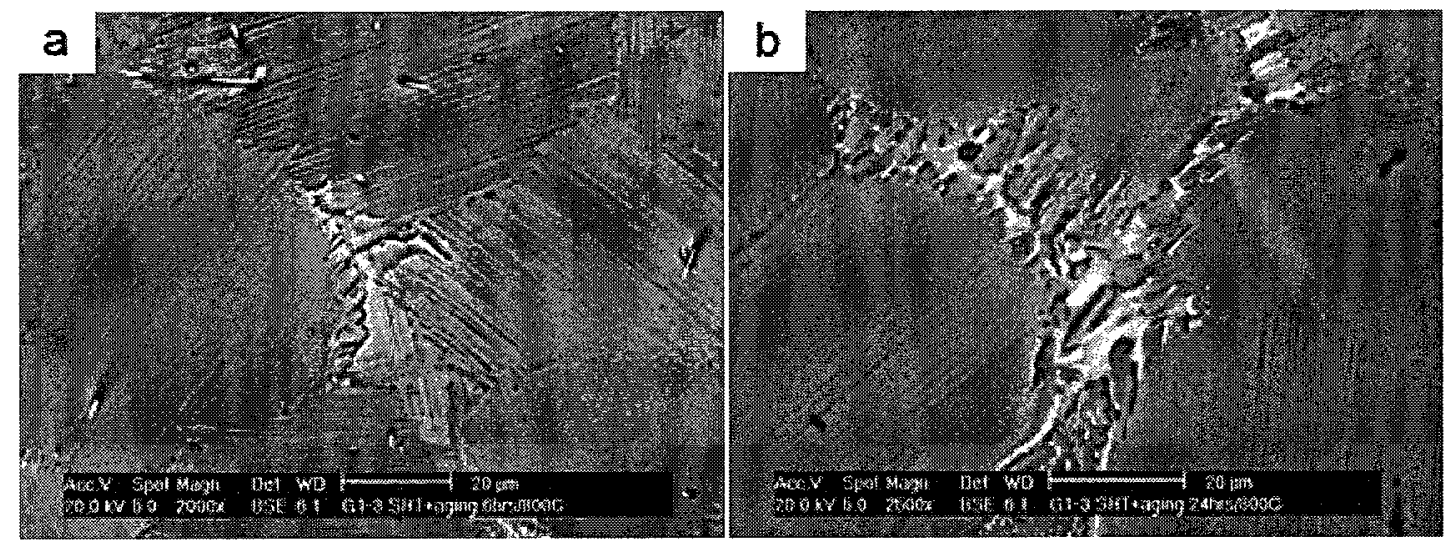

Figure 117. BSE images of alloy G1 aged at $800^{\circ} \mathrm{C}$ for a) 6 hours and b) 24 hours showing the precipitation of the $\beta$ phase at the lamellar colony boundary triple points. 

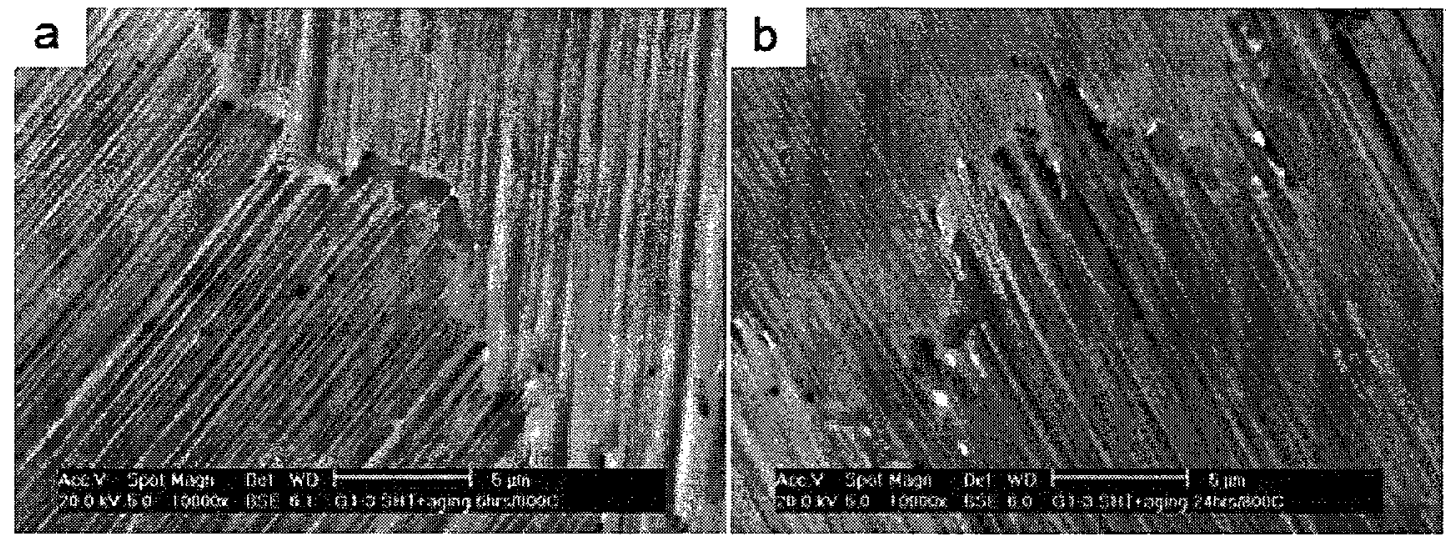

Figure 118. BSE images of alloy G1 aged at $800^{\circ} \mathrm{C}$ for a) 6 hours and b) 24 hours showing the fine $\beta$ precipitates that formed at the boundaries between two adjacent lamellar colonies.

In alloy $\mathrm{G} 2$, there was no increase in the average lamellar colony size during both the 6 and 24 hour aging heat treatments at $800^{\circ} \mathrm{C}$. The average colony size was the same as the prior SCSHT size of approximately $40 \mu \mathrm{m}$ in diameter. The colony size stability was again a result of $\beta$ phase precipitation at lamellar colony boundaries, which are shown in Figure 119. These precipitates are substantially smaller than those formed during aging at $950^{\circ} \mathrm{C}$ (see Figure 108), and would not be likely to adversely affect the creep properties of the alloy. However, the interfacial $\beta$ precipitates that are known to improve the primary creep resistance did not form during aging at $800^{\circ} \mathrm{C}$, as seen in Figure 110 . Therefore, an aging temperature of $800{ }^{\circ} \mathrm{C}$ is too low to develop the desired microstructure of alloy G2. 


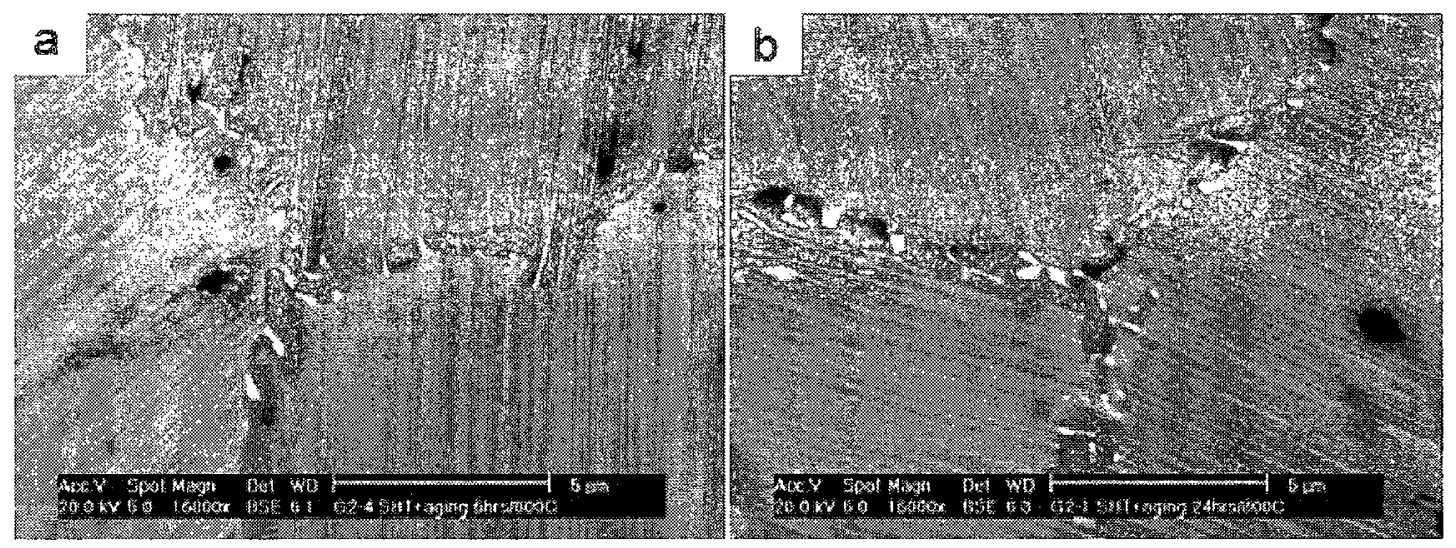

Figure 119. BSE images of alloy $\mathrm{G} 2$ aged at $800{ }^{\circ} \mathrm{C}$ for a) 6 hours and b) 24 hours showing the fine $\beta$ precipitates that formed at the lamellar colony boundaries.

\subsubsection{Aging at $900{ }^{\circ} \mathrm{C}$}

The next set of aging heat treatment trials were at $900{ }^{\circ} \mathrm{C}$ for 6 hours (only alloy G2), 24 hours, and 96 hours. The goal of aging alloy $\mathrm{G} 2$ at $900{ }^{\circ} \mathrm{C}$ was to maintain the fine intergranular $\beta$ precipitates that were seen in the samples aged at $800{ }^{\circ} \mathrm{C}$ while developing the interfacial precipitates that were seen in samples aged at $950^{\circ} \mathrm{C}$. The goal of aging alloy $\mathrm{G} 1$ at $900^{\circ} \mathrm{C}$ was in part to improve the morphology of the intergranular $\beta$ phase that formed at $800{ }^{\circ} \mathrm{C}$. Furthermore, at $900{ }^{\circ} \mathrm{C}$, alloy Gl would hopefully be kept within the three phase region of the equilibrium phase diagram, and the additional energy at that temperature would hopefully activate the formation of interfacial precipitates.

Figure 109 shows that aging alloy G1 for both 24 and 96 hours at $900{ }^{\circ} \mathrm{C}$ did not form $\beta$ precipitates at the lamellar interface. As such, some amount of lamellar coarsening through the dissolution of the $\alpha_{2}$ lamellae was observed. However, $\beta$ phase did 
precipitate at the lamellar colony boundaries. Large globular $\beta$ precipitates formed once again at the lamellar colony boundary triple points, as seen in Figure 120 (shown at higher magnification in Figure 107). The morphology was very similar to that which was observed in the samples aged at $800^{\circ} \mathrm{C}$. Once again, this morphology of $\beta$ precipitates would likely be detrimental to the creep properties.
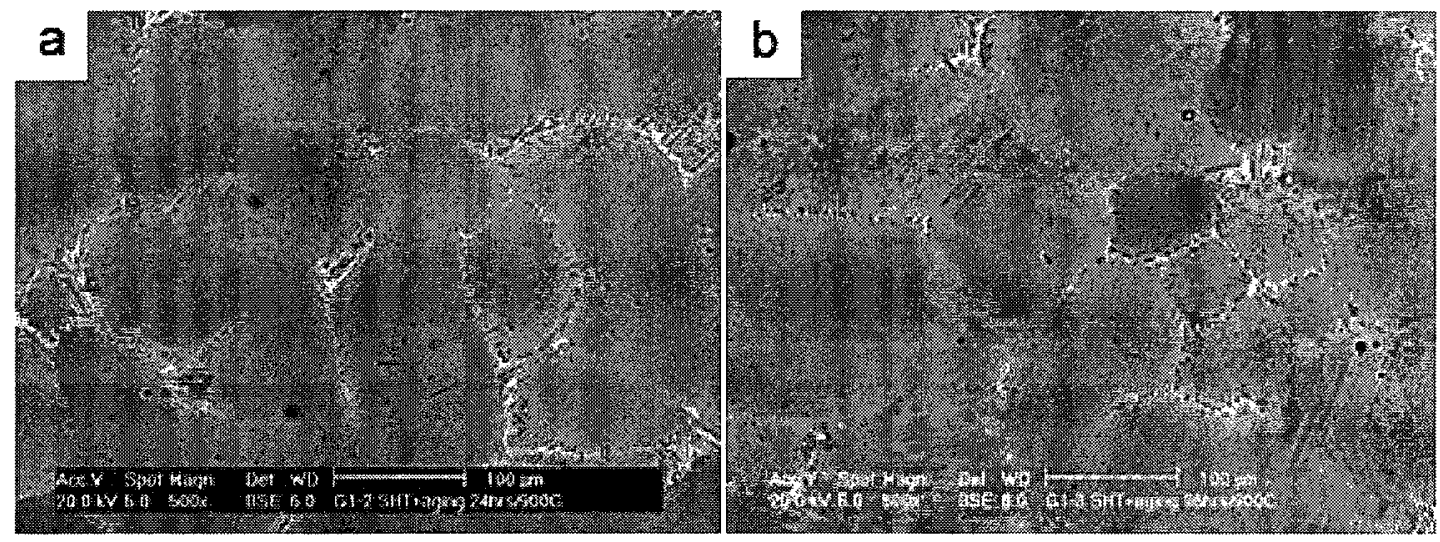

Figure 120. BSE images of alloy G1 aged at $900{ }^{\circ} \mathrm{C}$ for a) 24 hours and b) 96 hours showing the $\beta$ precipitates that formed at the lamellar colony boundary triple points.

The average lamellar colony size of alloy G1 aged at $900^{\circ} \mathrm{C}$ for 6 hours increased from the prior SCSHT size of $\sim 80 \mu \mathrm{m}$ to $\sim 150 \mu \mathrm{m}$. This increase in colony size was the same that was observed in the samples aged at $950^{\circ} \mathrm{C}$, which contained no $\beta$ precipitates. Therefore, the morphology of $\beta$ precipitates observed in samples aged at 800 and $900{ }^{\circ} \mathrm{C}$ did not effectively restrict the grain growth, and it was the decrease in aging temperature that was responsible for the increase grain size stability at $800^{\circ} \mathrm{C}$. However, the average lamellar colony size after 96 hours of aging was approximately the same as they were after aging for 24 hours. This result suggests that the mechanism through which the 
lamellar colonies grew was through the reduction of surface energy by the elimination of the smaller lamellar colonies $(\sim 25 \mu \mathrm{m})$. Once all the small lamellar colonies were consumed by larger ones, which occurred in the first 24 hours, the microstructure was relatively stable. Only a small amount of discontinuous coarsening was observed.

In alloy G2, aging at $900{ }^{\circ} \mathrm{C}$ for 6 hours resulted in a very different intergranular $\beta$ phase morphology. As seen in Figure 121, the $\beta$ phase morphology is a near solid $\beta$ grain lying at the lamellar colony boundary triple points, rather than fine individual precipitates along all colony boundaries. Initial suspicions that something had gone wrong during the heat treatment process were dispelled when a second attempt at the heat treatment resulted in exactly the same $\beta$ phase morphology. As a result of the soft nature of the $\beta$ phase at elevated temperature, this $\beta$ phase morphology would likely result in severely weakened grain boundaries at high temperatures leading to higher strain rates during creep. Furthermore, only extremely fine $\beta$ precipitates had formed at the lamellar interfaces as shown in Figure 110. The very small size of these precipitates may limit their effectiveness at blocking dislocation motion and thus improving the primary creep resistance.

Interestingly though, after aging for 24 hours and 96 hours, the $\beta$ phase morphologies were very different than they were after aging for 6 hours, as seen in Figure 122. After aging for 96 hours at $900{ }^{\circ} \mathrm{C}$ the intergranular $\beta$ precipitates resembled those that were observed in the sample aged at $950{ }^{\circ} \mathrm{C}$ for 24 hours. The large globular $\beta$ precipitates, 
shown at higher magnification in Figure 123, would limit the high temperature properties of the alloy by serving as sites for void nucleation. However, the intergranular $\beta$ precipitates that formed in the sample aged for 24 hours at $900{ }^{\circ} \mathrm{C}$ were relatively fine in comparison. In fact, they were also fine in comparison to those observed in the samples aged at $950{ }^{\circ} \mathrm{C}$ (see Figure 108). It is possible that these intergranular $\beta$ precipitate are small enough as to not adversely affect the creep properties. In addition, after aging for $900{ }^{\circ} \mathrm{C}$ for 24 hours a good number of well sized $\beta$ precipitates had formed at the lamellar interfaces, as shown in Figure 124. In the sample aged for 96 hours, there appeared to be a similar number of larger sized interfacial $\beta$ precipitates (see Figure 115). The microstructural stability of alloy $\mathrm{G} 2$ at $900^{\circ} \mathrm{C}$ was also evident. After aging for 96 hours the grain size did not increase. In considering that under the same aging conditions the grain size in alloy G1 increased from $\sim 80$ to $\sim 150 \mu \mathrm{m}$, the finer, more evenly distributed grain boundary $\beta$ precipitates in alloy G2 were significantly more effective at inhibiting coarsening.

Based on these results, alloy G2 aged at $900{ }^{\circ} \mathrm{C}$ for 24 hours resulted in the best combination of interfacial and intergranular $\beta$ phase precipitates. 

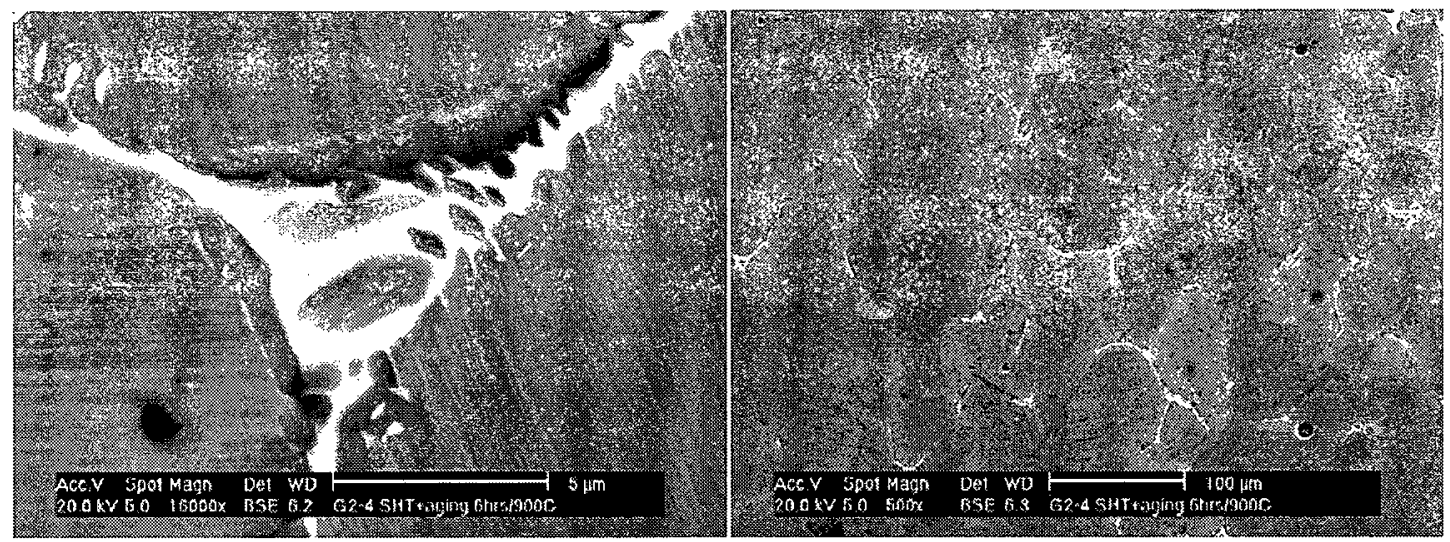

Figure 121. BSE images of alloy $\mathrm{G} 2$ aged at $900{ }^{\circ} \mathrm{C}$ for 6 hours showing the $\beta$ phase that formed at the lamellar colony boundaries.
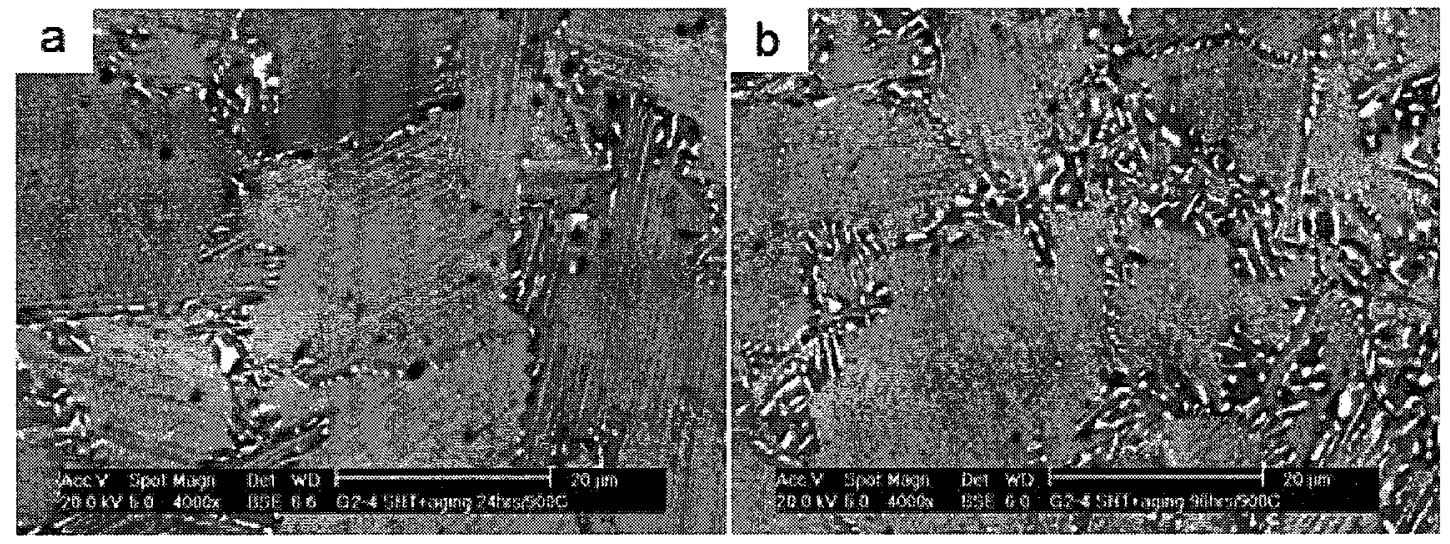

Figure 122. BSE images of alloy G2 aged at $900^{\circ} \mathrm{C}$ for a) 24 hours and b) 96 hours showing the formation of intergranular $\beta$ precipitates. 


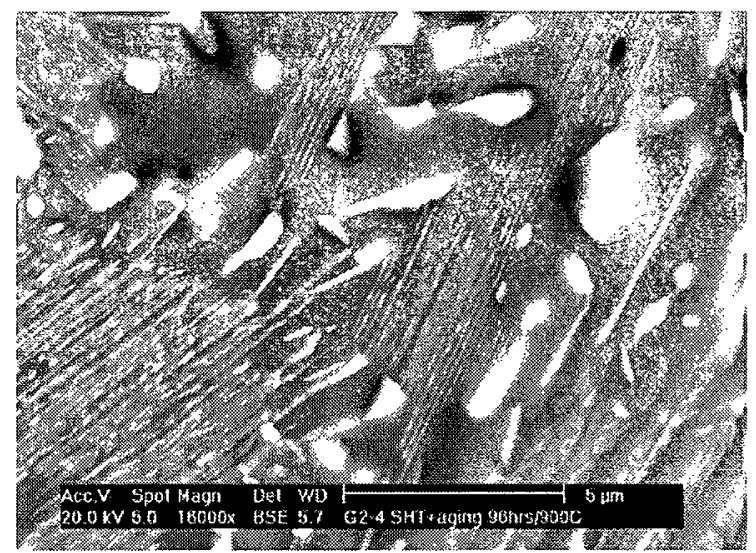

Figure 123. BSE micrograph of alloy $\mathrm{G} 2$ aged at $900{ }^{\circ} \mathrm{C}$ for 96 hours showing the $\beta$ phase that formed at the lamellar colony boundaries.

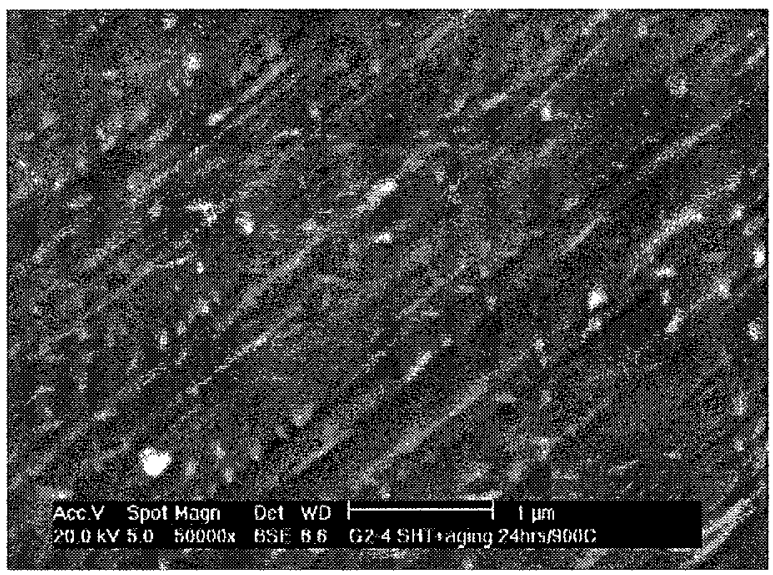

Figure 124. BSE micrograph of alloy $\mathrm{G} 2$ aged at $900^{\circ} \mathrm{C}$ for 24 hours showing the formation of $\beta$ precipitates at the lamellar interfaces.

\subsubsection{Microhardness Data}

The hardness of the lamellar structure of the aged samples was measured. Figure 125 shows the microhardness of alloys G1 and G2 aged at $800^{\circ} \mathrm{C}$. The aging time of 0 hours corresponds to the SCSHT condition. After aging for 6 hours, it can be seen that the hardness of the lamellar structure in alloy G1 drops. This initial drop can be associated 
with the degradation of the lamellar structure [37]. After aging for 24 hours, the softening effects of lamellar degradation are counteracted by solid solution strengthening of the $\gamma$ phase, resulting in an increase in the hardness. For the $\alpha_{2} \rightarrow \gamma$ transformation to proceed, which occurs during dissolution of the $\alpha_{2}$ lamellae, the $\alpha_{2}$ phase must return to a more stoichiometric composition. As a result, the alloying elements such as $\mathrm{Nb}$ and $\mathrm{Mn}$ are rejected into the surrounding $\gamma$ phase [37]. These elements, $\mathrm{Nb}$ in particular, are very effective solid solution strengtheners $[3,17,28]$. The microhardness of alloy G2, on the other hand, increases with aging time. This increase may be a result of solid solution strengthening with a negligible amount of lamellar degradation. The increase in hardness could also be a result of some degree of precipitation hardening. It is possible that some very small $\beta$ particles, which cannot be seen in the SEM, precipitated at the lamellar interfaces.

Figure 126 shows the measured microhardness of the samples aged at $900{ }^{\circ} \mathrm{C}$. After 24 hours of aging, the microhardness of alloy G1 drops significantly. This initial drop, which resembles that which occurred during aging at $800^{\circ} \mathrm{C}$, can once again be attributed to the degradation of the lamellar structure. The drop is more severe than what was observed in the samples aged at $800{ }^{\circ} \mathrm{C}$ since at the higher temperature the degradation of the lamellar structure is more pronounced and occurs more rapidly. Further aging up to 96 hours results in a very slight increase in hardness due to the effects of solid solution strengthening mentioned previously. After 6 hours of aging, the microhardness of alloy G2 also had an initial drop. However, the drop in hardness was not as severe as what was 
observed in alloy G1. The interfacial $\beta$ phase precipitates that form in alloy G2 during aging retard lamellar degradation and coarsening and therefore minimizes the initial drop in hardness [37]. Further aging up to 24 hours results in very little change in the microhardness. Similarly, after 96 hours of aging, the hardness increases only very slightly. Between 6 and 96 hours of aging, the solid solution strengthening effects are in balance with the softening effects of lamellar degradation.

Interestingly, the hardening rates of both alloy G1 and G2 between 24 and 96 hours of aging at $900{ }^{\circ} \mathrm{C}$ are very similar. This result suggests that the interfacial precipitates that only form in alloy G2 only minimize the initial drop in hardness and have very little effect thereafter. Alternatively, the similar hardening rates could be related to the different alloying elements in each alloy. Niobium has been found to be a very effective solid solution strengthener $[3,17,28]$. Alloy G1 contains 4 at.\% $\mathrm{Nb}$, whereas alloy $\mathrm{G} 2$ only contains 2 at.\% $\mathrm{Nb}$. Therefore, the higher $\mathrm{Nb}$ content in alloy $\mathrm{G} 1$ may be counteracting a faster and more pronounced lamellar degradation. In alloy G2, solid solution strengthening is not as essential to maintain the hardness since the interfacial precipitates resist lamellar degradation.

Figure 127 shows the measured microhardness for the samples aged at $950{ }^{\circ} \mathrm{C}$. It can be seen that both alloys G1 and G2 show an initial drop in microhardness. Similarly to the other aging temperatures, the initial drop in the hardness in alloy G2 is less severe than it is in alloy $G 1$ due to the formation of interfacial $\beta$ precipitates, which resist 
lamellar degradation. Further aging up to 24 hours results in a decrease in hardness in both alloys. This result suggests that softening through lamellar degradation dominates over the hardening effects of solid solution strengthening in both alloys.

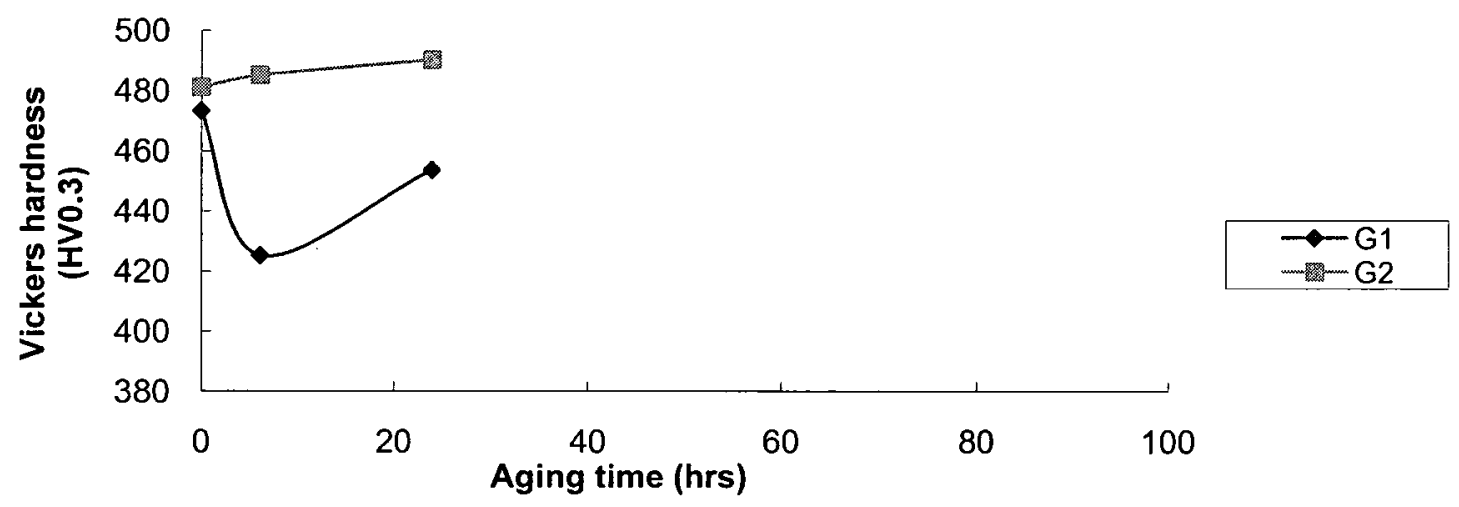

Figure 125. The effect of aging at $800^{\circ} \mathrm{C}$ on the lamellar grain microhardness.

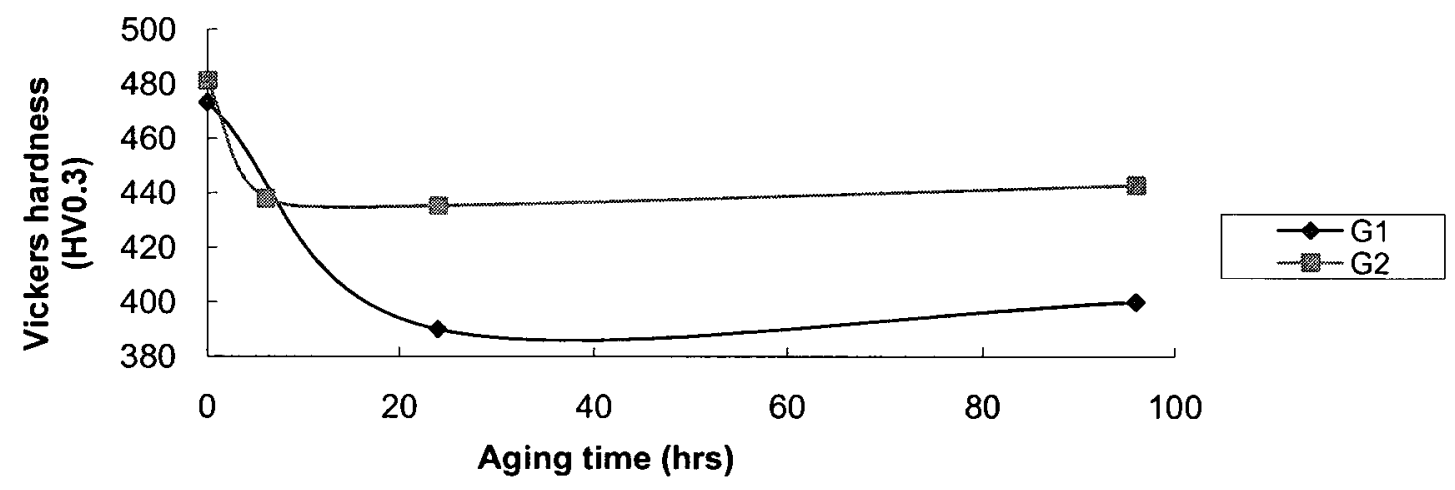

Figure 126. The effect of aging at $900^{\circ} \mathrm{C}$ on the lamellar grain microhardness. 


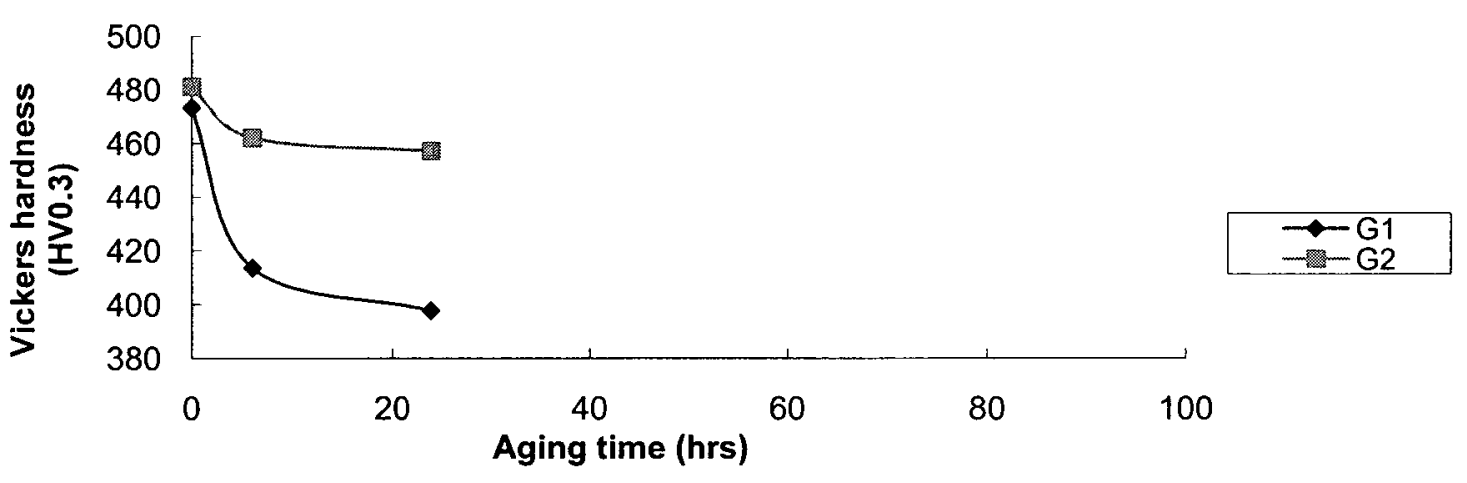

Figure 127. The effect of aging at $950^{\circ} \mathrm{C}$ on the lamellar grain microhardness.

\subsubsection{Summary}

The purpose of the aging heat treatments was to stabilize the lamellar structure and to form fine $\beta$ precipitates at the lamellar interfaces. Interfacial $\beta$ precipitates have been shown to significantly improve the primary creep resistance of a TiAl alloy by hindering dislocation emission and motion.

For alloy G1, the aging heat treatments did not result in any interfacial $\beta$ precipitates. Aging at $950^{\circ} \mathrm{C}$ resulted in severe grain growth through discontinuous coarsening and also resulted in lamellar degradation through the dissolution of the $\alpha_{2}$ lamellae. Aging at $800{ }^{\circ} \mathrm{C}$ and $900{ }^{\circ} \mathrm{C}$ resulted in the formation of large globular $\beta$ particles at the colony boundaries. This type of $\beta$ phase morphology has been shown to detrimentally affect the creep properties by acting as void initiation sites leading to a more rapid onset of tertiary creep $[15,35]$. The results of the aging trials on Alloy G1 suggest that the SCSHT microstructure may result in the best high temperature properties. 
For alloy G2, fine acicular interfacial $\beta$ precipitates formed during aging at $900{ }^{\circ} \mathrm{C}$ and $950{ }^{\circ} \mathrm{C}$. The size of the precipitates increased with aging time. However, the number of precipitates appeared to be unchanged when the aging time was increased. It was found that the interfacial precipitates improved the stability of the lamellar structure. In comparison to alloy G1, which contained no interfacial precipitates, there was significantly less lamellar degradation during aging. The microhardness results confirm that the lamellar degradation in alloy G1 is more severe since the initial drop in hardness in much larger than it is in alloy G2. With limited lamellar coarsening, the very fine lamellar spacing in alloy G2 would offer improved primary and secondary creep resistance.

Larger more globular $\beta$ precipitates also formed at the colony boundaries for most aging conditions. These precipitates appeared to increase in number and size with increasing aging temperature and time. These intergranular precipitates are detrimental to the high temperature properties since they can act as void initiation sites leading to a more rapid onset of tertiary creep. Therefore, it is imperative that they be kept as small as possible. The intergranular precipitates that formed during aging at $950{ }^{\circ} \mathrm{C}$ were likely too large and would significantly reduce the creep life. However, since almost no grain growth was observed in alloy G2 during aging, it is thought that the intergranular precipitates may effectively restricted grain growth. The small average lamellar colony size would offer improved ductility over a typical large grained fully lamellar TiAl alloy. 
For alloy G2, it was determined that aging at $900{ }^{\circ} \mathrm{C}$ for 24 hours resulted in the best microstructure for high temperature applications. At this aging condition, there was a combination of a large number well sized interfacial precipitates and relatively small intergranular precipitates. 


\section{Summary and Conclusions}

\section{Hot Isostatic Pressing (HIP)}

1) The cooling rate from the HIP temperature between the range of $3.0^{\circ} \mathrm{C} / \mathrm{min}$ to $17.5^{\circ} \mathrm{C} / \mathrm{min}$ has no effect on the $\beta$ phase volume fraction in both alloys.

2) The HIP temperature did not have a significant effect on $\beta$ phase volume fraction in alloy G1.

3) The HIP temperature did have an effect on volume fraction of the $\beta$ phase in alloy G2. The $\beta$ phase volume fraction decreased linearly from 9.5 vol. $\%$ when HIP'ed at $1200{ }^{\circ} \mathrm{C}$ to 3.8 vol. $\%$ when HIP'ed at $1300{ }^{\circ} \mathrm{C}$.

4) The lower HIP temperature of $1200{ }^{\circ} \mathrm{C}$ resulted in some grain size inhomogeneities. Increasing the HIP time from 2 to 4 hours had no improvement. Two different stepHIP processes were developed that maintained the same amount of $\beta$ phase as the $1200{ }^{\circ} \mathrm{C}$ HIP'ed sample $(\sim 10$ vol.\%), but with improved grain size homogeneity. However, the overall grain size increased from $2 \mu \mathrm{m}$, which was observed in samples HIP'ed at $1200^{\circ} \mathrm{C}$, to $4 \mu \mathrm{m}$.

5) Alloy G1 is likely not ideal for hot working as a result of the limited amount of $\beta$ phase present in the microstructure. The composition of alloy G1 does not contain an adequate amount of $\beta$ stabilizing alloying additions or a sufficiently low aluminum content to allow the $\beta$ phase to be stable at room temperature.

6) Alloy G2 HIP'ed at $1200{ }^{\circ} \mathrm{C}$ and both step-HIP processes, which have $\sim 10$ vol.\% $\beta$ phase evenly dispersed in the microstructure and a very fine grain size $(2-4 \mu \mathrm{m})$, results in microstructures that could offer excellent hot workability. 


\section{Step Cooled Solution Heat Treatments (SCSHT)}

1) For both alloys, the step cooled solution heat treatment with a furnace to air cool transition temperature of $1280{ }^{\circ} \mathrm{C}$ successfully produced a fully lamellar microstructure with a minimal amount of $\beta$ phase.

2) Both alloys have very fine SCSHT microstructures. The very small lamellar colony size would offer good strength and ductility.

\section{Aging Heat Treatments}

1) The aging heat treatments of alloy Gl did not result in any $\beta$ phase precipitates at the lamellar interfaces. The step cooled solution heat treated microstructure of alloy G1 may result in superior creep properties over the aged microstructure since aging caused a significant amount of lamellar degradation.

2) The $900{ }^{\circ} \mathrm{C}$ and $950{ }^{\circ} \mathrm{C}$ aging heat treatments produced fine acicular $\beta$ precipitates at the lamellar interfaces of alloy G2. The size of the precipitates increased with both aging temperature and time. These precipitates have been shown to improve the primary creep resistance of PM gamma TiAl alloys.

3) Large globular $\beta$ phase precipitates formed in alloy G2 for all aging conditions and increased in size and number for increasing aging temperature and time. These precipitates must be kept as small as possible since large intergranular precipitates are detrimental to the creep properties.

4) The precipitates at the lamellar interfaces in alloy G2 reduce lamellar degradation during aging. 
5) The precipitates at the colony boundaries in alloy G2 hinder grain growth during aging.

6) Aging alloy $\mathrm{G} 2$ at $900{ }^{\circ} \mathrm{C}$ for 24 hours appears to produce the best microstructure for high temperature applications. At this aging condition, the interfacial precipitates appear to have an optimum size and distribution, which have been shown to improve the primary creep resistance of $\mathrm{TiAl}$ alloys effectively, while the intergranular precipitates appear to be small enough as to not adversely affect the creep properties.

\subsection{Future Work}

In this thesis, the optimum HIP conditions and heat treatments for two PM beta gamma TiAl alloys have be determined based on microstructural characterization. However, it is essential that the results be confirmed through mechanical testing. Hot working trials of the as-HIP'ed samples, as well as tensile and creep tests of the SCSHT and aged samples are required to establish a greater understanding of the effects of various microstructural features.

The hot working trials should include either hot forging or hot rolling. The effects of both hot working temperature (between $1000^{\circ} \mathrm{C}$ and $1300^{\circ} \mathrm{C}$ ) and strain rates (between $10^{-2} \mathrm{~s}^{-1}$ and $1 \mathrm{~s}^{-1}$ ) should be investigated for total strains of $\sim 70 \%$. The measured flow stress as well as inspection for surface cracks would be used to evaluate the hot workability of the alloys as well as to develop the optimum hot working conditions. The 
hot working trials should also be used to investigate the effects of the various HIP conditions on the hot workability of the alloys. In particular, the trials should compare the hot workability of samples HIP'ed at $1200{ }^{\circ} \mathrm{C}$ to those HIP'ed using the step-HIP processes in order to determine the effects of grain size inhomogeniety and establish the optimum HIP conditions for each alloy.

Room temperature tensile tests should be done to compare the strength and ductility of the fine grained fully lamellar structures of the SCSHT and aged microstructures to each other and to that of a coarse grained fully lamellar conventional gamma TiAl alloy. It is expected that the fine microstructural scale of the two beta gamma alloys being studied should result in enhanced strength and ductility. The tensile tests would also elucidate the effects of interfacial and intergranular $\beta$ phase precipitates on strength and ductility.

Creep testing is essential to determine the legitimacy of beta gamma TiAl alloys for use in high temperature applications. These tests would also be used to evaluate the effects of the interfacial and intergranular $\beta$ phase precipitates on the high temperature properties. The creep properties of the SCSHT samples and the sample aged at various conditions could also be compared to confirm the optimum heat treating conditions. Additionally, creep testing at $760{ }^{\circ} \mathrm{C}$ and $276 \mathrm{MPa}$ would allow a comparison to a Ti-48Al-2Cr-2Nb $+x W$ (modified GE alloy) alloy that can be processed to contain similar $\beta$ phase precipitates. 


\section{References}

1 M. Peters, J. Kumpfert, C. H. Ward, C. Leyens. "Titanium Alloys For Aerospace Applications." Adv. Eng. Mater. 5, pp. 419-427, 2003.

2 A. Lasalmonie. "Intermetallics: Why is it so difficult to introduce them in gas turbine engines?" Intermetallics 14, pp. 1123-1129, 2006.

$3 \mathrm{X}$. Wu. "Review of alloy and process development of TiAl alloys." Intermetallics 14, pp. 1114-1122, 2006.

4 G. Lutjering, J.C. Williams. "Titanium Based Intermetallics," in Titanium: Engineering Materials and Processes, 3rd ed. Ed. Germany: Springer, 2007

5 D. J. Jarvis, D. Voss. "IMPRESS Integrated Project - An overview paper," Mater. Sci. Eng $A$, vol. 413-414, pp. 583-591, 2005.

$6 \mathrm{Y}-\mathrm{W}$. Kim, "Trends in the development of gamma TiAl alloys," Proceedings of the First Symposium on Gamma Titanium Aluminides, pp. 637-654, 1995.

7 P.A. Bartolotta, D.L. Krause. "Titanium aluminide applications in the high speed civil transport," Proceedings of the Symposium on Gamma Titanium Aluminides, pp. 3-10, 1999.

8 P.Bartolotta, J. Barrett, T. Kelly, R. Smashey. "The Use of Cast Ti-48Al-2Cr-2Nb in Jet Engines." JOM, pp. 48-51, 1997

9 P.A. McQuay, R. Simpkins, D.Y. Seo, T.R. Bieler, Proceedings of the Symposium on Gamma Titanium Aluminides, pp. 197-207, 1999.

10 A. Gilchrist, T.M. Pollock. "Cast gamma titanium aluminides for low pressure turbine blades: a design case study for intermetallics." in proceedings of the Symposium on Structural Intermetallics, 2001, pp. 3-12.

11 "GE Aviation", Internet: www.geae.com. [Oct. 16, 2009].

12 E. A. Loria. "Quo vadis gamma titanium aluminide." Intermetallics 9, pp. 997-1001, 2001.

13 R. Imayev, V. Imayev, T. Khismatullin, T. Oleneva. "Development of multiphase $\beta$ solidifiying $\gamma$-TiAl alloys with enhanced mechanical properties," Proceedings of the Symposium on Gamma Titanium Aluminides, pp. 239-247, 2008.

14 S.C. Huang, J.C. Chesnutt. "Gamma TiAl and its Alloys," in Intermetallic compounds: Principles and Practice, vol. 2. J.H. Westbrook and R.L. Fleischer, Ed. Chichester: John Wiley \& Sons, 1995, pp. 73-90.

15 H. Saari, S. Bulmer, D.Y. Seo, P. Au. "Microstructures and creep properties of powder metallurgy Ti-48Al-2Cr-2Nb+W," Proceeding from ASME Turbo Expo 2007: Power for Land, Sea, and Air, 2007 
16 Y-W. Kim, S-L. Kim, D.M. Dimiduk, C. Woodward. "Development of beta/ $\gamma$ Ti alloys," presented at the International Workshop on Gamma Alloy Technology, Bamberg, Germany, 2006

17 R. Gerling, H. Clemens, F.P. Schimansky: "Powder metallurgy processing of intermetallic gamma titanium aluminides," Adv. Eng. Mater. 6, No. 1-2 (2004), pp23-38

18 Y-W. Kim, "Advances in gamma alloy technology," presented at ASM/TMS Spring Symposium, Niskayuna, NY, 2005

19 T. Tetsui. "Effects of high niobium additions on the mechanical properties and hightemperature deformability of gamma TiAl alloy." Intermetallics 10, pp.239-245, 2002.

20 C. Suryanarayana, F.H. Froes, R.G. Rowe. "Rapid Solidification of Ti-Alloys." Int. Materials Reviews, vol. 36. No. 3, pp. 85-123

21 F.H. Froes, C. Suryanarayana. "Titanium Aluminides," in Physical Metallurgy and Processing of Intermetallic Compounds. N.S. Stoloff and V.K. Sikka, Ed. New York: Chapman \& Hall, 1996, pp. 297-350.

22 C. McCullough, J.J. Valencia, C.G. Levi, R. Mehrabian. "Phase Equilibria and solidification in Ti-Al Alloys." Act Metall, Mater., vol. 37, No. 5, pp. 1321-1336, 1989.

23 M.E. Hyman, C. McCullough, J.J. Valencia, C.G. Levi, R. Mehrabian. "Microstrcutural Evolution in TiAl alloys with B additions: conventional Solidification." Met. Trans., vol. 20A, pp. 1847-1859, 1989.

24 J.J. Valencia, C. McCullough, C.G. Levi, R. Mehrabian. "Solidification microstrcutres of supercooled Ti-Al alloys containing intermediate phases." Acta, Metall. Mater., vol. 37, No. 9, pp. 2517-2530, 1989.

25 S. Azad, R.K. Mandal, A.K. Singh. "Effect of Mo additions on the transformation beharior of $\left(\alpha_{2}+\gamma\right)$ based Ti-Al alloys." Mater. Sci. Eng. A, vol. 429, pp. 219-224, 2006.

26 J.H Perepzko, H.A. Lipsitt. "Update on binary and ternary phase diagrams," presented at ASM Aeromat '91, Long Beach, 20-23, May 1991.

27 F. Appel and M. Oehring. "Gamma-Titanium Aluminide Alloys: Alloy Design and Properties," in Titanium and Titanium Alloys; Fundamentals and Applications, C. Leyens and M. Peters, Eds. Weinheim, Germany: Wiley-VCH GmbH \& Co. KGaA, 2003.

28 F. Appel, U. Brossmann, U. Christoph, S. Eggert, P. Janschek, U. Lorenz, J. Müllauer, M. Oehring, J.D.H. Paul. "Recent progress in the development of gamma titanium aluminide alloys." Adv. Eng. Mater., vol. 2, No. 11, pp. 699-720, 2000. 
29 H. Saari. "The Processing of Gas Turbine Engine Hot Section Materials Through Directional Solidification.” M. A. Sc. thesis, Carleton University, Ottawa, Ontario, Canada, 1999.

30 J. Beddoes, W. Wallace, and L. Zhao. "Current Understanding of Creep Behaviour of Near Gamma-Titanium Aluminides." International Materials Reviews, vol. 40, pp. 197-217, 1995.

31 C.M. Austin, T.J. Kelly. "Gas turbine Engine Implementation of gamma titanium aluminide," presented at Superalloys 1996.

32 S. Bulmer. "The Microstructures and Mechanical Properties of Powder Metallurgy (PM) Ti-48Al-2Cr-2Nb-(0-1)W.” M. A. Sc. thesis, Carleton University, Ottawa, Ontario, Canada, 2008.

33 S-C. Huang, D.S. Shih. "Microstructure-property correlation in TiAl-base alloys," in Titanium Aluminide Alloys, pp. 105-122, 1991.

34 Y-W. Kim. "Strength and ductility in TiAl alloys." Intermetallics 6, pp. 623-628, 1998.

35 D.Y. Seo, H. Saari, P. Au, J. Beddoes. "Microstructure and creep of gamma TiAl containing $\beta$ stabilizer." Mater. Sci. For., vols. 539-543, pp. 1543-1548, 2007.

36 S. Bulmer, H. Saari, D.Y. Seo, P. Au, P. Patnaik. "The effect of heat treatments on the microstructure of Ti-48Al-2Cr-2Nb-Xw." Aerospace Materials and Manufacturing: Emerging Materials, Processes, and Repair Techniques, Met Soc, pp.135-146, 2006.

37 D.Y. Seo, S. Bulmer, H. Saari, P. Au. "Microstructure and mechanical properties of Ti-48Al-2Cr-2Nb-xW." Mater. Sci, For., vol. 561-565, pp. 481-486, 2007.

38 S. Li, X. Su, Y. Han, X. Xu, G. Chen. "Simulation of hot deformation of TiAl based alloy containing high Nb." Intermetallics 13, pp. 323-328, 2005.

39 X.J. Xu, J.P. Lin, Y.L. Wang, J.F. Gao, Z. Lin, G.L. Chen. "Effect of forging on microstructure and tensile properties of Ti-45Al-(8-9)Nb-(W,B,Y) alloy." Alloys and Compounds 414, pp. 175-180, 2006.

40 J.S. Kim, Y.H. Lee, Y-W. Kim, C.S. Lee. "High temperature deformation behavior of beta gamma TiAl alloy." Mater. Sci. For., vol. 539-543, pp. 1531-1536, 2007.

41 N. J. Rubinstein. (2007, July). "Rutland GE Plant Expands: Addition Will Allow Manufacture Of New GEnx Engine Blades." Rutland Business Journal. [On-line]. Available: http://vermonttoday.com/apps/pbcs.dll/article?AID=/20070701/RBJ/7080 2007/-1/RBJ02 [Oct. 16, 2009] 
42 W. Smarsly, H. Baur, G. Glitz, H. Clemens, T. Khan, M. Thomas. "Titanium aluminides for automotive and gas turbine applications." in proceedings of the Symposium on Structural Intermetallics, 2001, pp. 25-34

43 F. Appel, M. Oehring, J.D.H. Paul, Ch. Klinkenberg, T. Carneiro. "Physical aspects of hot-working gamma-based titanium aluminides." Intermetallics 12, pp. 791-802, 2004.

44 T. Tetsui, K. Shindo, S. Kobayashi, M Takeyama. "A newly developed hot worked TiAl alloy for blades and structural components." Scr. Mater. 47, pp. 399-403, 2002.

45 T. Tetsui, K. Shindo, S. Kaji, S. Kobayashi, M. Takeyama. "Fabrication of TiAl components by means of hot forging and machining." Intermetallics 13, pp. 971-978, 2005.

46 Y.H. Wang, J.P. Lin, Y.H. He, Y.L. Wang, G.L. Chen. "Microstructures and mechanical properties of $\mathrm{Ti}-45 \mathrm{Al}-8.5 \mathrm{Nb}-(\mathrm{W}, \mathrm{B}, \mathrm{Y})$ alloy by SPS-HIP route." Mater. Sci. and Eng. A, vol 489, pp. 55-61, 2008.

47 L.M. Hsiung, T.G. Nieh. "Microstructures and properties of powder metallurgy TiAl alloys." Mater. Sci. and Eng., vol. 364, pp. 1-10, 2004.

48 J. Beddoes, "The Processing of Powder Metallurgically Produced Near- $\gamma$ TiAl alloys." PhD thesis, Carleton University, Ottawa, Ontario, Canada, 1993.

49 C. McCullough, J.J. Valencia, C.G. Levi, R. Mehrabian. "Microstructural analysis of rapidly solidified TiAl-X powders." Mat. Sci. Eng., vol. A124, pp. 83-101, 1990.

50 J.A. Graves, J.H. Perepezko, C.H. Ward, F.H. Froes. "Microstructural development in rabidly solidified TiAl.” Scr. Metall. Mater., vol. 21A, No. 4, pp. 567-572, 1987.

51 A.S. Helle, K.E. Easterling, M.F. Ashby. "Hot Isostatic pressing Diagrams: New Developments." Acta Metall. Mater., vol. 33, No. 12, pp. 2163-2174, 1985.

52 B.W. Choi, Y.G. Deng, C. McCullough, B. Paden, R. Mehrabian. "Densification of rapidly solidified titanium aluminide powders $-\mathrm{I}$. Comparison of Experiments to HIP'ing models." Acta. Metall. Mater., pp. 2225-2243, 1990.

53 L. Shao, J. Beddoes, D. Morphy, W. Wallace. "Effect of HIP conditions on the microstructure of a near $\gamma$-TiAl $+\mathrm{W}$ powder alloy." Materials and Manufacturing Processes, vol. 9, No. 4, pp. 695-707, 1994.

54 Y. Wang, J. Lin, Y. He, Y. Wang, G. Chen. "Densification behavior of high Nb containing TiAl alloys through reactive hot pressing." Journal of University of Science and Technology Beijin, vol. 14, no. 3, pp. 251-255, 2007.

55 Y-W. Kim, Private communication, May 27, 2008.

56 Tetsui T. Tetsui, K. Shindo, S. Kobayashi, M Takeyama. "Strengthening a high strength TiAl alloy by hot forging." Intermetallics 11, pp. 299-306, 2003. 
57 X.J. Xu, L.H. Xu, J.P. Lin, Y.L. Wang, Z. Lin, G.L. Chen. "Pilot processing and microstructure control of high $\mathrm{Nb}$ containing TiAl alloy." Intermetallics 13, pp. 337$341,2005$.

58 J-D. Shi, Z. Pu, Z. Zhong, D. Zou. "Improving the ductility of $\gamma($ TiAl) based alloy by introducing disordered $\beta$ phase." Scr. Mater., vol. 27, pp. 1331-1336, 1992.

59 Y-W. Kim, S-L. Kim. "Phase/microstructure evolution and tensile properties in emerging group A and B beta gamma alloys," presented at THERMEC, Berlin, Germany, 2009.

60 Y-W. Kim, Private communication, April, 2009.

61 H. Clemens, H.F. Chladil, W. Wallgram, G.A. Zickler, R. Gerling, K.-D. Liss, S. Kremmer, V. Guther, W. Smarsly. "In and ex situ investigations of the $\beta$-phase in a $\mathrm{Nb}$ and Mo containing $\gamma$-TiAl based alloy." Intermetallics 16, pp. 827-833. 2008.

62 H. Clemens, W. Wallgram, S. Kremmer, V. Guther, A. Otto, A. Bartels. "Design of novel $\beta$-solidifying TiAl alloys with adjustable $\beta / \mathrm{B} 2$-phase fraction and excellent hot-workability." Adv. Eng. Mater., vol 10, no. 8, pp. 707-713, 2008.

63 D. Veeraraghavan, V.K. Vasudevan. "Kinetics of the transformation from $\alpha \rightarrow \gamma$ during continuous heating and cooling in a Ti-47.5 at.\% Al alloy," Proceedings of the First Symposium on Gamma Titanium Aluminides, pp. 157-164, 1995.

64 U. Habel, B. J. McTiernnan. "HIP temperature and properties of a gas-atomized $\gamma$ titanium aluminide alloy." Intermetallics 12, pp. 63-68, 2004.

65 M.A. Munoz-Morris, I. Gil., D.G. Morris. "Microstructural stability of g-based TiAl intermetallics containing $\beta$ phase." Intermetallics 13, pp. 929-936, 2005

66 H. Zhu, D. Y. Seo, K. Maruyama, and P. Au, "Microstructural stability of finegrained fully lamellar XD TiAl alloys by Step aging." Metallurgical and Materials Transactions $A$, vol. 36A, pp. 1339-1351, 2005.

67 D.Y. Seo, S. Bulmer, H. Saari, P. Au. "The effects of heat treatments and tungsten additions to the microstructures and tensile properties of powder metallurgy Ti-48Al2Cr-2Nb," presented at THERMEC, Berlin, Germany, 2009.

68 M. Oehring, F. Appel, J.D.H. Paul, R.M. Imayev, V.M. Imayev, V. Kustner, U. Lorenz. "Microstructure formation in cast $\beta$-solidifying $\gamma$-titanium aluminide alloys," presented at THERMEC, Berlin, Germany, 2009.

69 C.E. Wen, K. Yasue, J.G. Lin, Y.G. Zhang, C.Q. Chen. "The effect of lamellar spacing on the creep behavior of a fully lamellar TiAl alloy." Intermetallics 8 , pp. $525-529,2000$ 